\title{
IntechOpen
}

\section{Extracellular Vesicles and Their Importance in Human Health}

\author{
Edited by Ana Gil De Bona \\ and Jose Antonio Reales Calderon
}

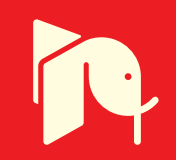





\section{Extracellular Vesicles and Their Importance in Human Health \\ Edited by Ana Gil De Bona \\ and Jose Antonio Reales Calderon}



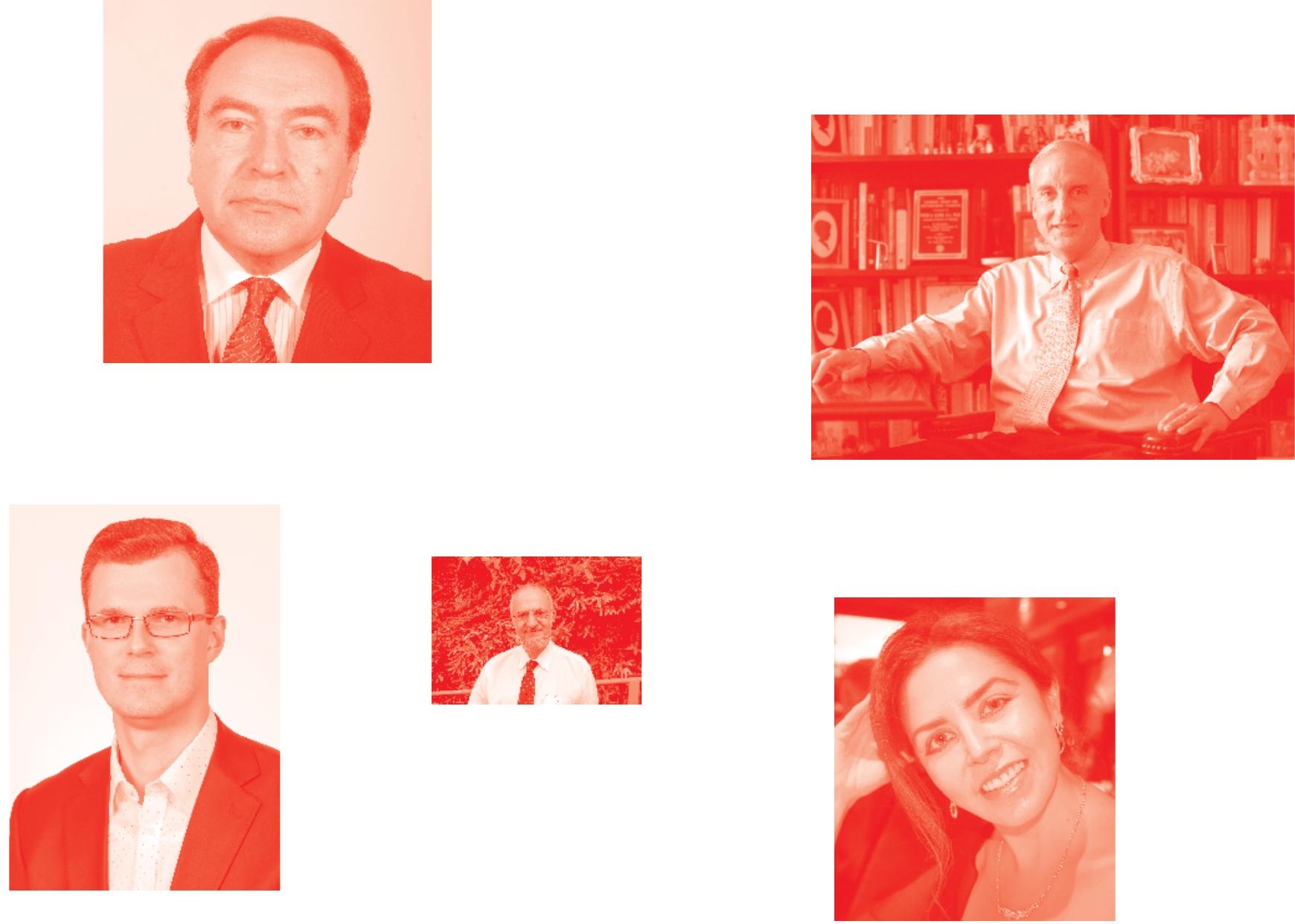

Supporting open minds since 2005
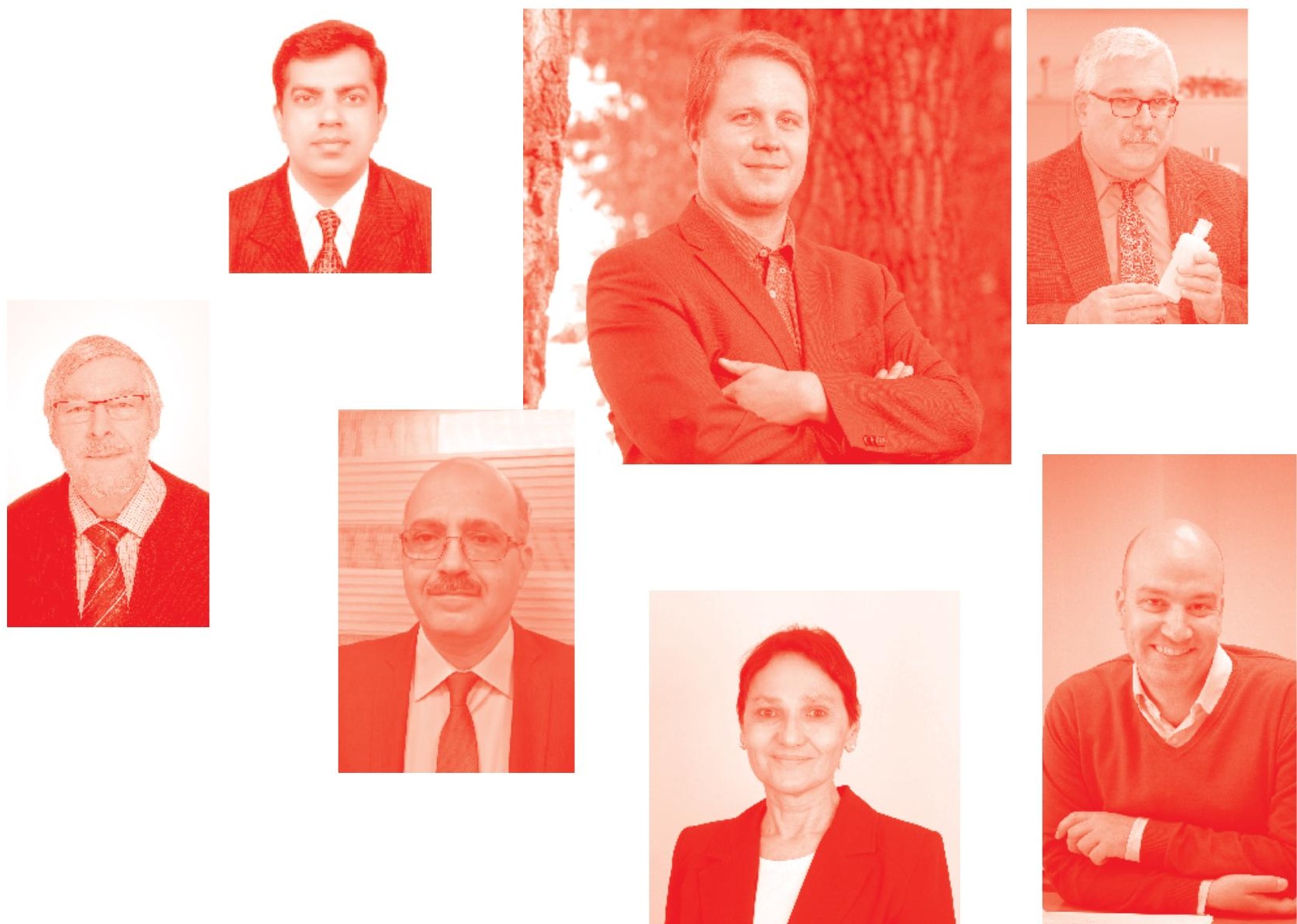
Extracellular Vesicles and Their Importance in Human Health

http : //dx. doi . org/10.5772/intechopen. 78874

Edited by Ana Gil De Bona and Jose Antonio Reales Calderon

\section{Contributors}

Sanda M. Cretoiu, Andrei-Dennis Voichitoiu, Beatrice Mihaela Radu, Dragos Cretoiu, Nicolae Suciu, Antonia Teona Deftu, Luciana-Alexandra Pavelescu, Dino G. Salinas, Sergey Sedykh, Georgy Nevinsky, Elena Ryabchikova, Evgeniya Burkova, Lada Purvinsh, Daria Klemeshova, Adriana Georgescu, Mihaela Gherghiceanu, Nicoleta Alexandru, Stefania Lucia Magda, Alina Constantin, Miruna Nemecz, Alexandru Filippi, Octavian Costin Ioghen, Laura Cristina Ceafalan, Gabriela Tanko, Florina Bojin, Virgil Paunescu, Dragos Vinereanu, Ewa Stepien, Nathan Robert Wall, Amber Gonda, Ron Moyron, Janviere Kabagwira, Paul Vallejos, Ana Gil De Bona

( ) The Editor(s) and the Author(s) 2020

The rights of the editor(s) and the author(s) have been asserted in accordance with the Copyright, Designs and Patents Act 1988. All rights to the book as a whole are reserved by INTECHOPEN LIMITED . The book as a whole (compilation) cannot be reproduced, distributed or used for commercial or non-commercial purposes without INTECHOPEN LIMITED's written permission. Enquiries concerning the use of the book should be directed to INTECHOPEN LIMITED rights and permissions department (permissions@intechopen.com).

Violations are liable to prosecution under the governing Copyright Law .

\section{(cc) BY}

Individual chapters of this publication are distributed under the terms of the Creative Commons Attribution 3.0 Unported License which permits commercial use, distribution and reproduction of the individual chapters, provided the original author(s) and source publication are appropriately acknowledged. If so indicated, certain images may not be included under the Creative Commons license. In such cases users will need to obtain permission from the license holder to reproduce the material. More details and guidelines concerning content reuse and adaptation can be found at http : //www . intechopen . com/copyright-policy . html .

\section{Notice}

Statements and opinions expressed in the chapters are these of the individual contributors and not necessarily those of the editors or publisher. No responsibility is accepted for the accuracy of information contained in the published chapters. The publisher assumes no responsibility for any damage or injury to persons or property arising out of the use of any materials, instructions, methods or ideas contained in the book.

First published in London, United Kingdom, 2020 by IntechOpen IntechOpen is the global imprint of INTECHOPEN LIMITED, registered in England and Wales, registration number: 11086078 , 7th floor, 10 Lower Thames Street, London,

EC3R 6AF, United Kingdom

Printed in Croatia

British Library Cataloguing-in-Publication Data

A catalogue record for this book is available from the British Library

Additional hard and PDF copies can be obtained from orders@intechopen.com

Extracellular Vesicles and Their Importance in Human Health

Edited by Ana Gil De Bona and Jose Antonio Reales Calderon

p. $\mathrm{cm}$.

Print ISBN 978-1-78923-943-0

Online ISBN 978-1-78923-944-7

eBook (PDF) ISBN 978-1-78984-583-9 


\section{We are IntechOpen, \\ the world's leading publisher of Open Access books}

\section{Built by scientists, for scientists}

\section{$4,600+$}

Open access books available

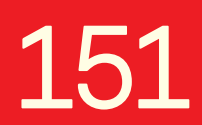

Countries delivered to

\section{$120,000+$}

International authors and editors



most cited scientists

Contributors from top 500 universities
$135 \mathrm{M}+$

Downloads
$12.2 \%$

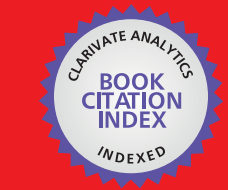

WEB OF SCIENCE ${ }^{\text {M }}$

Selection of our books indexed in the Book Citation Index in Web of Science ${ }^{\mathrm{TM}}$ Core Collection (BKCI)

\section{Interested in publishing with us? \\ Contact book.department@intechopen.com}

Numbers displayed above are based on latest data collected.

For more information visit www.intechopen.com 



\section{Meet the editors}

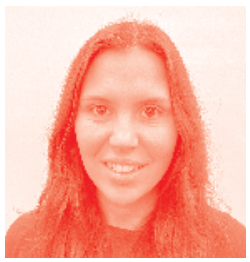

Dr. Ana Gil de Bona received her PhD in Microbiology and

Proteomics from Complutense University of Madrid, Spain. Her research mainly focused on the study of the proteomic profile of extracellular vesicles and the secretome in virulent and avirulent strains of Candida albicans. She continued her scientific carrier at the University of Massachusetts Medical School working on yeast genetics and proteomics. Her current research at the Forsyth Institute affiliated with Harvard School of Dental Medicine is focused on understanding how the organic matrix composition of enamel is affected by the oral environment in healthy and defective teeth. She has authored peer-reviewed research articles, reviews, and has presented her work to national and international scientific meetings.

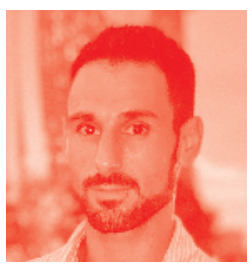

Dr. Jose Antonio Reales Calderon received his $\mathrm{PhD}$ in Microbiology/Immunology at the Complutense University of Madrid, Spain. During the PhD he performed a proteomic/phosphoproteomic study of the response of macrophages to Candida albicans. He has also enjoyed two different short stays, one at the University of Southern Denmark (Odense, Denmark) and one at MIT (Massachusetts, USA). After this, he obtained a postdoctoral position in a research network aimed at improving and developing high-quality basic, translational, and clinical research in the area of clinical microbiology and infectious diseases (Spanish Network for Research in Infectious Diseases). Currently, he is a senior research fellow at the Singapore Immunology Network (A*STAR) in Singapore. His current position allows him to study a booster of the innate immunity to protect against systemic infections. 



\section{Contents}

Preface

Section 1

Introduction to the Extracellular Vesicles

Chapter 1

Introductory Chapter: An Overview to the Extracellular Vesicles by Ana Gil-Bona and Jose Antonio Reales-Calderon

Chapter 2

Milk Exosomes: Isolation, Biochemistry, Morphology, and Perspectives of Use

by Sergey E. Sedykh, Evgeniya E. Burkova, Lada V. Purvinsh,

Daria A. Klemeshova, Elena I. Ryabchikova and Georgy A. Nevinsky

\section{Section 2}

The Biology of Extracellular Vesicles

Chapter 3

Cellular-Defined Microenvironmental Internalization of Exosomes by Amber Gonda, Ron Moyron, Janviere Kabagwira, Paul A. Vallejos and Nathan R. Wall

Chapter 4

Effects of Vesicular Membranes Reordering on the Activity of Lipid Metabolizing Enzymes

by Dino G. Salinas

\section{Section 3}

Extracellular Vesicles in Human Diseases

Chapter 5

Extracellular Vesicles in Cancer

by Andrei-Dennis Voichitoiu, Beatrice Mihaela Radu, Luciana Pavelescu, Dragos Cretoiu, Antonia Teona Deftu, Nicolae Suciu and Sanda Maria Cretoiu 
Chapter 6

Part One: Extracellular Vesicles as Valuable Players in Diabetic

Cardiovascular Diseases

by Mihaela Gherghiceanu, Nicoleta Alexandru, Stefania Lucia Magda,

Alina Constantin, Miruna Nemecz, Alexandru Filippi, Octavian Costin Ioghen, Laura Cristina Ceafalan, Florina Bojin, Gabriela Tanko, Virgil Paunescu,

Dragos Vinereanu, Ewa Stepien and Adriana Georgescu

Chapter 7

Part Two: Extracellular Vesicles as a Risk Factor in Neurodegenerative

Diseases

by Laura Cristina Ceafalan, Octavian Costin Ioghen, Daciana Silvia Marta, Alina Constantin, Nicoleta Alexandru, Miruna Nemecz, Gabriela Tanko, Alexandru Filippi, Stefania Lucia Magda, Florina Bojin, Virgil Paunescu, Dragos Vinereanu, Adriana Georgescu and Mihaela Gherghiceanu 


\section{Preface}

The study of extracellular vesicles (EVs) is a clear focus of the interest of the scientific community to understand the communication between cells, and is also being used in the healthcare system in several ways, from diagnosis to prognosis of a number of diseases. This new field of study is focused on identifying different types of EVs that are released by all the cells and their participation in different pathways. Their content is also different attending to the purpose of the cell. Therefore, they may represent a useful resource for knowledge in cell biology, cell communication, and participation in human diseases. Over the last few years, several efforts have studied the use of EVs as a useful source for diagnostic, prognostic, and therapeutic markers.

The goal of this book is to provide a clear picture of the current knowledge of the vesicles secreted by cells. The book reviews the field of EVs, including a description of EVs, the different purification techniques, their use in the medical field, and also their participation in different diseases. The book includes six chapters, each one focused on specific aspects. Each chapter provides an overview of EVs in the field of study and gives the reader a general idea of where the current research is heading. The chapters in this book are organized in three sections. Section 1, "Introduction to the extracellular vesicles," includes two chapters. Chapter 1 introduces the book with a general statement of EVs in human health. Chapter 2 is focused on the identification of EVs in human milk. EVs have been identified in different body fluids, but the study of milk EVs is not full characterized. The chapter describes a full characterization of the content of milk EVs (proteins, lipids, and nucleic acids) and a discussion of how milk EVs could be useful in medicine and biotechnology. The chapter also includes an exhaustive introduction to the isolation, purification, and analysis of EVs. The second section, "The biology of extracellular vesicles," is comprised of two chapters. Chapter 3 reviews different types of endocytosis pathways and how cell type can dictate the mechanisms of exosome internalization. EV internalization changes from cell to cell and within the same cell. The use of EVs for therapeutics could be addressed by the characterization of cell-EV interaction in the body. In Chapter 4, the author reviews applications of lipid metabolizing enzymes, due to analytical results of the kinetic theory of membrane enzymes. Three chapters comprise the third and last section of the book, "Extracellular vesicles in human diseases." Chapter 5 addresses the current knowledge about the role of EVs in cancer, focusing primarily on ovarian and breast cancer. The chapter gives a detailed introduction to the different EVs characterized, including a complete overview and their roles in tumor microenvironment, tumorigenesis, and metastasis. Chapter 6 describes the role of EVs in modulating diabetic cardiovascular diseases. This chapter describes the function of EVs in physiological processes and immune response and how EVs could be clinical biomarkers and therapeutic targets in diabetic cardiovascular diseases, including atherosclerosis, coronary artery disease, cerebrovascular disease, and peripheral arterial disease. Chapter 7 reviews the participation of EVs in neurodegenerative diseases. The authors present the biological content of EVs and the methods used for their isolation, analysis, and their importance in brain pathology and potential role in the prognosis and diagnosis of human health and disease. 
This book is the result of all the experts who have participated in the research of EVs over the years, making it possible to achieve a vast degree of knowledge in the field. We would like to thank all the authors who have contributed, the reviewers, the editorial office, and editors who have assisted with this book. Hopefully, this book will serve as a handbook for researchers in the area of EVs and inspire some future research ideas.

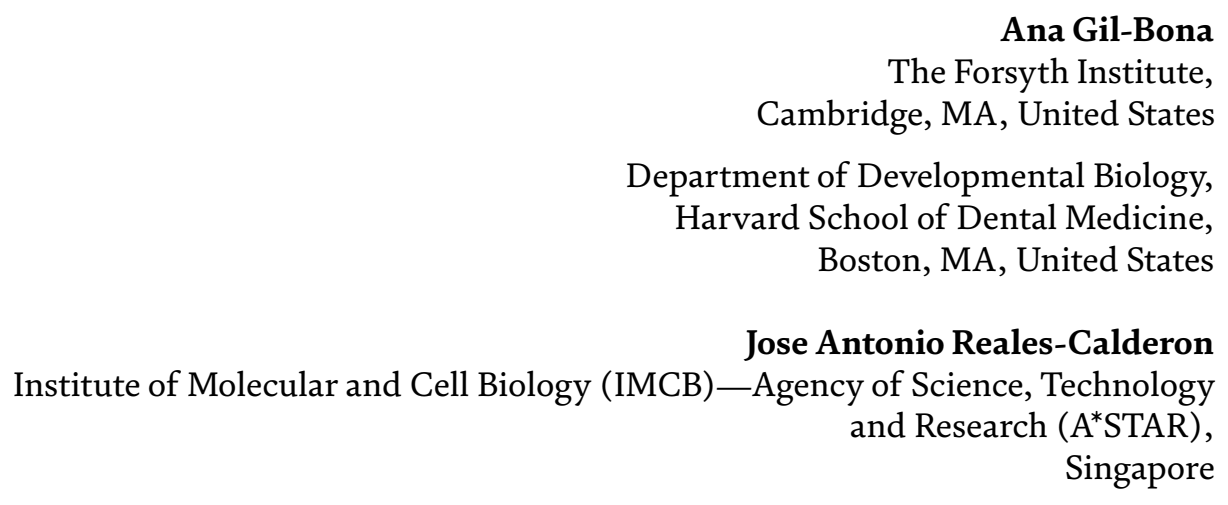


Section 1

\section{Introduction to the Extracellular Vesicles}





\title{
Introductory Chapter: An Overview to the Extracellular Vesicles
}

\author{
Ana Gil-Bona and Jose Antonio Reales-Calderon
}

\section{Extracellular vesicles}

Cells are basic structural, functional, and biological units delimited by a plasma membrane that contains all the molecules necessaries for living. Cells could be a complete organism, such as yeast or bacterium, or form part of a multicellular organism which is specialized, such as neurons or adipocytes. The communication between cells is very important to react to the environment and to initiate signaling cascades in all the organisms, from bacteria to eukaryotes. This communication involves the secretion of proteins to the extracellular environment through direct secretion (classical secretion pathways) or can be mediated by the secretion of extracellular vesicles (EVs). This communication allows cells sending and receiving messages about the inside and the outside environment. Different strategies are applied for cellular crosstalk. Current studies have emerged as EVs as an important mechanism of cell communication $[1,2]$. The secretion of EVs is a well conserved process through all the organisms, from bacteria to mammals [3].

The term extracellular vesicle includes a heterogeneous group of membrane vesicles with diverse origins, sizes, and shapes. EVs are being identified in almost all the cells, from prokaryotic to eukaryotic, and not only in healthy conditions but also associated with many diseases [4]. The composition, origin, and functions are the focus of attention of researchers and clinicians. The number of papers published yearly in Pubmed related to EVs has increased exponentially during the last 10 years (Figure 1). Despite the enormous amount of data published and because of that, there are many new questions unanswered. We still cannot claim the complete understanding of the function of these vesicles in the cell.

The release of EVs to the media allows the cell sending and receiving messages without direct interaction. The content of EVs could participate in controlling important processes, such as growth and differentiation, pathogenesis or metabolic processes. The diversity and complexity of EVs are enormous. Each cell can produce different types of EVs, varying the biogenesis process and the content. The term of EVs is a generic term for all types of vesicles. There are different types of EVs attending to their function, size, and content [5]. Three EV types are mainly accepted: exosomes (30-90 nm), microvesicles (100 up to $1 \mu \mathrm{m})$, and apoptotic bodies. The EVs are formed by lipid bilayer with integrated proteins. This capsule protects the inside content from the proteases and nucleases that can affect their content. EVs transport lipids, proteins, growth factors, and RNA. In summary, the EVs are able to transfer genetic material and proteins that can contribute to change the receiving cell. Although, the main components are the same, different EVs from different cells or different EVs from the same cell can possess different contents and characteristics. 


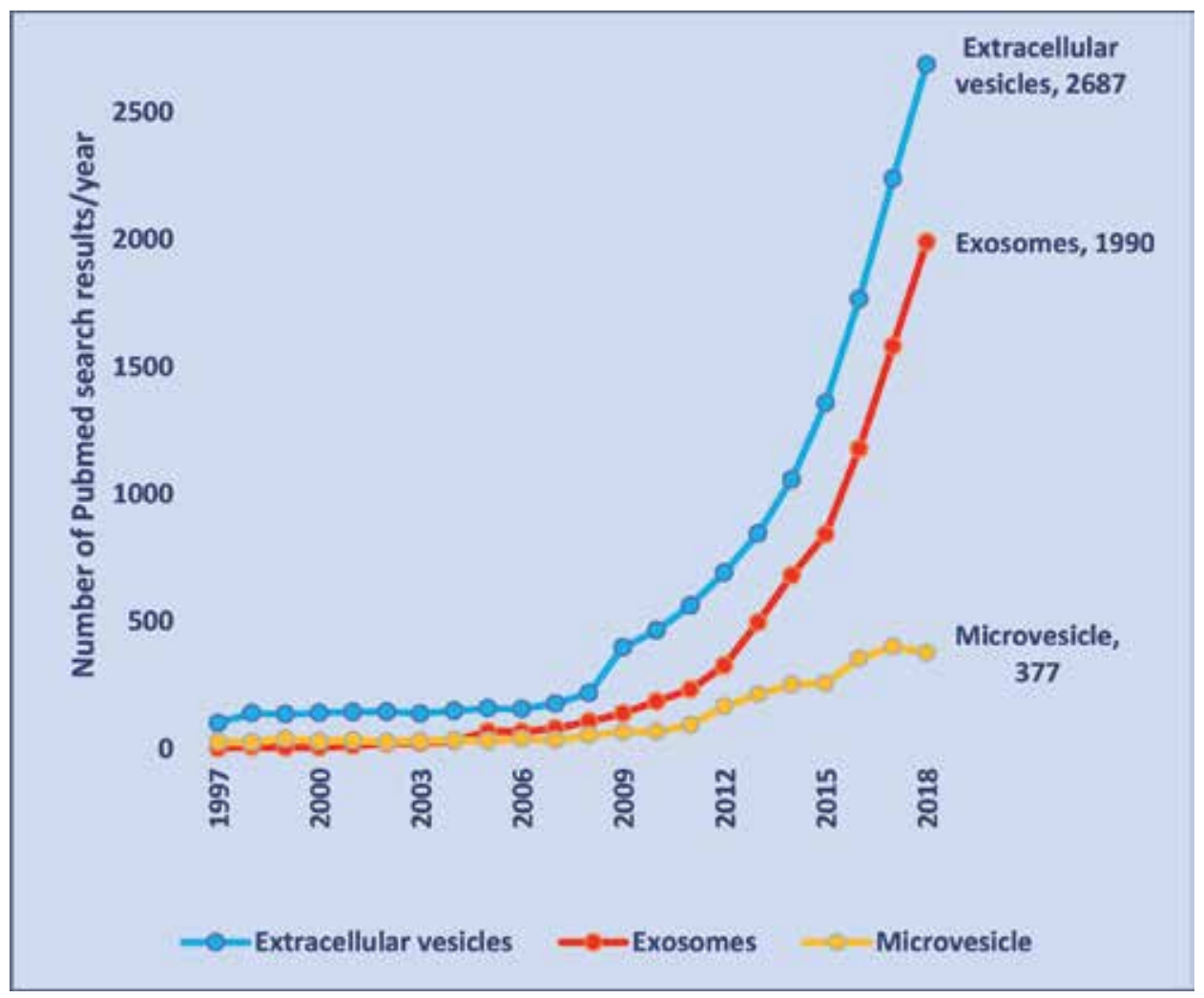

Figure 1.

Evolution of the number of papers published in PubMed over the past 21 years (1997-2018).

\section{Study of EVs}

EVs can be released and interact with the target cell through different mechanisms. Currently, there are several databases that serve as resource for EVs research: Vesiclepedia [6, 7], EVpedia [8-10], ExoCarta [11-14], and EVmiRNA [15]. These databases include data from different organisms, type of vesicle, and content type (protein, mRNA, miRNA, and lipid). The composition of each kind of EV derives from the cell and purpose of the vesicle realized to the media. As such, these vesicles became an important marker for diseases, including cancer, infectious diseases, renal diseases, and diabetes [16-20]. In order to achieve this, EVs must be characterized and analyze their confidence to be candidates for those used by humans. The isolation and purification of different sets of EVs in a single cell is complicated.

Even though several studies isolate EVs from all kinds of fluids, including blood, urine, saliva, tears, semen, and cerebrospinal fluid, there is not a consensus to determine the best isolation technique to purify EVs. Several approximations have been published to isolate and analyze EVs from different sources [5, 21-23]. Differential centrifugation and ultracentrifugation are necessary steps at the beginning of the process to avoid sample contamination with non-EVs contaminants that can confound the analysis (ex. cellular debris, protein aggregates or lipoproteins). After the centrifugation steps, there are several techniques that can be used to isolate and analyze the EVs $[24,25]$. Several common techniques are listed below:

- Differential ultracentrifugation

- Density gradient ultracentrifugation 
- Size exclusion chromatography

- Filtration

- Immunological separation

- Commercial precipitation kits

- Microfluidic chip

The methods summarized above are the most common. However, there are more variations of these methods used to purify EVs. All the methods have different advantages and disadvantages. Because of the diversity of the EVs, there is not a unique method to purify them. The selection of the method and the adaptation to the particular scenario is vital for the success of the isolation. After the EVs isolation, several procedures can be performed to characterize, quantify, and validate the correct purification of these organelles [5, 26-30]. The most common methods are listed below:

- Transmission electron microscopy (TEM)

- Atomic force microscopy (AFM)

- Nanoparticle tracking analysis (NTA)

- Dynamic light scattering (DLS)

- Single-particle tracking (SPT)

- Protein identification by mass spectrometry (MS)

- Western blot

- ELISA

- Flow cytometry

- RNA analysis

- In vitro functional analyses

- In vivo functional analyses

- Lipidomic analysis

\section{The role of the extracellular vesicles in human health}

Extracellular vesicles are released by many different cell types and organisms. The role of the EVs is mediated by the signals transmitted through them by the protein, lipids, and nucleic acids that are part of the EVs cargo. The release of the EVs to the environment allows the emitting cell to send messages to sites close or even far from the origin. These vesicles are able to transport biological information through 
the system with cell targeting properties, making them as great candidates for drug delivery systems [31-33]. EVs are naturally secreted by human cells and they are not strange for the system, avoiding the negative response by the immune cells. The use of EVs as drug delivery systems is focused on improving their ability to reach the target recipient cells and deliver the content, controlling the purity of EV preparation, and analyzing the best administration routes. The challenges are prolonging their circulating and improving targeting. The use of EVs as drug delivery systems is being studied for several disorders, including cancer, infectious diseases, brain disorders, liver diseases, and among others [34-37]. However, this field is still in the early stage of development with great potential for future applications, but also with big challenges to attempt [38].

More applications for EVs have been described. The specific cargo of the EVs makes them useful in the discovery of biomarkers for clinical diagnosis. Because EVs are secreted from almost all cells, they are found in various body fluids, making them easy to collect and analyze and playing a critical role in diagnosis of several conditions, such as cancer, Alzheimer's, epilepsy, and liver diseases [37, 39-42]. EVs participate in pathogenesis and can also be used as diagnosis or vaccines [33, 35, 43]. Last novel applications for EVs include using their signaling properties to repair injured muscle or use them as biomarkers for male infertility or pregnancy-related disorders [44-46].

\section{Conclusions}

This first chapter presents a big picture of the EVs research and application as a fast-growing field. There are many EVs studies trying to demonstrate their potential critical role in cell communication and their use in many different biomedical applications. The diversity of biogenesis mechanisms and their cargo content outstand many challenges and questions to be addressed. Advances in standardized methods for purification and analysis are necessary. The increasing knowledge of the different cargo compositions and secretion mechanisms to differentiate the healthy cells and the sick cells need to be clarified to use them as biomarkers, vaccines or therapy. The combination of knowledge and experts deriving from all the fields together with the progress on characterization methods is contributing to use EVs in the biomedical field. 
Introductory Chapter: An Overview to the Extracellular Vesicles

DOI: http://dx.doi.org/10.5772/intechopen.90820

\section{Author details}

Ana Gil-Bona, ${ }^{1,2 *}$ and Jose Antonio Reales-Calderon ${ }^{3}$

1 The Forsyth Institute, Cambridge, MA, United States

2 Department of Developmental Biology, Harvard School of Dental Medicine, Boston, MA, United States

3 Institute of Molecular and Cell Biology (IMCB)_Agency of Science, Technology and Research (A*STAR), Singapore

*Address all correspondence to: agildebona@forsyth.org

\section{IntechOpen}

(C) 2020 The Author(s). Licensee IntechOpen. This chapter is distributed under the terms of the Creative Commons Attribution License (http://creativecommons.org/licenses/ by/3.0), which permits unrestricted use, distribution, and reproduction in any medium, provided the original work is properly cited. (cc) BY 


\section{References}

[1] Maas SLN, Breakefield XO, Weaver AM. Extracellular vesicles: Unique intercellular delivery vehicles. Trends in Cell Biology. 2017;27(3):172-188

[2] Mathieu M et al. Specificities of secretion and uptake of exosomes and other extracellular vesicles for cellto-cell communication. Nature Cell Biology. 2019;21(1):9-17

[3] Raposo G, Stoorvogel W. Extracellular vesicles: Exosomes, microvesicles, and friends. The Journal of Cell Biology. 2013;200(4):373-383

[4] Gill S, Catchpole R, Forterre P. Extracellular membrane vesicles in the three domains of life and beyond. FEMS Microbiology Reviews. 2019;43(3):273-303

[5] Doyle LM, Wang MZ. Overview of extracellular vesicles, their origin, composition, purpose, and methods for exosome isolation and analysis. Cell. 2019;8(7):727

[6] Pathan M et al. Vesiclepedia 2019: A compendium of RNA, proteins, lipids and metabolites in extracellular vesicles. Nucleic Acids Research. 2019;47(D1):D516-D519

[7] Kalra $\mathrm{H}$ et al. Vesiclepedia: A compendium for extracellular vesicles with continuous community annotation. PLoS Biology. 2012;10(12):e1001450

[8] Kim DK et al. EVpedia: A community web resource for prokaryotic and eukaryotic extracellular vesicles research. Seminars in Cell \& Developmental Biology. 2015;40:4-7

[9] Kim DK et al. EVpedia: A community web portal for extracellular vesicles research. Bioinformatics. 2015;31(6):933-939
[10] Kim DK et al. EVpedia: An integrated database of highthroughput data for systemic analyses of extracellular vesicles. Journal of Extracellular Vesicles. 2013;2:1

[11] Keerthikumar S et al. ExoCarta: A web-based compendium of exosomal cargo. Journal of Molecular Biology. 2016;428(4):688-692

[12] Simpson RJ, Kalra H, Mathivanan S. ExoCarta as a resource for exosomal research. Journal of Extracellular Vesicles. 2012;1:1

[13] Mathivanan S et al. ExoCarta 2012: Database of exosomal proteins, RNA and lipids. Nucleic Acids Research. 2012;40:D1241-D1244

[14] Mathivanan S, Simpson RJ. ExoCarta: A compendium of exosomal proteins and RNA. Proteomics. 2009;9(21):4997-5000

[15] Liu T et al. EVmiRNA: A database of miRNA profiling in extracellular vesicles. Nucleic Acids Research. 2019;47(D1):D89-D93

[16] Freitas MS et al. Fungal extracellular vesicles as potential targets for immune interventions. mSphere. 2019;4(6):e00747-19

[17] Becker A et al. Extracellular vesicles in cancer: Cell-to-cell mediators of metastasis. Cancer Cell. 2016;30(6):836-848

[18] Urbanelli L et al. The role of extracellular vesicles in viral infection and transmission. Vaccines. 2019;7(3):102

[19] Kwon SH. Extracellular vesicles in renal physiology and clinical applications for renal disease. The Korean Journal of Internal Medicine. 2019;34(3):470-479 
[20] Pardo F et al. Extracellular vesicles in obesity and diabetes mellitus. Molecular Aspects of Medicine. 2018;60:81-91

[21] Zhu L et al. Cell derived extracellular vesicles: From isolation to functionalization and biomedical applications. Biomaterials Science. 2019;7(9):3552-3565

[22] Villa F, Quarto R, Tasso R. Extracellular vesicles as natural, safe and efficient drug delivery systems. Pharmaceutics. 2019;11(11):557

[23] Gardiner C et al. Techniques used for the isolation and characterization of extracellular vesicles: Results of a worldwide survey. Journal of Extracellular Vesicles. 2016;5:32945

[24] Konoshenko MY et al. Isolation of extracellular vesicles: General methodologies and latest trends. BioMed Research International. 2018;2018:8545347

[25] Gholizadeh S et al. Microfluidic approaches for isolation, detection, and characterization of extracellular vesicles: Current status and future directions. Biosensors \& Bioelectronics. 2017;91:588-605

[26] Rupert DLM et al. Methods for the physical characterization and quantification of extracellular vesicles in biological samples. Biochimica et Biophysica Acta-General Subjects. 2017;1861 (1 Pt A):3164-3179

[27] Shao $\mathrm{H}$ et al. New technologies for analysis of extracellular vesicles. Chemical Reviews. 2018;118(4):1917-1950

[28] Pocsfalvi G et al. Mass spectrometry of extracellular vesicles. Mass

Spectrometry Reviews. 2016;35(1):3-21

[29] Hartjes TA et al. Extracellular vesicle quantification and characterization:
Common methods and emerging approaches. Bioengineering. 2019;6(1):7

[30] Xu R et al. Extracellular vesicle isolation and characterization: Toward clinical application. The Journal of Clinical Investigation. 2016;126(4):1152-1162

[31] Vader P et al. Extracellular vesicles for drug delivery. Advanced Drug Delivery Reviews. 2016;106(Pt A): 148-156

[32] Raimondo S et al. Extracellular vesicles as biological shuttles for targeted therapies. International Journal of Molecular Sciences. 2019;20(8):1848

[33] Yamamoto T, Kosaka N, Ochiya T. Latest advances in extracellular vesicles: From bench to bedside. Science and Technology of Advanced Materials. 2019;20(1):746-757

[34] Walker S et al. Extracellular vesicle-based drug delivery systems for cancer treatment. Theranostics. 2019;9(26):8001-8017

[35] Rodrigues $M$ et al. Role of extracellular vesicles in viral and bacterial infections: Pathogenesis, diagnostics, and therapeutics.

Theranostics. 2018;8(10):2709-2721

[36] Rufino-Ramos D et al. Extracellular vesicles: Novel promising delivery systems for therapy of brain diseases. Journal of Controlled Release. 2017;262:247-258

[37] Szabo G, Momen-Heravi F. Extracellular vesicles in liver disease and potential as biomarkers and therapeutic targets. Nature Reviews. Gastroenterology \& Hepatology. 2017;14(8):455-466

[38] Surman M et al. Extracellular vesicles as drug delivery systemsMethods of production and 
potential therapeutic applications.

Current Pharmaceutical Design.

2019;25(2):132-154

[39] Gurunathan S et al. Review of the isolation, characterization, biological function, and multifarious therapeutic approaches of Exosomes.

Cell. 2019;8(4):307

[40] Lee S, Mankhong S, Kang JH. Extracellular vesicle as a source of Alzheimer's biomarkers: Opportunities and challenges. International Journal of Molecular Sciences. 2019;20(7):1728

[41] Upadhya D, Shetty AK. Promise of extracellular vesicles for diagnosis and treatment of epilepsy. Epilepsy \& Behavior. 2019:106499. DOI: https://doi. org/10.1016/j.yebeh.2019.106499

[42] Li TR et al. Extracellular vesicles as an emerging tool for the early detection of Alzheimer's disease. Mechanisms of Ageing and Development. 2019;184:111175

[43] Liu Y et al. Gram-positive bacterial extracellular vesicles and their impact on health and disease. Frontiers in Microbiology. 2018;9:1502

[44] Vickram AS et al. Human prostasomes an extracellular vesicleBiomarkers for male infertility and prostrate cancer: The journey from identification to current knowledge. International Journal of Biological Macromolecules. 2019. DOI: https://doi. org/10.1016/j.ijbiomac.2019.09.218

[45] Karin-Kujundzic V et al. Novel epigenetic biomarkers in pregnancyrelated disorders and cancers. Cell. 2019;8(11):1459

[46] Bittel DC, Jaiswal JK. Contribution of extracellular vesicles in rebuilding injured muscles. Frontiers in Physiology. 2019;10:828 


\title{
Milk Exosomes: Isolation, Biochemistry, Morphology, and Perspectives of Use
}

\author{
Sergey E. Sedykh, Evgeniya E. Burkova, Lada V. Purvinsh, \\ Daria A. Klemeshova, Elena I. Ryabchikova \\ and Georgy A. Nevinsky
}

\begin{abstract}
Cells of the multicellular organisms communicate with each other in many different ways, among which extracellular vesicles play a unique role. Almost all cell types secrete vesicles into the extracellular space and deliver their contents to recipient cells. Today, one of the groups of extracellular vesicles that is of particular interest for studying is exosomes-membrane vesicles with a diameter of 40-100 nm. Exosomes are secreted by cells and found in various biological fluids_-blood, tears, saliva, urine, cerebrospinal fluid, and milk. Exosomes provide not only targeted delivery of molecular signals to recipient cells but also carry unique markers, which makes them a promising substrate in diagnostic studies, primarily due to their small RNA and protein contents. The milk of cows, horses, humans, and other mammals is a unique source of exosomes since these organisms can produce liters of milk per day, which is much higher than the volume of exosomes produced in cell culture fluid or blood plasma. Unfortunately, milk exosomes are currently much less studied than exosomes of blood or culture fluid. This review examines the methods of the isolation, biochemical analysis (composition of proteins, lipids, and nucleic acids), morphology, and prospects for the use of milk exosomes.
\end{abstract}

Keywords: milk, exosomes, isolation, milk exosomes, proteins, lipids, nucleic acids, miRNA, morphology, electron microscopy

\section{Introduction}

Exosomes are membrane vesicles with a diameter of $40-100 \mathrm{~nm}$, secreted by cells and found in various biological fluids-blood, tears, saliva, urine, cerebrospinal fluid, and milk [1]. Exosomes deliver molecular signals to recipient cells and also carry unique markers of the parental cell, which makes them a promising substrate for noninvasive diagnostics (liquid biopsy) and targeted drug delivery. The microRNA and protein contents of exosomes are of particular interest $[2,3]$.

Milk contains proteins, lipids, nucleic acids, and its complexes and is not a simple source of nutrients. Since vesicles of different size and shapes were described in milk and since milking animals can produce liters of milk per day, which is much 
higher than the volume of culture fluid or blood plasma, milk is a unique source of exosomes. Unfortunately, milk exosomes are currently much less studied than exosomes of blood or culture fluid.

Milk exosomes may be used as carriers of drugs and therapeutic nucleic acids for delivery to cells. The basis of biological functions of milk exosomes is due to their components: lipids, proteins, and nucleic acids. The prospects for the further practical use of milk exosomes in medicine and biotechnology largely depend on investigations of the fine structure and biological functions of exosomes free of various contaminating impurities.

A clear classification of extracellular vesicles is difficult due to their considerable variability and, particularly, overlapping sizes. The term "extracellular vesicles" was introduced to designate all the vesicles secreted to the biological fluids, and the use of the term "exosomes" requires the fulfillment of some conditions $[4,5]$. The distinctive features of exosomes are the size $(40-100 \mathrm{~nm})$, floating density in a sucrose gradient (1.1-1.19 $\mathrm{g} / \mathrm{ml})$, a particular cup-shaped form under electron microscope examination, and specific biochemical composition.

Exosomes isolated from human [6], cow [7], horse [8], pig [9], rat [10], and camel [11] milk have been described so far. However, it has been shown that the molecular composition of human milk exosomes largely depends on the mother's lifestyle, lactation stage, and mother's contact with allergens [12]. It is known that a change in the composition of proteins [13] and nucleic acids [14] of cow milk exosomes occurs during the development of inflammation of the mammary gland.

\section{Methods of exosome isolation, purification, and analysis}

According to the international nomenclature, exosomes include vesicles of $40-100 \mathrm{~nm}$ in size, which are formed by invagination of the membrane of the multivesicular bodies and carry a number of specific markers, such as CD9, CD63, and CD81. Exosomes are round or cup-shaped.

Most investigations of exosomes confirm their presence using transmission electron microscopy (TEM) without a detailed analysis of the preparation composition. TEM is the best method of analysis of size, morphology, and integrity of exosomes, as well as of evaluating sample composition. TEM shows the presence of impurities in the preparations of exosomes, which can distort the results and lead to a false interpretation. For example, researchers describe samples of cow milk exosomes and present images that clearly show vesicles larger than $100 \mathrm{~nm}$ in size and other particles that do not have an outer membrane. However, when analyzing the results, this fact is not discussed [15].

To confirm that the isolated vesicles are exosomes, the International Society for Extracellular Vesicles recommends identification of specific exosomal membrane proteins - tetraspanins CD9, CD63, and CD81—using Western blotting, flow cytometry, or immunoelectron microscopy $[4,16]$. However, the first two methods fix all particles in a solution that have tetraspanins; therefore, there is no selectivity in analyzing membrane and non-membrane structures. The advantage of immunoelectron microscopy is the ability to detect exosomal markers directly on the surface of the vesicles.

When analyzing the literature data on exosomes obtained from the milk of human donor or other sources, one should take into account by which methods the exosome preparation was isolated and analyzed and what is the potential of these approaches in a generation of reliable data. Exosomes from different biological liquids including milk may be isolated with various methods such as centrifugation using special conditions, ultracentrifugation, ultracentrifugation in density 
gradients, and salting out and with other approaches [17-19]. It should be noted that these methods allow obtaining preparations only enriched with exosomes, but not pure ones. Different biological fluids including milk contain various proteins and their highly stable molecular weight associates, which can be co-isolated with various vesicles including exosomes during centrifugations. For example, it was recently shown that extract of the placenta and human milk contains very stable high-molecular-mass ( 1000 kDa) multiprotein complexes, in which the size is comparable to some extent with various vesicles $[20,21]$. Moreover, some free proteins and their complexes can nonspecifically or even specifically interact either with vesicle surface or their receptors and coprecipitate with the vesicles during centrifugations.

Reliability of literature data is questioned in [22] where more than 200 exosome preparations were isolated from various sources using sequential centrifugations; this method has been used in many papers. Exosomes' preparations contained many structures with low electron density and having no membranes; these structures were named "non-vesicles." Using TEM, two main types of "non-vesicles" were described: of $20-40 \mathrm{~nm}$ (up 10-40\% of all structures of the preparations) and of 40-100 nm. The morphology of the "non-vesicles" allowed referring them to lipoproteins of intermediate and low density (20-40 nm) and very low density (40-100 nm) [22]. Also, crude exosome preparations after different centrifugations without additional purification steps contained impurities of various components, including proteins and their complexes. In such types of exosome preparations, up to several hundred or thousand different contaminating co-isolating proteins and their complexes may be detected.

Recently our data confirmed the findings of [22]: using TEM we have shown that crude exosome preparations from human placenta and horse milk after centrifugation and ultracentrifugation (at 10,000 $\times \mathrm{g}, 16,500 \times \mathrm{g}$, and twice at 100,000 $\times \mathrm{g}$ ) contained many large $>100 \mathrm{~nm}$ membrane vesicles, smaller $<100 \mathrm{~nm}$ vesicles, and 20-100 nm non-vesicles [23]. Non-vesicles possessed medium electron density, distinct outer membrane, and spherical shape (Figure 1).

We observed a similar situation in the case of crude exosome preparations obtained from horse milk. All the same, components were identified in such preparations except ring-shaped structures of ferritin (Figure 2).

After preparations isolated from placenta [23] and horse milk [8] were enriched with exosomes by sequential centrifugation and ultracentrifugation, they were separated from co-isolating impurities using gel filtration on Sepharose 4B or Ultrogel (Figure 3A and B). The first peak corresponding to exosomes was successfully separated from contaminating proteins and other impurities of the second peak.

One can see from Figure 3 that gel filtration can noticeably differ in the $\mathrm{A}_{280}$ ratio of the first and second peaks. The first peak, corresponding to exosomes, can be significantly lower than the second peak, corresponding to coprecipitating impurities. As it was shown in $[8,23]$, the second peak may contain various proteins. Vesicle preparations of human placenta and horse milk obtained after gel filtration contained exosomes of various sizes (30-100 nm) but did not contain any visible amorphous protein material (Figures 1 and 2 ). In contrast to horse milk exosomes, preparations of human placenta exosomes even after gel filtration contain some supramolecular ring-shaped associates of ferritin (10-14 nm). One of the criteria for belonging vesicles to exosomes is the content of CD81 or CD63 on the surface [4]. Using TEM with anti-CD63 and anti-CD81 gold-labeled antibodies, we analyzed the vesicle preparation obtained with gel filtration (Figure 4C-G). Extra-purified exosomes obtained after gel filtration correspond to the exosomes in terms of morphology, size, and content of tetraspanins CD81 and CD63 on their surface (Figure 4). 

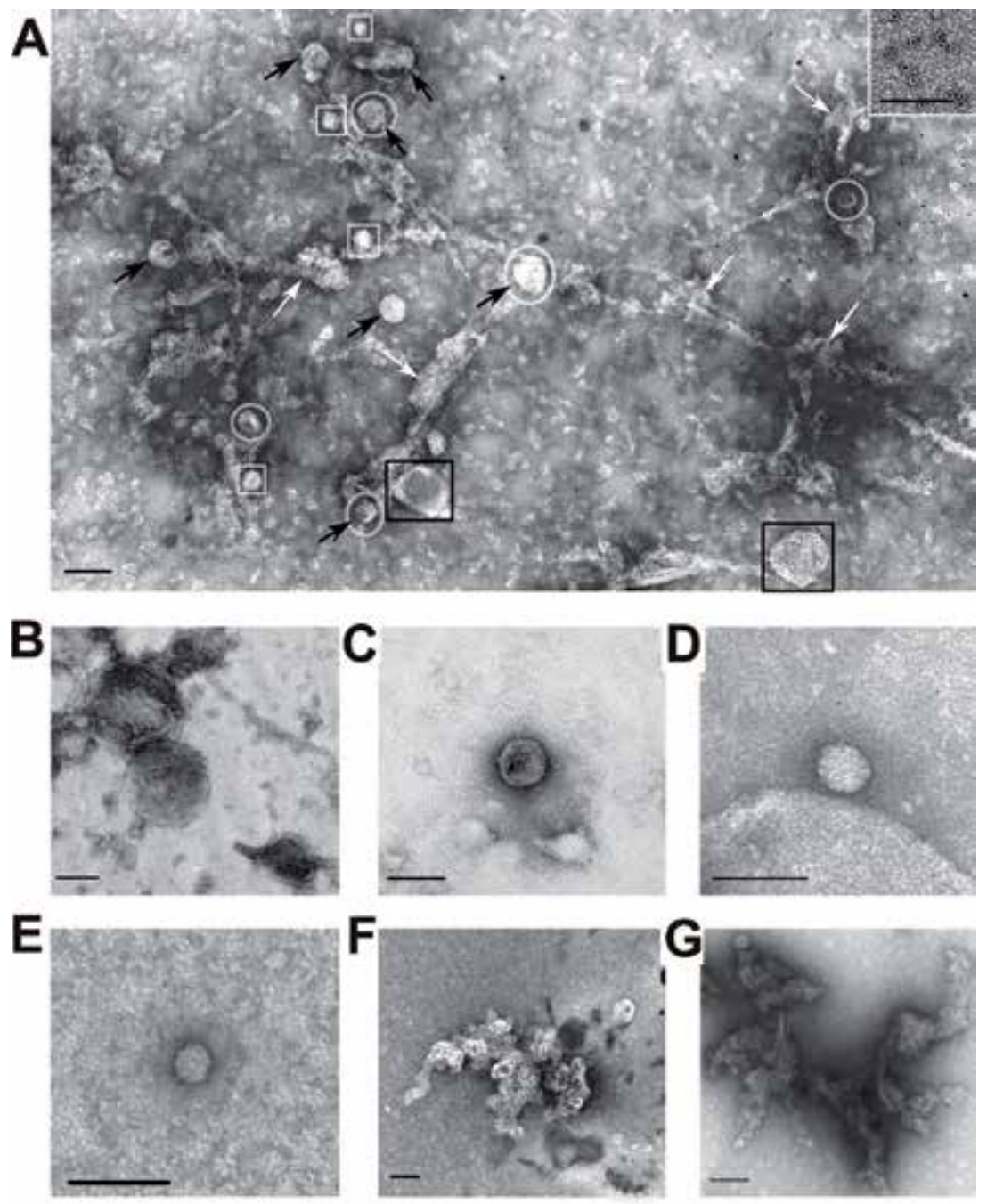

\section{Figure 1.}

Exosomes of human placenta after ultracentrifugation. (A) Vesicles $<100 \mathrm{~nm}$ (black arrows), vesicles $>100 \mathrm{~nm}$ (black squares), non-vesicles (white squares), amorphous aggregates of low electron density (white arrows), and particles associated with protein aggregates (white ovals). Individual structures in exosome preparations: Clumps of large vesicles $(>100 \mathrm{~nm})(B)$, vesicles $<100 \mathrm{~nm}(C)$, non-vesicles $(D, E)$, ring-shaped structures of ferritin (insert to $A$ ), clusters of aggregated proteins $(F)$, and shapeless aggregations with low electron density (G). Images were obtained using TEM with negative staining. Scale bar corresponds to $100 \mathrm{~nm}$.

Thus, various kinds of centrifugation and ultracentrifugation are not enough for a full purification of exosome preparations from coprecipitating impurities. Also, for improved exosome purification, it is necessarily what kind of ultracentrifugation was performed and how many times it was performed. The relative number of vesicles containing CD9 and CD81 tetraspanins was estimated using flow cytometry after the first and second ultracentrifugation and after gel filtration (Figure 5). It was shown that vesicle preparations after first $100,000 \times$ g ultracentrifugation contain only $~ 16 \%$ of CD9- and CD81-positive vesicles (Figure 5A and B). The second 100,000 $\times \mathrm{g}$ ultracentrifugation led to the increase of these markers in fivefold (up to $80-87 \%$ for CD81 and CD9, respectively; see Figure 5C and D). Thus, the number of impurities in the preparations of exosomes not subjected to the second 100,000 $\times$ g ultracentrifugation can be approximately 4-6 times higher. 

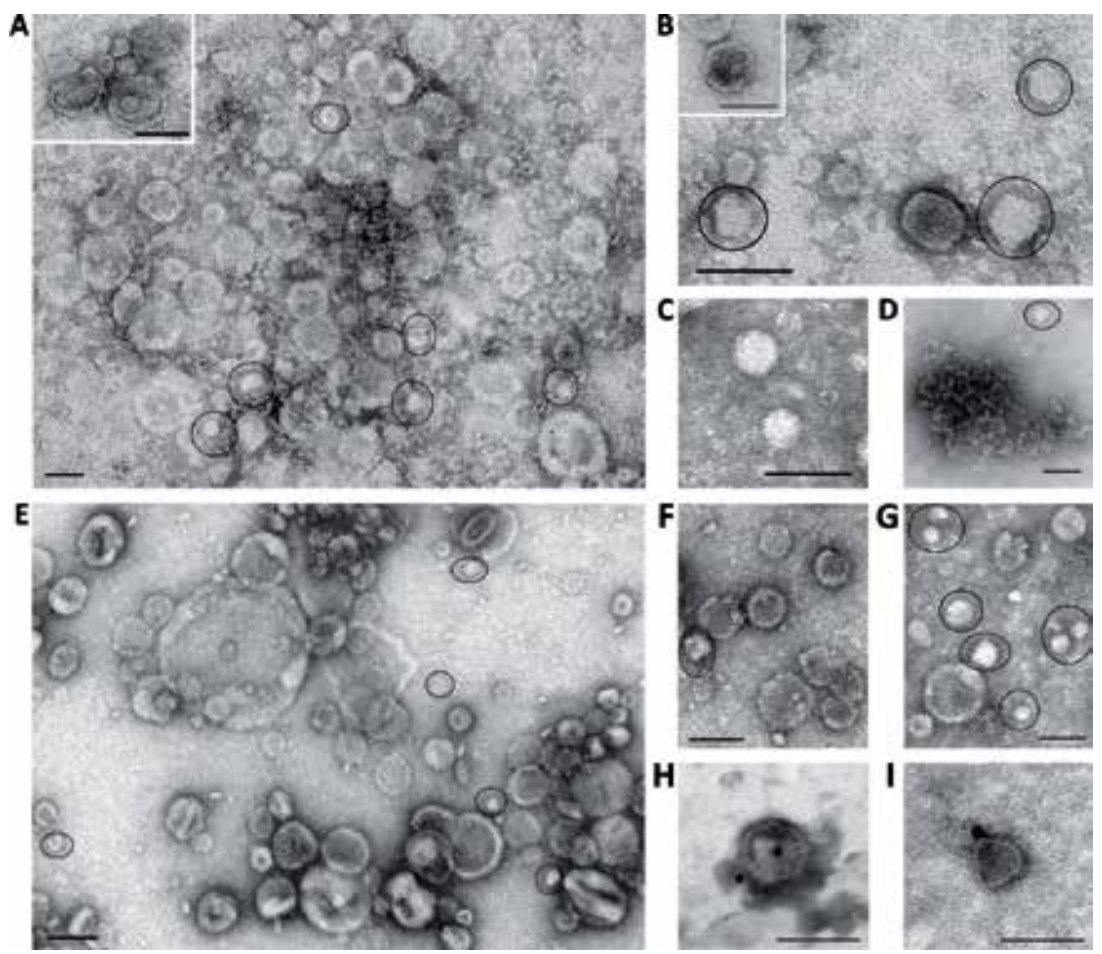

Figure 2.

Exosome preparations of horse milk after different steps of purification: Ultracentrifugation $(A-D)$ and gel filtration (E-I). (A) Aggregates of vesicles and non-vesicles, $(B)$ exosomes and non-vesicles (oval), $(C)$ nonvesicles, $(D)$ macromolecular aggregates, $(E)$ aggregates of large and small vesicles, $(F)$ exosomes, $(G)$ exosomes and non-vesicles, $(H)$ exosomes labeled with anti-CD81 antibody conjugates with gold spheres, and (I)

exosomes labeled with anti-CD63 antibody conjugates with gold spheres. The oval shapes denote non-vesicles; squares in (A and B) -Exosomes. Scale bar corresponds to $100 \mathrm{~nm}$.
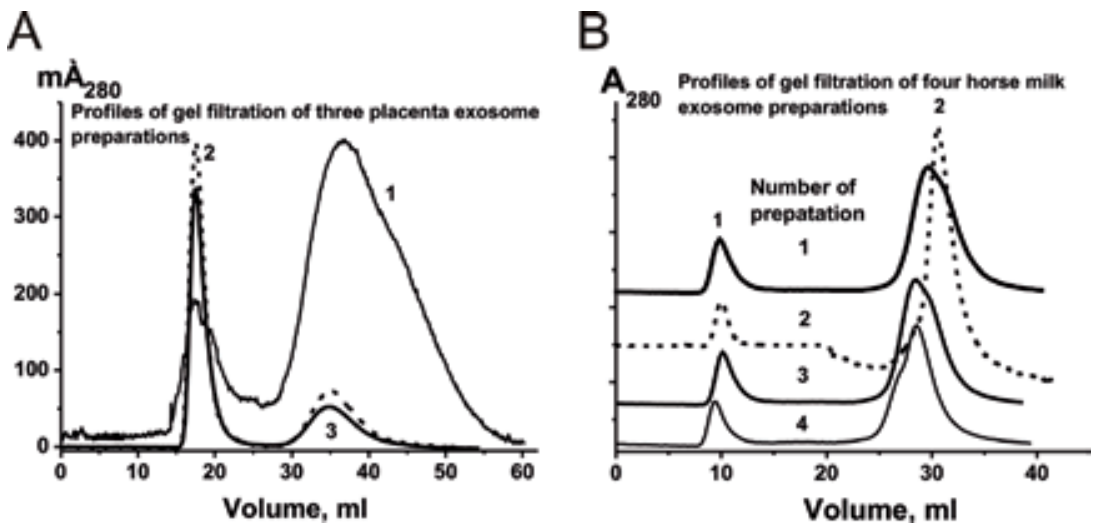

Figure 3.

Gel filtration of crude exosome preparations on Sepharose $4 B(A)$ and Ultrogel (B). Crude exosome preparations from human placenta $(A)$ and horse milk $(B)$ preparations were obtained by sequential centrifugation and ultrafiltration through filter $0.1 \mu \mathrm{m}(-)$, absorbance at $280 \mathrm{~nm}\left(A_{280}\right)$.

Exosomes of different origins according to literature data may contain varying amounts of proteins. For example, crude preparations of exosomes of dendritic cells can include more than 150-200 different proteins [24, 25]. An even more improbable result was obtained when analyzing proteins of the milk's exosomes of cows, whose preparations were isolated by centrifugation and ultracentrifugation in a 

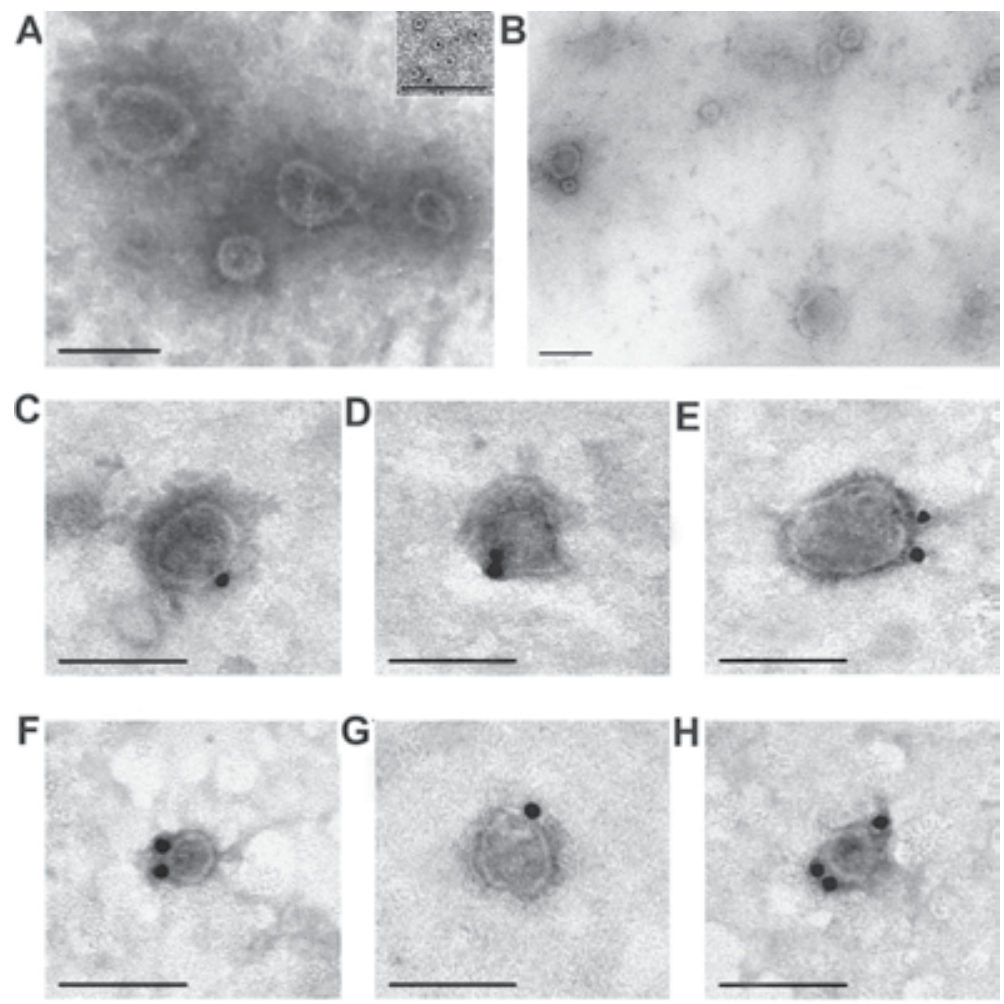

Figure 4.

Preparations of human placenta exosomes after filtration through $100 \mathrm{~nm}$ filter and gel filtration on Sepharose $4 B$. Vesicles $(A)$ and ferritin ring structures (10-14 $\mathrm{nm}$; inset in $A)$. Exosomes purified by gel-filtration (B), labeled with conjugates of gold nanoparticles with monoclonal antibodies against tetraspanin CD81 $(C-E)$ and CD63 $(\mathrm{F}-\mathrm{H})$. Transmission electron microscopy with negative contrast. Scale bar corresponds to $100 \mathrm{~nm}$.

sucrose gradient [26]. As a result, 2107 proteins have been identified, which include all major protein markers of exosomes previously detected.

We have analyzed a possible number of proteins in extra-purified exosomes after gel filtration. Exosome proteins were identified before and after gel filtration by MALDI MS and MS/MS spectrometry of protein tryptic hydrolysates after SDSPAGE and 2D electrophoresis (Figure 6).

Only 46 major and moderate protein spots were revealed on the gel after staining. Interestingly, only one of the spots corresponded to human serum albumin, lactoferrin, and lactadherin, while nine spots corresponded to different forms of beta-lactoglobulin. All other protein spots corresponded to various species of milk casein (number of spots): kappa-casein precursor (1), beta-casein (2), alpha-S1-casein (7), kappa-casein (10), and alpha-S1-casein precursor (14). Thus, the mixture of five relatively crude partially purified preparations of horse milk exosomes contains only nine different major and moderate proteins, while five of them consist of different caseins and their precursors.

It could be assumed that during gel filtration, the loss of a large part of the exosomes may occur, and as a consequence, the number of proteins analyzed in these exosomes may be underestimated. However, human placenta vesicles after gel filtration (fraction of the first peak) contain $~ 78 \%$ of CD9- and $74 \%$ of CD81positive vesicles (Figure $5 \mathrm{E}$ and $\mathrm{F}$ ). Thus, the yield of particles after gel filtration was relatively high up to $\sim 90 \%$. A similar result was obtained for horse milk exosomes. Consequently, the loss of the main part of the exosomes during gel filtration does not occur. 


\section{Flow cytometry analysis of the relative amount of exosomes containing on the surface CD9 and CD81 proteins after different stages of exosomes purifications}

CD9-exosomes

Exosomes after first ultracentrifugation

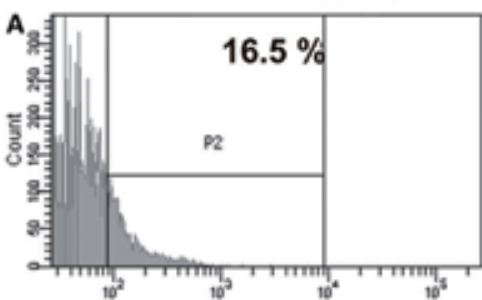

Exosomes after second ultracentrifugation


Exosomes after gel filtration (first peak)


Figure 5.

Flow cytometry analysis of exosome preparations after two stages of ultracentrifugation $(A-D)$ and gel-filtration $(E, F)$. The relative amount of vesicles containing CD9 (left) and CD81 (right) are shown.

After gel filtration, extra-purified exosomes isolated from horse milk contained only eight different major proteins, CD81, CD63, beta-lactoglobulin, and lactadherin, which were common to all preparations, and actin, butyrophilin, lactoferrin, and xanthine dehydrogenase which were found only in some of them [8]. Exosome preparations from human placenta contain only ten major proteins: CD81, CD63, hemoglobin subunits, interleukin-1 receptor, annexin A1, annexin A2, annexin A5, cytoplasmic actin, alkaline phosphatase, and serotransferrin [23].

After 2D electrophoresis, only 28 protein spots were found in human placenta exosomes, which corresponded to just nine different proteins and their isoforms. Overall, using 2 methods of electrophoretic analysis (1D and 2D electrophoresis), 12 proteins were identified in 4 exosome preparations: CD81, CD63, hemoglobin subunits, annexin A1, annexin A2, annexin A5, cytoplasmic actin, alpha-actin-4, alkaline phosphatase, serotransferrin, human serum albumin, and immunoglobulins. Ferritin completely disappears after gel filtration and exosome treatment with proteolytic enzymes. After treatment of exosome preparations with trypsin and chymotrypsin, the protein bands corresponding to human serum albumin and immunoglobulins according to SDS-PAGE data almost wholly disappeared. Therefore, it cannot be excluded that human serum albumin and immunoglobulins form relatively stable complexes with exosome membrane proteins (i.e., tetraspanins) or interact directly with the surface of exosomes. 


\section{Isoelectrofocusing $\quad \mathbf{k D a}$}

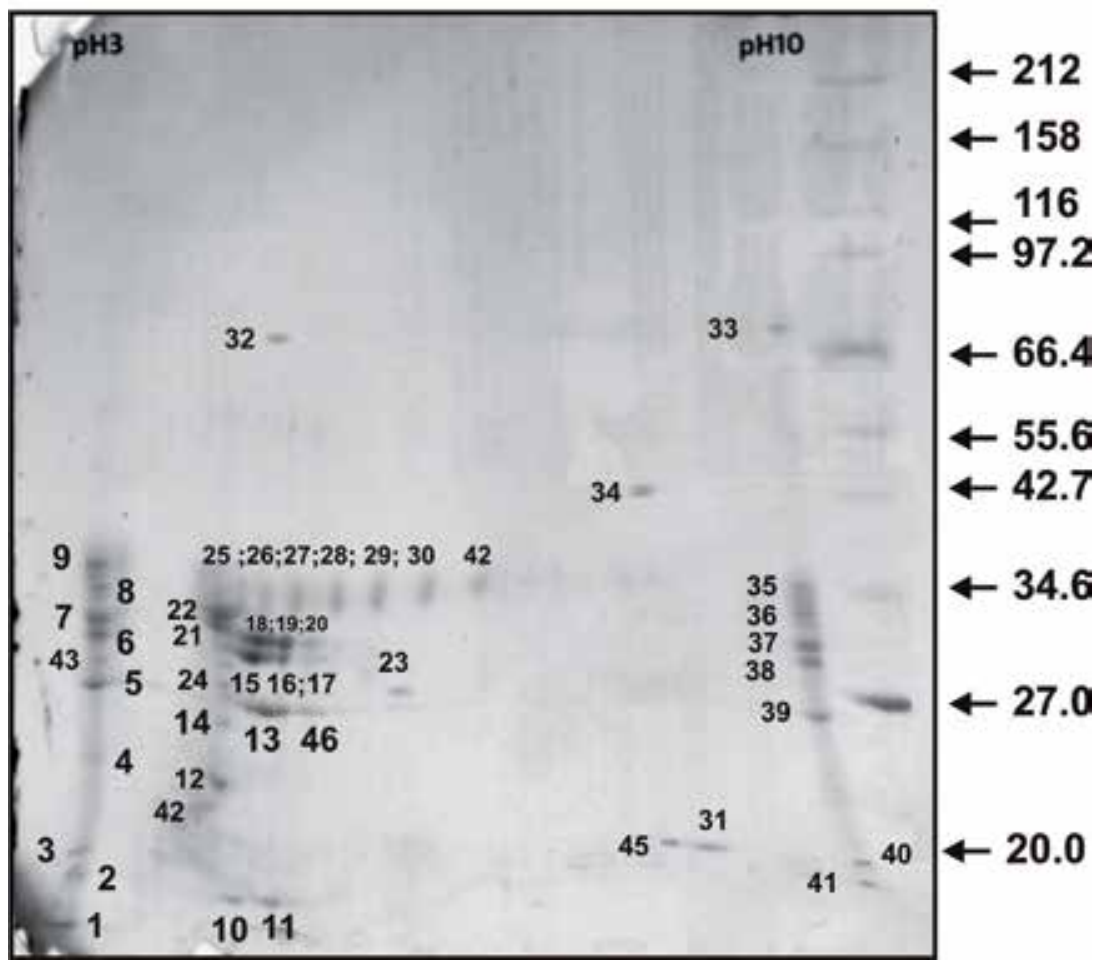

Figure 6.

2D gel electrophoresis of horse milk exosome proteins. A mixture of five crude horse milk exosome preparations was obtained by centrifugation and ultrafiltration through $100 \mathrm{~nm}$. The sample was separated by isoelectrofocusing and then by SDS-PAGE in denaturing conditions. The spots were stained with Coomassie $R-250$ and then cut; proteins were subjected to trypsinolysis for their identification using MALDI MS and MS/ MS spectrometry.

Authors of $[27,28]$ discovered proteins of oxidative phosphorylation in the urinary exosomes. It is known that the formation of exosomes occurs in the cell cytoplasm. However, oxidative phosphorylation is a typical function of the mitochondria. Mitochondrial enzymes of the oxidative phosphorylation and Krebs cycle are absent in the cytoplasm. The question may arise how these enzymes could get into the cytoplasm and then to exosomes. Mechanism of such a process has not been described anywhere. These results may be explained if the authors destroyed cells and the mitochondria and then co-isolated proteins of oxidative phosphorylation (or fragments of the mitochondria) with exosomes.

Several articles describe casein in milk exosome preparations. Precursors of caseins undergo posttranslational processing in the Golgi complex. The cytoplasm of mammary gland cells never contains any casein that may get inside the multivesicular bodies and exosomes. As one can see from Figure 6, crude horse milk exosome preparations include 46 major and moderate protein spots (number of spots) including some spots of casein isoforms: kappa-casein precursor (1), beta-casein (2), alpha-S1-casein (7), kappa-casein (10), and alpha-S1-casein precursor. Casein isomers were found only in crude exosome preparations, obtained by centrifugation. All forms of caseins have disappeared after gel filtration, and they were found just in the second peak containing contaminating proteins. Thus, it is possible that hundreds to thousands of proteins described in crude milk exosome preparations, in fact, are not intrinsic components of exosomes and are co-isolating impurities. 
In this regard, we could note a critical review by academician Sverdlov, who believes that in the case of exosomes, there is an incorrect overestimated quantitative assessment of their internal molecular components, which, in his figurative expression, "would certainly make Amedeo Avogadro cry" [29]. We are sure that the real number of exosome proteins described previously using crude preparations of milk exosomes may be very much overestimated.

It is necessary to note another potential method leading to overestimation of the protein content in exosomes. The technique identifies proteins of exosome crude preparations by bulk trypsinolysis of proteins with subsequent separation of peptides using various HPLC. For example, cow milk exosome preparations were isolated by centrifugation and ultracentrifugation [29]. Purified exosomes after trypsin treatment were subjected to reverse-phase chromatography and then fractionated on a nanoLC column connected to the tandem mass spectrometer. This approach generated near 2100 proteins detected in milk exosomes. The question is what possible errors in the estimation of protein number might be using this approach?

After SDS-PAGE all proteins and peptides with molecular mass $10 \mathrm{kDa}$ and less usually leave the gel during the gel staining with Coomassie blue. Exosomal peptides and small proteins are still practically not investigated. It was shown that peptides and small proteins are easily detected using cyano-hydroxycinnamic acid as a matrix for MALDI-TOF MS and MS/MS; these substances may be directly detected even in native cells [30-32]. Other low-molecular-mass components (lipids, sugars, oligonucleotides) will appear in the MALDI spectra in these conditions only if its content is 100-1000-fold higher than of peptides. Vesicles, eluted from anti-CD81-Sepharose with $0.15 \mathrm{M} \mathrm{NaCl}$ (Figure 7), contained a mixture of peptides and its complexes.

Small proteins and peptides of the fraction, eluted from anti-CD81-Sepharose with $0.15 \mathrm{M} \mathrm{NaCl}$, were analyzed by MALDI mass spectrometry in 2-12 kDa range.

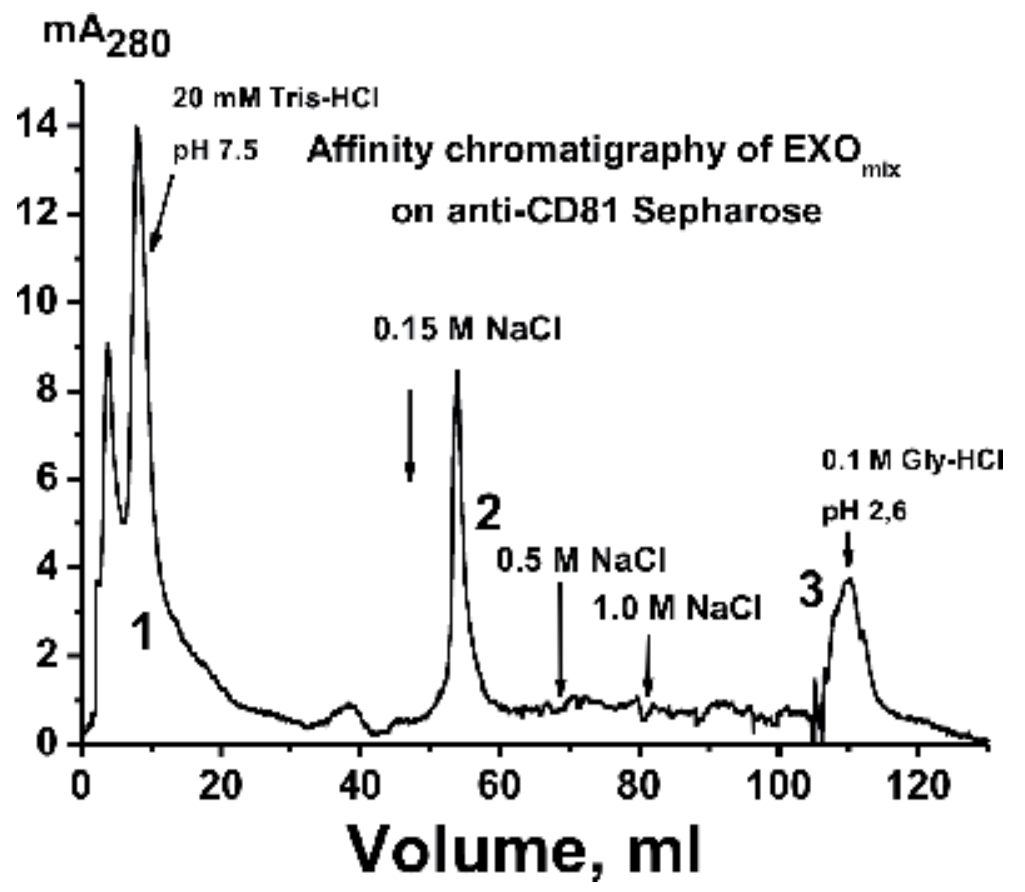

Figure 7 .

Affinity chromatography of a mixture of five exosome preparations on anti-CD81-Sepharose: (-), absorbance at $280 \mathrm{~nm}\left(A_{280}\right)$. Peak numbers and elution conditions are indicated in the picture. 


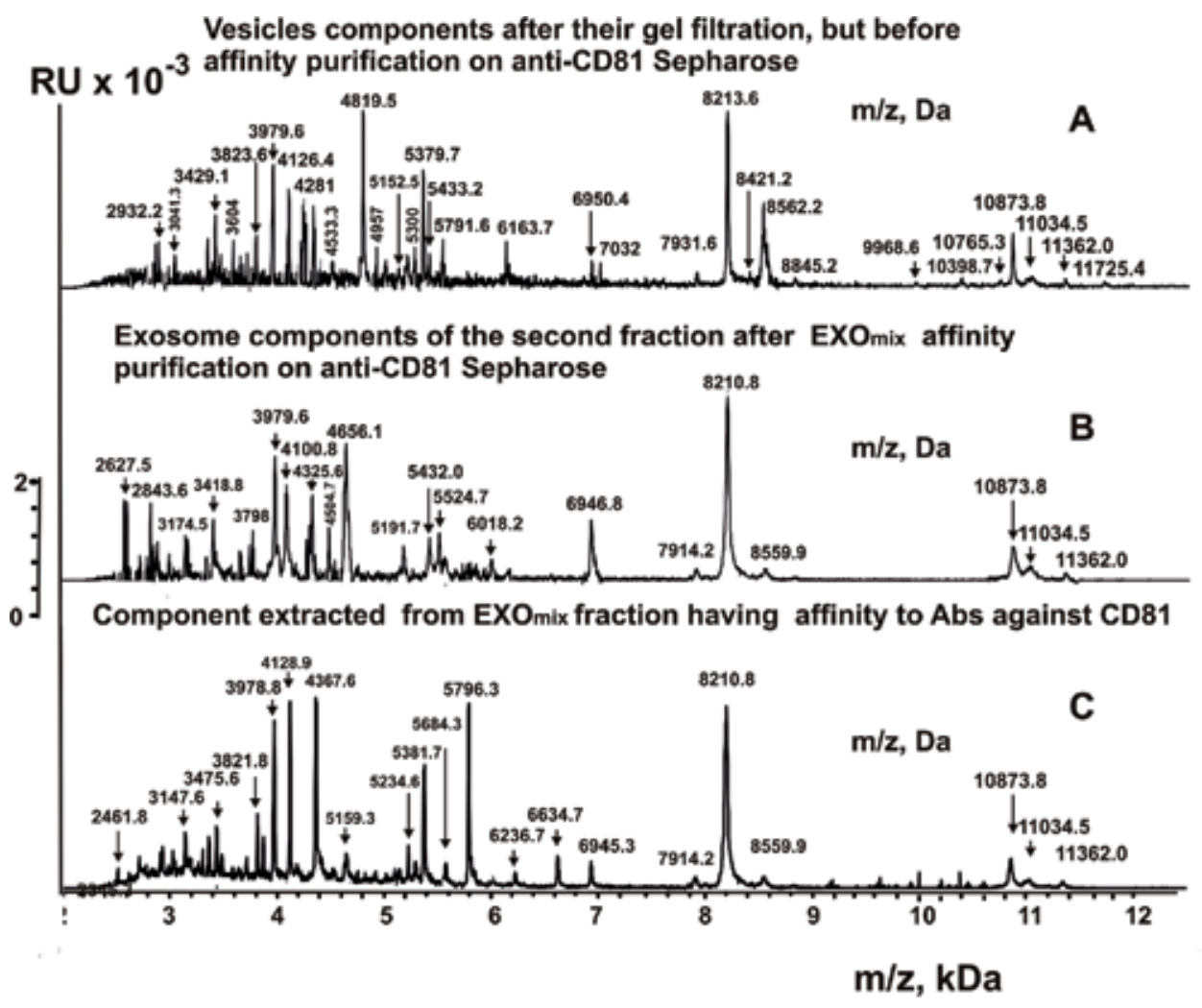

Figure 8.

MALDI mass spectra of human placenta exosomes obtained with gel filtration $(A)$ and anti-CD81-Sepharose before $(B)$ and after $(C)$ trifluoroacetic acid and acetonitrile treatment. The analysis was performed using 2-12 kDa range of MALDI-TOF mass spectrometer.

The samples were examined before and after destruction of exosomes with trifluoroacetic acid (Figure 8).

Similar results were obtained for horse milk exosomes before and after gel filtration and after affinity chromatography on anti-CD81-Sepharose. MALDI mass spectra demonstrate many various small proteins and peptides with molecular masses in the range 2-9 kDa. The fractions were treated with proteases. Figure 9A shows MALDI MS spectra of peptides before the protease treatment. Spectra after the incubation with trypsin (Figure 9B), chymotrypsin (Figure 9C), and proteinase $\mathrm{K}$ (Figure 9D) doesn't contain any peaks $>3 \mathrm{kDa}$ but include peaks corresponding to the shorter products after hydrolysis. Masses of these shorter products do not coincide with the ones in Figure 9A.

Exosomes of the horse milk and placenta in addition to proteins $>10 \mathrm{kDa}$ contain small proteins and peptides. These peptides may be analyzed with highly sensitive methods of shotgun ESI-MS/MS analysis and lead to the incorrect number of large proteins in the exosome preparations. The structure of these small proteins and peptides is not yet established; one cannot exclude that initially they may be fragments of larger proteins. In that case, the identification of large proteins from the results of the shotgun analysis of peptides will lead to an incorrect determination of many proteins.

Some literature data on the analysis of the various components of milk exosomes, including lipids, mRNA, microRNA, and proteins, are described below. In most of the published papers, milk vesicles were isolated using only different centrifugation, and analysis was done only on crude preparations of exosomes. 


\section{Exosomes of peak 2 after chromatography on anti-CD81 Sepharose}

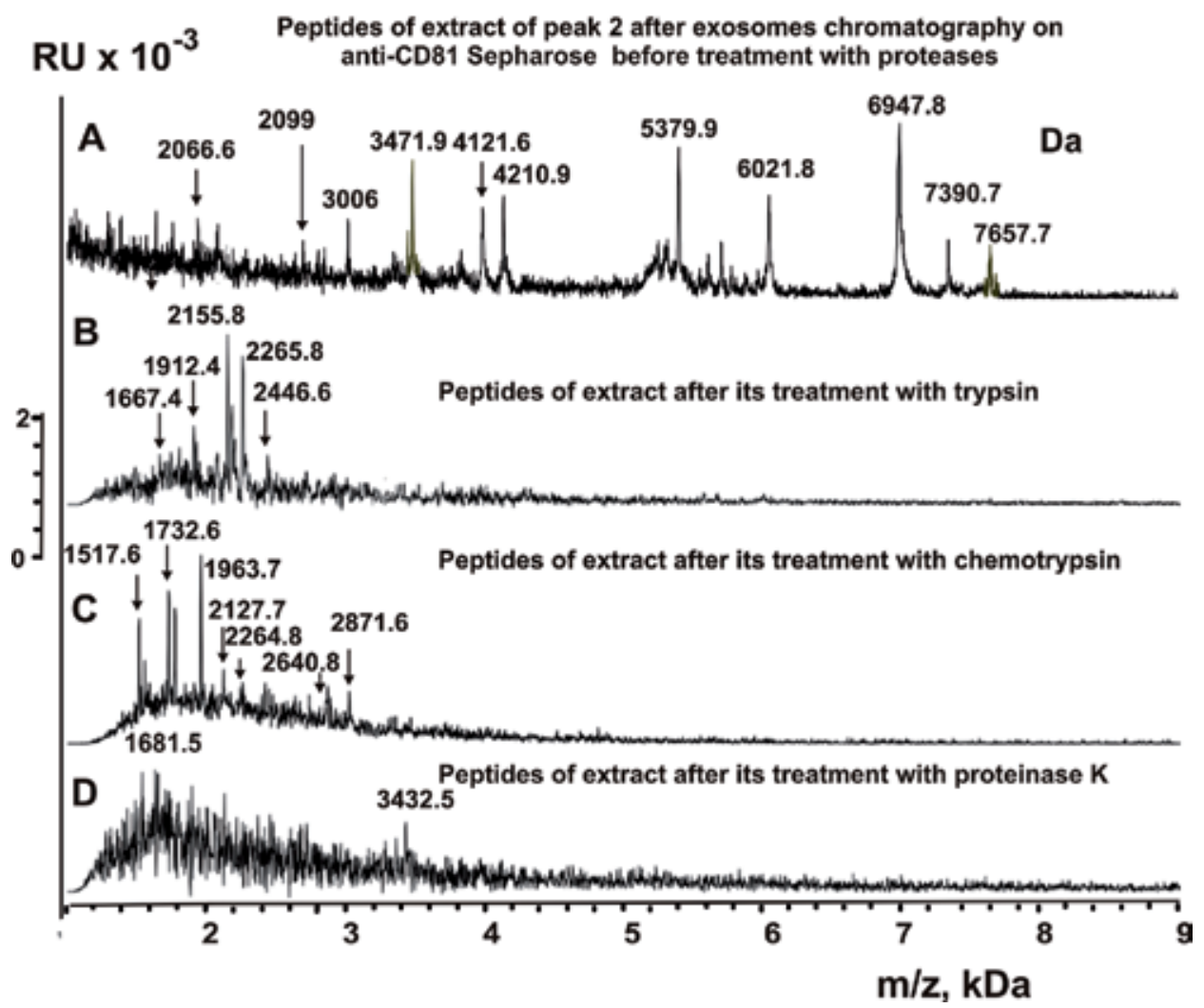

Figure 9.

MALDI mass spectra of $<10 \mathrm{kDa}$ extract of horse milk exosomes isolated on anti-CD81-Sepharose before $(A)$ and after their treatment with trypsin $(B)$, chymotrypsin $(C)$, and proteinase $K(D)$.

According to our data, the second peaks after gel filtration of exosomes (Figure 3) contain many different milk proteins as well as RNA, lipids, and oligosaccharides. Thus, the analysis of crude preparations of exosomes without additional purification can lead to the overestimation of proteins and other biochemical components of exosomes. Therefore, the literature data on milk exosomes described below must be analyzed very gingerly and critically, taking into account the above data.

\section{Biochemistry of milk exosomes}

There is no doubt that the biological functions of milk exosomes are due to the proteins, lipids, and nucleic acids that make up their composition. There are different estimations of the number of protein and nucleic acid molecules, which may be located in exosomes. Up to 16-20 thousands of different mRNA [33,34] and up to 2 thousands of proteins [35] are described in cow and human exomes in various works. Prof. Sverdlov in [29] shows that no more than 1,6 thousand of mRNA molecules may fit in a single exosome, since it sounds very doubtful that such amount of different mRNA molecules may be transferred with exosomes. We believe that the papers describing thousands of proteins and nucleic acids in the preparations of exosomes may be due to the analysis of insufficiently purified preparations of exosomes, coisolating with milk proteins and nucleic acids (of fat milk globules or other vesicular or non-vesicular particles). This assumption is well supported by the data, described 
in $[8,23]$. As mentioned above, most papers dedicated to the study of exosomes analyze very crude preparations. Below we describe the structure and possible biological functions of major components of milk exosomes following the data given in various papers without critical analysis. However, taking into account the data provided above, it is necessary to examine the given information critically.

\subsection{Proteins of milk exosomes}

Data on the protein composition of milk exosomes significantly varies between papers. There is no doubt that proteins play a crucial role in the physiology of milk exosomes; the other obvious thing is that most of the proteins, secreting in milk, cannot be a natural part of exosomes, due to the mechanism of exosome generation in the cell [8]. It was shown that the exosome proteome changes depending on the physical activity, nutrition, or various infections, suggesting that protein content of milk is an excellent biomarker [13]. Also, the data indicate that the concentration of exosomal proteins and the exosomes in milk is significantly lower in mature milk than the early stages of lactation [12].

Depending on the method of proteome analysis used, researchers found hundreds of proteins in milk obtained from different mammals: 100 [36], 200 [37], 400 [38], 600 [33], and even 1900 [35] or 2100 [26] proteins in exosome preparations. Such a significant difference may be due both to different levels of purification of the exosome preparations and to a substantial difference in the protein content in vesicles obtained from various sources. However, it is evident that exosomes cannot contain several thousand proteins.

According to literature data, exosomes can contain proteins that control the cytoskeleton dynamics and membrane fusion: Rab proteins (GTPase family) [39]; Alix, TSG101, and other proteins of the endosomal sorting complex [40]; and proteins that participate in the binding and transport of miRNA, target cell recognition, and fusion (tetraspanins CD9, CD63, CD81). Members of the tetraspanins family mediate the adhesion of exosomes on the surface of the recipient cell and are essential structural components of exosomal membranes [41, 42]. Also, one cannot exclude that exosomes may contain various enzymes: proteases and their activators, peroxidases, lipid kinases, and other proteins that exhibit catalytic activity [43]. Exosomes may be rich in cytoskeleton proteins (actin, tubulin, cofilin), proteins of membrane transport and heat shock (HSP60, HSP70, HSP90), and proteins involved in intracellular signal transduction like Wnt proteins, which activate the Wnt signaling pathway $[44,45]$. The presence of proteins involved in the formation of vesicles (ADP-ribosylation factor) [46] and membrane fusion EHD1 (testilin) [47] confirms the endosomal origin of exosomes. The presence of integrins in milk exosomes is an essential marker of the internalization and biological activity of extracellular vesicles, which can also be used to predict their possible direction of delivery [48]. In general, exosomes include proteins that make up the endosome, plasma membrane, or cytosol, while proteins from the nucleus, mitochondria, endoplasmic reticulum, and Golgi must be absent in exosomes. These observations emphasize the specificity of the formation of these vesicles and demonstrate that exosomes are a special subcellular compartment but not random cell fragments [49].

The proteins described above are common to all types of exosomes, including milk exosomes, which in addition to these proteins contain specific milk proteins. Several milk proteins were characterized in milk exosomes: caseins, lactoglobulin, lactoferrin, CD36, and polymeric immunoglobulin receptor precursor [6]. The CD36 protein in cells mediates phagocytosis and cell adhesion and binds low-density oxidized lipoproteins [50], but its role in milk exosomes requires further establishment. It is worth to say that not all the proteins described in the milk exosomes 
in literature may be really exosome components. For example, in highly purified preparations from horse milk, the caseins were not defined as exosomal components but co-isolated with exosomes during the ultrafiltration and ultracentrifugation and were separated from exosomal fraction by gel filtration [8]. In this regard, additional studies of milk exosomes that do not contain impurities of co-isolating proteins are required. Improvement of methods of exosome purification will make it possible to determine the protein composition of milk exosomes more accurately and to understand the role of specific proteins in their structure and functions.

Since the formation of the exosomal membrane occurs from the endosomal membrane, the exosomes carry similar protein markers as the cells secreting them. An example is the peripheral membrane protein MFG-E8 (lactadherin), a glycoprotein containing several domains, some of which are necessary for binding to the membrane, while some others carry integrin binding sites. Expression of MFG-E8 in the cells increases the secretion of vesicles since MFG-E8 may play a unique role in the secretion of membrane vesicles by budding or splitting the plasma membrane or by exocytosis of multivesicular bodies [51]. The expression of this protein in mammary gland increases during lactation. Human milk exosomes contain TGFb2 protein, the increased expression level of which is associated with the development of breast cancer [52].

Compared to cow milk fat globule membrane, the same proteins were the most abundant in cow milk exosomes: butyrophilin, xanthine oxidase, adipophilin, and lactadherin [26]. During the mastitis caused by Staphylococcus aureus, relative concentrations of several proteins were increased 9-20 times in cow milk exosomes: protein S100-A12, cathelicidin-2, annexin A3, myeloperoxidase, haptoglobin, histone $\mathrm{H} 2 \mathrm{~A}$, and $\mathrm{H} 4$ [13].

Flow cytometry has shown that human B-cell exosomes, unlike human milk ones, give a positive signal to tetraspanins CD40, CD54, and CD80 in addition to CD63 and CD81, which are detected in milk exosomes. On the contrary, MUC-1 protein is present in milk exosomes but absent in B-cell-derived exosomes [6].

In the sediments obtained by the centrifuging of cow's milk at 35,000 $\times \mathrm{g}$ and $100,000 \times \mathrm{g}, \mathrm{CD} 9, \mathrm{CD} 63$, and CD81 tetraspanins were found mainly in the sediment after $100,000 \times \mathrm{g}$, indicating the presence of exosomes. Also, sediment obtained by $100,000 \times \mathrm{g}$ centrifugation contained a higher number of complement proteins $\mathrm{C} 2$, C6, and C7 than the 35,000 $\times$ g one, which indicates the presence of multiple types of extracellular vesicles of this sediment. Complement C8 beta chain, C1GALT1specific chaperone 1 , cartilage-associated protein, $\alpha$-mannosidase 2 , and procollagenlysine 2-oxoglutarate 5-dioxygenase 3 were found only in the $100,000 \times \mathrm{g}$ fraction. Functional analysis of these proteins revealed three functions: galactosidase, glycosyltransferase, and peptidase activities. It cannot be excluded that proteins found in the milk exosome fraction are involved in the regulation of translation, protein maturation, and maintenance of the cellular structure. Also, analysis of human cells after fusion with milk exosomes has shown some exciting changes in expression of proteins responsible for translation (ribosomal subunits, initiation, and elongation), innate immunity, vesicular transport, and cell migration [48].

Some data indicate that human milk exosomes have a unique composition of proteins, distinct from other milk components. Transmembrane (CD9, CD63, CD81, lactadherin, guanine nucleotide-binding protein), cytosolic (annexins A2, A4-7, and A11, Ras-related proteins Rab, syntenin), and also intracellular proteins (endoplasmin, calnexin) are presented in human milk exosomes. The unique combination of proteins with different biological roles, cell growth, inflammation, and others indicates that milk exosomes may play a key role in the infant's intestinal immune system. The list of the most represented exosomal proteins according to the literature data is combined in Table 1. 


\begin{tabular}{|c|c|c|c|c|}
\hline $\begin{array}{l}\text { Source } \\
\text { of milk } \\
\text { exosomes }\end{array}$ & $\begin{array}{l}\text { Most represented } \\
\text { proteins }\end{array}$ & $\begin{array}{c}\text { Number } \\
\text { of proteins } \\
\text { described }\end{array}$ & $\begin{array}{l}\text { Method of protein } \\
\text { analysis }\end{array}$ & $\begin{array}{l}\text { Protein content } \\
\text { compared in }\end{array}$ \\
\hline Cow [26] & $\begin{array}{c}\text { Butyrophilin } \\
\text { Xanthine oxidase } \\
\text { Adipophilin } \\
\text { Lactadherin }\end{array}$ & 2107 & Trypsinolysis, LC-MS/MS & $\begin{array}{l}\text { Exosomes and } \\
\text { milk fat globule } \\
\text { membrane }\end{array}$ \\
\hline $\begin{array}{l}\text { Human } \\
{[36]}\end{array}$ & $\begin{array}{c}\text { Lactoferrin } \\
\text { Tenascin } \\
\text { Serum albumin } \\
\beta \text {-Casein } \\
\text { Xanthine } \\
\text { dehydrogenase } \\
\text { Polymeric Ig receptor }\end{array}$ & 115 & Trypsinolysis, LC-MS/MS & $\begin{array}{c}\text { During } 12 \text { months of } \\
\text { lactation }\end{array}$ \\
\hline Cow [13] & $\begin{array}{l}\text { Butyrophilin } \\
\text { Xanthine } \\
\text { dehydrogenase } \\
\text { Lactadherin } \\
\text { Fatty acid synthase }\end{array}$ & 2299 & $\begin{array}{c}\text { Trypsinolysis, LC-MS/MS } \\
\text { with iTRAQ }\end{array}$ & Norm and mastitis \\
\hline $\begin{array}{l}\text { Human } \\
\text { [35] }\end{array}$ & $\begin{array}{c}\text { CD9, CD63, CD81 } \\
\text { Flotilin } \\
\text { Lactadherin } \\
\text { Annexins } \\
\text { G-protein subunits } \\
\text { Ras-related proteins } \\
\text { Rab } \\
\text { syntenin }\end{array}$ & 2698 & $\begin{array}{l}\text { SDS-PAGE, trypsinolysis, } \\
\text { LC-MS/MS }\end{array}$ & $\begin{array}{c}\text { Extracellular vesicles } \\
\text { and high-density } \\
\text { complexes }\end{array}$ \\
\hline Horse [8] & $\begin{array}{l}\beta \text {-Lactoglobulin } \\
\text { Lactadherin } \\
\text { Actin } \\
\text { Butyrophilin } \\
\text { Lactoferrin }\end{array}$ & 8 & $\begin{array}{c}\text { SDS-PAGE, } \\
\text { 2D-electrophoresis, } \\
\text { trypsinolysis, } \\
\text { MALDI-TOF-MS/MS }\end{array}$ & $\begin{array}{l}\text { Before and after gel } \\
\quad \text { filtration }\end{array}$ \\
\hline Swine [33] & $\begin{array}{c}\text { Fibronectin } \\
\text { Thrombospondin } \\
\text { Albumin } \\
\text { Lactotransferrin } \\
\text { Ceruloplasmin } \\
\text { Complement C4 } \\
\alpha \text {-Glucosidase }\end{array}$ & 571 & $\begin{array}{l}\text { SDS-PAGE, trypsinolysis, } \\
\text { LC-MS/MS }\end{array}$ & \\
\hline
\end{tabular}

Table 1.

Most represented proteins of milk exosomes.

The data on the protein composition of milk exosomes gives new information on the structure and biological significance of these vesicles and reveals the potential role of exosomes in the physiology of the mammary gland. Investigation of the proteome of highly purified milk exosomes compared to milk proteome can shed light on the real protein composition of exosomes; these data may be translated to the exosomes obtained from other biological liquids. Results of milk exosome proteome analysis will possibly lead to their use in medicine as biocompatible carriers of drugs or personal therapy tools.

However, as shown above, not all proteins found in crude vesicle preparations are proper exosome proteins. At the same time, it is possible that some proteins associated with the surface of the vesicles may also play some unique role in the exosomes' functioning. The identification of hundreds and thousands of proteins 
in the composition of the exosomes seems to us enormously overestimated. Also, the diversity of proteins found in exosomes raises questions about whether proteins that coprecipitated with these vesicles, as well as possible intrinsic minor proteins of exosomes, have an or have no important role in the biological functions of exosomes.

\subsection{Lipids of exosomes}

The exosome membrane is enriched with specific lipids (phosphatidylcholine, cholesterol, sphingomyelin, ceramides) and has a unique protein composition that characterizes them as independent compartments [53,54]. The minimum size of exosomes depends on the structure of the lipid bilayer, which is about $5 \mathrm{~nm}$ thick and has sufficient rigidity to form vesicles of $40 \mathrm{~nm}$ in size [55]. The lipid composition of exosomes greatly varies, due to differences in cell types, conditions of cell growth and development, as well as the use of different methods for isolating exosomes and analyzing them.

The first works on the lipid composition of exosomes were carried out using a thin layer and gas-liquid chromatography. The results obtained using these methods cannot be considered fully quantitative, since the phosphatidylcholine, phosphatidylserine, phosphatidylinositol, and phosphatidic acids migrate together and are presented in the single band after separation. Similarly, sphingomyelin and ganglioside GM3 are not separated and, therefore, are taken into account together in the quantitative analysis. Today, these methods are considered obsolete for the analysis of lipids of exosomes, and most studies use modern mass spectrometry technology [56].

It was found that different classes of lipids are asymmetrically distributed in the membrane of exosomes, so sphingomyelin and other sphingolipids, as well as phosphatidylcholines, are mainly located in the outer layer of the membrane, while the different classes of lipids are located in the inner layer [57]. However, the established asymmetry of the membrane bilayer can be altered by the action of particular enzymes, such as flippases, floppases, and scramblases [58, 59].

Phosphatidylserine in exosomes, as in the plasma membrane, is located in the inner lipid layer [57], but several studies have shown its presence also in the outer layer together with annexin 5. It is known that the presence of phosphatidylserine in the outer lipid layer activates blood cells and acts as a signal to macrophages to capture [60].

The composition of certain classes of lipids in the exosomal membranes secreted by different cell types may be similar or not to the parental cells. Exosomes contain up to 2-3 times more cholesterol, sphingomyelin, glycosphingolipids, serine, and saturated fatty acids. In addition, GM3 ganglioside [56, 61], ceramides, and their derivatives $[57,62,63]$ are also present in exosomes in significant amounts. In most cases, exosomes contain fewer phosphatidylcholines than their parent cells, and no noticeable differences in the content of phosphatidylserine in exosomes and parent cells were found [64].

The bis(monoacylglycero)phosphates (BMP) are present in the membranes of the intraluminal vesicles of multivesicular bodies and, as stated in [57], can also be contained in the exosomes. It was shown that BMP are not transferred to exosomes but, with high probability, are included in the intraluminal vesicles of those multivesicular bodies that are associated with lysosomes. In this regard, it is believed that the primary purpose of the BMP is to promote the stability and integrity of the lysosomes. Also, it is a necessary cofactor in the process of catabolism of sphingolipids in lysosomes [65]. 
The stiffness of exosomal membranes increases with the transition from acidic to neutral $\mathrm{pH}$ values, suggesting that during the secretion of the exosomes from the multivesicular bodies, some reorganization of the membrane occurs. At neutral $\mathrm{pH}$, the packaging of lipids on the surface of exosomes is dense, but the transmembrane movement of lipids increases. Such a flip-flop effect (the transition of an individual molecule from one layer to another) disrupts the asymmetric distribution of lipids between the membrane layers. A uniform distribution of phosphatidylethanolamine between the two layers of the exosomal membrane [66] was shown; on the contrary, in the plasma membrane, it is located mainly in the inner lipid layer [67].

The lipids of the exosomal membranes are not inert molecules but participate in the biogenesis of vesicles and affect their biological activity. Besides, exosomes carry carbohydrate groups on the outer surface; the presence of mannose, polylactosamine, $\alpha-2,6$ sialic acid, and complex N-linked glycans was shown [68].

Lipids form the basis of the exosome membrane; the composition of exosomal lipids significantly differs from the composition of lipids of non-vesicular structures.

The above data reflect the content of lipids and oligosaccharides in the composition of mainly crude preparations of exosomes. However, as noted above, the second peak after gel filtration of exosome preparations also contains various lipids and oligosaccharides. Therefore, it cannot be excluded that part of the lipids and polysaccharides found in the vesicles will be attributed in the future to the highmolecular complexes co-isolating with exosomes during different centrifugations.

\subsection{Nucleic acids of milk exosomes}

Several works show that milk exosomes contain different types of nucleic acids, including functional mRNA with a poly(A) tract at the $3^{\prime}$-end $[33,34,41]$ and microRNA $[34,69,70]$. Currently the composition of nucleic acids in milk exosomes is described in the case of human $[71,72]$, cow $[73,74]$, porcine $[33,75]$, and rat [10] milk.

As we have noted above, the number of individual RNA molecules in some papers may be overestimated due to various reasons. For example, it has been shown that exosomes of porcine milk contain up to 16,304 mRNA. Most of these molecules may be involved in the development of the immune system, cell proliferation, and intercellular signal transduction. Protein products of identified mRNAs might be involved in the regulation of metabolism and the growth of the piglet's intestines [33].

Among the 19,230 mRNAs found in cow milk exosomes, the most common mRNA molecules are various isoforms of the mRNA of milk and ribosomal proteins: inositol 1,4,5-triphosphate receptor type 1; $\alpha$-lactalbumin; $\beta$-lactoglobulin; caseins $\beta, \kappa$, and $\alpha$; ribosomal proteins S28, S3, P0, L32, L21, and H1 histone; and many others. Since the expression level of most of the 50 most represented transcripts in exosomes exceeds the standard in supernatants obtained by ultracentrifugation, the authors of the [34] conclude that the mRNAs are concentrated in the exosomes of milk. Unfortunately, it is difficult to agree with this statement, since the process of enrichment of exosomes with mRNA transcript molecules during their biogenesis is entirely unclear, as well as it is difficult to suggest a mechanism by which this unimaginable number of mRNA molecules can fit into an exosome with a diameter of 40-100 nm. At the same time, human and porcine milk exosomes contain little or no $18 \mathrm{~S}$ and $28 \mathrm{~S}$ rRNA $[41,70]$, which correlate with the mechanism of exosome biogenesis. 
It is shown that miRNA is ubiquitous in tissues and biological fluids and was previously isolated from and associated with exosomes formed from various biological fluids (serum, saliva, urine) and homogenates of body tissues, including the mammary gland [76]. Some studies have shown that the exclusion of milk exosomes and their contents, including exosomal miRNAs, from nutrition in newborns leads to impaired purine metabolism, as well as impaired spatial learning and memory in humans and mice $[72,77]$. These data indicate the undesirability of feeding newborns with infant formulas since their content of microRNAs is absent or much lower than breast milk [78].

Analysis of nucleic acids isolated from human milk exosomes revealed about 452 pre-miRNAs, which is approximately $32 \%$ of 1424 miRNAs described for humans. These 452 pre-miRNAs lead to the generation of 639 mature miRNAs, many of which are involved in the regulation of immune responses. At the same time, the distribution of different miRNAs in human milk exosomes is irregular; some miRNAs are represented in a million copies and others in single molecules. Ten miRNAs compose up to $62 \%$ of the total number of miRNA; the most represented miRNAs are miR-30b-5p, miR-141-3p, miR-148a-3p, miR182-5p, miRs let-7a-5p and let-7f-5p, miR-29a-3p, miR-146b-5p, miR-182-5p, miR-200a-3p, and miR-378a-3p [79]. Interestingly miR-148a-3p may comprise up to $35 \%$ of the total number of miRNAs of human milk exosomes. miR-148a specifically controls the expression of several genes, including the TGIF2, which encodes a transcription factor, inducing the expression of various transporters and drug-metabolizing enzymes [80], and the DNMT3B gene, which encodes DNA methyltransferase [81].

Transcriptome of cow milk exosomes contain various miRNAs, the most common of which are bta-miR-320a-1, bta-miR-193a, bta-miR-2284x, bta-mir-181b-1, bta -miR-19b-2, bta-miR-135a-1, bta-miR-200c, bta-miR-142, bta-miR-2887-1, bta-miR-30b, bta-miR-let7i, and bta-miR-6522 [72]. It was shown that cow milk exosomes penetrate intestinal and choroidal epithelial cells [82, 83] and macrophages [34], accumulate in peripheral tissues [84, 85], and transfer miRNA to the recipient cells [86]. Analysis of exosome bioavailability between species showed that microRNA of cow milk exosomes, after oral delivery to other organisms, is protected under the low $\mathrm{pH}$, RNase, and other factors of the gastrointestinal tract $[78,87,88]$.

Analysis of miRNA content in porcine milk exosomes revealed 366 premiRNAs, which can give rise to 315 mature miRNAs, and 176 of them were described in other sources. Functional analysis of porcine milk miRNA indicates their role in immune responses, and 14 of 20 of most represented miRNAs may be involved in the regulation of milk IgA production [69]. Also, it was shown that miR-148a, widely represented in the exosomes of human [71] and cow [89] milk, is also highly expressed during lactation in exosomes of porcine milk [70]. Other highly expressed miRNAs of porcine milk are miR-181 family (181a/181b/181c/181d), miR-30 family (b/c/d/e), let-7 family (a/b/d/f), and miR98 family. Thus, miRNAs included in these families can participate in the development of the digestive tract in piglets [69].

Nucleic acids play an essential role in biological functions of milk exosomes. The further investigations of milk exosome miRNA and mRNA variety will significantly expand the prospects of their practical use. However, when analyzing different RNA in exosomes, it should not be forgotten that exosomal preparations used in most of the papers described above were crude. Therefore, some of the detected RNA may be in the fraction with co-isolating proteins and their complexes, which may be separated from exosomes with gel filtration. 


\section{Milk exosomes: perspectives of use}

The first paper describing human milk exosomes was published in 2007 [6] and dedicated to the interaction of exosomes with blood cells in cell cultures. Preparations of human milk vesicles inhibited interleukin-2, $\gamma$-interferon, and tumor necrosis factor $\alpha$ production by peripheral blood mononuclear cells and stimulated the increase of Foxp $3^{+}$cell proportion in vitro.

Exosomes are natural vesicles with very promising perspectives for drug therapeutic nucleic acid delivery into the cells. One of the unresolved problems so far is the development of universal sources for isolation of preparative amounts of exosomes. The use of milk allows researchers to obtain exosome preparation several liters of milk at once that makes milk a cheap and unique source of exosomes.

Milk exosomes can be used for targeted drug delivery to cells. It is shown that exosomes of cow [83] and human [88] milk penetrate intestinal crypt-like cells. The possibility of milk exosomes to be used as agents for delivery of proteins, nucleic acids, and drugs makes the subject of its investigation extremely relevant. Since the components of cow milk can be used for therapy with significant limitations, since in this case the transmission of prion diseases cannot be excluded [90], analysis of exosomes isolated from other milk sources is very actual.

Encapsulation of curcumin in buffalo milk exosomes increased its stability in salivary, gastric, pancreatic secrets as well as in bile juice. Also, curcumin encapsulated in milk exosomes was successfully uptaken and trans-epithelial transported in Caco-2 cells [91]. Since curcumin is a hydrophobic and water-insoluble molecule, it binds to the exosomes and probably incorporates in exosomal membranes. Hydrophobic drug molecules (paclitaxel [92], doxorubicin [93], and others) can also be delivered via milk exosomes with the same mechanism. Similar results were obtained in the case of chemically synthesized siRNA [86]. Transfection of siRNA in cow milk exosomes protects it from the activity of digestive juices and increases delivery to Caco-2 cells compared to the control samples.

According to several works, milk exosomes contain antibody molecules on the surface. Transport of IgG molecules in the intestine occurs as a result of binding to neonatal Fc receptor ( $\mathrm{FcRn}$ ). Cow milk-derived exosomes were successfully delivered to the mice liver, heart, spleen, lungs, and kidneys after the oral administration [94].

Auspicious work shows the possibility of transfer of bovine leukemia virus proteins Env (gp51) and Gag (p24), but not viral DNA with milk exosomes obtained from infected cattle [95]. This route of viral protein delivery doesn't require viral infection since that may have the potential of use for immunization and/or vaccination.

Incubation of human milk exosomes, but not the blood plasma exosomes with monocyte-derived dendritic cells, results in DC-SIGN inhibition of HIV infection of dendritic cells and protects from HIV transfer to CD4 ${ }^{+} \mathrm{T}$ lymphocytes [96]. These results may partially explain why some breastfeed infants do not get infected from HIV-infected mothers.

Yak milk exosomes facilitate survival of intestine cells in hypoxic conditions in vitro and have significantly higher activity than cow milk exosomes. Yak milkderived exosomes also decrease the expression of p53, increase the expression of oxygen-sensitive prolyl hydroxylase, and decrease the expression of vascular endothelial growth factor via the hypoxia-inducible factor- $\alpha$ in cell cultures [97]. Human milk exosomes protect intestinal epithelium cells in vitro from oxidative stress and probably defend newborns from enterocolitis [98]. 
It should be noted that the correct use of vesicles for medicine still requires extra-purified exosome preparation and analysis of the functioning of such exosomes. Also, it cannot be excluded that any proteins and other biologically active molecules firmly connected with the surface of vesicles can also be necessary for the manifestation of exosome biological functions. However, this issue also requires further research.

\section{Conclusions}

Milk is more than a source of nutrients and vitamins for newborn [99]; it contains different proteins and protein complexes [100] with very diverse functions. Milk is a biological liquid containing vesicles of different size and shapes. Exosomes are natural vesicles with a diameter of 40-100 nm and are found in milk obtained from human, cow, horse, camel, mice, rat, swine, and some other mammalian species. There is no doubt that milk obtained from any source contains such structures. Many biological effects are attributed to exosomes, and researchers are particularly interested in milk exosomes, since they can be used as carriers of drugs and therapeutic nucleic acids for delivery to cells. The physicochemical properties and biological functions of exosomes are primarily determined by their biochemical composition-the structure of lipids, proteins, and nucleic acids. The prospects for the further practical use of milk exosomes in medicine and biotechnology largely depend on investigations of the fine structure and biological functions of exosomes free of various contaminating impurities.

\section{Acknowledgements}

This research was made possible by a grant of the Russian Scientific Foundation to Sergey Sedykh \#18-74-10055 (isolation, biochemistry, morphology of milk exosomes) and by the Russian State funded budget project of ICBFM SB RAS to Georgy Nevinsky \# AAAA-A17-117020210023-1 (perspectives of use).

\section{Conflict of interest}

The authors declare no conflict of interest. 


\section{Author details}

Sergey E. Sedykh ${ }^{1,2 *}$, Evgeniya E. Burkova ${ }^{1,2}$, Lada V. Purvinsh ${ }^{1,2}$, Daria A. Klemeshova ${ }^{1}$, Elena I. Ryabchikova ${ }^{1,2}$ and Georgy A. Nevinsky ${ }^{1,2}$

1 Siberian Branch Russian Academy of Sciences, Institute of Chemical Biology and Fundamental Medicine, Novosibirsk, Russian Federation

2 Faculty of Natural Sciences, Novosibirsk State University, Novosibirsk, Russian Federation

*Address all correspondence to: sedyh@niboch.nsc.ru

\section{IntechOpen}

(C) 2019 The Author(s). Licensee IntechOpen. This chapter is distributed under the terms of the Creative Commons Attribution License (http://creativecommons.org/licenses/ by/3.0), which permits unrestricted use, distribution, and reproduction in any medium, provided the original work is properly cited. (cc) BY 


\section{References}

[1] Qin J, Xu Q. Functions and application of exosomes. Acta Poloniae Pharmaceutica;71:537-543

[2] De Toro J, Herschlik L, Waldner C, Mongini C. Emerging roles of exosomes in normal and pathological conditions: New insights for diagnosis and therapeutic applications. Frontiers in Immunology. 2015;6:203. DOI: 10.3389/ fimmu.2015.00203

[3] Sato-Kuwabara Y, Melo SA, Soares FA, Calin GA. The fusion of two worlds: Non-coding RNAs and extracellular vesicles-diagnostic and therapeutic implications (review). International Journal of Oncology. 2015;46:17-27. DOI: 10.3892/ijo.2014.2712

[4] Lötvall J, Hill AF, Hochberg F, Buzás EI, Di Vizio D, Gardiner C, et al. Minimal experimental requirements for definition of extracellular vesicles and their functions: A position statement from the International Society for Extracellular Vesicles. Journal of Extracellular Vesicles. 2014;3:1-6. DOI: 10.3402/jev.v3.26913

[5] Théry C, Witwer KW, Aikawa E, Alcaraz MJ, Anderson JD,

Andriantsitohaina R, et al. Minimal information for studies of extracellular vesicles 2018 (MISEV2018): A position statement of the International Society for Extracellular Vesicles and update of the MISEV2014 guidelines. Journal of Extracellular Vesicles. 2019;8:1535750. DOI: 10.1080/20013078.2018.1535750

[6] Admyre C, Johansson SM, Qazi KR, Filen J-J, Lahesmaa R, Norman M, et al. Exosomes with immune modulatory features are present in human breast milk. The Journal of Immunology. 2007;179:1969-1978. DOI: 10.4049/ jimmunol.179.3.1969

[7] Hata T, Murakami K, Nakatani H, Yamamoto Y, Matsuda T, Aoki N.
Isolation of bovine milk-derived microvesicles carrying mRNAs and microRNAs. Biochemical and Biophysical Research Communications. 2010;396:528-533. DOI: 10.1016/j.

bbrc.2010.04.135

[8] Sedykh SE, Purvinish LV, Monogarov AS, Burkova EE, Grigor'eva AE, Bulgakov DV, et al. Purified horse milk exosomes contain an unpredictable small number of major proteins. Biochimie Open. 2017;4:61-72. DOI: 10.1016/j.biopen.2017.02.004

[9] Chen T, Xie M-Y, Sun J-J, Ye R-S, Cheng X, Sun R-P, et al. Porcine milkderived exosomes promote proliferation of intestinal epithelial cells. Scientific Reports. 2016;6:33862. DOI: 10.1038/ srep33862

[10] Hock A, Miyake H, Li B, Lee C, Ermini L, Koike Y, et al. Breast milkderived exosomes promote intestinal epithelial cell growth. Journal of Pediatric Surgery. 2017;52:755-759. DOI: 10.1016/j.jpedsurg.2017.01.032

[11] Yassin AM, Abdel Hamid MI, Farid OA, Amer H, Warda M. Dromedary milk exosomes as mammary transcriptome nanovehicle: Their isolation, vesicular and phospholipidomic characterizations. Journal of Advanced Research. 2016;7:749-756. DOI: 10.1016/j. jare.2015.10.003

[12] Torregrosa Paredes P, Gutzeit C, Johansson S, Admyre C, Stenius F, Alm J, et al. Differences in exosome populations in human breast milk in relation to allergic sensitization and lifestyle. Allergy. 2014;69:463-471. DOI: 10.1111/all.12357

[13] Reinhardt TA, Sacco RE, Nonnecke BJ, Lippolis JD. Bovine milk proteome: Quantitative changes in normal milk exosomes, milk fat globule 
membranes and whey proteomes resulting from Staphylococcus aureus mastitis. Journal of Proteomics. 2013;82:141-154. DOI: 10.1016/j. jprot.2013.02.013

[14] Sun J, Aswath K, Schroeder SG, Lippolis JD, Reinhardt TA, Sonstegard TS. MicroRNA expression profiles of bovine milk exosomes in response to Staphylococcus aureus infection. BMC Genomics. 2015;16:806. DOI: $10.1186 / \mathrm{s} 12864-015-2044-9$

[15] Vaswani K, Koh YQ, Almughlliq FB, Peiris HN, Mitchell MD. A method for the isolation and enrichment of purified bovine milk exosomes. Reproductive Biology. 2017;17:341-348. DOI: 10.1016/j. repbio.2017.09.007

[16] Witwer KW, Soekmadji C, Hill AF, Wauben MH, Buzás EI, Di Vizio D, et al. Updating the MISEV minimal requirements for extracellular vesicle studies: Building bridges to reproducibility. Journal of Extracellular Vesicles. 2017;6:1396823. DOI: 10.1080/20013078.2017.1396823

[17] Zonneveld MI, Brisson AR, Van Herwijnen MJC, Tan S, Van De Lest CHA, Redegeld FA, et al. Recovery of extracellular vesicles from human breast milk is influenced by sample collection and vesicle isolation procedures. Journal of Extracellular Vesicles. 2014;3:24215

[18] Yamada T, Inoshima Y, Matsuda T, Ishiguro N. Comparison of methods for isolating exosomes from bovine milk. Journal of Veterinary Medical Science. 2012;74:1523-1525. DOI: 10.1292/ jvms.12-0032

[19] Cvjetkovic A, Lötvall J, Lässer C. The influence of rotor type and centrifugation time on the yield and purity of extracellular vesicles. Journal of Extracellular Vesicles. 2014;3:3-4. DOI: $10.3402 /$ jev.v3.23111
[20] Soboleva SE, Dmitrenok PS, Verkhovod TD, Buneva VN, Sedykh SE, Nevinsky GA. Very stable high molecular mass multiprotein complex with DNase and amylase activities in human milk. Journal of Molecular Recognition. 2015;28:20-34. DOI: 10.1002/jmr.2409

[21] Burkova EE, Dmitrenok PS, Sedykh SE, Buneva VN, Soboleva SE, Nevinsky GA. Extremely stable soluble high molecular mass multiprotein complex with DNase activity in human placental tissue. PLoS One. 2014;9:e111234. DOI: 10.1371/journal. pone. 0111234

[22] Grigor'eva AE, Dyrkheeva NS, Bryzgunova OE, Tamkovich SN, Chelobanov BP, Ryabchikova EI. Contamination of exosome preparations, isolated from biological fluids. Biomeditsinskaia Khimiia. 2017;63:91-96. DOI: 10.18097/ PBMC2017630191

[23] Burkova EE, Dmitrenok PS, Bulgakov DV, Vlassov VV, Ryabchikova EI, Nevinsky GA. Exosomes from human placenta purified by affinity chromatography on sepharose bearing immobilized antibodies against CD81 tetraspanin contain many peptides and small proteins. IUBMB Life. 2018;70:1144-1155. DOI: 10.1002/iub.1928

[24] Morelli AE, Larregina AT, Shufesky WJ, Sullivan MLG, Stolz DB, Papworth GD, et al. Endocytosis, intracellular sorting, and processing of exosomes by dendritic cells. Blood. 2004;104:3257-3266. DOI: 10.1182/

blood-2004-03-0824

[25] Segura E. ICAM-1 on exosomes from mature dendritic cells is critical for efficient naive T-cell priming. Blood. 2005;106:216-223. DOI: 10.1182/ blood-2005-01-0220

[26] Reinhardt TA, Lippolis JD, Nonnecke BJ, Sacco RE. Bovine milk exosome 
proteome. Journal of Proteomics. 2012;75:1486-1492. DOI: $10.1016 / j$. jprot.2011.11.017

[27] Bruschi M, Ravera S, Santucci L, Candiano G, Bartolucci M, Calzia D, et al. The human urinary exosome as a potential metabolic effector cargo. Expert Review of Proteomics. 2015;12:425-432. DOI: $10.1586 / 14789450.2015 .1055324$

[28] Bruschi M, Santucci L, Ravera S, Candiano G, Bartolucci M, Calzia D, et al. Human urinary exosome proteome unveils its aerobic respiratory ability. Journal of Proteomics. 2016;136:25-34. DOI: 10.1016/j. jprot.2016.02.001

[29] Sverdlov ED. Amedeo avogadro's cry: What is $1 \mu \mathrm{g}$ of exosomes? BioEssays. 2012;34:873-875. DOI: 10.1002/bies.201200045

[30] Pislyagin E, Manzhulo I, Gorpenchenko T, Dmitrenok P, Avilov S, Silchenko A, et al. Cucumarioside A2-2 causes macrophage activation in mouse spleen. Marine Drugs. 2017;15:341. DOI: 10.3390/md15110341

[31] Welker M. Proteomics for routine identification of microorganisms. Proteomics. 2011;11:3143-3153. DOI: 10.1002/pmic.201100049

[32] Pislyagin EA, Manzhulo IV, Dmitrenok PS, Aminin DL. Cucumarioside A2-2 causes changes in the morphology and proliferative activity in mouse spleen. Acta Histochemica. 2016;118:387-392. DOI: 10.1016/j.acthis.2016.03.009

[33] Chen T, Xi Q-Y, Sun J-J, Ye R-S, Cheng X, Sun R-P, et al. Revelation of mRNAs and proteins in porcine milk exosomes by transcriptomic and proteomic analysis. BMC Veterinary Research. 2017;13:101. DOI: 10.1186/ s12917-017-1021-8

[34] Izumi $H$, Tsuda M, Sato $Y$, Kosaka N, Ochiya T, Iwamoto H, et al. Bovine milk exosomes contain microRNA and mRNA and are taken up by human macrophages. Journal of Dairy Science. 2015;98:2920-2933. DOI: 10.3168/jds.2014-9076

[35] van Herwijnen MJC, Zonneveld MI, Goerdayal S, Noltet-t' Hoen ENM, Garssen J, Stahl B, et al. Comprehensive proteomic analysis of human milkderived extracellular vesicles unveils a novel functional proteome distinct from other milk components. Molecular \& Cellular Proteomics. 2016;15:3412-3423. DOI: $10.1074 /$ mcp.M116.060426

[36] Liao Y, Alvarado R, Phinney B, Lönnerdal B. Proteomic characterization of human milk whey proteins during a twelve-month lactation period. Journal of Proteome Research. 2011;10: 1746-1754. DOI: 10.1021/pr101028k

[37] Picariello G, Ferranti P, Mamone G, Klouckova I, Mechref Y, Novotny MV, et al. Gel-free shotgun proteomic analysis of human milk. Journal of Chromatography A. 2012;1227:219-233. DOI: 10.1016/j.chroma.2012.01.014

[38] Murakami K, Lagarde M, Yuki Y. Identification of minor proteins of human colostrum and mature milk by two-dimensional electrophoresis. Electrophoresis. 1998;19:2521-2527. DOI: 10.1002/elps.1150191427

[39] Savina A, Fader CM, Damiani MT, Colombo MI. Rab11 promotes docking and fusion of multivesicular bodies in a calcium-dependent manner. Traffic. 2005;6:131-143. DOI: 10.1111/j.1600-0854.2004.00257.x

[40] Hurley JH, Odorizzi G. Get on the exosome bus with ALIX. Nature Cell Biology. 2012;14:654-655. DOI: 10.1038/ ncb2530

[41] Lässer C, Alikhani VS, Ekström K, Eldh M, Paredes PT, Bossios A, et al. Human saliva, plasma and breast milk exosomes contain RNA: 
Uptake by macrophages. Journal of Translational Medicine. 2011;9:9. DOI: 10.1186/1479-5876-9-9

[42] Pols MS, Klumperman J. Trafficking and function of the tetraspanin CD63. Experimental Cell Research. 2009;315:1584-1592. DOI: 10.1016/j.yexcr.2008.09.020

[43] Li A, Zhang T, Zheng M, Liu Y, Chen Z. Exosomal proteins as potential markers of tumor diagnosis. Journal of Hematology \& Oncology. 2017;10:175. DOI: 10.1186/ s13045-017-0542-8

[44] Luga V, Zhang L, Viloria-Petit AM, Ogunjimi AA, Inanlou MR, Chiu E, et al. Exosomes mediate stromal mobilization of autocrine WntPCP Signaling in breast cancer cell migration. Cell. 2012;151:1542-1556. DOI: 10.1016/j.cell.2012.11.024

[45] Gross JC, Chaudhary V, Bartscherer K, Boutros M. Active Wnt proteins are secreted on exosomes. Nature Cell Biology. 2012;14:1036-1045. DOI: $10.1038 / \mathrm{ncb} 2574$

[46] McMahon HT, Mills IG. COP and clathrin-coated vesicle budding: Different pathways, common approaches. Current Opinion in Cell Biology. 2004;16:379-391. DOI: 10.1016/j.ceb.2004.06.009

[47] Naslavsky N, Boehm M, Backlund PS, Caplan S. Rabenosyn-5 and EHD1 interact and sequentially regulate protein recycling to the plasma membrane. Molecular Biology of the Cell. 2004;15:2410-2422. DOI: 10.1091/ mbc.e03-10-0733

[48] Samuel M, Chisanga D, Liem M, Keerthikumar S, Anand S, Ang C-S, et al. Bovine milk-derived exosomes from colostrum are enriched with proteins implicated in immune response and growth. Scientific Reports. 2017;7:5933. DOI: $10.1038 / \mathrm{s} 41598-017-06288-8$
[49] Théry C, Boussac $M$, Véron $P$, Ricciardi-Castagnoli P, Raposo G, Garin J, et al. Proteomic analysis of dendritic cellderived exosomes: A secreted subcellular compartment distinct from apoptotic vesicles. Journal of Immunology. 2001;166:7309-7318

[50] Febbraio M, Hajjar DP, Silverstein RL. CD36: A class B scavenger receptor involved in angiogenesis, atherosclerosis, inflammation, and lipid metabolism. Journal of Clinical Investigation. 2001;108:785-791. DOI: 10.1172/ JCI14006

[51] Oshima K, Aoki N, Kato T, Kitajima K, Matsuda T. Secretion of a peripheral membrane protein, MFG-E8, as a complex with membrane vesicles. European Journal of Biochemistry. 2002;269:1209-1218

[52] Qin W, Tsukasaki Y, Dasgupta S, Mukhopadhyay N, Ikebe M, Sauter ER. Exosomes in human breast milk promote EMT. Clinical Cancer Research. 2016;22:4517-4524. DOI: 10.1158/10780432.CCR-16-0135

[53] Mathivanan S, Ji H, Simpson RJ. Exosomes: Extracellular organelles important in intercellular communication. Journal of Proteomics. 2010;73:1907-1920. DOI: 10.1016/j. jprot.2010.06.006

[54] Mathivanan S, Simpson RJ. ExoCarta: A compendium of exosomal proteins and RNA. Proteomics. 2009;9:4997-5000. DOI: 10.1002/ pmic. 200900351

[55] Vlassov AV, Magdaleno S, Setterquist R, Conrad R. Exosomes: Current knowledge of their composition, biological functions, and diagnostic and therapeutic potentials. Biochimica et Biophysica Acta. 2012;1820:940-948. DOI: 10.1016/j. bbagen.2012.03.017 
[56] Wubbolts R, Leckie RS, Veenhuizen PTM, Schwarzmann G, Möbius W, Hoernschemeyer J, et al. Proteomic and biochemical analyses of human B cell-derived exosomes. Journal of Biological Chemistry. 2003;278:10963-10972. DOI: 10.1074/ jbc.M207550200

[57] van Meer G, Voelker DR, Feigenson GW. Membrane lipids: Where they are and how they behave. Nature Reviews Molecular Cell Biology. 2008;9:112-124. DOI: $10.1038 / \mathrm{nrm} 2330$

[58] Hankins HM, Baldridge RD, Xu P, Graham TR. Role of flippases, scramblases and transfer proteins in phosphatidylserine subcellular distribution. Traffic. 2015;16:35-47. DOI: $10.1111 /$ tra.12233

[59] Clark MR. Flippin' lipids. Nature Immunology. 2011;12:373-375. DOI: 10.1038/ni.2024

[60] Segawa K, Nagata S. An apoptotic 'eat me' signal: Phosphatidylserine exposure. Trends in Cell Biology. 2015;25:639-650. DOI: 10.1016/j. tcb.2015.08.003

[61] Llorente A, Skotland T, Sylvänne T, Kauhanen D, Róg T, Orłowski A, et al. Molecular lipidomics of exosomes released by $\mathrm{PC}-3$ prostate cancer cells. Biochimica et Biophysica Acta (BBA)-Molecular and Cell Biology of Lipids. 2013;1831:1302-1309. DOI: 10.1016/j.bbalip.2013.04.011

[62] Laulagnier K, Vincent-Schneider H, Hamdi S, Subra C, Lankar D, Record M. Characterization of exosome subpopulations from RBL-2H3 cells using fluorescent lipids. Blood Cells, Molecules, and Diseases. 2005;35: 116-121. DOI: 10.1016/j.bcmd.2005. 05.010

[63] Trajkovic K, Hsu C, Chiantia S, Rajendran L, Wenzel D, Wieland F, et al.
Ceramide triggers budding of exosome vesicles into multivesicular endosomes. Science. 2008;319:1244-1247. DOI: 10.1126/science. 1153124

[64] Skotland T, Sandvig K, Llorente A. Lipids in exosomes: Current knowledge and the way forward. Progress in Lipid Research. 2017;66:30-41. DOI: 10.1016/j. plipres.2017.03.001

[65] Petersen NHT, Kirkegaard T, Olsen OD, Jäättelä M. Connecting Hsp70, sphingolipid metabolism and lysosomal stability. Cell Cycle. 2010;9:2305-2309. DOI: 10.4161/ cc.9.12.12052

[66] Laulagnier K, Motta C, Hamdi S, Roy S, Fauvelle F, Pageaux J-F, et al. Mast cell- and dendritic cell-derived exosomes display a specific lipid composition and an unusual membrane organization. Biochemical Journal. 2004;380:161-171. DOI: 10.1042/ bj20031594

[67] Zwaal RF, Schroit AJ.

Pathophysiologic implications of membrane phospholipid asymmetry in blood cells. Blood. 1997;89:1121-1132

[68] Batista BS, Eng WS, Pilobello KT, Hendricks-Muñoz KD, Mahal LK. Identification of a conserved glycan signature for microvesicles. Journal of Proteome Research. 2011;10:4624-4633. DOI: $10.1021 /$ pr200434y

[69] Chen T, Xi Q-Y, Ye R-S, Cheng X, Qi Q-E, Wang S-B, et al. Exploration of microRNAs in porcine milk exosomes. BMC Genomics. 2014;15:100. DOI: 10.1186/1471-2164-15-100

[70] Gu Y, Li M, Wang T, Liang Y, Zhong Z, Wang X, et al. Lactationrelated microRNA expression profiles of porcine breast milk exosomes. PLoS One. 2012;7:e43691. DOI: 10.1371/ journal.pone.0043691 
[71] Zhou Q, Li M, Wang X, Li Q, Wang $T$, Zhu Q, et al. Immune-related microRNAs are abundant in breast milk exosomes. International Journal of Biological Sciences. 2011;8:118-123

[72] Kahn S, Liao Y, Du X, Xu W, Li J, Lönnerdal B. Exosomal microRNAs in milk from mothers delivering preterm infants survive in vitro digestion and are taken up by human intestinal cells. Molecular Nutrition \& Food Research. 2018;62:1701050. DOI: $10.1002 /$ mnfr.201701050

[73] Colitti M, Sgorlon S, Licastro D, Stefanon B. Differential expression of miRNAs in milk exosomes of cows subjected to group relocation. Research in Veterinary Science. 2019;122:148-155. DOI: 10.1016/j. rvsc.2018.11.024

[74] Leiferman A, Shu J, Grove R, Cui J, Adamec J, Zempleni J. A diet defined by its content of bovine milk exosomes and their RNA cargos has moderate effects on gene expression, amino acid profiles and grip strength in skeletal muscle in C57BL/6 mice. The Journal of Nutritional Biochemistry. 2018;59:123-128. DOI: 10.1016/j.jnutbio.2018.06.007

[75] Zhang S, Chen F, Zhang Y, Lv Y, Heng J, Min T, et al. Recent progress of porcine milk components and mammary gland function. Journal of Animal Science and Biotechnology. 2018;9:77. DOI: 10.1186/ s40104-018-0291-8

[76] Munch EM, Harris RA, Mohammad M, Benham AL, Pejerrey SM, Showalter L, et al. Transcriptome profiling of microRNA by next-gen deep sequencing reveals known and novel miRNA species in the lipid fraction of human breast milk. PLoS One. 2013;8:e50564. DOI: 10.1371/journal.pone.0050564

[77] Mutai E, Zhou F, Zempleni J. Depletion of dietary bovine milk exosomes impairs sensorimotor gating and spatial learning in C57BL/6 mice. FASEB Journal: Official Publication of the Federation of American Societies for Experimental Biology. 2017;30:150-154

[78] Izumi H, Kosaka N, Shimizu T, Sekine K, Ochiya T, Takase M. Bovine milk contains microRNA and messenger RNA that are stable under degradative conditions. Journal of Dairy Science. 2012;95:4831-4841. DOI: $10.3168 /$ jds.2012-5489

[79] Lukasik A, Zielenkiewicz P. In silico identification of plant miRNAs in mammalian breast milk exosomes-A small step forward? PLoS One. 2014;9:e99963. DOI: 10.1371/journal. pone.0099963

[80] Takagi S, Nakajima M, Mohri T, Yokoi T. Post-transcriptional regulation of human pregnane $\mathrm{X}$ receptor by microRNA affects the expression of cytochrome P450 3A4. Journal of Biological Chemistry. 2008;283:9674-9680. DOI: 10.1074/jbc. M709382200

[81] Duursma AM, Kedde M, Schrier M, le Sage C, Agami R. miR-148 targets human DNMT3b protein coding region. RNA. 2008;14:872-877. DOI: 10.1261/ rna.972008

[82] Wolf T, Baier SR, Zempleni J. The intestinal transport of bovine milk exosomes is mediated by endocytosis in human colon carcinoma Caco-2 cells and rat small intestinal IEC- 6 cells1-3. Journal of Nutrition. 2015;145: 2201-2206. DOI: 10.3945/jn.115.218586

[83] Kusuma RJ, Manca S, Frieme T, Sukreet S, Nguyen C, Zempleni J. Human vascular endothelial cells transport foreign exosomes from cow's milk by endocytosis. American Journal of Physiology-Cell Physiology. 2016;310:C800-C807. DOI: 10.1152/ ajpcell.00169.2015

[84] Munagala R, Aqil F, Jeyabalan J, Gupta RC. Bovine milk-derived 
exosomes for drug delivery. Cancer Letters. 2016;371:48-61. DOI: 10.1016/j. canlet.2015.10.020

[85] Manca S, Giraud D, Zempleni J. Bioavailability and biodistribution of fluorophore-labeled exosomes from cow's milk after intravenous and oral administration in C57Bl/6J mice. FASEB Journal: Official Publication of the Federation of American Societies for Experimental Biology. 2016;30:690-698

[86] Shandilya S, Rani P, Onteru SK, Singh D. Small interfering RNA in milk exosomes is resistant to digestion and crosses the intestinal barrier in vitro. Journal of Agricultural and Food Chemistry. 2017;65:9506-9513. DOI: 10.1021/acs.jafc.7b03123

[87] Benmoussa A, Lee CHC, Laffont B, Savard P, Laugier J, Boilard E, et al. Commercial dairy cow milk microRNAs resist digestion under simulated gastrointestinal tract conditions. The Journal of Nutrition. 2016;146:22062215. DOI: 10.3945/jn.116.237651

[88] Liao Y, Du X, Li J, Lönnerdal B. Human milk exosomes and their microRNAs survive digestion in vitro and are taken up by human intestinal cells. Molecular Nutrition \& Food Research. 2017;61:1-11. DOI: 10.1002/ mnfr.201700082

[89] Chen X, Gao C, Li H, Huang L, Sun Q, Dong Y, et al. Identification and characterization of microRNAs in raw milk during different periods of lactation, commercial fluid, and powdered milk products. Cell Research. 2010;20:11281137. DOI: $10.1038 /$ cr.2010.80

[90] Franscini N, El Gedaily A, Matthey U, Franitza S, Sy MS, Bürkle A, et al. Prion protein in milk. PLoS One. 2006;1:1-5. DOI: 10.1371/journal. pone. 0000071

[91] Vashisht M, Rani P, Onteru SK, Singh D. Curcumin encapsulated in milk exosomes resists human digestion and possesses enhanced intestinal permeability in vitro. Applied Biochemistry and Biotechnology. 2017;183:993-1007. DOI: 10.1007/s12010-017-2478-4

[92] Kim MS, Haney MJ, Zhao Y, Mahajan V, Deygen I, Klyachko NL, et al. Development of exosome-encapsulated paclitaxel to overcome MDR in cancer cells. Nanomedicine: Nanotechnology, Biology, and Medicine. 2016;12:655-664. DOI: 10.1016/j.nano.2015.10.012

[93] Tian Y, Li S, Song J, Ji T, Zhu M, Anderson GJ, et al. A doxorubicin delivery platform using engineered natural membrane vesicle exosomes for targeted tumor therapy. Biomaterials. 2014;35:2383-2390. DOI: 10.1016/j. biomaterials.2013.11.083

[94] Betker JL, Angle BM, Graner MW, Anchordoquy TJ. The potential of exosomes from cow milk for oral delivery. Journal of Pharmaceutical Sciences. 2019;108(4):1496-1505. DOI: 10.1016/j.xphs.2018.11.022

[95] Yamada T, Shigemura H, Ishiguro N, Inoshima Y. Cell infectivity in relation to bovine leukemia virus gp51 and p24 in bovine milk exosomes. PLoS One. 2013;8:e77359. DOI: 10.1371/journal. pone. 0077359

[96] Näslund TI, Paquin-Proulx D, Paredes PT, Vallhov H, Sandberg JK, Gabrielsson S. Exosomes from breast milk inhibit HIV-1 infection of dendritic cells and subsequent viral transfer to CD4+ T cells. AIDS. 2014;28:171-180. DOI: 10.1097/QAD.0000000000000159

[97] Gao HN, Guo HY, Zhang H, Xie XL, Wen PC, Ren FZ. Yak milk-derived exosomes promote proliferation of intestinal epithelial cells in hypoxic environment. Journal of Dairy Science. 2019;102(2):985-996. DOI: 10.3168/ jds.2018-14946

[98] Martin C, Patel M, Williams S, Arora H, Sims B. Human breast 
milk-derived exosomes attenuate cell

death in intestinal epithelial cells.

Innate Immunity. 2018;24:278-284. DOI:

$10.1177 / 1753425918785715$

[99] Sedykh SE, Buneva VN,

Nevinsky GA. Human milk lactoferrin

and antibodies: Catalytic activities, complexes, and other features. In: Milk Proteins-From Structure to Biological Properties and Health Aspects. Rijeka, Croatia: InTech; 2016. pp. 51-80. DOI: $10.5772 / 63200$

[100] Burkova EE, Dmitrenok PS, Bulgakov DV, Ermakov EA, Buneva VN, Soboleva SE, et al. Identification of major proteins of a very stable high molecular mass multi-protein complex of human placental tissue possessing nine different catalytic activities. Biochemistry and Analytical Biochemistry. 2018;07:1-2. DOI: 10.4172/2161-1009.1000351 


\section{Section 2 \\ The Biology of \\ Extracellular Vesicles}





\title{
Cellular-Defined Microenvironmental Internalization of Exosomes
}

\author{
Amber Gonda, Ron Moyron, Janviere Kabagwira, \\ Paul A. Vallejos and Nathan R. Wall
}

\begin{abstract}
The extracellular environment exhibits a potent effect on cellular growth and development. Exosomes secreted into this milieu carry functional proteins and nucleic acids from the cell of origin to recipient cells, facilitating intercellular communication. This interaction is particularly influential in the tumor microenvironment, transporting oncogenes and oncoproteins within a tumor and to distant sites. The mechanisms by which cells internalize exosomes vary greatly and the factors dictating this process are still unknown. Most cancers show evidence of exosomal transfer of material, but differences in cell type can dictate the effectiveness and extent of the process. Improving therapeutics requires addressing specific cellular functions, illustrating the need to better understand the forces involved in exosome-cell interactions. This review summarizes what is known about the different types of cells that play a role in exosome internalization.
\end{abstract}

Keywords: exosome, endocytosis, receptors, internalization, uptake

\section{Introduction}

Intercellular communication is essential to homeostasis and is largely dependent on the cellular secretome [1]. An emerging awareness of the role that the extracellular environment plays is evident in the field of secreted vesicles. The vesicular contribution to the tumor microenvironment (TME) has furthered our understanding of the communication between cells and the surrounding stroma [2]. This relationship has also elucidated many potential therapeutic targets and possible transporters of chemotherapeutics [3,4]. There are multiple extracellular vesicle types, characterized by biogenesis, size, and common protein markers [5, 6]. Of these, exosomes are the smallest, with sizes ranging from 30 to $150 \mathrm{~nm}$ [6]. These vesicles have the most complex synthesis, emerging from the endocytic pathway. They arise from intraluminal invaginations into a multivesicular body (MVB) and are released from the cell when the MVB fuses with the plasma membrane. Exosomes consist of intracellular material surrounded by a lipid membrane that reflects the cellular membrane of the host cell [7]. These specific vesicles have demonstrated promise in several fields of research, including rheumatoid arthritis $[8,9]$ and neurodegenerative disease [10], but primarily in cancer [11, 12]. Tumor-derived exosomes (TEX) contain oncoproteins and oncogenes from the cell of origin and thus are 
very influential in intercellular communication. Numerous studies have used these luminal proteins and genes to better understand tumor growth and metastasis, as well as for improving diagnostic, prognostic, and therapeutic methods [13, 14].

While there has been an exponential growth in research focused on exosome biology, clarification on the mechanisms of transport between the cell of origin and the recipient cell is essential to maximizing on exosome potential in treating and diagnosing disease. The methods by which exosomes influence the cells with which they interact are still under review. Some exosomes have been shown to fuse to the recipient cell $[15,16]$, while others are internalized by specific receptor-ligand interactions $[17,18]$ or by stimulating an indirect uptake by macropinocytosis [19]. Exosome binding to cells has been seen both as a mechanism of transferring luminal contents $[15,16]$ and as an initial step in the endocytosis process $[17,20]$. The significance of the effects of cell-exosome binding in comparison to internalization is still unknown. Most types of endocytosis have been described in the process of exosome uptake [21], but which factors determine the specific mechanism used, are still unclear. Previous reviews have clearly identified a number of ligands and receptors involved in exosome trafficking [21-23], but little is known about the dependence of uptake mechanism on cell-type. This review presents the current understanding of the endocytosis process utilized by specific cells involved in exosomal internalization.

\section{Endocy tosis pathways}

Endocytosis is a basic cellular function that is performed by all cell types in the process of maintaining homeostasis. Many of the molecules essential for cellular function are small enough to cross the cell membrane either passively or actively, however, other structures, such as exosomes, are too large and require a more complicated process. This general process of internalization is called endocytosis and is separated into various types based on the shape [24] and the size of particles internalized [25]. There are many well-written reviews covering the specifics of the endocytic pathways $[25,26]$, but here we will address them only superficially. Classification under the umbrella of endocytosis varies, but the major methods include phagocytosis, macropinocytosis, clathrin-mediated endocytosis, caveolinmediated endocytosis, and clathrin/caveolin-independent or lipid raft-mediated endocytosis $[25,26]$. Receptor-mediated endocytosis (RME) is an additional type that is often considered to be a subcategory under several of those previously mentioned (Figure 1).

\subsection{Phagocytosis}

Phagocytosis is the mechanism by which specialized cells (such as macrophages and monocytes) engulf large particles $(>0.5 \mu \mathrm{m})$ by way of receptor/ligand interactions [25, 27] (Figure 1A). Promiscuous receptors allow for a broad range of ligand recognition and binding, facilitating a key role phagocytes play in clearing apoptotic cells [27]. Exosomes, derived from a diverse population of cells, present a vast array of available ligands that make phagocytes ideal recipient cells. This process of phagocytosis is designed to not only internalize extracellular material by enveloping it, but also to regulate the immune response by presenting degraded proteins as antigens on the phagocyte surface [25]. Tumor-derived exosomes influence immune involvement in the tumor $[28,29]$ which may be facilitated by this mechanism of endocytosis. Other non-phagocytic cells, such as epithelial cells, Sertoli, liver endothelial, astrocytes, and cancer cells have also been shown to perform 
phagocytosis [27], potentially expanding the impact of exosomal communication. It is therefore important to define how the process of phagocytosis influences exosome function and if that influence is cell type dependent.

\subsection{Macropinocytosis}

While phagocytosis or "cell eating" involves ingestion of large molecules, macropinocytosis ("cell drinking") internalizes slightly smaller particles ( $>1 \mu \mathrm{m})$ [25] (Figure 1B). This method is a way for cells to sample the external environment without specific receptors or ligands. It is a constitutive process in specialized antigen presenting cells, but is stimulated by growth factors in most others [30]. Macropinocytosis has a unique membrane ruffling process caused by projections from the cell surface encircling extracellular fluid and fusing to the membrane [25], resulting in an increased membrane surface area and volume of engulfed material. Nakase et al., showed that stimulation of the epidermal growth factor (EGF)
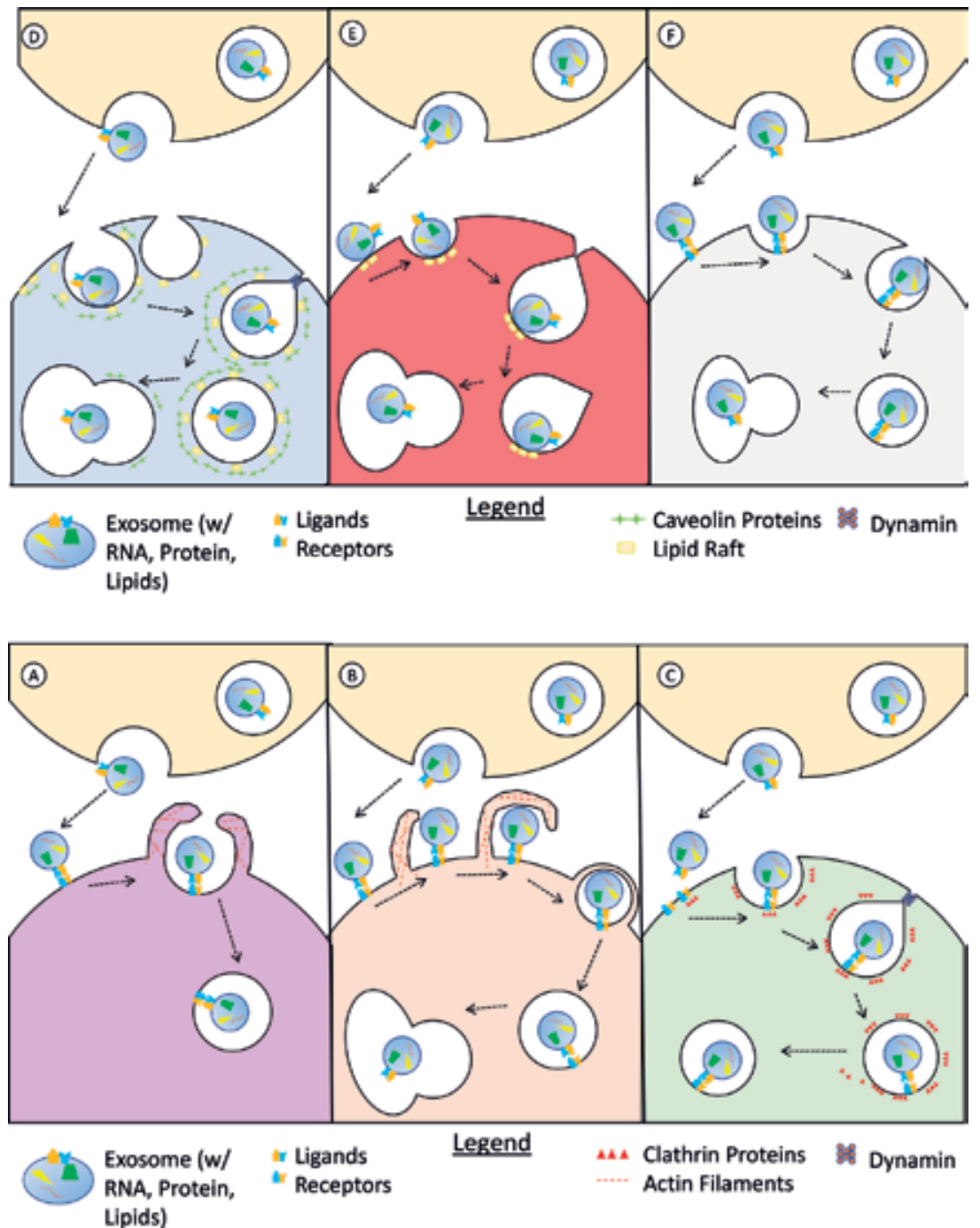

Figure 1.

Endocytosis pathways involved in exosome uptake: (A) Phagocytosis, (B) Macropinocytosis, (C) Clathrinmediated endocytosis, (D) Caveolin-mediated endocytosis, (E) Lipid Raft-dependent or clathrin-/caveolinindependent endocytosis, $(F)$ Receptor-mediated endocytosis. 
receptor, either by soluble EGF or exosome-bound, increased exosome internalization 27-fold through the activation of macropinocytosis [19].

\subsection{Clathrin-dependent endocytosis}

The next three mechanisms, clathrin-dependent, caveolae-dependent, and clathrin/caveolae-independent, are facilitated by specific membrane proteins/ structures: clathrin, caveolae, and lipid rafts. Clathrin is an intracellular protein that forms a coat around an invaginating vesicle facilitating formation and internalization [31] (Figure 1C). These vesicles internalize material around $120 \mathrm{~nm}$ [25], which is within the exosome size range. Stimulation can occur through receptor/ ligand mediation or can be constitutive, depending on cell-type and receptor presence, but clathrin-mediated endocytosis (CME) occurs in all cell types [31]. Data continues to show that the extracellular cargo of these clathrin-coated vesicles can drive the specific mechanisms and protein interactions of internalization [32], giving way for exosome surface proteins to influence uptake. Two proteins used extensively to describe the details of CME are transferrin (Tf) and low density lipoprotein (LDL) and their respective receptors [25], which are all (except LDL) found on the surface of exosomes $[33,34]$. Overexpression of transferrin receptors on cancer cells [35] may also contribute to increased exosomal uptake and clathrinmediated endocytosis in tumors, as there have been shown to be 50-80 percent more receptors on the cancer cell compared to the non-cancer cell [36].

\subsection{Caveolin-dependent endocytosis}

Caveolin is similar to clathrin, as it forms a coat around membrane invaginations called caveolae and facilitates the entry of extracellular material

(Figure 1D). These are particularly prevalent on endothelial cells but have been found on a wide distribution of cell types [25]. Caveolae are about half the size of clathrin-coated vesicles, limiting their cargo to smaller structures [25] but still covering some of the exosome size range. This type of endocytosis as well as lipid raft-dependent uptake, plays a key role in lipid transport and homeostasis [25]. One of the defining factors of the exosome membrane is its slightly altered lipid profile, which has been shown to influence internalization [37]. Two proteins commonly active in caveolae-dependent endocytosis, which have also been identified on the surface of exosomes, are the insulin receptor and albumin $[34,38,39]$. The cellular insulin receptor itself has also recently been found to influence exosome uptake [18].

\subsection{Lipid raft dependent or clathrin-/caveolin-independent endocytosis}

Lipid dependence is not only characteristic of caveolae-dependent endocytosis, but also clathrin/caveolae-independent processes. Lipid raft-dependent (or clathrin/ caveolae-independent) endocytosis is similar to caveolae-dependent, except for the absence of the protein cav-1. Lipid rafts are 40-50 nm sections of the membrane with a high percentage of glycosphingolipids and cholesterol, and are anchoring points for many membrane proteins [40]. Lipid rafts are involved in exosome biogenesis and trafficking [41-43] and exosome uptake has been reduced by blocking lipid raft endocytosis [44] (Figure 1E).

\subsection{Receptor mediated endocytosis}

As mentioned previously, RME is an endocytosis pathway that can fit under several of the other categories (Figure 1F). The term and pathway were originally 
Cellular-Defined Microenvironmental Internalization of Exosomes

DOI: http://dx.doi.org/10.5772/intechopen.86020

\begin{tabular}{|c|c|c|c|c|}
\hline $\begin{array}{l}\text { Endocytosis } \\
\text { pathway }\end{array}$ & $\begin{array}{l}\text { Recipient } \\
\text { cell type }\end{array}$ & Recipient cell line & Exosome cell of origin & References \\
\hline \multirow[t]{11}{*}{ Phagocytosis } & Macrophage & RAW264.7 & $\begin{array}{l}\text { Leukemia cell (K562 } \\
\text { or MT4) }\end{array}$ & [20] \\
\hline & Macrophage & $\mathrm{J} 774$ & Rat reticulocyte & [52] \\
\hline & Macrophage & Primary & Trophoblast (Sw71) & [58] \\
\hline & Monocytes & Primary & Activated T cell & [50] \\
\hline & Macrophage & Peritoneal & $\begin{array}{l}\text { Mouse melanoma cell } \\
\text { (B16BL6) }\end{array}$ & [51] \\
\hline & Macrophage & $\begin{array}{l}\text { Mouse bone } \\
\text { marrow-derived }\end{array}$ & Mouse CRC (CT-26) & [54] \\
\hline & Microglia & MG6 & $\begin{array}{l}\text { Pheochromocytoma } \\
\text { (PC12) }\end{array}$ & [117] \\
\hline & Microglia & BV-2 & Neuron (N2a) & [49] \\
\hline & Dendritic cell & Mouse primary & Mouse dendritic cell & [15] \\
\hline & Epithelial & $\begin{array}{l}\text { Ovarian cancer } \\
\text { (SKOV3) }\end{array}$ & $\begin{array}{l}\text { Ovarian cancer cell } \\
\text { (SKOV3) }\end{array}$ & [97] \\
\hline & Epithelial & Alveolar cells (A549) & Dendritic cell & {$[66]$} \\
\hline \multirow[t]{7}{*}{ Macropinocytosis } & Epithelial & $\begin{array}{l}\text { Cervical cancer } \\
\text { (HeLa) }\end{array}$ & $\begin{array}{l}\text { Epidermoid carcinoma } \\
\text { (A431) }\end{array}$ & [90] \\
\hline & Epithelial & $\begin{array}{l}\text { Epidermoid } \\
\text { carcinoma } \\
\text { (A431), Pancreatic } \\
\text { carcinoma (MIA } \\
\text { PaCa-2) }\end{array}$ & $\begin{array}{l}\text { Cervical cancer cell } \\
\text { (HeLa) }\end{array}$ & [19] \\
\hline & Epithelial & $\begin{array}{l}\text { Ovarian cancer } \\
\text { (SKOV3) }\end{array}$ & $\begin{array}{l}\text { Ovarian cancer cell } \\
\text { (SKOV3) }\end{array}$ & [97] \\
\hline & Epithelial & $\begin{array}{l}\text { Breast cancer } \\
\text { (MCF7) }\end{array}$ & $\begin{array}{l}\text { Normal breast } \\
\text { epithelial cell (MCF- } \\
\text { 10A)-exosome } \\
\text { mimetics }\end{array}$ & [96] \\
\hline & Endothelial & $\begin{array}{l}\text { Cerebral vascular } \\
\text { (hCMEC D3) }\end{array}$ & $\begin{array}{l}\text { Macrophage } \\
\text { (RAW264.7) }\end{array}$ & [89] \\
\hline & Microglia & Primary mouse & $\begin{array}{l}\text { Mouse oligodendrocyte } \\
\text { (Oli-neu) }\end{array}$ & [56] \\
\hline & $\begin{array}{l}\text { Neuron } \\
\text { precursor } \\
\text { cell }\end{array}$ & $\begin{array}{l}\text { Pheochromocytoma } \\
\text { (PC12) }\end{array}$ & $\begin{array}{l}\text { Pheochromocytoma } \\
\text { (PC12) }\end{array}$ & [114] \\
\hline \multirow[t]{6}{*}{$\begin{array}{l}\text { Clathrin-mediated } \\
\text { endocytosis }\end{array}$} & Epithelial & $\begin{array}{l}\text { Ovarian cancer } \\
\text { (SKOV3) }\end{array}$ & $\begin{array}{l}\text { Ovarian cancer cell } \\
\text { (SKOV3) }\end{array}$ & [97] \\
\hline & Epithelial & Alveolar cells (A549) & Dendritic cell & [66] \\
\hline & Epithelial & $\begin{array}{l}\text { Gastric cancer (AGS, } \\
\text { MKN1) }\end{array}$ & $\begin{array}{l}\text { Gastric cancer cell } \\
\text { (AGS, MKN1) }\end{array}$ & [94] \\
\hline & Epithelial & $\begin{array}{l}\text { Breast cancer } \\
\text { (MCF7) }\end{array}$ & $\begin{array}{l}\text { Normal breast } \\
\text { epithelial cell (MCF- } \\
\text { 10A)-exosome } \\
\text { mimetics }\end{array}$ & [96] \\
\hline & Endothelial & $\begin{array}{l}\text { Cerebral vascular } \\
\text { endothelial (hCMEC } \\
\text { D3) }\end{array}$ & $\begin{array}{l}\text { Macrophage } \\
\text { (RAW264.7) }\end{array}$ & [89] \\
\hline & Endothelial & $\begin{array}{l}\text { Brain microvascular } \\
\text { endothelial }\end{array}$ & $\begin{array}{l}\text { Embryonic kidney cell } \\
\text { (Hek293T) }\end{array}$ & [87] \\
\hline
\end{tabular}




\begin{tabular}{|c|c|c|c|c|}
\hline $\begin{array}{l}\text { Endocytosis } \\
\text { pathway }\end{array}$ & $\begin{array}{l}\text { Recipient } \\
\text { cell type }\end{array}$ & Recipient cell line & Exosome cell of origin & References \\
\hline & Neuron & $\begin{array}{l}\text { Cortical mouse } \\
\text { neuron }\end{array}$ & $\begin{array}{l}\text { Oligodendrocyte } \\
\text { (Oli-neu) }\end{array}$ & {$[115]$} \\
\hline & $\begin{array}{l}\text { Neuron } \\
\text { precursor } \\
\text { cell }\end{array}$ & $\begin{array}{l}\text { Pheochromocytoma } \\
\text { (PC12) }\end{array}$ & $\begin{array}{l}\text { Pheochromocytoma } \\
\text { (PC12) }\end{array}$ & [114] \\
\hline \multirow{5}{*}{$\begin{array}{l}\text { Caveolin- } \\
\text { dependent } \\
\text { endocytosis }\end{array}$} & Epithelial & $\begin{array}{l}\text { Cervical cancer } \\
\text { (HeLa) }\end{array}$ & $\begin{array}{l}\text { Epidermoid carcinoma } \\
\text { (A431) }\end{array}$ & [90] \\
\hline & Epithelial & $\begin{array}{l}\text { (CNE1, HONE1, } \\
\text { NU-GC-3, A549) }\end{array}$ & EBV-infected B cells & [95] \\
\hline & Epithelial & $\begin{array}{l}\text { Breast cancer } \\
\text { (MCF7) }\end{array}$ & $\begin{array}{l}\text { Normal breast } \\
\text { epithelial cell (MCF- } \\
\text { 10A)_exosome } \\
\text { mimetics }\end{array}$ & [96] \\
\hline & Endothelial & $\begin{array}{l}\text { Cerebral vascular } \\
\text { endothelial (hCMEC } \\
\text { D3) }\end{array}$ & $\begin{array}{l}\text { Macrophage } \\
\text { (RAW264.7) }\end{array}$ & [89] \\
\hline & Endothelial & $\begin{array}{l}\text { Brain microvascular } \\
\text { endothelial }\end{array}$ & $\begin{array}{l}\text { Embryonic kidney cell } \\
\text { (Hek293T) }\end{array}$ & [87] \\
\hline \multirow{8}{*}{$\begin{array}{l}\text { Lipid raft- } \\
\text { dependent } \\
\text { endocytosis }\end{array}$} & Dendritic cell & Mouse primary & Mouse dendritic cell & {$[15]$} \\
\hline & $\begin{array}{l}\text { Dendritic cell } \\
\text { (DC), T cell }\end{array}$ & $\begin{array}{l}\text { Monocyte derived } \\
\text { primary DC, T cell } \\
\text { (Jurkat) }\end{array}$ & T cell (Jurkat) & {$[75]$} \\
\hline & $\begin{array}{l}\text { Epithelial, } \\
\text { endothelial }\end{array}$ & $\begin{array}{l}\text { Glioblastoma } \\
\text { (U87), umbilical } \\
\text { vein endothelial } \\
\text { (HUVEC) }\end{array}$ & Glioblastoma (U87) & [43] \\
\hline & Epithelial & $\begin{array}{l}\text { Ovarian cancer } \\
\text { (SKOV3) }\end{array}$ & $\begin{array}{l}\text { Ovarian cancer cell } \\
\text { (SKOV3) }\end{array}$ & [97] \\
\hline & Epithelial & $\begin{array}{l}\text { Breast carcinoma } \\
\text { (BT549) }\end{array}$ & $\begin{array}{l}\text { Breast carcinoma } \\
\text { (BT549) }\end{array}$ & {$[44]$} \\
\hline & $\begin{array}{l}\text { Epithelial, } \\
\text { macrophage, } \\
\text { endothelial }\end{array}$ & $\begin{array}{l}\text { Melanoma (A375), } \\
\text { (RAW264.7), dermal } \\
\text { microvascular } \\
\text { endothelial } \\
\text { (HMVEC) }\end{array}$ & Melanoma (A375) & {$[46]$} \\
\hline & Endothelial & $\begin{array}{l}\text { Brain microvascular } \\
\text { endothelial }\end{array}$ & $\begin{array}{l}\text { Embryonic kidney cell } \\
\text { (Hek293T) }\end{array}$ & [87] \\
\hline & $\mathrm{B}$ cell & $\begin{array}{l}\text { Mantle cell } \\
\text { lymphoma (Jeko1) }\end{array}$ & $\begin{array}{l}\text { Mantle cell lymphoma } \\
\text { (Jeko1) }\end{array}$ & [61] \\
\hline
\end{tabular}

Table 1.

Endocytosis pathways involved in exosome internalization in various cell types.

considered to be interchangeable with CME, but it is now understood that not all RME is dependent on clathrin [25]. Receptor-ligand interactions play a role in phagocytosis [25, 27], macropinocytosis [19], and lipid raft-dependent endocytosis [40]. Exosome internalization has been linked to multiple receptor-ligand interactions in each of these pathways $[19,20]$. Each subtype of endocytosis has been 
identified in the exosome internalization process (Table 1) but additional research is needed to determine the driving factors behind the specific mechanisms. One hypothesized factor is that the recipient cell type may determine the specific type of internalization.

\section{Cell type-specific internalization of exosomes}

\subsection{Phagocytes}

As introduced previously, some cells are uniquely designed to internalize extracellular material through phagocytosis. Those cells generally considered "professional" phagocytes are monocytes, macrophages, and neutrophils [25] with dendritic cells, osteoclasts, and eosinophils occasionally included [27]. Phagocytosis is dependent on receptor/ligand interactions, relying on a vast array of different receptors and ligands. Some of the established receptors include Fc receptors, integrins, pattern-recognition receptors, phosphatidylserine (PS) receptors, and scavenger receptors [45]. Macrophage uptake of exosomes has been shown to involve many of these receptors including scavenger receptors [46-48], PS/PS receptors $[20,48-51]$, lectins $[17,52,53]$ and Fc receptors [54].

However, internalization of extracellular material by phagocytes does not always fit perfectly with the hallmarks of phagocytosis. Some phagocytic receptors, such as integrins $\left(\alpha_{v} \beta_{3}\right)$, scavenger receptors (CD68 and CD36), and CD14, facilitate the tethering of apoptotic cells to the phagocyte surface, but then are unable to initiate internalization without other means, such as PS and PS receptor binding [55]. The PS/ PS receptor interaction also stimulates membrane ruffling and vacuole appearanceclassic hallmarks of macropinocytosis [55]. Phagocytes are primarily involved in phagocytosis, but this evidence supports the idea that multiple modes of endocytosis are operational in the same cell. This is not unique to apoptotic cell uptake, but has been seen with exosome internalization by microglia (phagocytic cells in the brain) exhibiting a dependence on PS in a macropinocytic manner $[49,56]$. Cooperation between multiple receptors appears to be an important characteristic of endocytosis in phagocytic cells. Plebenak et al., showed that the scavenger receptor SR-B1 on macrophages, when blocked, reduces exosome uptake, but with further testing on melanoma cells this blocking was dependent both on the receptor as well as on cholesterol flux in the lipid rafts [46], broadening the endocytosis landscape of phagocytes to include lipid raft-dependent endocytosis.

The dependence of phagocytosis on extracellular- facing PS, which on healthy cells is expressed only on the cytosolic side of the membrane, is evidence that the material to be ingested influences the endocytic pathway of phagocytes. Further support of this interaction is found in the hypothesis that exosomes "target" specific recipient cells $[48,57]$. Macrophage uptake (Figure 2A) of TEX is dependent on the presence of cellular scavenger receptors or exosomal PS $[20,46,48,51,56]$, while non-tumor cellderived exosomes require the presence of a heterogeneity of receptors. When internalized by macrophages and monocytes, hepatic stellate cell-derived exosomes require Fc receptors [54]; B cell, dendritic cell and reticulocyte-derived exosomes use lectins [52, 53]; trophoblast-derived exosomes bind to integrins [58]; and T cell-derived exosomes need scavenger receptors [50] (Table 2). Costa-Silva et al., showed that when comparing TEX to normal cell-derived exosomes, Kupffer cells, liver-specific macrophages, preferentially internalized TEX [57]. The significance of the exosome surface topography is therefore influential in directing a specific endocytosis pathway. Phagocytes are responsible for internalization of extracellular material and are so 


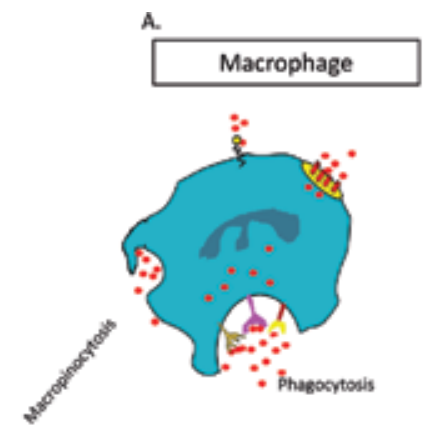

B.



c. Dendritic cell

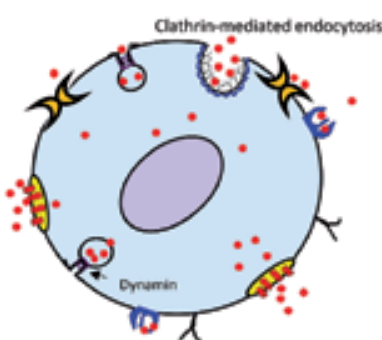

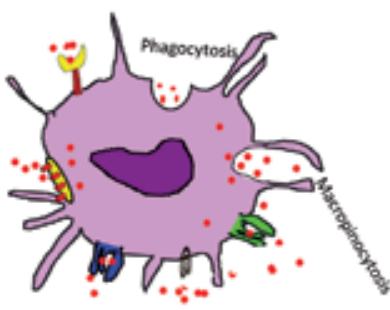

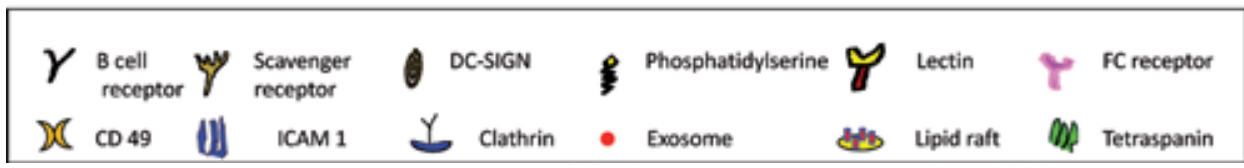

Figure 2.

Cell-specific internalization of exosomes by antigen presenting cells: $(A)$ macrophage, $(B) B$ cell and (C) Dendritic cells each employ multiple endocytic pathways in the uptake of exosomes. Macrophages utilize multiple endocytic pathways in the uptake of exosomes. B Cells and dendritic cells (DC) both employ multiple endocytic pathways in the uptake of exsomes. Lipid rafts, integrins and adhesion molecules are used by $B$ cells while tetraspanins and adhesion molecules are the more common receptors found in DC-exosome interactions. Intercellular adhesion molecule 1 (ICAM-1), Dendritic Cell-Specific Intercellular adhesion molecule-3Grabbing Non-integrin (DC-SIGN).

named based on the primary use of phagocytosis, but as seen above, other endocytic pathways are utilized, especially in the context of exosomal internalization.

\subsection{Antigen presenting cells}

The antigen presenting cells (APCs) include primary phagocytes such as macrophages, but also B cells and dendritic cells [59]. The immune response is heavily dependent on the recognition of foreign structures, such as peptides, for activation. These APCs sample the extracellular environment, digest and display peptides on their surface, and then present these peptides to immune cells that can execute the response. The intercellular trafficking of immune regulating proteins, such as the major histocompatibility complexes (MHC) [28], by exosomes has the potential to either stimulate or block the immune response, dependent on the exosomal contents [17]. Uptake of exosomes plays an important role in B cell and DC cell proliferation, protein presentation, and interactions with other immune cells [17].

B cells perform multiple functions as an immune cell, including presenting antigens to $\mathrm{T}$ cells in order to stimulate additional immune responses. B cells traditionally operate though clathrin-mediated endocytosis, relying heavily on the B-cell receptor [60]. However, when it comes to exosome internalization, B cells have shown a greater dependence on lipid rafts and various receptors, such as adhesion molecules and tetraspanins [17] than on clathrin, indicating a preference for clathrin-independent and receptor-mediated endocytosis (Figure 2B). In analyzing B cell uptake of exosomes, using the mantle cell lymphoma (mutated immature B cell) cell line, Jeko-1, Hazan-Halevy et al., found dynamin, epidermal growth factor receptor (EGFR), and cholesterol to be involved in exosome internalization instead of clathrin [61]. EGFR is a well-established target in cancer therapy, particularly with lung cancer [62] and its role in exosome internalization may lend clarity and power to multiple existing and future chemotherapeutics. Additional exosomal surface proteins, with receptor functions, have been identified as participants in 
Cellular-Defined Microenvironmental Internalization of Exosomes

DOI: http://dx.doi.org/10.5772/intechopen.86020

\begin{tabular}{|c|c|c|c|}
\hline Protein & Cell type & Exosome origin & References \\
\hline Scavenger receptor & Macrophage & $\begin{array}{l}\text { Hek293 (embryonic } \\
\text { kidney cells) }\end{array}$ & [47] \\
\hline Phosphatidylserine (PS) & Macrophage, microglia & $\begin{array}{l}\text { Neuron, melanoma, } \\
\text { oligodendrocytes }\end{array}$ & {$[49-51,56]$} \\
\hline PS receptor & Macrophage & Activated T cells & [50] \\
\hline TIM4 & Macrophage & $\begin{array}{l}\text { K562, MT4 (leukemia } \\
\text { cell lines) }\end{array}$ & {$[20]$} \\
\hline Lectins & $\begin{array}{l}\text { Lymph node cells, splenic cells, } \\
\text { pancreatic adenocarcinoma, } \\
\text { lung fibroblast, macrophage, } \\
\text { dendritic cell, hCMEC/ } \\
\text { D3(brain endothelial cells), } \\
\text { platelet, HeLa }\end{array}$ & $\begin{array}{l}\text { Pancreatic } \\
\text { adenocarcinoma, } \\
\text { reticulocyte, B } \\
\text { cell, macrophage, } \\
\text { mesenchymal stem } \\
\text { cell }\end{array}$ & $\begin{array}{c}{[17,48,52,} \\
53,65,89,72, \\
103]\end{array}$ \\
\hline Fc receptors & Macrophage & $\begin{array}{l}\text { CT26 (colon } \\
\text { carcinoma cells) }\end{array}$ & [54] \\
\hline Integrins & Macrophage, B cell & $\begin{array}{l}\text { Trophoblast, } \\
\text { pancreatic } \\
\text { adenocarcinoma cells }\end{array}$ & {$[17,58]$} \\
\hline Tetraspanins & $\begin{array}{l}\text { B cell, pancreatic } \\
\text { adenocarcinoma, endothelial } \\
\text { cell }\end{array}$ & $\begin{array}{l}\text { Pancreatic } \\
\text { adenocarcinoma cells }\end{array}$ & {$[17,48,106]$} \\
\hline EGFR & $\begin{array}{l}\text { A431 (epidermoid carcinoma } \\
\text { cells) }\end{array}$ & HeLa cells & [19] \\
\hline CD11c & Lymph node cells/splenic cells & $\begin{array}{l}\text { Pancreatic } \\
\text { adenocarcinoma cells }\end{array}$ & [17] \\
\hline CD11b & Lymph node cells/splenic cells & $\begin{array}{l}\text { Pancreatic } \\
\text { adenocarcinoma cells }\end{array}$ & [17] \\
\hline CD44 & Lymph node cells/splenic cells & $\begin{array}{l}\text { Pancreatic } \\
\text { adenocarcinoma cells }\end{array}$ & [17] \\
\hline CD49d/CD106 & Lymph node cells/splenic cells & $\begin{array}{l}\text { Pancreatic } \\
\text { adenocarcinoma cells }\end{array}$ & [17] \\
\hline Tspan8 & Endothelial cell & $\begin{array}{l}\text { Pancreatic } \\
\text { adenocarcinoma cells }\end{array}$ & {$[48,106]$} \\
\hline ICAM-1/LFA-1 & $\begin{array}{l}\text { Dendritic cell, hCMEC/D3 } \\
\text { (brain endothelial cells), aortic } \\
\text { endothelium, HUVEC }\end{array}$ & $\begin{array}{l}\text { Dendritic cells, } \\
\text { pancreatic } \\
\text { adenocarcinoma cells, } \\
\text { T cells, macrophage }\end{array}$ & $\begin{array}{c}{[16,17,37,65,} \\
69,89]\end{array}$ \\
\hline DC-SIGN & Dendritic cell & Breast milk & {$[70]$} \\
\hline HSPG & $\begin{array}{l}\text { U87 (glioblastoma cells), CAG } \\
\text { (myeloma), HUVEC, SW780 } \\
\text { (bladder cancer cells) }\end{array}$ & $\begin{array}{l}\text { U-87 cells, myeloma } \\
\text { cells, SW780 cells }\end{array}$ & $\begin{array}{c}{[63,99,100,} \\
101]\end{array}$ \\
\hline Cad-11 & $\begin{array}{l}\text { PC3-mm2 (prostate cancer } \\
\text { cells) }\end{array}$ & Osteoblasts & [104] \\
\hline Syncytin & Choriocarcinoma cells & Trophoblasts & [105] \\
\hline SNAP 25 & Neuron & $\begin{array}{l}\text { Mesenchymal stromal } \\
\text { cells }\end{array}$ & [116] \\
\hline CD62L & $\begin{array}{l}\text { Lymph node cells, splenic cells, } \\
\text { pancreatic adenocarcinoma, } \\
\text { lung fibroblasts }\end{array}$ & $\begin{array}{l}\text { Pancreatic } \\
\text { adenocarcinoma }\end{array}$ & {$[17,48]$} \\
\hline
\end{tabular}




\begin{tabular}{lllc}
\hline Protein & Cell type & Exosome origin & References \\
\hline Galectin 5 & Macrophage & Reticulocyte & {$[52]$} \\
\hline $\begin{array}{l}\text { CD169/ } \alpha 2,3-\text { linked sialic } \\
\text { acid }\end{array}$ & Lymph node cells, splenic cells & B cell & {$[53]$} \\
\hline $\begin{array}{l}\text { C-type lectin/C-type } \\
\text { lectin receptor }\end{array}$ & $\begin{array}{l}\text { Dendritic cell, brain } \\
\text { endothelial cell (hCMEC/D3) }\end{array}$ & Macrophage & {$[65,89]$} \\
\hline P-selectin/PSGL-1 & Platelet & Macrophage & {$[72]$} \\
\hline
\end{tabular}

Table 2.

Proteins involved in exosomal uptake.

B cell internalization of TEX, including integrins (CD49) and cell adhesion molecules (intercellular adhesion molecule 1-ICAM-1/CD54 and CD62L) [17].

These protein interactions between the cell and the exosomal membranes are essential steps in the influence the exosome has on the recipient cell. Exosomes derived from myeloma cells, cancerous plasma (mature B) cells, are dependent on the interaction between exosomal fibronectin and cellular heparan sulfate in order to form a bond between cell and exosome, resulting in modification of intracellular signaling [63]. As seen with these cells, the effects caused by the exosomes are not entirely dependent on uptake, even though the standard operation of APCs requires internalization. Some exosome-cell binding (as opposed to internalization) may be sufficient, or specifically designed, to alter intracellular processes, including signaling, as is also seen with dendritic cell-derived exosomes and $T$ cell function [16]. While the influence of heparan sulfate on internalization in B cells is still unclear, there is evidence linking heparan sulfate proteoglycans to exosomal internalization which indicates that while it wasn't assessed in these cells, the uptake may still be present [21-23]. Whether these differing mechanisms and protein participants of uptake in the B cell population are dependent on normal versus oncologic physiology of recipient cells, or on the origin of the exosome population (tumor-derived versus non-tumor derived) is yet to be determined.

These heterogeneous protein profiles are specific to each cell type and contribute to the comparative ability of each cell to internalize exosomes. In line with the role of B cells, it was found that they readily take in exosomes, in contrast to other immune cells such as T cells and natural killer cells [61,64]. This suggests that certain immune cells are more effective at endocytosing exosomes than others, consistent with the primary functions of these specific cell types. Additional groups have shown that while B cells internalize exosomes, the uptake is significantly less than that of macrophages and dendritic cells, but similar to T cells [17]. This was shown in non-mutated mouse cells and may also illustrate important differences between cancer cell and normal cell internalization mechanisms.

Dendritic cells (DC) can be classified as both APCs and as phagocytes since internalization of extracellular material is a crucial part of their role in the immune system. Endocytosis pathways involved in exosome uptake in these cells have been tested with various endocytic blockers, including cytochalasin D (inhibits actin polymerization), EDTA (chelates calcium), and decreased temperature (reducing active cellular processes) $[15,37,65,66]$. As dendritic cells mature, their mode of endocytosis changes; starting first with macropinocytosis, and then in the mature cell, receptor-mediated endocytosis and phagocytosis prevails [67] (Figure 2C). Despite the evidence of phagocytosis in mature DCs, it was demonstrated that immature DCs are more adept at exosomal uptake [37, 68]. Developmental preference for exosome uptake may shed light on why cancer cells, which often have 
similar profiles to developing cells and are subject to continuous proliferation, are so responsive to modification by exosomes. Also, immature DCs play a role in immunologic tolerance and so are less likely to activate T cells, while mature DCs activate T cell immunity [15]. This down-regulation of the adaptive immune response by immature DCs would be advantageous for tumors and so TEX may specifically target immature DCs, explaining the increase in uptake. While the mechanism is still unknown, dendritic cells are also more likely to take up TEX or DC-derived exosomes than $\mathrm{B}$ and $\mathrm{T}$ cells, as seen with fluorescent staining in vitro and in vivo in a rat model of pancreatic adenocarcinoma [17] and flow cytometry analysis of mouse bone marrow derived cells [15]. The CD11c membrane protein present on the DC and not on the other cells, was found to be involved in the internalization of TEX, as uptake decreased in the presence of an antibody to CD11c. The expression of this protein unique to DCs may contribute to the disparity in uptake among the immune cell types [17]. Recipient cell specificity in exosome uptake and DC interconnection with immune effector cells is another potential area of immunetherapeutic manipulation.

Many of the studies of exosome internalization by DCs have revealed dependence on various adhesion molecules. The ubiquity of these proteins on exosomes, leukocytes, and endothelial cells promotes the non-specific internalization characteristic of DCs. The involvement of ICAM-1 and/or its ligand, lymphocyte function-associated antigen (LFA-1), in DC-exosome interaction has been shown both in vitro and in vivo [16, 17, 37, 65, 69]. These interactions are not unique to exosome uptake as DCs regularly depend on a wide range of adhesion molecules, including a dendritic cell-specific intercellular adhesion molecule-3 grabbing non-integrin (DC-SIGN) [70]. This particular adhesion molecule has been shown to be more effective at exosome uptake by DCs, when looking at breast milk-derived exosomes, than the ICAM-1/LFA-1 binding [71]. In addition to adhesion molecules, C-type lectin and its receptor have also been identified in DC-exosome binding [65]. These glycan binding proteins have also been identified as exosome uptake mediators in other cell types, including macrophages [52] and platelets [72].

In addition to binding to membrane receptors, dendritic cell endocytosis is dependent on lipid rafts and the lipid components of the cell membrane, particularly with viral or bacterial uptake $[73,74]$. As viruses and exosomes are similar in size, endocytosis mechanisms are often common between these two structures [22]. Lipid-dependent endocytosis is evident in exosome uptake by DCs as illustrated with DC- and T-cell derived exosomes $[15,75]$. While proteins have been the most common structure analyzed in connection with exosomal uptake, the membrane cholesterol concentration of recipient cells [15] as well as the lipid profile of the exosomal membrane [75] both play a role in uptake of exosomes by dendritic cells and need further clarification.

\subsection{Circulating cells}

In addition to the previously mentioned cells, two other circulating cells/structures have also been found to endocytose exosomes, platelets and T cells. Platelets are cell fragments involved in blood coagulation that are unique in their formation as they are devoid of a nucleus and some organelles. Despite a reduced intracellular load, they are involved in binding extracellular vesicles. They do so through the interaction of cellular P-selectin and vesicular P-selectin glycoprotein ligand-1 (PSGL-1) as well as PS [72]. Data suggests that binding facilitates fusion of the exosomes to the platelets, transferring of material and enhancing platelet coagulation activity [72]. This speaks to the impact of these exosomes on intracellular 
A.



B.
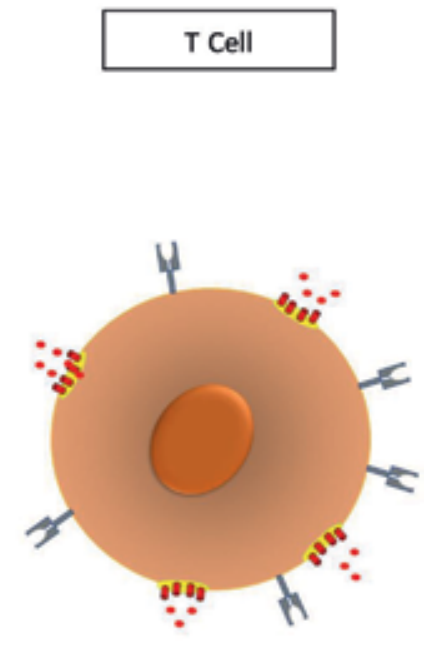

Figure 3.

Cell-specific internalization of exosomes: (A) Platelet-exosome interactions have been linked to fusion as well as the binding to PSGL-1 and phosphatidylserine, (B) T cell are influenced through their surface interactions with exosomes.

communication, both in the variability and specificity of recipient cells, since binding and fusion occurred preferentially in the activated platelets [72] (Figure 3A). The exosomes in this study came from monocytes, suggesting this interaction could be a key player in coagulation at a site of injury.

$\mathrm{T}$ cells are the effector cells of the immune system and intercellular communication is essential for activation. Endocytosis, while not a primary function of T cells, is important to T cell receptor signaling [76] as well as other functions. Dynamin-dependent endocytosis [76], phagocytosis [77], and RME [78] are some of the mechanisms involved in T cell interaction with its surrounding environment. In relation to exosomes, T cells operate through RME [17, 79, 80] and lipid raft-dependent endocytosis [75]. However, T cells do not always readily uptake exosomes as was found in a comparison with other blood cell types. In a peripheral blood mononuclear cell culture, when uptake by monocytes was blocked, internalization by T-cells increased [47], suggesting that T cell uptake may be an adaptive response to increased exosome concentration. When exosome uptake was compared to multiple splenic leukocytes [15] or peripheral blood leukocytes [64], T cells showed minimal internalization. T cell activity is often regulated by surface interactions with other cells, such as with the $\mathrm{T}$ cell receptor and the MHC II/antigen interaction with APCs. Exosomal influence on T cells may therefore operate similarly with surface interaction instead of exosome internalization (Figure 3B). When cultured with DC or DC-derived exosomes, T cells acquired functional surface molecules including MHC II from exosomes through direct exosome interaction with the T cell membrane, while still showing little evidence of internalization [81]. Mouse T cells do not express MHC II and after incubation with these exosomes, this protein was identified on the surface of the T cell, suggesting the binding of exosomes to cellular membranes is sufficient to transfer material, without internalization [81]. Further research into the transfer of material between exosomes and immune cells may elucidate the role exosomes play in immune regulation in the tumor microenvironment. Depending on the cell 
A.

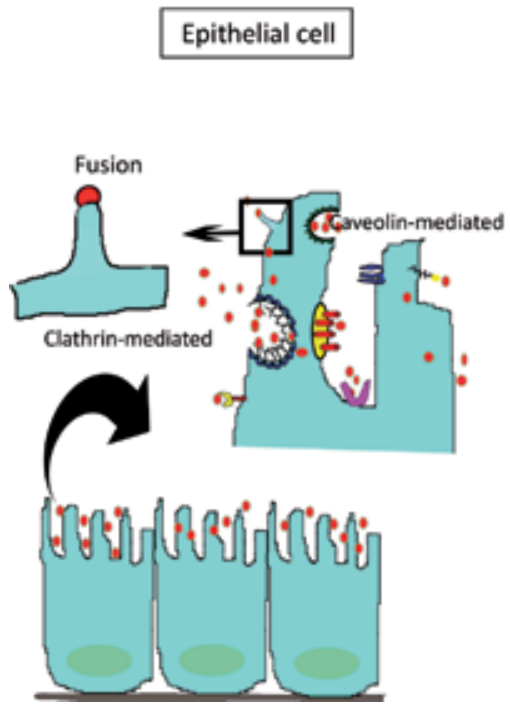

B.

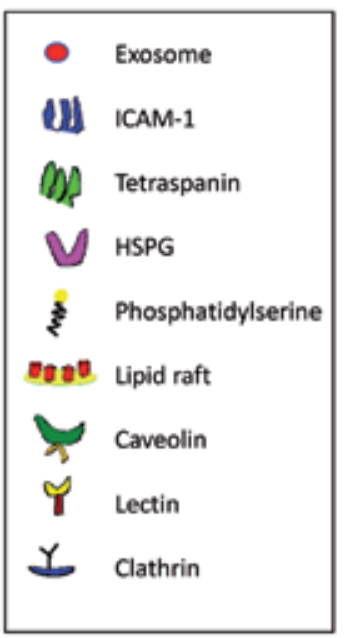

Endothelial cell

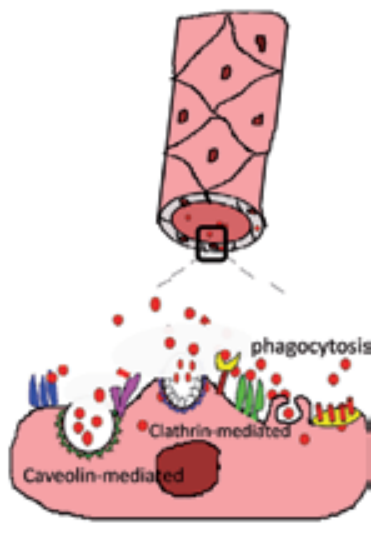

Figure 4.

Cell-specific internalization of exosomes: $(A)$ epithelial and $(B)$ endothelial cells. Epithelial cells and endothelial cells show the most diversity in exosome uptake of all the cell types. Multiple receptor involved in the internalization process are expressed on both cell types, including tetraspanins, adhesion molecules, and heparan sulfate peptidoglycans (HSPG). Intercellular adhesion molecule 1 (ICAM-1).

type involved, exosome-mediated communication and manipulation may not be entirely dependent on endocytosis.

\subsection{Epithelial and endothelial cells}

Epithelial and endothelial cells are responsible for lining most of the organs, spaces, and blood vessels in the body. They are in a prime position to be exposed to and actively endocytose a wide variety of extracellular material. Due to this broad selection, the specific mechanisms utilized are dependent on the cell subtype as well as the character of the endocytosed material [82-84]. With such variability, it is no surprise that exosome uptake by epithelial and endothelial cells is just as diverse (Figure 4). Cellular location of these cells is crucial in cancer biology as most of the TEX will be in close proximity to epithelial and endothelial cells either in the circulatory system or during paracrine spread in solid tumors. While there have been many studies on cell-exosome interaction in these cells, there is still much work needed to clearly understand all of the factors that dictate the endocytic mechanism of epithelial and endothelial cells from different tissues.

A unique finding in exosome studies with epithelial and endothelial cells is the dependence of uptake on intracellular signaling. Svensson et al., discovered that exosome internalization is dependent on the proper functioning of the signaling pathway, ERK1/2-HSP27 [43]. The promotion of endocytosis through intracellular signaling has been shown previously with EGFR-cSrc-ERK1/2 pathways in epithelial cells [85] and the Ras-PI3K pathway with virus uptake by fibroblasts [86]. However, little is known about how these pathways facilitate exosome internalization. The ability of exosomes to cross the blood-brain barrier and be endocytosed by the microvascular endothelial cells in the brain is also dependent on signaling. Tumor necrosis factor $(\mathrm{TNF} \alpha)$ signaling, as is seen in stroke models, enhances exosome uptake [87]. Intracellular signaling may provide a regulatory mechanism 
to control exosome internalization. Some studies described previously have shown that fusion of exosomes to the cell membrane, without endocytosis, can influence intracellular signaling [63], but these are the first to show how intracellular signaling specifically impacts the endocytosis mechanism of exosomes. These results illustrate the complexity of exosome-cell interactions and where additional research is needed. The interdependence of exosome-cell interactions and intracellular signaling are unexplored areas with vast therapeutic potential and are necessary to better understand how extracellular vesicles influence their environment.

Other characteristics are influential in directing endocytosis in epithelial cells including vesicle size, lipid profile, and protein profile (Figure 4A). In epithelial cells, particle size dictates entry mechanism with macropinocytosis as one of the pathways operative at a size range that corresponds with exosomes [88]. This pattern is supported by multiple studies where exosome internalization was decreased when key aspects of macropinocytosis were targeted. Macropinocytosis was blocked with an inhibitor of $\mathrm{Na}^{+} / \mathrm{H}^{+}$exchange (which affects Rac1 activation and actin reorganization) in human cerebral microvascular endothelial cells (hCMEC/D3) [89] and HeLa cells, as well as with an inhibitor of phosphoinositide 3-kinase (PI3K) (influences membrane ruffling and macropinosome formation) $[19,90]$ with concomitant decreases in exosome internalization. Assessing the same pathway but from an activating instead of inhibiting direction, exosome internalization was stimulated by activation of epidermal growth factor receptor (which activates Rac family members) in HeLa cells [19]. Membrane extensions, or filopodia, that facilitate the formation of the macropinosome and are regulated by Rac1 activation have also been shown to influence exosome internalization in hepatocyte (Huh7) and kidney (Hek293) cells [91], furthering the support that exosomes utilize macropinocytosis in multiple epithelial cell lines.

The lipid profile of the exosomes and membrane integrity of the cell are also important contributors to vesicle uptake in several different types of epithelial and endothelial cells. While macrophages readily recognize external-facing PS, these cells can also utilize exosomal PS in the process of internalization, as was shown when pre-incubating exosomes with Annexin V inhibited uptake by HeLa cells (cervical cancer epithelial cells), A375 and A431 cells (squamous skin cancer cells) [92] and in human umbilical vein endothelial cells (HUVEC) [93]. Disruption of cellular lipid raft integrity through cholesterol depletion or sequestration reduced exosome uptake in U87 human glioblastoma epithelial cells [43], hCME/D3 human cerebral microvascular cells [89], HeLa cells [43, 90], HUVECs [43, 46], and A375 cells [46]. Lipid rafts play a key role in many of the functions of epithelial cells, including the protein binding interactions between cell and extracellular environment. Also, some of the most central components to epithelial cell function are proteins that interact closely with the environment such as integrins and adhesion molecules, and are anchored into lipid rafts.

Protein interactions are essential to epithelial and endothelial function and are closely tied to several of the most common endocytosis pathways used by these cells. Clathrin-dependent endocytosis has been shown in gastric [94], nasopharyngeal [95], breast [96], ovarian cancer epithelial cells [97] and HUVECs [98]. Caveolin-dependence was seen in breast [96] and nasopharyngeal cancer [95], however, caveolin-1 showed negative regulation in glioblastoma cell lines [43] (Figure 4B). General receptor-mediated uptake has been shown with several proteins including heparan sulfate peptidoglycan (HSPG) in glioblastoma cells and HUVECs $[99,100]$ and in the transitional epithelial cells of the bladder [101]; 
intercellular adhesion molecule (ICAM1) in hCMEC/D3 cells [89], rat aortic endothelial cells [48], and HUVECs [102]; lectins in cervical cancer [103], HUVECs [102], rat aortic endothelial cells [48] and hCMEC/D3 cells [89]; cad-11 in prostate cancer [104]; syncytin proteins in choriocarcinoma [105] and tetraspanins in an in vivo rat model of pancreatic cancer $[48,106]$. The nature of cellular research has limited most of the epithelial endocytosis studies to cell lines, which consist entirely of transformed cells, and it is still unknown whether these trends are translatable to normal healthy epithelial and endothelial cells. While the mechanisms remain unknown, cultured primary normal epithelial cells take up TEX [107] highlighting a role for exosome intercellular communication in normal cell physiology.

\subsection{Fibroblasts}

The extracellular matrix (ECM) and stroma are important contributors to cellular homeostasis and function. This is particularly evident in tumors when evaluating the role of the tumor microenvironment (TME) on the survival and progression of the tumor cells. Fibroblasts are the major component of this extracellular environment. In normal physiology, they promote stromal stability, while in cancer, they contribute to altered ECM, increased angiogenesis, and metastasis [108]. These cells are in a pivotal position to interact with circulating exosomes and their internalization can have a compounding effect on the surrounding environment. Fibroblasts have been shown to participate primarily in clathrin-mediated endocytosis $[109,110]$ and occasionally receptor-mediated endocytosis [111]. Interestingly, RME [48, 106] and macropinocytosis [91] are the mechanisms by which fibroblasts have been shown to internalize exosomes (Figure 5). Tetraspanins are important proteins in fibroblast function and migration [112]. This protein family is well represented on the exosomal surface and is key to the uptake in many different cell types [48]. Additionally, evidence shows that the smaller the size of the vesicle, the more likely the fibroblast is to use receptors to internalize particles [111]. These three qualities lend support to the evidence of RME as a key pathway for fibroblasts to endocytose exosomes.

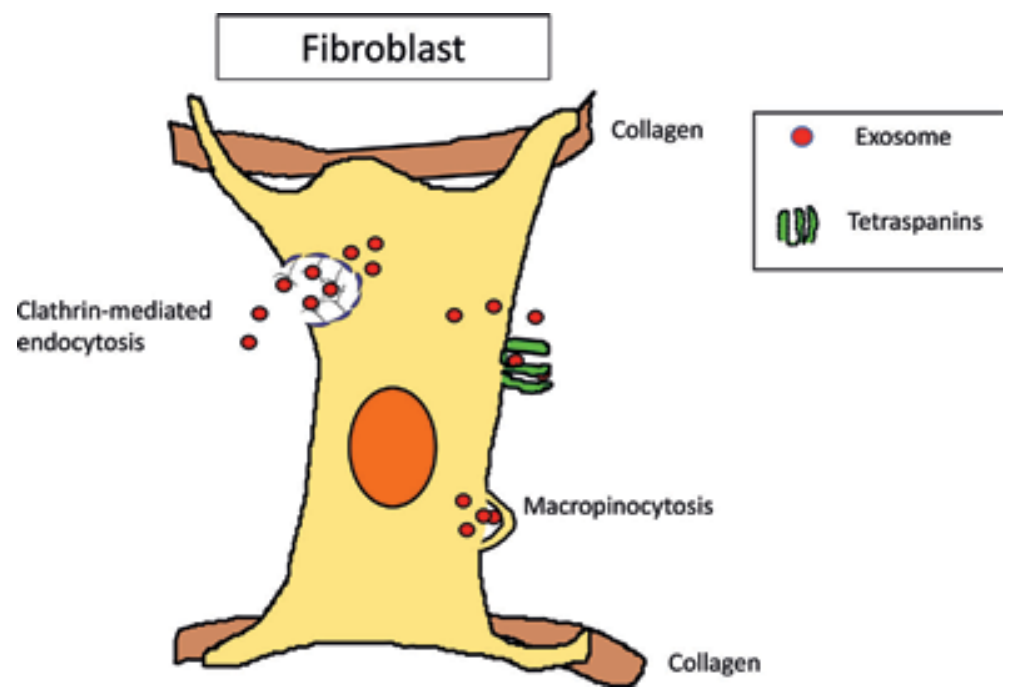

Figure 5.

Cell-specific internalization of exosomes: fibroblasts. Fibroblasts take up exosomes with tetraspanins and utilize multiple endocytic pathways. 


\subsection{Neurons and glial cells}

The nervous system is a uniquely isolated environment with limited connection to the systemic circulation. This characteristic has long impeded therapeutic delivery for brain pathologies. The potential of exosome transport, however, is particularly poignant, as exosomes have been observed selectively targeting neurons and glial cells, successfully crossing the blood brain barrier [113]. Improving our understanding of endocytosis mechanisms involved in these particular cells is essential to therapeutic progression. Clathrinmediated endocytosis is the most commonly observed pathway with exosomal trafficking between neurons and glial cells [114, 115]. However, some neurons also utilize macropinocytosis [114] and specific receptors, such as SNAP25 (a SNARE family protein) [116], to take up exosomes (Figure 6). Microglia performs phagocytosis similar to their counterparts in the extra-neuronal environment [117]. Using exosomes from two different sources, Chivet et al., illustrated the specificity of exosome targeting seen elsewhere in the body, is also evident in the nervous system. Exosomes from a neuroblastoma cell line (N2a) were preferentially internalized by astrocytes and oligodendrocytes, whereas exosomes from cortical neurons were primarily taken up by hippocampal neurons [118]. It was also shown that pre-synaptic regions were the primary site of internalization of these exosomes [118]. Endocytosis is an important process in the pre-synaptic membrane to recycle released synaptic vesicles [119], indicating that the exosomes may capitalize on this constitutive process for entrance to the neuron. Whether exosomes primarily utilize the specific clathrin-mediated endocytosis in this region [119] or are simply taken by chance with the constant bulk endocytosis [120] still remains unclear. Exosome uptake is a developing area of neuro-research, but with significant potential for therapeutics, it is growing rapidly.

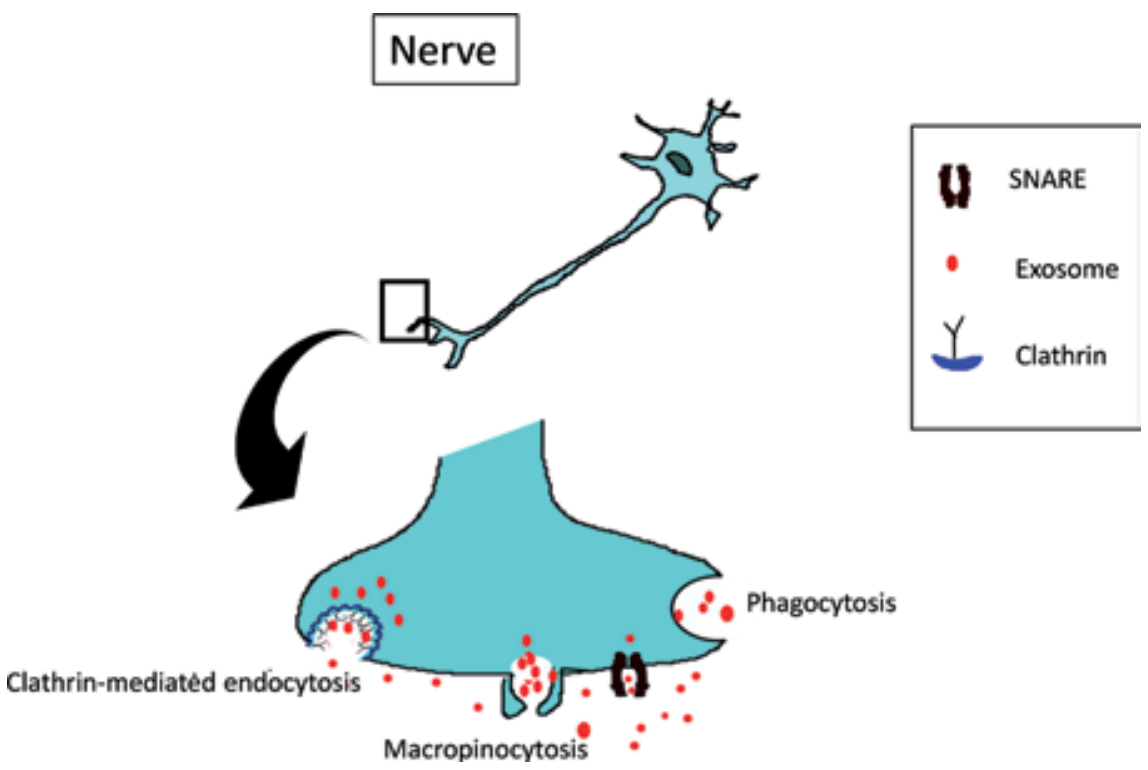

Figure 6.

Cell-specific internalization of exosomes: neurons. Neurons use similar pathways but receptor/ligand binding has less variability. Synaptosomal associated protein 25 (SNAP25). 


\section{Conclusion}

Exosomes are internalized by a multitude of cell types and play an important role in cellular physiology. Our grasp of the mechanisms of this internalization is growing as we are better able to identify characteristics of the cell and the vesicles that facilitate uptake. Pathologic states, such as cancer, have played an integral role in our understanding of how the cellular-exosomal interaction proceeds. Clarity is still needed to better understand the mechanisms by which exosome internalization is so varied from cell to cell and within the same cell. As we have seen with fibroblasts, the vesicle size can dictate mechanism of uptake [111]. The presence or abundance of specific proteins such as scavenger receptors on macrophages [46-48] and lipid profiles in several types of cells, such as external-facing phosphatidylserine $[20,48,49,56]$ all contribute to the specificity of uptake. As has been discussed, cell type can dictate uptake mechanism, particularly with phagocytic cells and professional antigen presenting cells, but even within these specialized cells, differing mechanisms occur regularly and further evaluation is needed to parse the primary determinants.

Various types of endocytosis have been identified as possible mechanisms of intercellular transport of exosomal contents to include macropinocytosis [19, 56, 114], phagocytosis [20], clathrin-mediated [52, 114], caveolin-dependent [95], lipid raft-dependent [43, 46], and clathrin-/caveolin-independent [61] endocytosis. Though much about these processes is unique, there are some aspects where functional overlap exists between them. Macropinocytosis is a form of endocytosis that consists of membrane ruffles forming intracellular vesicles to internalize large amounts of extracellular fluid [30]. This varies from other forms of endocytosis in its formation of separate and distinct intracellular vesicles (macropinosomes) and the internalization of material that is considered non-specific exosomal has been recorded in microglia [56], human epidermoid carcinomaderived A431 cells stimulated by endothelial growth factor receptor (EGFR) and by the pancreatic cancer MiaPaCa-2 cell line [19]. Macropinocytosis is not selective in which molecules are internalized from the extracellular environment, and so uptake may be dictated simply by proximity to the cells and not targeted by the exosome specifically [121]. However, it has been shown that some exosomes naturally induce macropinocytosis internalization [90] and others, through manipulation of exosomal content, can selectively activate this mechanism in order to increase uptake [122]. Phagocytosis is a much more common method of taking up exosomes, especially with phagocytic cells of the immune system. Feng et al., showed that two leukemia cell lines, K562 and MT4, solely utilized phagocytosis for exosome internalization [20,121].

Four other general categories of endocytosis focus on specific cellular proteins that facilitate the uptake of particles. Clathrin and caveolin are both cytosolic proteins that form specific pits with which to internalize various substances [25]. The exact reasons why and when a cell uses clathrin, caveolin, or neither, is still incompletely understood but particle size and cell type seem to play a role $[43,115,121]$. Caveolin-dependent endocytosis is important in albumin uptake, cholesterol transport, and intracellular signaling. Due to the small size of the caveolae, its endocytosed material tends to be smaller than $60 \mathrm{~nm}$ [25]. Clathrin-dependent mechanisms however can internalize particles up to $120 \mathrm{~nm}$. The size restrictions may indicate, with further investigation into which uptake mechanism is utilized by which cells, a possible functional difference between vesicle sizes within the current exosome size range [121]. The clathrin-dependent process is involved in many different cell types and functions ranging from vesicle 
recycling in the neuronal synapse to organ development and ion homeostasis [25]. Many of the common, well-known endocytosis receptors utilize clathrin coated pits, such as low-density lipoprotein receptor (LDLR) and transferrin receptor (TfR). One of the most commonly used ways to determine which of these mechanisms is in operation is through inhibitory drugs or knocking down certain key players [121]. Dynamin, a GTPase, facilitates the fission of the intracellular clathrin coated vesicle $[25,123]$. Dynasore, an inhibitor of dynamin, has been utilized to effectively block endocytosis of extracellular vesicles and establish clathrin-mediated endocytosis as a mechanism of uptake for these vesicles [21, 52, 56]. Following siRNA downregulation of caveolin-1 (the primary protein involved in caveolae-dependent endocytosis), exosome internalization was significantly reduced in B cells $[95,121]$. Inhibitory drugs have also been useful in the determination of a third mechanism, lipid-raft mediated endocytosis. The lipid raft is a small portion of the plasma membrane, rich in sphingolipids and sterols, that facilitates various cellular processes [124]. Use of methyl- $\beta$-cyclodextrin $(M \beta C D)$, which alters the cholesterol content of the membrane and disrupts lipid rafts, has been seen by several groups to impair exosomal internalization [43, 44, 97]. While lipid raft-dependent endocytosis is the primary clathrin- and caveolaeindependent mechanism, other pathways and independent interactions have been described in the internalization of exosomes [61, 124]. Endocytosis is the primary method of exosomal delivery of its contents but research is still needed to understand what determines the specific mechanism whether it is cell type, exosome type, or condition specific [121].

Exosome stability, ubiquitous presence, and influential contents make them ideal candidates for therapeutic modalities in a wide variety of pathologies. The significance of exosomal contribution to the cellular network throughout the body still carries untapped potential for conquering some of the most pressing current health challenges including cancer and neurodegeneration. Understanding how these exosomes interact with and enter the myriad of cells in the body will empower our ability to capitalize on this natural social network. 


\section{Author details}

Amber Gonda ${ }^{1,2 \dagger}$, Ron Moyron ${ }^{1,3 \dagger}$, Janviere Kabagwira ${ }^{1,3 \dagger}$, Paul A. Vallejos ${ }^{1 \dagger}$ and Nathan R. Wall ${ }^{1,3 * \dagger}$

1 Center for Health Disparities \& Molecular Medicine, Loma Linda, CA, USA

2 Department of Pathology and Anatomy, Loma Linda, CA, USA

3 Division of Biochemistry, Department of Basic Sciences, Loma Linda University School of Medicine, Loma Linda, CA, USA

*Address all correspondence to: nwall@llu.edu

† All authors contributed to the design of this review, while AG, RM, PV and JK drafted the manuscript. AG, RM, and NRW revised and finalized the manuscript.

\section{IntechOpen}

(C) 2019 The Author(s). Licensee IntechOpen. This chapter is distributed under the terms of the Creative Commons Attribution License (http://creativecommons.org/licenses/ by/3.0), which permits unrestricted use, distribution, and reproduction in any medium, provided the original work is properly cited. (cc) BY 


\section{References}

[1] Zullo J, Matsumoto K, Xavier S, Ratliff B, Goligorsky MS. The cell secretome, a mediator of cell-to-cell communication. Prostaglandins \& Other Lipid Mediators. 2015;120:17-20 [Epub May 6, 2015]. DOI: 10.1016/j. prostaglandins.2015.03.012

[2] Quail DF, Joyce JA.

Microenvironmental regulation of tumor progression and metastasis. Nature Medicine. 2013;19(11):1423-1437 [Epub Oct 11, 2013]. DOI: 10.1038/ nm.3394

[3] Osterman CJ, Lynch JC, Leaf P, Gonda A, Ferguson Bennit HR, Griffiths D, et al. Curcumin modulates pancreatic adenocarcinoma cellderived exosomal function. PloS One. 2015;10(7):e0132845 [Epub Jul 16, 2015]. DOI: 10.1371/journal. pone. 0132845

[4] Marleau AM, Chen CS, Joyce JA, Tullis RH. Exosome removal as a therapeutic adjuvant in cancer. Journal of Translational Medicine. 2012;10:134 [Epub Jun 29, 2012]. DOI: $10.1186 / 1479-5876-10-134$

[5] Lotvall J, Hill AF, Hochberg F, Buzas EI, Di Vizio D, Gardiner C, et al. Minimal experimental requirements for definition of extracellular vesicles and their functions: A position statement from the International Society for Extracellular Vesicles. Journal of Extracellular Vesicles. 2014;3:26913 [Epub Dec 30, 2014]. DOI: 10.3402/jev. v3.26913

[6] Kalra H, Drummen GP, Mathivanan S. Focus on extracellular vesicles: Introducing the next small big thing. International journal of Molecular Sciences. 2016;17(2) [Epub Feb 11, 2016]. DOI: $10.3390 / \mathrm{ijms} 17020170$

[7] Li SP, Lin ZX, Jiang XY, Yu XY. Exosomal cargo-loading and synthetic exosome-mimics as potential therapeutic tools. Acta Pharmacologica Sinica. 2018;39(4):542-551 [Epub Feb 29, 2018]. DOI: 10.1038/aps.2017.178

[8] Ahn JK, Oh JM, Lee J, Bae EK, Ahn KS, Cha HS, et al. Increased extracellular survivin in the synovial fluid of rheumatoid arthritis patients: Fibroblast-like synoviocytes as a potential source of extracellular survivin. Inflammation. 2010;33(6):381-388. [Epub Mar 3, 2010]. DOI: 10.1007/s10753-010-9196-1

[9] Bokarewa M, Lindblad S, Bokarew D, Tarkowski A. Balance between survivin, a key member of the apoptosis inhibitor family, and its specific antibodies determines erosivity in rheumatoid arthritis. Arthritis Research \& Therapy. 2005;7(2):R349-R358 [Epub Mar 4, 2005]. DOI: $10.1186 / \operatorname{ar} 1498$

[10] De Toro J, Herschlik L, Waldner C, Mongini C. Emerging roles of exosomes in normal and pathological conditions: New insights for diagnosis and therapeutic applications. Frontiers in Immunology. 2015;6:203 [Epub May 23, 2015]. DOI: 10.3389/ fimmu.2015.00203

[11] Rak J. Extracellular vesiclesBiomarkers and effectors of the cellular interactome in cancer. Frontiers in Pharmacology. 2013;4:21 [Epub Mar 20, 2013]. DOI: 10.3389/fphar.2013.00021

[12] Kahlert C, Kalluri R. Exosomes in tumor microenvironment influence cancer progression and metastasis. Journal of Molecular Medicine (Berlin, Germany). 2013;91(4):431-437

[Epub Mar 23, 2013]. DOI: $10.1007 /$ s00109-013-1020-6

[13] Couto N, Caja S, Maia J, Strano Moraes MC, Costa-Silva B. Exosomes as emerging players in cancer biology. Biochimie. 2018 (in press). 
[Epub Mar 21, 2018]. DOI: 10.1016/j. biochi.2018.03.006

[14] Turay D, Khan S, Diaz Osterman CJ, Curtis MP, Khaira B, Neidigh JW, et al. Proteomic profiling of serumderived exosomes from ethnically diverse prostate cancer patients. Cancer Investigation. 2016;34(1):

1-11 [Epub Nov 5, 2015]. DOI: $10.3109 / 07357907.2015 .1081921$

[15] Montecalvo A, Larregina AT, Shufesky WJ, Stolz DB, Sullivan ML, Karlsson JM, et al. Mechanism of transfer of functional microRNAs between mouse dendritic cells via exosomes. Blood. 2012;119(3):756-766 [Epub Oct 28, 2011]. DOI: 10.1182/ blood-2011-02-338004

[16] Segura E, Guerin C, Hogg N, Amigorena S, Thery C. CD8+ dendritic cells use LFA-1 to capture MHC-peptide complexes from exosomes in vivo. Journal of Immunology (Baltimore, MD: 1950). 2007;179(3):1489-1496. [Epub Jul 21, 2007]

[17] Zech D, Rana S, Buchler MW, Zoller M. Tumor-exosomes and leukocyte activation: An ambivalent crosstalk. Cell Communication and Signaling: CCS. 2012;10(1):37 [Epub Nov 30, 2012]. DOI: $10.1186 / 1478-811 x-10-37$

[18] Gonda AKJ, Senthil GN, Ferguson Bennit HR, Neidigh J, Khan S, Wall NR. Exosomal survivin facilitates vesicle internalization. Oncotarget. 9 Oct 2018;9(79):34919-34934. DOI: 10.18632/ oncotarget.26182. eCollection 9 Oct 2018. PMID:30405884

[19] Nakase I, Kobayashi NB, Takatani-Nakase T, Yoshida T. Active macropinocytosis induction by stimulation of epidermal growth factor receptor and oncogenic Ras expression potentiates cellular uptake efficacy of exosomes. Scientific Reports. 2015;5:10300 [Epub Jun 4, 2015]. DOI: 10.1038/srep10300
[20] Feng D, Zhao WL, Ye YY, Bai XC, Liu RQ, Chang LF, et al. Cellular internalization of exosomes occurs through phagocytosis. Traffic (Copenhagen, Denmark). 2010;11(5):675-687. [Epub Feb 9, 2010]. DOI: 10.1111/j.1600-0854.2010.01041.x

[21] Mulcahy LA, Pink RC, Carter DR. Routes and mechanisms of extracellular vesicle uptake. Journal of Extracellular Vesicles. 4 Aug 2014. DOI: 10.3402/jev. v3.24641. eCollection 2014. Review. PMID: 25143819

[22] van Dongen HM, Masoumi N, Witwer KW, Pegtel DM. Extracellular vesicles exploit viral entry routes for cargo delivery. Microbiology and Molecular Biology Reviews. 2016;80(2):369-386 [Epub Mar 5, 2016]. DOI: $10.1128 / \mathrm{mmbr} .00063-15$

[23] French KC, Antonyak MA, Cerione RA. Extracellular vesicle docking at the cellular port: Extracellular vesicle binding and uptake. Seminars in Cell \& Developmental Biology. 2017;67: 48-55. [Epub 2017/01/21. DOI: 10.1016/j. semcdb.2017.01.002

[24] Richards DM, Endres RG. Target shape dependence in a simple model of receptor-mediated endocytosis and phagocytosis. Proceedings of the National Academy of Sciences of the United States of America. 2016;113(22):6113-6118 [Epub May 8, 2016]. DOI: $10.1073 /$ pnas. 1521974113

[25] Conner SD, Schmid SL. Regulated portals of entry into the cell. Nature. 2003;422(6927):37-44 [Epub Mar 7, 2003]. DOI: $10.1038 /$ nature01451

[26] Schmid SL, Sorkin A, Zerial M. Endocytosis: Past, present, and future. Cold Spring Harbor Perspectives in Biology. 2014;6(12):a022509 [Epub Nov2, 2014]. DOI: $10.1101 /$ cshperspect.a022509

[27] Gordon S. Phagocytosis: An immunobiologic process. Immunity. 
2016;44(3):463-475. [Epub

Mar 18, 2016]. DOI: 10.1016/j.

immuni.2016.02.026

[28] Whiteside TL. Immune modulation of T-cell and NK (natural killer) cell activities by TEXs (tumour-derived exosomes). Biochemical Society Transactions. 2013;41(1):245-251 [Epub Jan 30, 2013]. DOI: 10.1042/ bst20120265

[29] Ferguson Bennit HR, Gonda A, McMullen JRW, Kabagwira J, Wall NR. Peripheral blood cell interactions of cancer-derived exosomes affect immune function. Cancer Microenvironment: Official Journal of the International Cancer Microenvironment Society. 30 Mar 2018. [Epub ahead of print] DOI: 10.1007/s12307-018-0209-1. PMID:29603062

[30] Lim JP, Gleeson PA.

Macropinocytosis: An endocytic pathway for internalising large gulps. Immunology and Cell Biology. 2011;89(8):836-843

[31] McMahon HT, Boucrot E. Molecular mechanism and physiological functions of clathrin-mediated endocytosis.

Nature reviews Molecular cell biology. 2011;12(8):517-533. [Epub Jul 23, 2011]. DOI: $10.1038 / \mathrm{nrm} 3151$

[32] Benmerah A, Lamaze C. Clathrincoated pits: Vive la difference? Traffic (Copenhagen, Denmark). 2007;8(8):970-982 [Epub Jun 6, 2007]. DOI: 10.1111/j.1600-0854.2007.00585.x

[33] He M, Qin H, Poon TC, Sze SC, Ding X, Co NN, et al. Hepatocellular carcinoma-derived exosomes promote motility of immortalized hepatocyte through transfer of oncogenic proteins and RNAs. Carcinogenesis. 2015;36(9):1008-1018. [Epub Jun 10, 2015]. DOI: $10.1093 /$ carcin/bgv081

[34] Xu R, Greening DW, Rai A, Ji H, Simpson RJ. Highly-purified exosomes and shed microvesicles isolated from the human colon cancer cell line LIM1863 by sequential centrifugal ultrafiltration are biochemically and functionally distinct. Methods (San Diego, CA). 2015;87:11-25 [Epub Apr 19, 2015]. DOI: 10.1016/j. ymeth.2015.04.008

[35] Daniels-Wells TR, Penichet ML. Transferrin receptor 1: A target for antibody-mediated cancer therapy. Immunotherapy. 2016;8(9):991-994. [Epub Jul 5, 2016]. DOI: 10.2217/ imt-2016-0050

[36] Singh M, Mugler K, Hailoo DW, Burke S, Nemesure B, Torkko $\mathrm{K}$, et al. Differential expression of transferrin receptor ( $T f R$ ) in a spectrum of normal to malignant breast tissues: Implications for in situ and invasive carcinoma. Applied Immunohistochemistry \& Molecular Morphology. 2011;19(5):417-423.

[Epub Feb 8, 2011]. DOI: $10.1097 /$

PAI.0b013e318209716e

[37] Morelli AE, Larregina AT, Shufesky WJ, Sullivan ML, Stolz DB, Papworth GD, et al. Endocytosis, intracellular sorting, and processing of exosomes by dendritic cells. Blood. 2004;104(10):3257-3266. [Epub Jul 31, 2004]. DOI: $10.1182 /$ blood-2004-03-0824

[38] Lajoie P, Nabi IR. Lipid rafts, caveolae, and their endocytosis. International Review of Cell and Molecular Biology. 2010;282:135-163. [Epub Jul 16, 2010]. DOI: 10.1016/ s1937-6448(10)82003-9

[39] Buschow SI, van Balkom BW, Aalberts M, Heck AJ, Wauben M, Stoorvogel W. MHC class II-associated proteins in B-cell exosomes and potential functional implications for exosome biogenesis. Immunology and Cell Biology. 2010;88(8):851-856. [Epub May 12, 2010]. DOI: 10.1038/ icb.2010.64 
[40] Ewers H, Helenius A. Lipidmediated endocytosis. Cold Spring Harbor Perspectives in Biology. 2011;3(8):a004721 [Epub May 18, 2011]. DOI: $10.1101 /$ cshperspect.a004721

[41] Pienimaeki-Roemer A, Kuhlmann K, Bottcher A, Konovalova T, Black A, Orso E, et al. Lipidomic and proteomic characterization of platelet extracellular vesicle subfractions from senescent platelets. Transfusion. 2015;55(3):507-521. [Epub Oct 22, 2014]. DOI: $10.1111 /$ trf.12874

[42] Phuyal S, Hessvik NP, Skotland T, Sandvig K, Llorente A. Regulation of exosome release by glycosphingolipids and flotillins. The FEBS Journal. 2014;281(9):2214-2227. [Epub Mar 13, 2014]. DOI: $10.1111 /$ febs. 12775

[43] Svensson KJ, Christianson HC, Wittrup A, Bourseau-Guilmain E, Lindqvist E, Svensson LM, et al. Exosome uptake depends on ERK1/2heat shock protein 27 signaling and lipid Raft-mediated endocytosis negatively regulated by caveolin- 1 . The Journal of Biological Chemistry. 2013;288(24):17713-17724 [Epub May 9, 2013]. DOI: 10.1074/jbc.M112.445403

[44] Koumangoye RB, Sakwe AM, Goodwin JS, Patel T, Ochieng J. Detachment of breast tumor cells induces rapid secretion of exosomes which subsequently mediate cellular adhesion and spreading. PloS One. 2011;6(9):e24234 [Epub Sep 15, 2011]. DOI: 10.1371/journal.pone.0024234

[45] Freeman GJ, Casasnovas JM, Umetsu DT, DeKruyff RH. TIM genes: A family of cell surface phosphatidylserine receptors that regulate innate and adaptive immunity. Immunological Reviews. 2010;235(1):172-189 [Epub Jun 12, 2010]. DOI: 10.1111/j.0105-2896.2010.00903.x

[46] Plebanek MP, Mutharasan RK, Volpert O, Matov A, Gatlin JC,
Thaxton CS. Nanoparticle targeting and cholesterol flux through scavenger receptor type B-1 inhibits cellular exosome uptake. Scientific Reports. 2015;5:15724 [Epub Oct 30, 2015]. DOI: 10.1038/srep15724

[47] Watson DC, Bayik D, Srivatsan A, Bergamaschi C, Valentin A, Niu $\mathrm{G}$, et al. Efficient production and enhanced tumor delivery of engineered extracellular vesicles. Biomaterials. 2016;105:195-205. [Epub Aug 16, 2016]. DOI: 10.1016/j.biomaterials.2016.07.003

[48] Rana S, Yue S, Stadel D, Zoller M. Toward tailored exosomes: The exosomal tetraspanin web contributes to target cell selection. The international Journal of Biochemistry \& Cell Biology. 2012;44(9):1574-1584. [Epub Jun 26, 2012]. DOI: 10.1016/j. biocel.2012.06.018

[49] Yuyama K, Sun H, Mitsutake S, Igarashi Y. Sphingolipid-modulated exosome secretion promotes clearance of amyloid-beta by microglia. The Journal of Biological Chemistry. 2012;287(14):10977-10989 [Epub Feb 4, 2012]. DOI: 10.1074/jbc.M111.324616

[50] Zakharova L, Svetlova M, Fomina AF. T cell exosomes induce cholesterol accumulation in human monocytes via phosphatidylserine receptor. Journal of Cellular Physiology. 2007;212(1):174-181. [Epub Feb 15, 2007]. DOI: $10.1002 /$ jcp.21013

[51] Matsumoto A, Takahashi Y, Nishikawa M, Sano K, Morishita M, Charoenviriyakul C, et al. Role of phosphatidylserine-derived negative surface charges in the recognition and uptake of intravenously injected B16BL6-derived exosomes by macrophages. Journal of Pharmaceutical Sciences. 2017;106(1):168-175. DOI: 10.1016/j.xphs.2016.07.022

[52] Barres C, Blanc L, Bette-Bobillo P, Andre S, Mamoun R, Gabius 
HJ, et al. Galectin-5 is bound onto the surface of rat reticulocyte exosomes and modulates vesicle uptake by macrophages. Blood. 2010;115(3):696-705. [Epub Nov 12, 2009]. DOI: $10.1182 /$ blood-2009-07-231449

[53] Saunderson SC, Dunn AC, Crocker PR, McLellan AD. CD169 mediates the capture of exosomes in spleen and lymph node. Blood. 2014;123(2):208-216 [Epub Nov 21, 2013]. DOI: $10.1182 /$ blood-2013-03-489732

[54] Chen Z, Yang L, Cui Y, Zhou Y, Yin X, Guo J, et al. Cytoskeletoncentric protein transportation by exosomes transforms tumorfavorable macrophages. Oncotarget. 2016;7(41):67387-67402 [Epub Sep 8, 2016]. DOI: $10.18632 / o n c o t a r g e t .11794$

[55] Hoffmann PR, de Cathelineau AM, Ogden CA, Leverrier Y, Bratton DL, Daleke DL, et al. Phosphatidylserine (PS) induces PS receptor-mediated macropinocytosis and promotes clearance of apoptotic cells. The Journal of Cell Biology. 2001;155(4):649-659 [Epub Nov 14, 2001]. DOI: 10.1083/ jcb.200108080

[56] Fitzner D, Schnaars M, van Rossum D, Krishnamoorthy G, Dibaj P, Bakhti $\mathrm{M}$, et al. Selective transfer of exosomes from oligodendrocytes to microglia by macropinocytosis. Journal of Cell Science. 2011;124(Pt 3):447-458. [Epub Jan 19, 2011]. DOI: 10.1242/jcs.074088

[57] Costa-Silva B, Aiello NM, Ocean AJ, Singh S, Zhang H, Thakur BK, et al. Pancreatic cancer exosomes initiate premetastatic niche formation in the liver. Nature Cell Biology. 2015;17(6):816-826. [Epub May 20, 2015]. DOI: 10.1038/ ncb3169

[58] Atay S, Gercel-Taylor C, Taylor DD. Human trophoblast-derived exosomal fibronectin induces pro-inflammatory IL-1beta production by macrophages. American Journal of Reproductive Immunology (New York, NY: 1989). 2011;66(4):259269 [Epub Mar 18, 2011]. DOI: 10.1111/j.1600-0897.2011.00995.x

[59] Wilke CM, Kryczek I, Zou W. Antigen-presenting cell (APC) subsets in ovarian cancer. International Reviews of Immunology. 2011;30(2-3): 120-126. [Epub May 12, 2011]. DOI: $10.3109 / 08830185.2011 .567362$

[60] Hoogeboom R, Tolar P. Molecular mechanisms of $\mathrm{B}$ cell antigen gathering and endocytosis. Current Topics in Microbiology and Immunology. 2016;393:45-63. [Epub Sep 5, 2015]. DOI: 10.1007/82_2015_476

[61] Hazan-Halevy I, Rosenblum D, Weinstein S, Bairey O, Raanani P, Peer D. Cell-specific uptake of mantle cell lymphoma-derived exosomes by malignant and non-malignant B-lymphocytes. Cancer Letters. 2015;364(1):59-69 [Epub May 3, 2015]. DOI: 10.1016/j.canlet.2015.04.026

[62] Suda K, Mitsudomi T. Role of EGFR mutations in lung cancers: Prognosis and tumor chemosensitivity. Archives of Toxicology. 2015;89(8):1227-1240. [Epub May 20, 2015]. DOI: 10.1007/ s00204-015-1524-7

[63] Purushothaman A, Bandari SK, Liu J, Mobley JA, Brown EE, Sanderson RD. Fibronectin on the surface of myeloma cell-derived exosomes mediates exosome-cell interactions. The Journal of Biological Chemistry. 2016;291(4):1652-1663 [Epub Nov 26, 2015]. DOI: $10.1074 / j b c . M 115.686295$

[64] Ferguson Bennit HR GA, Oppegard LJ, Chi DP, Khan S, Wall NR. Uptake of lymphoma-derived exosomes by peripheral blood leukocytes. Blood and Lymphatic Cancer: Targets and Therapy. 2017;7:9-23. DOI: 10.2147/BLCTT. S130826 
[65] Hao S, Bai O, Li F, Yuan J, Laferte S, Xiang J. Mature dendritic cells pulsed with exosomes stimulate efficient cytotoxic T-lymphocyte responses and antitumour immunity. Immunology. 2007;120(1):90-102 [Epub Nov 1, 2006]. DOI: 10.1111/j.1365-2567.2006.02483.x

[66] Obregon C, Rothen-Rutishauser B, Gerber P, Gehr P, Nicod LP. Active uptake of dendritic cell-derived exovesicles by epithelial cells induces the release of inflammatory mediators through a TNF-alpha-mediated pathway. The American Journal of Pathology. 2009;175(2):696-705 [Epub Jul 25, 2009]. DOI: 10.2353/ ajpath.2009.080716

[67] Platt CD, Ma JK, Chalouni C, Ebersold M, Bou-Reslan H, Carano RA, et al. Mature dendritic cells use endocytic receptors to capture and present antigens. Proceedings of the National Academy of Sciences of the United States of America. 2010;107(9):4287-4292 [Epub Feb 10, 2010]. DOI: $10.1073 /$ pnas.0910609107

[68] Pegtel DM, Cosmopoulos K, Thorley-Lawson DA, van Eijndhoven MA, Hopmans ES, Lindenberg JL, et al. Functional delivery of viral miRNAs via exosomes. Proceedings of the National Academy of Sciences of the United States of America. 2010;107(14):6328-6333 [Epub Mar 23, 2010]. DOI: 10.1073/ pnas.0914843107

[69] Xie Y, Zhang H, Li W, Deng Y, Munegowda MA, Chibbar R, et al. Dendritic cells recruit $\mathrm{T}$ cell exosomes via exosomal LFA-1 leading to inhibition of CD8+ CTL responses through downregulation of peptide/MHC class I and Fas ligand-mediated cytotoxicity. Journal of Immunology (Baltimore, MD: 1950). 2010;185(9):5268-5278 [Epub Oct 1, 2010]. DOI: 10.4049/ jimmunol.1000386

[70] Garcia-Vallejo JJ, van Kooyk Y. The physiological role of DC-SIGN: A tale of mice and men. Trends in Immunology.
2013;34(10):482-486. [Epub Apr 24, 2013]. DOI: 10.1016/j.it.2013.03.001

[71] Naslund TI, Paquin-Proulx D, Paredes PT, Vallhov H, Sandberg JK, Gabrielsson S. Exosomes from breast milk inhibit HIV-1 infection of dendritic cells and subsequent viral transfer to CD4+ T cells. AIDS (London, England). 2014;28(2):171-180 [Epub Jan 15, 2014]. DOI: $10.1097 / q a d .0000000000000159$

[72] Del Conde I, Shrimpton CN, Thiagarajan P, Lopez JA. Tissue-factorbearing microvesicles arise from lipid rafts and fuse with activated platelets to initiate coagulation. Blood. 2005;106(5):1604-1611. [Epub Mar 3, 2005]. DOI: 10.1182/blood-2004-03-1095

[73] Lemire P, Houde M, Segura M. Encapsulated group B Streptococcus modulates dendritic cell functions via lipid rafts and clathrinmediated endocytosis. Cellular Microbiology. 2012;14(11):17071719. [Epub Jun 28, 2012]. DOI: 10.1111/j.1462-5822.2012.01830.x

[74] Sharma R, Ghasparian A, Robinson JA, McCullough KC. Synthetic virus-like particles target dendritic cell lipid rafts for rapid endocytosis primarily but not exclusively by macropinocytosis. PloS One. 2012;7(8):e43248 [Epub Aug 21, 2012]. DOI: $10.1371 /$ journal.pone. 0043248

[75] Izquierdo-Useros N, NaranjoGomez M, Archer J, Hatch SC, Erkizia I, Blanco J, et al. Capture and transfer of HIV-1 particles by mature dendritic cells converges with the exosome-dissemination pathway. Blood. 2009;113(12):2732-2741

[Epub Oct 24, 2008]. DOI: 10.1182/ blood-2008-05-158642

[76] Willinger T, Staron M, Ferguson SM, De Camilli P, Flavell RA. Dynamin 2-dependent endocytosis sustains T-cell receptor signaling and drives metabolic reprogramming in $\mathrm{T}$ lymphocytes. Proceedings of the National Academy 
of Sciences of the United States of America. 2015;112(14):4423-4428 [Epub Apr 2, 2015]. DOI: 10.1073/ pnas.1504279112

[77] Alarcon B, Martinez-Martin N. RRas2, RhoG and T-cell phagocytosis. Small GTPases. 2012;3(2):97-101 [Epub Jul 14, 2012]. DOI: 10.4161/sgtp.19138

[78] Shah DK, Zuniga-Pflucker JC. Notch receptor-ligand interactions during $\mathrm{T}$ cell development, a ligand endocytosisdriven mechanism. Current Topics in Microbiology and Immunology. 2012;360:19-46. [Epub May 15, 2012]. DOI: $10.1007 / 82 \_2012 \_225$

[79] Nanjundappa RH, Wang R, Xie Y, Umeshappa CS, Chibbar R, Wei Y, et al. GP120-specific exosometargeted $\mathrm{T}$ cell-based vaccine capable of stimulating DC- and CD4(+) T-independent CTL responses. Vaccine. 2011;29(19):3538-3547. [Epub Mar 17, 2011]. DOI: 10.1016/j. vaccine.2011.02.095

[80] Nolte-'t Hoen EN, Buschow SI, Anderton SM, Stoorvogel W, Wauben $\mathrm{MH}$. Activated T cells recruit exosomes secreted by dendritic cells via LFA1. Blood. 2009;113(9):1977-1981. [Epub Dec 10, 2008]. DOI: 10.1182/ blood-2008-08-174094

[81] Buschow SI, Nolte-'t Hoen EN, van Niel G, Pols MS, ten Broeke T, Lauwen $\mathrm{M}$, et al. MHC II in dendritic cells is targeted to lysosomes or T cell-induced exosomes via distinct multivesicular body pathways. Traffic (Copenhagen, Denmark). 2009;10(10):1528-1542 [Epub Aug 18, 2009]. DOI: 10.1111/j.1600-0854.2009.00963.x

[82] Asmat TM, Agarwal V, Saleh M, Hammerschmidt S. Endocytosis of Streptococcus pneumoniae via the polymeric immunoglobulin receptor of epithelial cells relies on clathrin and caveolin dependent mechanisms. International Journal of Medical
Microbiology. 2014;304(8):1233-1246. [Epub Dec 3, 2014]. DOI: 10.1016/j. ijmm.2014.10.001

[83] Devadas D, Koithan T, Diestel R, Prank U, Sodeik B, Dohner K. Herpes simplex virus internalization into epithelial cells requires $\mathrm{Na}^{+} / \mathrm{H}^{+}$ exchangers and p21-activated kinases but neither clathrin- nor caveolinmediated endocytosis. Journal of Virology. 2014;88(22):13378-13395 [Epub Sep 12, 2014]. DOI: 10.1128/ jvi.03631-13

[84] Takano M, Kawami M, Aoki A, Yumoto R. Receptor-mediated endocytosis of macromolecules and strategy to enhance their transport in alveolar epithelial cells. Expert Opinion on Drug Delivery. 2015;12(5):813-825. [Epub Dec 17, 2014]. DOI: 10.1517/17425247.2015.992778

[85] Rincon-Heredia R, Flores-Benitez D, Flores-Maldonado C, BonillaDelgado J, Garcia-Hernandez V, Verdejo-Torres $\mathrm{O}$, et al. Ouabain induces endocytosis and degradation of tight junction proteins through ERK1/2dependent pathways. Experimental Cell Research. 2014;320(1):108-118. [Epub Oct 22, 2013]. DOI: 10.1016/j. yexcr.2013.10.008

[86] Fujioka Y, Tsuda M, Hattori T, Sasaki J, Sasaki T, Miyazaki T, et al. The Ras-PI3K signaling pathway is involved in clathrin-independent endocytosis and the internalization of influenza viruses. PloS One. 2011;6(1):e16324 [Epub Feb 2, 2011]. DOI: 10.1371/ journal.pone.0016324

[87] Chen CC, Liu L, Ma F, Wong CW, Guo XE, Chacko JV, et al. Elucidation of exosome migration across the blood-brain barrier model in vitro. Cellular and Molecular Bioengineering. 2016;9(4):509-529 [Epub Apr 11, 2017]. DOI: $10.1007 / \mathrm{s} 12195-016-0458-3$ 
[88] Turner L, Bitto NJ, Steer DL, Lo C, D'Costa K, Ramm G, et al. Helicobacter pylori outer membrane vesicle size determines their mechanisms of host cell entry and protein content. Frontiers in Immunology. 2018;9:1466 [Epub Jul 18, 2018]. DOI: 10.3389/ fimmu.2018.01466

[89] Yuan D, Zhao Y, Banks WA, Bullock KM, Haney M, Batrakova E, et al. Macrophage exosomes as natural nanocarriers for protein delivery to inflamed brain. Biomaterials. 2017;142:1-12. [Epub Jul 18, 2017]. DOI: 10.1016/j.biomaterials.2017.07.011

[90] Costa Verdera H, Gitz-Francois JJ, Schiffelers RM, Vader P. Cellular uptake of extracellular vesicles is mediated by clathrin-independent endocytosis and macropinocytosis. Journal of Controlled Release: Official Journal of the Controlled Release Society. 2017;266:100-108. [Epub Sep 19, 2017]. DOI: 10.1016/j.jconrel.2017.09.019

[91] Heusermann W, Hean J, Trojer D, Steib E, von Bueren S, Graff-Meyer A, et al. Exosomes surf on filopodia to enter cells at endocytic hot spots, traffic within endosomes, and are targeted to the ER. The Journal of Cell Biology. 2016;213(2):173-184 [Epub Apr 27, 2016]. DOI: $10.1083 /$ jcb.201506084

[92] Al-Nedawi K, Meehan B, Kerbel RS, Allison AC, Rak J. Endothelial expression of autocrine VEGF upon the uptake of tumor-derived microvesicles containing oncogenic EGFR. Proceedings of the National Academy of Sciences of the United States of America. 2009;106(10):3794-3799 [Epub Feb 24, 2009]. DOI: $10.1073 /$ pnas. 0804543106

[93] Wei X, Liu C, Wang H, Wang L, Xiao F, Guo Z, et al. Surface phosphatidylserine is responsible for the internalization on microvesicles derived from hypoxia-induced human bone marrow mesenchymal stem cells into human endothelial cells.
PloS One. 2016;11(1):e0147360 [Epub Jan 26, 2016]. DOI: 10.1371/journal. pone. 0147360

[94] Yoon JH, Ham IH, Kim O, Ashktorab H, Smoot DT, Nam SW, et al. Gastrokine 1 protein is a potential theragnostic target for gastric cancer. Gastric Cancer: Official Journal of the International Gastric Cancer Association and the Japanese Gastric Cancer Association. 2018. [Epub Apr 29, 2018]. DOI: $10.1007 / \mathrm{s} 10120-018-0828-8$

[95] Nanbo A, Kawanishi E, Yoshida R, Yoshiyama H. Exosomes derived from Epstein-Barr virus-infected cells are internalized via caveola-dependent endocytosis and promote phenotypic modulation in target cells. Journal of Virology. 2013;87(18):10334-10347 [Epub Jul 19, 2013]. DOI: 10.1128/ jvi.01310-13

[96] Yang Z, Xie J, Zhu J, Kang C, Chiang C, Wang $\mathrm{X}$, et al. Functional exosomemimic for delivery of siRNA to cancer: In vitro and in vivo evaluation. Journal of Controlled Release: Official Journal of the Controlled Release Society. 2016;243:160-171. [Epub Nov 5, 2016]. DOI: 10.1016/j.jconrel.2016.10.008

[97] Escrevente C, Keller S, Altevogt $\mathrm{P}$, Costa J. Interaction and uptake of exosomes by ovarian cancer cells. BMC Cancer. 2011;11:108 [Epub Mar 29, 2011]. DOI: 10.1186/1471-2407-11-108

[98] Chiba M, Kubota S, Sato K, Monzen S. Exosomes released from pancreatic cancer cells enhance angiogenic activities via dynamindependent endocytosis in endothelial cells in vitro. Scientific Reports. 2018;8(1):11972 [Epub Aug 12, 2018]. DOI: $10.1038 / \mathrm{s} 41598-018-30446-1$

[99] Christianson HC, Belting M. Heparan sulfate proteoglycan as a cell-surface endocytosis receptor. Matrix Biology: Journal of the International Society for Matrix Biology. 2014;35:51-55. 
[Epub Oct 23, 2013]. DOI: 10.1016/j. matbio.2013.10.004

[100] Atai NA, Balaj L, van Veen H, Breakefield XO, Jarzyna PA, Van Noorden CJ, et al. Heparin blocks transfer of extracellular vesicles between donor and recipient cells. Journal of Neuro-Oncology. 2013;115(3):343-351 [Epub Sep 5, 2013]. DOI: $10.1007 / \mathrm{s} 11060-013-1235-\mathrm{y}$

[101] Franzen CA, Simms PE, Van Huis AF, Foreman KE, Kuo PC, Gupta GN. Characterization of uptake and internalization of exosomes by bladder cancer cells. BioMed Research International. 2014;2014:619829 [Epub Feb 28, 2014]. DOI: 10.1155/2014/619829

[102] Jang SC, Kim OY, Yoon CM, Choi DS, Roh TY, Park J, et al. Bioinspired exosome-mimetic nanovesicles for targeted delivery of chemotherapeutics to malignant tumors. ACS Nano. 2013;7(9):7698-7710. [Epub Sep 6, 2013]. DOI: $10.1021 / \mathrm{nn} 402232 \mathrm{~g}$

[103] Shimoda A, Tahara Y, Sawada SI, Sasaki Y, Akiyoshi K. Glycan profiling analysis using evanescentfield fluorescence-assisted lectin array: Importance of sugar recognition for cellular uptake of exosomes from mesenchymal stem cells. Biochemical and Biophysical Research Communications. 2017;491(3):701-707. [Epub Jul 29, 2017]. DOI: 10.1016/j. bbrc.2017.07.126

[104] Bilen MA, Pan T, Lee YC, Lin SC, Yu G, Pan J, et al. Proteomics profiling of exosomes from primary mouse osteoblasts under proliferation versus mineralization conditions and characterization of their uptake into prostate cancer cells. Journal of Proteome Research. 2017;16(8):2709-2728. [Epub Jul 5, 2017]. DOI: 10.1021/acs. jproteome.6b00981

[105] Vargas A, Zhou S, Ethier-Chiasson M, Flipo D, Lafond J, Gilbert C, et al.
Syncytin proteins incorporated in placenta exosomes are important for cell uptake and show variation in abundance in serum exosomes from patients with preeclampsia. FASEB Journal: Official Publication of the Federation of American Societies for Experimental Biology. 2014;28(8):3703-3719. [Epub May 9, 2014]. DOI: 10.1096/fj.13-239053

[106] Nazarenko I, Rana S, Baumann A, McAlear J, Hellwig A, Trendelenburg $M$, et al. Cell surface tetraspanin Tspan8 contributes to molecular pathways of exosome-induced endothelial cell activation. Cancer Research. 2010;70 (4):1668-1678. [Epub Feb 4, 2010]. DOI: $10.1158 / 0008-5472$. can-09-2470

[107] Dutta S, Warshall C, Bandyopadhyay C, Dutta D, Chandran B. Interactions between exosomes from breast cancer cells and primary mammary epithelial cells leads to generation of reactive oxygen species which induce DNA damage response, stabilization of p53 and autophagy in epithelial cells. PloS One. 2014;9(5):e97580 [Epub May 17, 2014]. DOI: 10.1371/journal. pone. 0097580

[108] Bhome R, Bullock MD, Al Saihati HA, Goh RW, Primrose JN, Sayan AE, et al. A top-down view of the tumor microenvironment: Structure, cells and signaling. Frontiers in Cell and Developmental Biology. 2015;3:33 [Epub Jun 16, 2015]. DOI: 10.3389/ fcell.2015.00033

[109] Ng CT, Tang FM, Li JJ, Ong C, Yung LL, Bay BH. Clathrin-mediated endocytosis of gold nanoparticles in vitro. Anatomical record (Hoboken, NJ: 2007). 2015;298(2):418-427 [Epub Sep 23, 2014]. DOI: 10.1002/ar.23051

[110] Veettil MV, Bandyopadhyay C, Dutta D, Chandran B. Interaction of KSHV with host cell surface receptors and cell entry. Viruses. 
2014;6(10):4024-4046 [Epub Oct 25, 2014]. DOI: $10.3390 / v 6104024$

[111] Bozavikov P, Rajshankar D, Lee W, McCulloch CA. Particle size influences fibronectin internalization and degradation by fibroblasts. Experimental Cell Research. 2014;328(1):172-185. [Epub Jul 6, 2014]. DOI: 10.1016/j.yexcr.2014.06.018

[112] Geary SM, Cowin AJ, Copeland B, Baleato RM, Miyazaki K, Ashman LK. The role of the tetraspanin CD151 in primary keratinocyte and fibroblast functions: Implications for wound healing. Experimental Cell Research. 2008;314(11-12):2165-2175. [Epub Jun 7, 2008]. DOI: 10.1016/j. yexcr.2008.04.011

[113] Alvarez-Erviti L, Seow Y, Yin H, Betts C, Lakhal S, Wood MJ. Delivery of siRNA to the mouse brain by systemic injection of targeted exosomes. Nature Biotechnology. 2011;29(4):341-345. [Epub Mar 23, 2011]. DOI: $10.1038 /$ nbt.1807

[114] Tian T, Zhu YL, Zhou YY, Liang GF, Wang YY, Hu FH, et al. Exosome uptake through clathrin-mediated endocytosis and macropinocytosis and mediating miR-21 delivery. The Journal of Biological Chemistry. 2014;289(32):22258-22267 [Epub Jun 22, 2014]. DOI: $10.1074 /$ jbc.M114.588046

[115] Fruhbeis C, Frohlich D, Kuo WP, Amphornrat J, Thilemann S, Saab AS, et al. Neurotransmittertriggered transfer of exosomes mediates oligodendrocyte-neuron communication. PLoS Biology. 2013;11(7):e1001604 [Epub Jul 23, 2013]. DOI: 10.1371/journal.pbio.1001604

[116] Zhang Y, Chopp M, Liu XS, Katakowski M, Wang X, Tian X, et al. Exosomes derived from mesenchymal stromal cells promote axonal growth of cortical neurons. Molecular Neurobiology. 2017;54(4):2659-2673 [Epub Mar 20, 2016]. DOI: $10.1007 / s 12035-016-9851-0$
[117] Bahrini I, Song JH, Diez D, Hanayama R. Neuronal exosomes facilitate synaptic pruning by up-regulating complement factors in microglia. Scientific Reports. 2015;5:7989 [Epub Jan 24, 2015]. DOI: 10.1038/srep07989

[118] Chivet M, Javalet C, Laulagnier $\mathrm{K}$, Blot B, Hemming FJ, Sadoul R. Exosomes secreted by cortical neurons upon glutamatergic synapse activation specifically interact with neurons. Journal of Extracellular Vesicles. 2014;3:24722. DOI: 10.3402/ jev.v3.24722

[119] Granseth B, Odermatt B, Royle SJ, Lagnado L. Clathrin-mediated endocytosis is the dominant mechanism of vesicle retrieval at hippocampal synapses. Neuron. 2006;51(6):773-786. [Epub Sep 20, 2006]. DOI: 10.1016/j. neuron.2006.08.029

[120] Cousin MA. Synaptic vesicle endocytosis and endosomal recycling in central nerve terminals: Discrete trafficking routes? The Neuroscientist: A Review Journal Bringing Neurobiology, Neurology and Psychiatry. 2015;21(4):413-423. [Epub Jul 17, 2014]. DOI: $10.1177 / 1073858414542251$

[121] Gonda A, Kabagwira J, Senthil GN, Wall NR. Internalization of exosomes through receptor-mediated endocytosis. Molecular Cancer Research. 2019;17(2):337-347. [Epub Nov 30, 2018]. DOI: 10.1158/1541-7786. MCR-18-0891

[122] Nakase I, Noguchi K, Fujii I, Futaki $\mathrm{S}$. Vectorization of biomacromolecules into cells using extracellular vesicles with enhanced internalization induced by macropinocytosis. Scientific Reports. 2016;6:34937 [Epub Oct 18, 2016]. DOI: 10.1038/srep34937

[123] Lanzetti L, Di Fiore PP.

Endocytosis and cancer: An 'insider' network with dangerous liaisons. 
Traffic (Copenhagen, Denmark).

2008;9(12):2011-2021. DOI:

10.1111/j.1600-0854.2008.00816.x

[124] El-Sayed A, Harashima H.

Endocytosis of gene delivery vectors:

From clathrin-dependent to lipid

raft-mediated endocytosis. Molecular

Therapy. 2013;21(6):1118-1130. DOI:

10.1038/mt.2013.54 


\title{
Effects of Vesicular Membranes Reordering on the Activity of Lipid Metabolizing Enzymes
}

\author{
Dino G. Salinas
}

\begin{abstract}
The activity of membrane enzymes could be highly determined by the order of the lipid of the membrane and the enzyme distribution. Particularly, the reordering of phospholipid substrates and the local fluctuations of the lipid phases have been included in mathematical models to explain the modulation of the activity of membrane enzymes in extracellular vesicles, liposomes, or microvesicles. The applied principles are different to those derived from the classic considerations such as $3 \mathrm{D}$ environment, aqueous, and homogeneous media. Instead, the lateral diffusion of enzyme and substrate and highly nonhomogeneous $2 \mathrm{D}$ environment determine fluctuations of enzymatic activity capable to explain metabolic effects, such as in case of peptide-induced membrane components reordering. In this chapter, we review some applications to lipid metabolizing enzymes, due to analytical results of the kinetic theory of membrane enzymes.
\end{abstract}

Keywords: phospholipid domain, substrate reordering, lipolytic enzyme, phospholipase, enzyme kinetics, lipid phase, micelle, membrane

\section{Introduction}

The so-called extracellular vesicles (EVs) are either exosomes or microvesicles, which are formed from intracellular multivesicular bodies or plasma membrane, respectively $[1,2]$. The lipid content of EVs plays a key role in various pathophysiological processes [3] as well as the native proteins on their surface, many of them having functions in cellular metabolism and signal transductions, such as phospholipases [4]. Interestingly, some membrane protein-related human diseases arise from dysregulation of signal transduction pathways [2]. Moreover, some phospholipases are very important for biogenesis of EVs and there are many phospholipases in EVs [5-7]. About the lipid phase of EVs, lipid exchange between vesicles has been described [8], exosomes can vectorize some lipids acting as transport, and the lipid composition can be modified by in vitro manipulation [7]. On the other hand, microdomains of EVs could be transferred to a target membrane cells by means of membrane fusion, and as a consequence, the lipid substrate redistribution could be able to affect the activity of lipid metabolizing enzymes.

Taking into account all the abovementioned causes and effects of the EVs related to both lipid substrate reordering and their metabolizing enzymes, the understanding of the effect of lipid-substrate reordering over the enzyme activity could be 
essential to the development of therapeutic purposes as well as to insight the carcinogenesis and to perform enzyme kinetics experiments. We hope that this purpose of understanding the enzyme kinetics in the lipid phase will be fulfilled at least partially in the remainder of this chapter.

Numerous processes associated with the cell membranes are mediated by the action of lipid metabolizing enzymes. Knowing how the changes of membrane properties affect the activity of these enzymes allows us to explain disease mechanisms and pharmacological activities. Specifically, the knowledge about the mechanisms of the reactions catalyzed by these lipid metabolizing enzymes can contribute to the understanding of several regulation and signaling phenomena in cells. Thus, the enzymes of the phospholipase C family (PLC) [9] are involved in lipid signaling pathways affecting levels of free calcium and protein phosphorylation [10, 11], regulating secretion, transport, metabolism, gene expression, and protein translation. Since phospholipases react in a lipid-water interface, different kinetic experimental systems have been developed using phospholipid vesicles, phospholipid and detergent mixed micelles, or phospholipid monolayers. As a first step, the watersoluble enzyme would bind to the lipid phase, then having many catalytic cycles with the lipid substrate before the enzyme returns to the aqueous solution.

To study the kinetic measurements of phospholipases, the theory known as surface dilution kinetics [12] has been applied. This theory allows to estimate the main enzyme kinetic parameters considering the effects of the substrate staying into the lipid phase ("surface dilution") on the enzyme activity. Similar to the most enzyme kinetic models, in this theory, the mass action law and the steady-state assumption for enzyme intermediaries are applied. In the calculations with regard to molecules in water phase, their concentrations are used. Instead, in the case of calculations of molecules dissolved in lipid phase, their mole fractions are used.

Using this theory and its associated experiments, it has been proposed that many lipid metabolizing enzymes follow a mechanism composed by two binding steps of the enzyme on the lipid phase: a first binding step to the lipid phase followed by a second binding step to the substrate. More specifically, depending on the first binding step, there are two possible kinetic models: in the phospholipid-binding model, first the enzyme binds specifically to the phospholipid substrate; $\mathrm{n}$ the surface-binding model, first the enzyme binds to any lipid phase region. In homogeneous substrate distribution conditions, these are the kinetic equations derived for the phospholipid-binding model (Eq. 1) and the surface-binding model (Eq. 2) [12, 13]:

$$
\begin{gathered}
V=\frac{k C_{E_{T}} f^{2}}{\frac{k_{m} k_{s}}{C_{L}}+k_{m} f+f^{2}} \\
V=\frac{k C_{E_{T}} f}{\frac{k_{m} k_{s}}{C_{L}}+k_{m}+f}
\end{gathered}
$$

where $V$ is the rate of product formation (mol/[volume-time]), $f$ is the mole fraction of the substrate (dimensionless), $C_{E_{T}}$ is the total enzyme concentration (mol/volume), $C_{L}$ is the total lipid concentration (mol/volume), $k$ is the catalytic time constant (time $\left.{ }^{-1}\right), k_{s}$ is the dissociation constant (mol/volume), and $k_{m}$ is the interfacial Michaelis constant (dimensionless).

A more complex approach must consider that phospholipids can be reordered in lateral domains [14-16] because of their interactions with either phospholipids, cytoskeleton, or charged soluble molecules, and then more adequate mathematical expressions are necessary involving phospholipid reordering. For example, phosphatidylinositol 4,5-biphosphate (PIP2) and phosphatidylserine (PS) can be reordered in lateral domains because of the direct interactions with $\mathrm{Ca}^{2+}$ or basic 

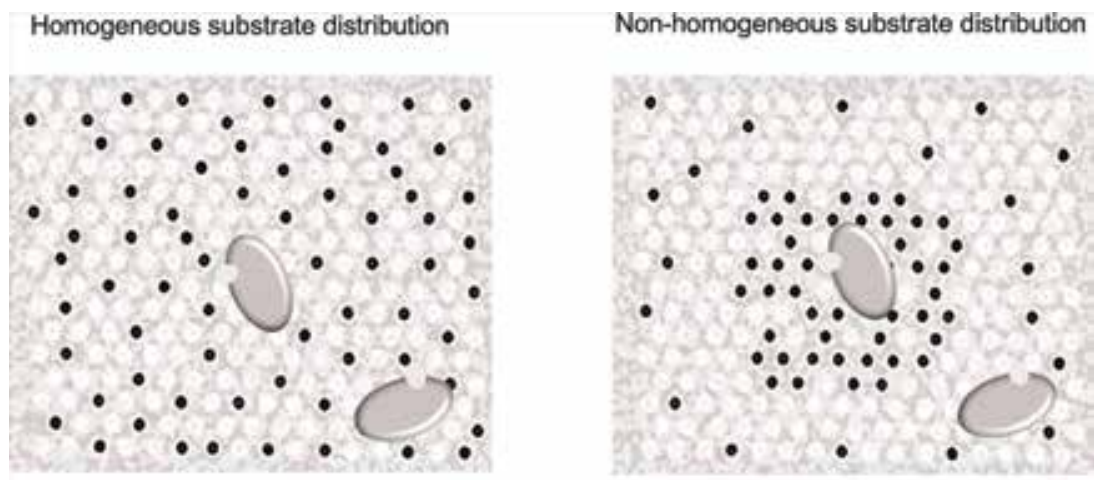

Lipolytic enzyme

Phospholipid substrate

Figure 1.

A generalization of the surface dilution kinetics theory applied to lipolytic enzymes has been necessary for cases of nonhomogeneous substrate distribution. This is because the reordering of the phospholipid substrate could have important effects on the activity of lipolytic enzymes. In the figure, for the nonhomogeneous substrate distribution, two domain phases can be distinguished: enriched substrate domain and nonenriched substrate domain (named elsewhere as nondomain phase) depending on whether the domain phase corresponds to the lipid phase with the largest substrate molar fraction or not, respectively.

molecules such as the protein myristoylated alanine-rich $\mathrm{C}$ kinase substrate (MARCKS) or pentalysine (Lys5, one of the first five amino acid residues of the region of bovine MARCKS) [17]. In biological membranes, the microdomain structure and dynamics are widely diverse, considering the scaffolding of cell proteins [18].

In order to find the effects of lipid substrate domain formation on enzyme activities, it is necessary for an extended mathematical formulation starting for similar principles to those of the original surface dilution kinetics theory. That is because the total activity could be integrated by each one of these substrate domains, i.e., whenever there is a phospholipid substrate (e.g., Figure 1), and therefore, the formation of domains enriched in a phospholipid substrate could either increase (inside the enriched domain) or decrease (outside the enriched domain; i.e., inside the nonenriched domain) the total enzymatic activity on the membrane. For this reason, it is useful to propose a comprehensive quantitative model that explicitly takes into account the enzyme activity in the different phospholipid phases, which here are frequently called substrate domains or simply "domains," to distinguish them from the eventual thermodynamic phases on membranes. Below, a theoretical frame for lipid binary membrane systems is shown, and then the theoretical frame is extended to a more realistic lipid phases with any number of domains, including continuous gradient of phospholipid substrate (thereby, considering an infinite number of infinitesimal domains).

\section{Changes in the lipolytic enzyme activity due to substrate reordering}

In the calculations of the lipase activities in membranes, it is assumed that whatever the structure of the lipid phase (micelle, liposome, or monolayer), all the lipids in the lipid-water interface expose the same area to the aqueous phase. As a consequence, the area of the lipid phase surface is proportional to the amount of lipid molecules. Then, at the beginning of the reaction, the lipid area will be 
constant regardless of any substrate reordering. However, depending on the enzymatic model, the substrate reordering effectively could change the enzyme activity, having many differences between homogenous or nonhomogeneous substrate distributions.

To understand how the substrate lateral reordering might affect the enzyme kinetics, a mathematical approach has been developed for the models having two steps binding between the enzyme and the lipid phase. First, the simple nonhomogeneous case of a binary condition is considered where the substrate can be distributed in two coexisting lateral phases: an enriched domain and a nonenriched domain (usually named nondomain). Finally, a more general expression corresponding to any gradients of substrate molar fraction will be shown.

As in the case of homogenous distribution of substrate on lipid phase [12], in the simple nonhomogeneous distribution given by a binary substrate distribution (i.e., two mixed lipid molecules, one of them being the substrate), the kinetics surface dilution theory is applied to the surface-binding model and to the phospholipid-binding model [19]:

1. For the phospholipid-binding model (Figure 2A), the enzyme activity $(V)$ depends on the substrate reordering in according to

$$
V=\frac{k C_{E_{T}}\left(a_{1} f_{S^{1}}^{2}+a_{2} f_{S^{2}}^{2}\right)}{\frac{k_{m} k_{s}}{C_{L}}+k_{m} f+a_{1} f_{S^{1}}^{2}+a_{2} f_{S^{2}}^{2}}
$$

A

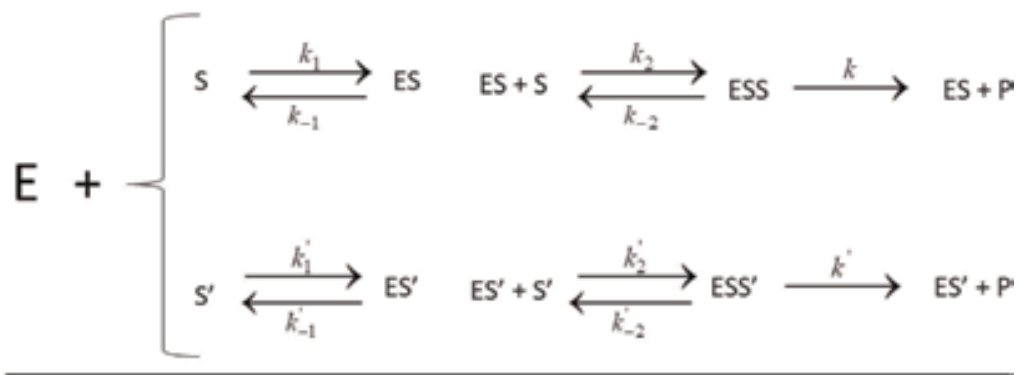

SURFACE BINDING MODEL FOR TWO SUBSTRATE DOMAINS

B

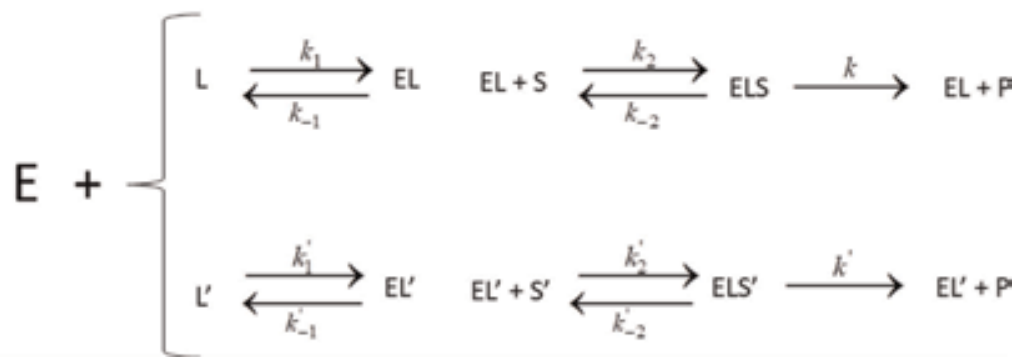

Figure 2.

$A$ and $B$ represent two different Lipolytic enzyme kinetic models for a lipid phase with two substrate domains: enriched substrate domain and nonenriched substrate domain. L, lipid molecule; $S$, phospholipid substrate; E, lipolytic enzyme; ES and ESS, enzyme-substrate complexes; and P, product. Individual kinetic constants are shown $\left(k, k^{\prime}, k_{1}, k_{1}^{\prime}, k_{-1}, k_{-1}^{\prime}, k_{2}, k_{2}^{\prime}, k_{-2}, k_{-2}^{\prime}\right)$. In the text: $k_{m} \equiv \frac{k_{-2}+k}{k_{2}}$ and $k_{s} \equiv \frac{k_{-1}}{k_{1}}$. The association of symbols and parameters to a particular domain is indicated by mean of primed or nonprimated signs in each case. 
where $f_{S^{i}}$ and $a_{i}$ are the substrate molar fraction and the fraction of the total lipid area in the $i$ th phase ( $i=1$ or 2 ), respectively, and such that

$$
a_{1} f_{S^{1}}+a_{2} f_{S^{2}}=f
$$

and

$$
a_{1}+a_{2}=1
$$

According to Eq. (4), $f$ is the average of the substrate molar fraction weighed by the domain areas.

In Eq. 3, we can see that $V$ depends hyperbolically on

$$
\left\langle f_{S^{i}}^{2}\right\rangle \equiv a_{1} f_{S^{1}}^{2}+a_{2} f_{S^{2}}^{2}
$$

the average of the square of the substrate mole fraction weighted by the phase area. These mean values have minimal and maximal values equal to $f^{2}$ and $f$, respectively. Therefore, there are for $V$ minimal and maximal values $\left(V_{\min }\right.$ and $V_{\max }$, respectively):

$$
V_{\text {min }}=\frac{E_{T} k f^{2}}{\frac{k_{m} k_{s}}{L}+k_{m} f+f^{2}}
$$

We can see that $V_{\min }$ corresponds to $V$ for a lipid homogeneous phase (Eq. 1) $[12,13]$

$$
V_{\max }=\frac{E_{T} k f}{\frac{k_{m} k_{s}}{L}+k_{m} f+f}
$$

Curiously, in spite of Eq. 8 deduced for the phospholipid-binding model with any substrate distribution, this equation is equal to Eq. 2, which corresponds to the case of surface-binding model with homogeneous substrate distribution on the membrane.

According to Eq. 3, if the homogeneous distribution of the substrate on the membrane is broken (i.e., substrate reordering such that $\left\langle f_{S^{i}}^{2}\right\rangle>f^{2}$ ), then the enzyme activity will increase. In particular, the total enzyme activity increases when the recruitment of substrate to the enriched-substrate domain (e.g., phase 1) increases, due to an increase of either the domain mol fraction $\left(f_{S^{1}}\right)$ or the extension of the domain $\left(a_{1}\right)$.

2. On the other hand, for the surface-binding model (Figure 2B), the enzymatic activity in a two-phase membrane equals to the enzyme activity in a homogeneous lipid phase, following the equation:

$$
V=\frac{C_{E_{T}} k f}{\frac{k_{m} k_{s}}{C_{L}}+k_{m}+f}
$$

and applying the same restrictions given by Eqs. 4 and 5 .

The differences between the behaviors of both enzymatic models are much more than the differences between the corresponding equations for the enzymatic activities (Eqs. 3 and 9). Following this theory, important differences exist in both the ratio of the substrate regarding the two substrate domains and the total enzyme binding to membrane. 
The ratio between the enzymes binding into the two domains (indicated as primed and nonprimed) is described as follows:

for the phospholipid-binding model:

$$
\frac{E_{S}+E_{S S}}{E_{S}^{\prime}+E_{S S}^{\prime}}=\frac{f_{d}\left(k_{m}+f_{d}\right)}{f_{n}\left(k_{m}+f_{n}\right)}
$$

for the surface-binding model:

$$
\frac{E_{S}+E_{S S}}{E_{S}^{\prime}+E_{S S}^{\prime}}=\frac{k_{m}+f_{d}}{k_{m}+f_{n}}
$$

Furthermore, there are different expressions for the molar concentration of total enzyme binding to the lipid phase, $\left[E_{B}\right]$ :

Naming the molar concentration of total enzyme binding to the lipid phase $\left[E_{B}\right]$, we have:

$$
\begin{aligned}
{\left[E_{B}\right] } & \equiv L a\left(E_{S}+E_{S S}\right)+L(1-a)\left(E_{S}^{\prime}+E_{S S}^{\prime}\right) \\
& =E_{T}\left(\frac{k_{m} f+\left\langle f_{i}^{2}\right\rangle}{\frac{k_{m} k_{s}}{L}+k_{m} f+\left\langle f_{i}^{2}\right\rangle}\right)
\end{aligned}
$$

for the phospholipid-binding model,

and

$$
\begin{aligned}
{\left[E_{B}\right] } & \equiv L a\left(E_{S}+E_{S S}\right)+L(1-a)\left(E_{S}^{\prime}+E_{S S}^{\prime}\right) \\
& =E_{T}\left(\frac{k_{m}+f}{\frac{k_{m} k_{s}}{L}+k_{m}+f}\right)
\end{aligned}
$$

for the surface-binding model.

Then, due to the difference between Eqs. 12 and 13, the two enzymatic models could be easily distinguishable by means of the observed change in the total lipid metabolizing enzyme binding to the lipid phase under substrate reordering: phospholipid-binding model predicts changes in total membrane enzyme upon domain formation, unlike the surface-binding model, in which there are no changes in total membrane enzyme, whatever the distribution of the substrate is.

\section{Redistribution effect versus competitive effect of a lipid-inducing domain peptide}

Similar to the enzyme, again we will not consider the substrate dilution due to the protein insertion in the bilayer. That is because the number of molecules binding to the lipid phase is much smaller than the number of the phospholipid substrate molecules, and besides, the domain-inducing peptide either would not penetrate the lipid phase or its interface concentration can be considered negligible.

As seen before, depending on the enzymatic model, substrate redistribution such as the transitions from homogeneous distribution to nonhomogeneous 
distribution could change the enzyme activity. However, another effect must be considered when there are domains that have been induced by soluble peptides (e.g., basic peptides such as pentalysine), which interact directly with the phospholipid substrate of the membrane (i.e., acidic phospholipid such as PIP2). In this case, such interaction could be enough to consider a competitive effect over the enzyme activity; i.e., in the lipid-water interface, the domain-inducing peptide would compete with the enzyme for the substrate, because there would be less free substrate to bind to the enzyme. Then, we have proposed that the superposition of both redistribution and competitive effects may explain some results in the literature that appear as contradictory. [19]

\subsection{The kinetic effects of peptide induction of phospholipid domains}

In order to calculate the effects on the PLC- $\beta$ activity (a lipolytic enzyme) on $\mathrm{PIP}_{2}$ (lipid substrate) due to pentalysine-induced domain formation, it has been assumed that the stoichiometry of binding is one lipid substrate per one domaininducing peptide [19]. In case of larger stoichiometry for the phospholipid binding to the peptide (as Kim et al. describes [20]), this would imply that the competitive effect from peptides tends to decrease the enzyme activity more dramatically at low substrate molar fractions in the 1:1 stoichiometric case. Then, to estimate the amount of substrate bound to all the domain-inducing peptides in any lipid phase, it was assumed that the domain-inducing peptide near the surface of the lipid phase is in equilibrium with the phospholipid substrate, obeying a Langmuir isotherm, and this peptide concentration was determined by the electrochemical equilibrium in according with a Boltzmann-like relationship, which included the membrane potential in the lipid phase and the peptide concentration in the bulk solution [21]. Moreover, knowing the substrate binding to the domain-inducing peptide, free substrate can be calculated, and then the molar fraction of free substrate can be taken into account into the deduced previous kinetic models (Eqs. 3 and 9).

As a result, if there is competition effect due to peptide binding substrate, in case of the surface-binding model, the enzymatic activity will always diminish because the substrate reordering has no effect in the enzyme activity. Instead, in case of the phospholipid-binding model with peptide-induced breakage of substrate homogeneity the enzyme activity may either increase or decrease depending on the difference between the competitive effect (diminishing the enzyme activity) and the substrate distribution effect (increasing the enzyme activity) [19]. A theoretical estimation of PLC $\beta$, acting on PIP2 as substrate, and having enriched substrate domain induced by pentalysine, has been shown in Figure 4 of Salinas et al. 2005 [19]. A maximum for an enriched domain, with acute declination for others, are shown.

\section{Lypolitic enzyme activity in lipid phases with multiple substrate domains}

The above kinetics expressions can be generalized to any amount of substrate domains, even to infinite number of domains, and this latter is very useful for modeling any kind of substrate distribution in the total lipid phase [22].

In this extended theoretical frame, we have the following:

In homogenous condition, $f$ is the molar fraction of phospholipid substrate.

$\mathrm{S}$ reorders into $\mathrm{n}$ homogeneous domains, with the ith domain $(i=1,2, \ldots, \mathrm{n})$ with normalized area ai and molar fraction $\mathrm{f}_{\mathrm{i}}$ of $\mathrm{S}$.

The total conservation equation is given as: 


$$
1=\sum_{i=1}^{n} a_{i}
$$

The cross-sectional areas of any lipid molecules in any phases are equal and conserved, and then the total phospholipid S normalized area conservation equation is given as:

$$
f=\sum_{i=1}^{n} a_{i} f_{S^{i}}
$$

Thus, again, it can be demonstrated that the enzyme activity for the surface kinetic model does not depend on the substrate ordering, and it is equal to the enzyme activity for the completely homogenous substrate distribution case (Eq. 2). For the phospholipid-binding model, the enzyme activity even depends on the reordering of the substrate on the lipid phase, such that some terms in Eq. 1 must be replaced by more general ones, even more than in Eq. 3. Thus, in case of multiple domains in the phospholipid-binding model, it has been demonstrated theoretically that the enzymatic activity on $n$ substrate domains is given as:

$$
V=\frac{k C_{E_{T}}\left\langle f_{S^{i}}^{2}\right\rangle}{\frac{k_{m} k_{s}}{C_{L}}+k_{m} f+\left\langle f_{S^{i}}^{2}\right\rangle}
$$

where $f$ is defined in according to Eq. 15 and $\left\langle f_{S^{i}}^{2}\right\rangle$ is the average of the square of the substrate molar fraction weighted by the domain areas:

$$
\left\langle f_{S^{i}}^{2}\right\rangle \equiv \sum_{i=1}^{n} a_{i} f_{S^{i}}^{2}
$$

Two abovementioned results can be represented by Eqs. 16 and 17: First, when the lipid substrate distribution is completely homogeneous $(n=1)$, Eq. 1 is obtained. Secondly, when there are only two domains of lipid substrate (enriched substrate domain and nonenriched substrate domain; $n=2$ ), Eq. 3 is obtained.

To calculate any $V$-value, $\left\langle f_{S^{i}}^{2}\right\rangle$ must be calculated as a summation over the whole surface of the lipid phase. Thus, minimum and maximum $\mathrm{V}$-values are calculated from minimum and maximum $\left\langle f_{S^{i}}^{2}\right\rangle$ values, respectively:

$$
\left\langle f_{S^{i}}^{2}\right\rangle_{\min }=\sum_{i=1}^{n} a_{i} f^{2}=f^{2} \sum_{i=1}^{n} a_{i}=f^{2}
$$

(using Eq. 14, i.e., the conservation of the total lipid area) and

$$
\left\langle f_{S^{i}}^{2}\right\rangle_{\max }=f
$$

Thus, the minimum $V$-value as a function of substrate distribution was obtained for a homogeneous distribution $\left(f_{S^{i}}=f\right)$. The maximum $V$-value was obtained for one domain composed only by molecules of phospholipid substrate, and the other one without substrate (e.g., $f_{1}=1$ and $f_{2}=0$ ). Then, the enzymatic activities are within the following limiting values when there are multiple membrane domains:

$$
\frac{k C_{E_{T}} f^{2}}{\frac{k_{m} k_{s}}{C_{L}}+k_{m} f+f^{2}} \leq V \leq \frac{k C_{E_{T}} f}{\frac{k_{m} k_{s}}{C_{L}}+k_{m} f+f}
$$




\section{Effects of Poisson distribution of substrate on enzyme activity following the phospholipid binding model}

Since the extended theory shown above does not consider boundaries, the same can be applied to a population of lipid particles (like vesicles or micelles), each one as a substrate domain represented in a summation term in Eq. 17.

Frequently, data from in vitro kinetic studies of lipid metabolizing enzymes have been interpreted as indicating cooperative phenomena [23-25]. Alternatively, there is an explanation based on the idea that phospholipid substrate molecules are not homogeneously distributed within a population of lipid particles, although simultaneously we can suppose the substrate having homogeneous distribution within each particle. Then, modeling the nonhomogeneous substrate distribution on the population of lipid particles, it is assumed that the probability of finding a substrate molecule on a lipid particle does not depend on the number of previous substrate molecules in the same lipid particle. A consequence of this assumption is a Poisson distribution of the substrate on the mixture of the lipid particles.

Defining $\alpha$ as the average number of lipid molecules per lipid particle (in micellar case, this parameter is known as aggregation number), and according to Eq. 17 and Poisson-distributed substrate, it can be demonstrated that [22]

$$
\left\langle f_{S^{i}}^{2}\right\rangle=f^{2}\left(1+\frac{1}{f \alpha}\right)
$$

We consider a lipolytic enzyme following the phospholipid-binding model in a system of multiple domains of substrate, and such that the lipid phase is composed by a mixture of lipid particles, each one with homogeneously distributed substrate, but Poisson distributed over the same population of particles. Then, the $\left\langle f_{S^{i}}^{2}\right\rangle$ value in Eq. 21 is replaced into Eq. 16 obtaining

$$
V=\frac{k C_{E_{T}} f^{2}\left(1+\frac{1}{f \alpha}\right)}{\frac{k_{m} k_{s}}{C_{L}}+k_{m} f+f^{2}\left(1+\frac{1}{f \alpha}\right)}
$$

That is, Eq. 22 is an expression of the rates of enzyme activity on Poissondistributed phospholipid substrates. Applying this equation to published kinetic parameters for PLC acting on PIP2 in Triton X-100 micelles $\left(C_{L}=200 \mu \mathrm{M}\right.$, $k_{m}=0.13$, and $k_{s}=170 \mu \mathrm{M}$ ) [23], the ratio between "the enzyme activity on micelles with Poisson-distributed substrate" (Eq. 22) and "the enzyme activity on micelles with homogeneously distributed substrate" (Eq. 1) was calculated. Assuming a range of $f$ from $10^{-1}$ to $10^{-3}$ (as in published work $[12,13]$ ), activity ratios between 1.0 and $6.0(\alpha=200)$ and between 1.1 and $11.0(\alpha=100)$ were obtained. We can see that without considering cooperative effects, a simple explanation for a very high departure from the homogeneous standard model may be that the increases in enzyme activity are due to Poisson distribution of the substrate.

\subsection{Substrate-distribution dependence of PLA2 activity in mixed micelles}

The mentioned kinetic theory applied to Poisson-distributed substrate on lipid particles has been verified with experimental results, and their obtained parameters have been compared with those of the canonical phospholipid-binding model originally developed for homogeneously distributed substrate on mixed micelles 


\begin{tabular}{|c|c|c|c|}
\hline & & $\begin{array}{l}\text { Phospholipid-binding model } \\
\text { with homogeneous substrate } \\
\text { distribution }\end{array}$ & $\begin{array}{l}\text { Phospholipid-binding } \\
\text { model with Poisson- } \\
\text { distributed substrate }\end{array}$ \\
\hline \multirow{2}{*}{$\begin{array}{l}\text { Kinetic parameters for PLA2 } \\
\text { activity on Triton X-100/thio- } \\
\text { PC mixed micelles }\end{array}$} & $k_{m}=$ & 0.0532 & 0.0216 \\
\hline & $k_{S}=$ & $1.9168 \mathrm{mM}$ & $6.2170 \mathrm{mM}$ \\
\hline \multirow{2}{*}{$\begin{array}{l}\text { Kinetic parameters for PLA2 } \\
\text { activity on Triton X-100/thio- } \\
\text { PE mixed micelles }\end{array}$} & $k_{m}=$ & 0.1379 & 0.0942 \\
\hline & $k_{S}=$ & $0.1132 \mathrm{mM}$ & $0.4107 \mathrm{mM}$ \\
\hline
\end{tabular}

Parameter values are taken from Table II in Salinas et al. 2011 [14].

Table 1.

Values for fitting kinetic parameters for PLA2 activity on Triton X-10o mixed micelles regarding either homogeneous substrate distribution or Poisson substrate distribution, with adjustable $\varepsilon_{T_{t}}$ parameter (the molar concentration of detergent that is not kinetically active, a proposed parameter that enhance the fitting).

$[12,13]$. Both models ("nonhomogeneous model" and "homogeneous model," respectively) can be represented simultaneously by the following general equation:

$$
V=\frac{k C_{E_{T}} f^{2}}{\frac{\left(k_{m} / F_{f, \alpha}\right) k_{s}}{C_{L}}+\left(k_{m} / F_{f, \alpha}\right) f+f^{2}}
$$

where

$$
F_{f, \alpha}=1,
$$

in a homogeneous model (Eq. 1), and

$$
F_{f, \alpha}=1+\frac{1}{\alpha f},
$$

in a nonhomogeneous model (Eq. 22).

In micelles, it has been found that $\alpha$, the average number of lipid molecules per mixed micelle (i.e., the aggregation number), depends on the molar fraction of phospholipid (but not on total detergent concentration [26]) within the concentration range of Triton X-100 and phospholipid used in Hendrickson et al.'s study [13]. Therefore, in order to find the parameters for modeling, the functional dependence of $\alpha$ from $f$ must be taken into account in micellar experiments [22].

In Table 1, all the values of parameters $k_{m}$ and $k_{S}$ obtained for homogeneous and nonhomogeneous substrate distributions are compared. The differences indicate that the values of these kinetic parameters can depend critically on the distribution of the substrate.

\section{Discussion}

To understand the effect of lipid substrate reordering on their metabolizing enzymes, theoretical results are shown. A simple kinetic model considers a nonhomogeneous membrane with the lipid substrate reordered in two domains with different molar fractions. The results are included in a more general extended theory considering substrate multidomains on either lipid surface of vesicles. Because the calculations do not regard any domain boundaries, the same models obtained from this theory (Eqs. 2 and 16) can be applied on a mixture of lipid particles (vesicles or micelles). 
Here, only two kinetic models have been considered, but similar theoretical framework could be applied on other ones. The general mathematical expression for the surface-binding model does not depend on whether the substrate distribution is homogeneous or nonhomogeneous (Eq. 2). Thus, in this kinetic model, any substrate distribution changing has no kinetic effect.

On the contrary, considering the phospholipid-binding model, the calculations predict how the substrate distribution may affect the activity of the lipid metabolizing enzyme. In particular, the enzyme activity is increased by the transition from the homogeneous substrate distribution to any nonhomogeneous one (Eqs. 16 and 17).

Concordantly, in erythrocytes, the $\mathrm{Ca}^{2+}$-induced domains increase the activity of PLA2 [27], an enzyme that follows the phospholipid-binding model [12, 13]. The increased activity agrees with an observed enzyme reordering, which may be due to formed enriched-substrate domains. Then, there will be more enzyme molecules binding to areas of higher substrate molar fraction, causing a larger local enzyme activity. On the other hand, PLC $\beta$ kinetic data from micellar experiments have fitted to the phospholipid-binding model using Hill coefficients [28-30], but the usage of this type of coefficients was not useful in monolayers having with large increases in enzyme activity after small increases in the PIP2 fraction [31]. The analysis of pressure versus area isotherm of the monolayers suggested a nonhomogeneous distribution of the lipids and was proposed that the PIP2 molecules get together into enriched lateral domains, favoring the PLC $\beta$ activity, an enzyme following the phospholipid-binding model. This agrees with what is expected from the theory presented here.

In other cases, since basic molecules can induce formation of acidic phospholipid domains in membranes, the increased activity of PLC $\delta 1$ and PLC $\delta 3$ by addition of polyamines or basic proteins such as spermine, protamine, histone, and melittin [32] also can be explained by substrate redistribution. Differently, PLC $\beta$ activity decreases in experiments with vesicles containing acidic phospholipid domains induced by the basic molecules, pentalysine, spermine, and MARCKS (151-175) [17]. However, assuming that PLC $\beta$ is a phospholipid-binding enzyme, the decrease in enzyme activity may be due to a high competitive effect of the substrate-domaininducing peptide. Such competitive effect overcomes the rise in activity that substrate redistribution would produce. Finally, the importance of each effect is dependent on the used amount of domain-inducing molecule and this could explain the apparent contradictory results of the activities of lipid-metabolizing enzymes, such as PLC (an enzyme following the phospholipid-binding model [24, 29, 30] upon addition of domain-inducing molecules [17, 23, 32, 33]).

Substrate distribution also must be considered in in vitro kinetic experiments of enzymes following the phospholipid-binding model. In this sense, the application of the theory developed here is useful for kinetic experiments with mixed lipid particles (i.e., liposomes or micelles, instead of lipid domains). We assumed that each one of the particles will have a homogeneous molar fraction, which follows a Poisson distribution on the lipid particles [34, 35].

If the average of substrate molecules per lipid particle in suspension $(f \alpha)$ is very large $(f \alpha \gg 1)$, then Eq. 22 predicts that the enzymatic activity tends to the value obtained for a homogeneously distributed substrate (Eq. 1, or its equivalent, Eqs. 23 and 24). However, in case of decreased average of substrate molecules per lipid particle in suspension $(f \alpha \ll 1)$, Eq. 22 predicts that the enzyme activity will be larger than in the homogeneous case at equal $f$ value. Concordantly, some PLC isoenzymes [24, 29, 30] and PLA2 [13] have an increased activity in cases of small substrate molar fractions, similar to cooperative phenomena. However, if these kinetic data could be fitted to Eq. 22, they will contribute to a more simple 
explanation based on the substrate distribution. In other case, in experiments with PLA2, increase in enzyme activity has been associated with decrease of the size of lipid vesicles, suggesting that PLA2 activity happens in areas with structural defects [36]. Again, here our approach based on substrate distribution provides a simple alternative explanation: if the substrate molar fraction in the mixture of lipid particles is Poisson distributed, then Eq. 22 could be applied. Considering that substrate is fixed ( $f$ fixed), the decreasing vesicle sizes ( $\alpha$ decrease) produces decreasing average of substrate molecules per vesicle $(f \alpha)$. Therefore, in according to Eq. 22, at low values of $f \alpha$ and for Poisson-distributed substrate, the relative enzyme activity must increase more notoriously, regarding the case of homogeneous distribution of substrate as reference.

The application of the theoretical model (Eq. 22) in published results of the PLA2 activity on Triton X-100 mixed micelles of phospholipids [13], considering Poisson-distribution substrate, allows a very good fit to the data. Interestingly, the estimated values of the kinetic parameters strongly depend on whether the substrate distribution used in the fitting is distributed either homogeneously or according to Poisson.

On the other hand, detergent-based micelles are not capable to mimic the lipid environment of membranes. In such case, the activities of most membrane protein could be affected. As a solution, liposomes or high-density apolipoprotein particles have been proposed [2]. However, compared with those experimental models, the EVs offer a number of potential benefits, such as providing a more adequate membrane environment for membrane proteins, in terms of both dynamics and stability.

In summary, depending on the enzyme model, the lipid substrate reordering can regulate the enzyme activity, giving to the membrane organization a topological role in the control of cell process. In order to a good estimation of kinetic parameters in phospholipase enzymology, in vitro kinetic experiments must consider the substrate distribution effects. Also, many complex metabolic effects of substratedomain-inducing molecules can be explained by a result of the balance between the competitive effects of the substrate domain inducers and substrate redistribution. All these considerations should be taken into account even in case of EVs, in relation to their formation, functionality, and action on membrane targets.

\section{Author details}

Dino G. Salinas

Centro de Investigación Biomédica, Facultad de Medicina, Universidad Diego

Portales, Santiago, Chile

*Address all correspondence to: dino.salinas@udp.cl

\section{IntechOpen}

(C) 2019 The Author(s). Licensee IntechOpen. This chapter is distributed under the terms of the Creative Commons Attribution License (http://creativecommons.org/licenses/ by/3.0), which permits unrestricted use, distribution, and reproduction in any medium, provided the original work is properly cited. (c) BY 


\section{References}

[1] Maas SLN, Breakefield XO, Weaver AM. Extracellular vesicles: Unique intercellular delivery vehicles. Trends in Cell Biology. 2017;27(3):172-188

[2] Yang Y, Hong Y, Cho E, Kim GB, Kim IS. Extracellular vesicles as a platform for membrane-associated therapeutic protein delivery. Journal of Extracellular Vesicles. 2018;7(1): 1440131

[3] Record M. Introduction to the thematic review series on extracellular vesicles: A focus on the role of lipids. Journal of Lipid Research. 2018;59(8): 1313-1315

[4] Dennis EA. Introduction to thematic review series: Phospholipases: Central role in lipid signaling and disease. Journal of Lipid Research. 2015;56(7): 1245-1247

[5] Record M, Poirot M, Silvente-Poirot $\mathrm{S}$. Emerging concepts on the role of exosomes in lipid metabolic diseases. Biochimie. 2014;96:67-74

[6] Cheung KL, Jarrett R, Subramaniam S, Salimi M, Gutowska-Owsiak D, Chen $\mathrm{YL}$, et al. Psoriatic T cells recognize neolipid antigens generated by mast cell phospholipase delivered by exosomes and presented by CD1a. The Journal of Experimental Medicine. 2016;213(11): 2399-2412

[7] Record M, Carayon K, Poirot M, Silvente-Poirot S. Exosomes as new vesicular lipid transporters involved in cell-cell communication and various pathophysiologies. Biochimica et Biophysica Acta. 2014;1841(1):108-120

[8] Cajal Y, Berg OG, Jain MK. Direct vesicle-vesicle exchange of phospholipids mediated by polymyxin B. Biochemical and Biophysical Research Communications. 1995;210(3): 746-752
[9] Hurley JH, Grobler JA. Protein kinase $\mathrm{C}$ and phospholipase C: Bilayer interactions and regulation. Current Opinion in Structural Biology. 1997;7: 557-565

[10] Berridge MJ. Inositol triphosphate and calcium signaling. Nature. 1993;361: 315-325

[11] Clapham DE. Calcium signalling. Cell. 1995;80:259-268

[12] Carman GM, Deems RA, Dennis EA. Lipid signaling enzymes and surface dilution kinetics. The Journal of Biological Chemistry. 1995;270: 18711-18714

[13] Hendrickson HS, Dennis EA. Kinetic analysis of the dual phospholipid model for phospholipase A2 action. The Journal of Biological Chemistry. 1984;259: 5734-5739

[14] Edidin M. Lipid microdomains in cell surface membranes. Current Opinion in Structural Biology. 1997;7: 528-532

[15] Mouritsen OG, J申rgensen K. Smallscale lipid-membrane structure: Simulation versus experiment. Current Opinion in Structural Biology. 1997;7: 518-527

[16] Mouritsen OG, Bagatolli LA. Lipid domains in model membranes: A brief historical perspective. Essays in Biochemistry. 2015;57:1-19

[17] Glaser M, Wanaski S, Buser CA, Bogulavsky V, Rashidzada W, Morris A, et al. Myristoylated alanine-rich $\mathrm{C}$ kinase substrate (MARCKS) produces reversible inhibition of phospholipase $\mathrm{C}$ by secuestration of phosphatidylinositol 4,5-biphosphate in lateral domains. The Journal of Biological Chemistry. 1996; 271:26187-26193 
[18] Harder T. Formation of functional cell membrane domains: The interplay of lipid- and protein-mediated interactions. Philosophical transactions of the Royal Society of London. Series B. 2003;358:863-868

[19] Salinas DG, De La Fuente M, Reyes JG. Changes of enzyme activity in lipid signaling pathways related to substrate reordering. Biophysical Journal. 2005; 89:885-894

[20] Kim J, Mosior M, Chung LA, Wu H, McLaughlin S. Binding of peptides with basic residues to membranes containing acidic phospholipids. Biophysical Journal. 1991;60:135-148

[21] Denisov G, Wanaski S, Luan P, Glaser M, McLaughlin S. Binding of Basic Peptides to Membranes Produces Lateral Domains Enriched in the Acidic Lipids Phosphatidylserine and Phosphatidylinositol 4,5-Biphosphate: An Electrostatic Model and Experimental Results. Biophysical Journal. 1998;74:731-744

[22] Salinas DG, Reyes JG, De la Fuente M. Lipid metabolizing enzyme activities modulated by phospholipid substrate lateral distribution. Bulletin of Mathematical Biology. 2011;73(9): 2045-2067

[23] James SR, Paterson A, Harden TK, Downes CP. Kinetic analysis of phospholipase $\mathrm{C}$ beta isoforms using phospholipid-detergent mixed micelles. Evidence for interfacial catalysis involving distinct micelle binding and catalytic steps. The Journal of Biological Chemistry. 1995;270:11872-11881

[24] Hernandez-Sotomayor SM, De Los Santos-Briones C, Munoz-Sanchez JA, Loyola-Vargas VM. Kinetic analysis of phospholipase $\mathrm{C}$ from catharanthus roseus transformed roots using different assays. Plant Physiology. 1999;120:

1075-1082
[25] Jones GA, Carpenter G. The regulation of phospholipase C-gamma 1 by phosphatidic acid. Assessment of kinetic parameters. The Journal of Biological Chemistry. 1993;268: 20845-20850

[26] Thomas MJ, Pang K, Chen Q, Lyles D, Hantgan R, Waite M. Lipid exchange between mixed micelles of phospholipid and triton X-100. Biochimica et Biophysica Acta. 1999;1417:144-156

[27] Jensen LB, Burgess NK, Gonda DD, Spencer E, Wilson-Ashworth HA, Driscoll E, et al. Mechanisms governing the level of susceptibility of erythrocyte membranes to secretory phospholipase A2. Biophysical Journal. 2005;88: 2692-2705

[28] Hernández SM, De Los Santos C, Muñoz JA, Loyola VM. Kinetic analysis of phospholipase $\mathrm{C}$ from Catharanthus roseus transformed roots using different assays. Plant Physiology. 1999;120: 1075-1081

[29] James SR, Paterson A, Harden TK, Downes CP. Kinetic analysis of phospholipase $C \beta$ isoforms using phospholipid-detergent mixed micelles. Evidence for interfacial catalysis involving distinct micelle binding and catalytic steps. The Journal of Biological Chemistry. 1995;270:11872-11881

[30] Jones GA, Carpenter G. The regulation of phospholipase $\mathrm{C}-\gamma 1$ by phosphatidic acid. Assessment of kinetic parameters. The Journal of Biological Chemistry. 1993;268:20845-20850

[31] James SR, Paterson A, Harden TK, Demel RA, Downes CP. Dependence of the activity of phospholipase $C \beta$ on surface pressure and surface composition in phospholipid monolayers and its implications for their regulation. Biochemistry. 1997;36: 848-855 
Effects of Vesicular Membranes Reordering on the Activity of Lipid Metabolizing Enzymes DOI: http://dx.doi.org/10.5772/intechopen. 85972

[32] Pawelczyk T, Matecki A.

Expression, purification and kinetic

properties of human recombinant

phospholipase C delta 3. Acta

Biochimica Polonica. 1997;44:221-229

[33] Zhou C, Horstman D, Carpenter G, Roberts MF. Action of

phosphatidylinositol-specific

phospholipase Cgamma1 on soluble and micellar substrates. Separating effects on catalysis from modulation of the surface. The Journal of Biological

Chemistry. 1999;274:2786-2793

[34] Lichtenberg D, Robson RJ, Dennis EA. Solubilization of phospholipids by detergents. Structural and kinetic aspects. Biochimica et Biophysica Acta. 1983;737:285-304

[35] Sehgal P, Mogensen JE, Otzen DE. Using micellar mole fractions to assess membrane protein stability in mixed micelles. Biochimica et Biophysica Acta. 2005;1716:59-68

[36] Jorgensen K, Davidsen J, Mouritsen OG. Biophysical mechanisms of phospholipase A2 activation and their use in liposome-based drug delivery. FEBS Letters. 2002;531:23-27 

Section 3

\section{Extracellular Vesicles in Human Diseases}





\title{
Chapter 5
}

\section{Extracellular Vesicles in Cancer}

\author{
Andrei-Dennis Voichitoiu, Beatrice Mihaela Radu, \\ Luciana Pavelescu, Dragos Cretoiu, Antonia Teona Deftu, \\ Nicolae Suciu and Sanda Maria Cretoiu
}

\begin{abstract}
Extracellular vesicles (EVs) represent a generic term for all the secreted vesicles, which include exosomes, microvesicles, and apoptotic bodies. EVs are key partners in the intercellular communication and play an essential role in multiple physiological and pathological conditions. EVs are shuttles for cargo molecules, such as RNA (mRNA, microRNA, and other noncoding RNAs), DNA, proteins (receptors, transcription factors, enzymes, and extracellular matrix proteins), and lipids. In pathological states, including cancer, EVs might represent either useful biomarkers or can be used for therapeutic purposes. Moreover, in cancer, it was demonstrated that EVs play an essential role in drug resistance. Here, we review the role played by EVs in the most common forms of cancer, with a special focus on ovarian and breast cancers.
\end{abstract}

Keywords: extracellular vesicles, cancer, biomarker, cargo, therapy

\section{Introduction}

Extracellular vesicles (EVs) are cell-derived membranous vesicles (from normal or cancerous cells) bearing packages of information within or on their surface. Their content can influence neighboring or remote cells, and therefore, EVs are considered to play an important role in intercellular communication [1]. Different functional molecules (proteins, mRNA, and microRNAs) are transferred between cells with the aid of EVs. The content of EVs is highly variable and dependent of the cell of origin. The EVs in human blood originate from platelets, leukocytes, erythrocytes, endothelial cells, vascular smooth muscle cells, and cancer cells (for review see [2]). It is now widely accepted that extracellular vesicles also represent a potential resource for biomarkers.

The first study suggesting the existence of extracellular vesicles was carried out in 1946 [3]. In a 1967 report, membrane particles derived from activated platelets, termed "platelet dust," were commonly considered as a waste product or cellular debris directly budded from the plasma membrane [4]. Both prokaryotes and higher eukaryotes can release EVs. Different terms are used to describe EVs due to varying methods of isolation and due to the biogenesis mechanism. The terminologies of EVs include microvesicles, dexosomes, texosomes, archaeosomes, argosomes, prostasomes, epididymosomes, and oncosomes [5]. Gradually, while building up knowledge about EVs, a need for its classification emerged and the International Society for Extracellular Vesicles (ISEV) was founded [6]. This society 
provided some criteria to classify EVs into three groups: microvesicles (MVs), exosomes, and apoptotic bodies (for details visit www.isev.org). These vesicles are secreted by both normal cells and cancerous cells as means of cell-to-cell communication. Alternatively, they may be prepared artificially from the engineered artificial lipid vesicles called liposomes in which EVs' features, components, or cargos are incorporated and are the most likely to be useful for drug delivery [7].

EVs are actively involved in cell-to-cell communication, inflammation, chronic disease development and progression, pre-metastatic niche formation, and the metastatic organotropism of different tumor types [8]. Tumor-derived EVs (TEVs) have been reported to play major roles in the onset, progression, and metastasis of cancer, including ovarian [9], breast [10], colorectal [11, 12], prostate cancer [13], and melanoma [14-16].

Here, we review knowledge about EVs in cancer, with a focus on breast and ovarian cancers. We discuss the importance of the content of EVs (e.g., nucleic acids, and proteins) in cancer development, metastasis, and drug resistance.

\section{The variety of extracellular vesicles}

Replacing EVs includes a heterogeneous population of membrane vesicles categorized depending on the mechanism by which they are released from cells. According to their size and mechanisms of biogenesis, EVs can be categorized into three classes: (a) exosomes, (b) ectosomes or shedding microvesicles, and (c) apoptotic bodies $[17,18]$. Differentiation criteria are based on their size, content, and by a certain combination of markers (Figure 1 and Table 1 ). Cancerous cells have been described to release exosomes and ectosomes and some other additional subpopulations of EVs [19].

\subsection{Exosomes}

Exosomes are EVs with multivesicular endosomal origin released by all cell types [33]. Exosomes are found in physiological fluids such as blood and plasma $[34,35]$, urine [36], cerebral fluid [37], saliva [38, 39], seminal fluid [40], breast milk [41, 42], and amniotic fluid [43, 44]. The presence of EVs has been reported in interstitial spaces since they are released by B cells [45], T cells [46], dendritic cells [47], platelets [48], Schwann cells [49], tumor cells [50], cardiomyocytes [51], endothelial cells [52], stem cells [50], and telocytes [53-55]. Exosomes are able to influence cells from the local environment and also distant target cells, thus regulating intercellular signaling [56]. Their size varies between 30 and $100 \mathrm{~nm}$, and as membrane vesicles, they are delineated by a specific lipid bilayer similar to that of the cells they originate from [57]. Studies have shown that while normal human blood contains about 2000 trillion exosomes, the blood of cancer patients contains a double amount, about 4000 trillion exosomes [57]. In noncancerous cells, exosome secretion was suggested to play a role in cellular homeostasis by removing harmful cytoplasmic DNA of normal cells and in preventing viral hijacking of host cells by excreting viral DNA from cells as shown by Takahashi et al. [58].

The plasma of cancer patients contains different types of exosomes, some released by normal cells and others released by cancerous cells, explaining the heterogeneity in size (30-150 nm) of the exosomal population [59]. Exosomes can be isolated from cancer patients' plasma with a variety of methods [60]. They are based not only on classical techniques such as ultracentrifugation, but also on some modern ones such as size exclusion chromatography [61]. 

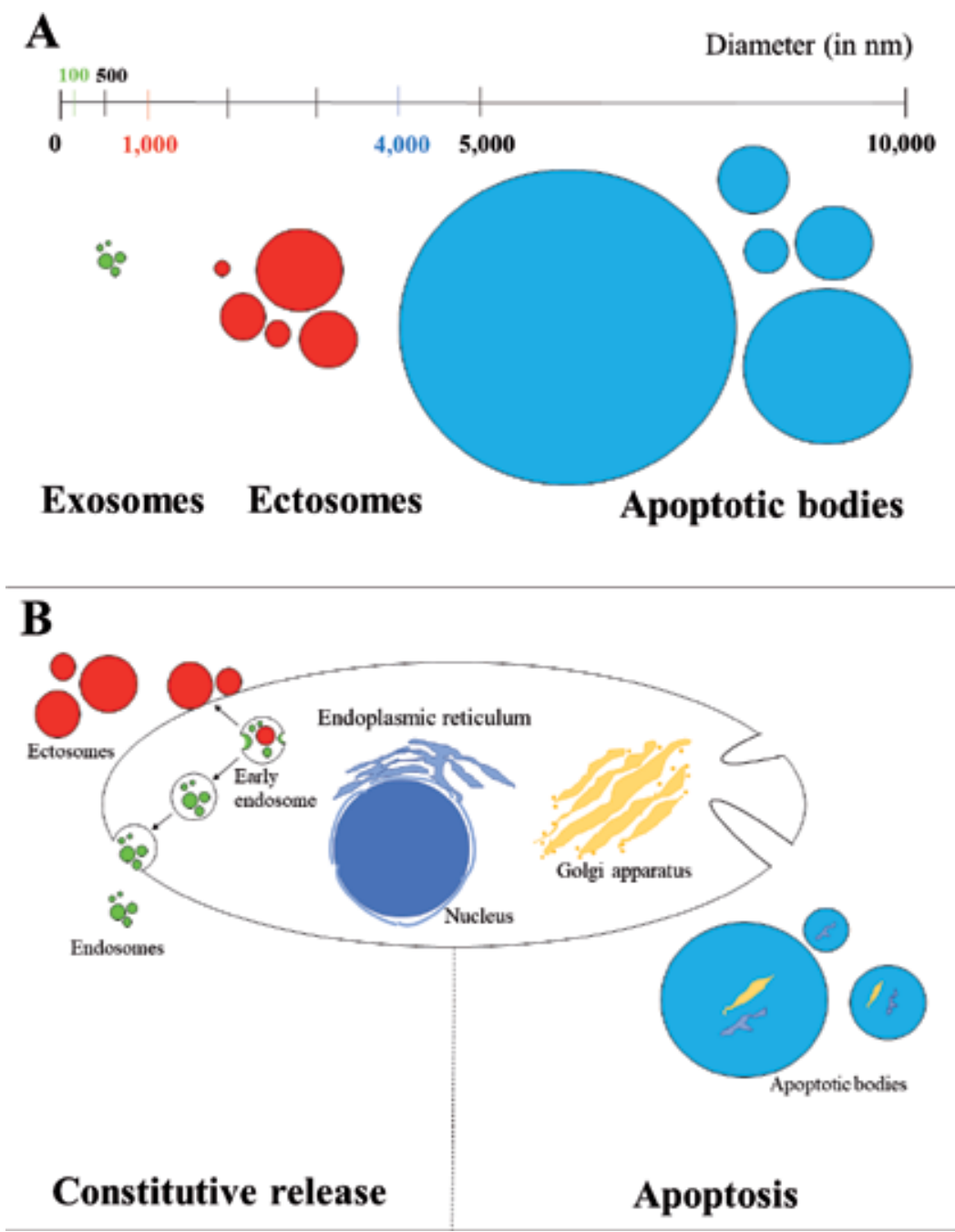

Figure 1.

Classification of $E V$ s based on their diameter (expressed in $n m$ ) (A) or on their mechanism of biogenesis (B).

Tumor cell-derived exosomes are able to promote inflammation and are able to compromise innate immunity by delivering different signals, which affect the proliferation, apoptosis, cytokine production, and reprogramming of T cells [62].

\subsection{Ectosomes}

Ectosomes are a heterogeneous vesicle population, ranging in diameter between 100 and $1000 \mathrm{~nm}$. Discovered in approximately the same time as exosomes, in 1990 s, ectosomes did not attract the same interest as the study of exosomes. While the interest in exosomes reached the maximum between 2008 and 2010, the ectosomes had its peak in 2012 [20,63].

Ectosomes are known under different names, which might be misleading (Table 1), while ecto is a prefix that means outwardly, externally, and is therefore suggestive of their way of forming. The mechanism of formation of ectosomes differs greatly from that of exosomes, as well as their cargo molecules. Ectosome formation does not require exocytosis. Ectosomes are formed by direct outward 


\begin{tabular}{|c|c|c|c|}
\hline & Exosomes & Ectosomes & Apoptotic bodies \\
\hline Size & $30-100 \mathrm{~nm}$ & $100-1000 \mathrm{~nm}$ & $500-4000 \mathrm{~nm}$ \\
\hline $\begin{array}{l}\text { Sedimentation } \\
\text { rate }\end{array}$ & $100,000-120,000 \times g$ & $16,000-20,000 \times g$ & $5000-16,000 \times g$ \\
\hline Biogenesis & $\begin{array}{l}\text { Endosomal pathway, } \\
\text { accumulated within the } \\
\text { multivesicular bodies, } \\
\text { exocytosis [20] }\end{array}$ & $\begin{array}{l}\text { Generated directly from } \\
\text { the plasma membrane by } \\
\text { shedding [21] }\end{array}$ & $\begin{array}{l}\text { Cell fragmentation } \\
\text { Blebbing or zeiosis- } \\
\text { bulge of membrane by } \\
\text { increasing the surface area } \\
\text { through tearing [22] }\end{array}$ \\
\hline $\begin{array}{l}\text { Types of } \\
\text { generation }\end{array}$ & Constitutive & Regulated & Regulated \\
\hline Filtration & $20-200 \mathrm{~nm}$ & $>200 \mathrm{~nm}$ & $>1000 \mathrm{~nm}$ \\
\hline $\begin{array}{l}\text { Intracellular } \\
\text { storage }\end{array}$ & Yes & No & No \\
\hline Marker proteins & $\begin{array}{l}\text { CD 9, CD63 and CD61, } \\
\text { tetraspanins, HSP70, } \\
\text { HSP90, Alix, Rab5a/b } \\
\text { [23-25] }\end{array}$ & $\begin{array}{l}\text { TyA and C1a, ARF6 and } \\
\text { VCAMP3, } \beta 1 \text { integrins, } \\
\text { selectins, CD40, MMP, } \\
\text { lineage markers, and } \\
\text { ezrin [26-28] }\end{array}$ & $\begin{array}{l}\text { Calreticulin, TSP and C3b, } \\
\text { and histones }[29,30] \text {. }\end{array}$ \\
\hline Content & $\begin{array}{l}\text { Proteins, cholesterol, } \\
\text { ceramide, noncoding } \\
\text { RNA, mRNA, miRNA, } \\
\text { and cytosol [31] }\end{array}$ & $\begin{array}{l}\text { Proteins, } \\
\text { phosphatidylserine, } \\
\text { cholesterol, mRNA, } \\
\text { miRNA, and cytosol [31] }\end{array}$ & $\begin{array}{l}\text { Proteins, } \\
\text { phosphatidylserine, DNA, } \\
\text { rRNA, and cytosol [18] }\end{array}$ \\
\hline Organelles & No & No & Yes \\
\hline $\begin{array}{l}\text { Alternative } \\
\text { names }\end{array}$ & $\begin{array}{l}\text { Prostasomes, } \\
\text { tolerosomes, dexosomes, } \\
\text { nanovesicles, } \\
\text { exosome-like vesicles, } \\
\text { and others } \\
{[18,32]}\end{array}$ & $\begin{array}{l}\text { Nanoparticles, } \\
\text { microparticles, } \\
\text { microvesicles, shedding } \\
\text { vesicles, shedding } \\
\text { bodies, exovesicles, } \\
\text { secretory vesicles, and } \\
\text { oncosomes [18] }\end{array}$ & Apoptotic blebs [18] \\
\hline $\begin{array}{l}\text { Impact on the } \\
\text { immune system }\end{array}$ & Immunostimulators & Immunosuppressors & Immunosuppressors \\
\hline
\end{tabular}

Table 1.

Classification of EVs based on size and their biogenesis.

budding of the plasma membrane in specialized microdomains of the plasmalemma, the phenomenon known as microvesicle shedding [29]. They are released both by cells in normal resting state and by cells upon stimulation. Ectosome fusion with the plasma membrane of a recipient cell is followed by changes in antigens, enzymes, and other proteins in a specific site of plasmalemma, while their content release into the cytoplasm can alter the recipients' cell gene expression $[64,65]$. Tumor-derived ectosomes were shown to have immunosuppressive properties by inducing the chemotaxis of granulocytes, lymphocytes, and monocytes due to several chemokines (e.g., particularly IL-8) transported in ectosomes [66].

Oncosomes are a particular type of ectosomes, excessively large, which can even reach $1000 \mathrm{~nm}$, characteristic to advanced cancers. There is a confusion in the use of these terms in the literature and that is why we thought to treat oncosomes as a particular category of ectosomes. The generic name of ectosomes can include oncosomes, while the name of oncosomes excludes ectosomes released from normal cells. Oncosomes content is adapted to serve cancer metabolism, so they will contain enzymes involved in glucose, glutamine, and amino acid metabolism. Furthermore, oncosomes are enriched in proteins, which have a 
role in cell migration, angiogenesis, and cancer progression and metastasis [28]. Oncosomes allow intercellular transfer of oncogenes, hence the motivation to be considered as existing biomarkers in the blood or plasma of patients for the detection of cancer [67].

\subsection{Apoptotic bodies}

Apoptotic bodies (ApoBDs) are the largest type of extracellular vesicles (typically $1-5 \mu \mathrm{m}$ in diameter) visible during an apoptotic process. Kerr in 1972 proposed the term "apoptotic body" [68]. ApoBDs are released as blebs of cells undergoing apoptosis and consist of cytoplasm, organelles with or without a nuclear fragment. It has also been shown that ApoBDs can harbor proteins, lipids, DNA, rRNA, organelles, and cytosol [18]; this is the reason why the disassembly of an apoptotic cell into ApoBDs can mediate intercellular communication and may contribute to the development of various disease states [69]. These bodies are then phagocytosed by macrophages or neoplastic cells and degraded within phagolysosomes. Their formation has been proposed to play an important role in the clearance of apoptotic cells by phagocytes. Different cell types can generate ApoBDs via different mechanisms [70]. These ApoBDs can be classified based on cell-type-specific surface markers and content. Jiang et al. showed that ApoBDs share the same surface markers as their cell of origin; this is the reason why apoptotic bodies are very different and can be divided into specific subclasses [70].

ApoBD occurs spontaneously in untreated malignant neoplasms, and is implicated in both physiological involution and atrophy of various tissues and organs. Pathological settings include inflammation [71], autoimmunity [72-74], viral infection [75], and tumorigenesis because they participate in the horizontal transfer of oncogenes due to their nuclear material content from the dying cells [76].

\section{Extracellular vesicles and tumor microenvironment}

Tumor masses are composed of cancer cells and stromal cells, in which one include mesenchymal cells, fibroblasts and immune cells, and extracellular matrix (ECM) components. All these cells emit EVs and participate in the creation of a unique tumor nanoenvironment. EVs are capable of horizontal transfer of bioactive content to interact with cells in the tumor microenvironment. These interactions can include fusion of the EV with the plasmalemma of the recipient cell or endocytosis of the EVs [77]. EVs represent the bidirectional way of interaction between stromal and cancer cells as a mean to exchange information and modify the tumor microenvironment. Therefore, the content of these vesicles is of great significance in the evolution of the cancer, since it was shown to modulate the complex signaling networks that facilitate tumor progression [78].

\subsection{Nucleic acids}

Circulating DNA can be found in free form or contained in EVs and is thought to be the future in cancer diagnosis and treatment monitoring. This will be possible because the DNA fragments contained in EVs are relatively intact (average $15 \mathrm{kbp}$ ) by comparison with the circulating cell-free one (average $130 \mathrm{bp}$ ) due to the protection offered by the lipid bilayer [79]. Vagner et al. showed in a very recent study that the majority of the extracellular DNA is contained in large oncosomes, rather than in exosomes, both in vitro and in the patients' plasma and has all cancer-specific genomic alterations [80]. The majority of the DNA contained 
in tumor-derived exosomes is double stranded and represent the whole genomic DNA, suggesting its usefulness in identifying mutations present in parental tumor cells, as it was indicated by Thakur et al. [81]. Wyatt et al. showed that cancerderived DNA is sufficient to identify the DNA alterations from metastatic tissue and is very important because it integrates somatic information from more than one metastatic lesion [82].

The presence of retrotransposons, cDNAs, and ncRNAs has also been reported in EVs and appears to be a unique feature of tumor cells [83]. Several studies reported a correlation between increased retrotransposon activity and tumorigenesis [84]. For example, LINE-1 hypomethylation in various human cancers was intensively studied since it is considered to be an early event in tumorigenesis and to be linked with the induction of proto-oncogenes [85]. Loss of LINE-1 methylation was found to associate with more aggressive progression of colorectal cancer [86]. Moreover, LINE-1 hypomethylation level can be considered as an important epigenetic process, which became a potential prognostic factor for ovarian multistep carcinogenesis [87].

miRNAs represent potential candidates responsible for influencing the tumor microenvironment; however, little is known about the mechanism by which they produce changes in the transcriptome of target cells [88].

\subsection{Proteins}

Proteins exported in EVs are signaling molecules that interfere in a whole series of processes such as cell metabolism, cell invasion and growth, angiogenesis, and mRNA processing [89]. Among these, it is worth mentioning that the epidermal growth factor receptor vIII (EGFRvIII), mutant Ras family members, or c-Met have been proposed as cancer biomarkers [90,91]. Other proangiogenic regulators, such as VEGF and bFGF, are harbored in EVs shed from cancerous cells promoting new blood vessel formation [92].

Moreover, EVs also transfer proteases such as MMP-2, MMP-9, and MT1-MMP and become responsible for the partial degradation of the extracellular matrix [93]. The content is released in an acidic environment after the vesicle is stabilized in the extracellular matrix with the aid of $\beta 1$ integrin adhesion molecules [94].

\subsection{Lipids}

Naturally, EVs also contain a lipid component, which consists of the main membrane lipids: sphingomyelin, phosphatidylserine, and glycosphingolipids and cholesterol, but they also carry polyunsaturated fatty acids PUFAs, mainly arachidonic acid and linoleic acid $[95,96]$. Sphingomyelin, as a component of the EVS, was firstly reported by Kim et al. who described its angiogenic properties [97] . In addition, it has been shown that the lipid content of exosomes suppresses critical cancer survival pathways such as notch leading to cancer cell death of human pancreatic tumoral SOJ-6 cells [98]. Moreover, other important signaling mediators, such as prostaglandins, arachidonic acid, phospholipase A2, and phospholipase $\mathrm{C}$ and $\mathrm{D}$, are also found in EVs [99]. The prostaglandins found in breast-cancer-derived exosomes, such as PGE2, are responsible for promoting tumor growth by inducing the release of pro-inflammatory cytokines such as IL-6 and VEGF, which induce the accumulation of myeloid-derived suppressor cells capable to differentiate into macrophages in the tumor microenvironment [100, 101]. PGE2 indeed makes the connection between cancer and macrophages and can promote tumorigenesis by enhancing the expression of programmed cell death protein ligand 1 (PD-L1) responsible for tumor escape from immune system during cancer progression [102]. 
Cancer stem cells (CSCs) are held directly responsible to promote cancer initiation and progression. Also, there are several studies showing their importance in therapy resistance, recurrence, and metastasis [103]. CSCs themselves do not exist as a static population, their stemness being supported by the mesenchymal stem cells, endothelial cells, fibroblasts, or immune cells by paracrine signaling [104]. For example, in breast cancer, the overexpression of the chemokines CXCL14 and CXCL12 in myoepithelial cells and myofibroblasts favors the metastasis [105]. Cancer-associated fibroblasts (CAF) release exosomes, which induce the stemness of breast cancer cell lines, developing an aggressive cancer cell phenotype [106]. Also, the ECM molecules are relevant for breast cancer colonization, which contribute to the control of CSC. In this sense, tenascin C, a protein in the ECM, contributes in the formation of the stem niche by protecting CSC from immune surveillance [107]. In breast cancer, high levels of tenascin $C$ are associated with poor clinical outcome in breast cancer due to lung cancer metastasis [108].

\section{Role of extracellular vesicles in tumorigenesis}

The role of EVs in tumorigenesis was described in various types of cancer, including ovarian [109-111] and breast cancers [112, 113]. EVs undergo several alterations in tumorigenesis, including changes in their biogenesis, release rate and/ or protein content, incorporation of oncogenic and mutant macromolecules, mediated release of genomic DNA, and uptake of tumoral cells [114]. The transfer of DNA between apoptotic tumoral cells and other cells is important in tumorigenesis. In vitro, it was shown that apoptotic bodies derived from cancer cells are responsible for triggering the expression of oncogenes in fibroblasts due to the information contained in tumor-derived EVs [76].

In ovarian or breast cancer, investigating the content of EVs might give important informations on tumorigenesis. To detail, exosomes released by IGROV1 ovarian cancer cells (with high content of RNA-binding proteins, such as LIN28A or LIN28B), but not by OV420 ovarian cancer cells, were taken up by HEK293 cells, contributing to the tumor development [109]. Moreover, in hypoxia conditions, SKOV3 human epithelial ovarian cancer cells release exosomes with high content of miR-940 that stimulate the M2 macrophage phenotype, and in turn, M2 subtype macrophages stimulate the tumor cell migration and proliferation [111]. The majority of circulating miRNA, packed in EVs, can be used as biomarkers in ovarian cancer, but their use is not only limited for diagnosing the existence of the cancer, but also being reliable markers for monitoring the tumor histology, stage, or the patient outcome [110].

The content of EVs released from two human breast cancer cell lines, MCF-7 (less invasive) and MDA-MB-231 (more invasive), was analyzed, and approximately, 270 proteins were identified [113]. In circulating EVs, epidermal growth factor-like repeats and discoidin I-like domains 3 (EDIL3) are the extracellular matrix (ECM) protein that was described to play a critical role in tumorigenesis by the activation of integrin-focal adhesion kinase (FAK) signaling cascade [113]. Breast-cancer-derived EVs (e.g., exosomes) present a cell-independent microRNA biogenesis from pre-miRNAs (like Dicer, AGO2, or TRBP) to mature miRNAs [112]. In particular, exosomes detected in the cells and sera of patients affected by breast cancer were shown to stimulate tumorigenesis in nontumoral epithelial cells by a Dicer-dependent mechanism [112]. It was also demonstrated that in the breast tumor microenvironment, there is a downregulation of the tumor suppressor $\mathrm{p} 85 \alpha$, which is clinically relevant in tumorigenesis, and the mechanism involves the loss of p85 $\alpha$ expression in stromal fibroblasts promoting breast cancer progression by the epithelial-to-mesenchymal transition [111]. 


\section{Extracellular vesicles and metastatic niches}

Tumor microenvironment was described to undergo series of molecular and cellular changes to form the metastatic-designated sites, called pre-metastatic niche $[115,116]$. The formation of pre-metastatic niche requires the cross talk between primary tumor-derived components, and the microenvironment of the host stromal components and of the tumor-mobilized bone-marrow-derived cells [117].

Interestingly, the role of EVs in metastatic niches can be exploited in novel therapeutic approaches. Indeed, technologies based on exosomes, separated from the ascitic fluid of ovarian cancer patients, embedded in a 3D scaffold metastatic trap, were successfully tested in murine models of ovarian metastasis in order to improve survival [118]. Numerous studies indicated that tumor-derived exosomes might play a role in promoting angiogenesis and modulation of the immune system $[119,120]$. Moreover, exosomes derived from cancerous tumor are capable of remodeling the surrounding parenchyma, thus supporting tumor progression and the generation of the pre-metastatic niche $[121,122]$.

\section{Role of extracellular vesicles in metastasis}

EVs have been described to play an essential role in the local and distant communication between cancer cells and their environment and in contributing to the progression of metastasis [123]. Although the function of EVs in metastasis is not completely understood, studies show that miRNAs isolated from EVs are actively involved in complex metastatic processes, including local invasion, angiogenesis, immune modulation, metastatic niche preparation, colonization, and dormancy [123].

EVs play an essential role in the tumor metastasis by ensuring the cross talk between tumor and the adipose tissue, and obesity was described to influence the metastatic behavior of tumors, especially in melanoma, breast, and ovarian cancers [124].

In breast cancer, metastatic exosomes creating a facilitating local environment for metastasis was demonstrated, and annexin II contained in these exosomes contributes to this process by promoting angiogenesis [125].

\section{Tumor-derived extracellular vesicles in ovarian cancer}

Nawaz et al. have recently done an extensive review on the role of EVs in ovarian cancer and concluded that the gaining of new insights into these mechanisms would contribute to the identification of new biomarkers among the ovarian-cancerderived EVs and to the development of efficient EVs-based immunotherapies [126]. Proteomic analysis of exosomes derived from two human ovarian cancer cell lines (i.e., OVCAR-3 and IGROV1) indicated the presence of 2230 proteins, 1017 proteins being common for both cell lines, 380 proteins being newly reported compared to the ExoCarta database, and some of them being associated with tumorigenesis and metastasis and might represent promising biomarkers [127].

Additionally, matrix metalloproteinase-1 (MMP1) might be a very good biomarker for the ovarian cancer due to its overexpression in ascites-derived EVs in correlation with the degree of malignancy and the low prognosis for the ovarian cancer patients [128]. Moreover, the peritoneal dissemination of ovarian cancer is facilitated by malignant EVs containing MMP1 derived from the ascites of patients, and EVs were demonstrated to induce apoptosis in mesothelial cells [128]. 
The mechanisms of drug resistance development also involve the release of EVs from ovarian cancer cells upon exposure to drug (i.e., cisplatin) and induce invasiveness [129].

\section{Breast-cancer-derived extracellular vesicles}

In breast cancer, EVs can play two essential roles "diagnosis biomarkers" or "therapeutic targets." Thus, breast cancer induces the release of exosomes from salivary glands, being potential markers for early diagnosis [130]. Interestingly, EVs serve as a cargo not only for nucleic acids and proteins, but also for anticancer drugs. Considering the critical contribution of EVs in facilitating tumorigenesis, metastasis, and drug resistance [130], they could be considered as potential therapeutic targets in breast cancer.

Moreover, the analysis of EVs can help to distinguish the "degree of aggressiveness" in breast cancer. To detail, EVs derived from the aggressive human breast cancer MDA-MB-231 cell line, but not from the less invasive human breast cancer MCF-7 cell line, were demonstrated to induce platelet activation and aggregation by tissue factor-independent and tissue factor-dependent procoagulant activities [131]. EVs have been demonstrated to be involved in the cross talk between neighboring cancer cells and to transmit phenotypic aggressive traits from one cell to another. To date, EVs released by Hs578Ts(i) 8 triple-negative breast cancer cells were able to increase the invasion, proliferation, and migration characteristics of Hs578T cells [132].

\section{Extracellular vesicles as biomarkers—new diagnostic tools}

In different body fluids, especially plasma and serum, EVs biomarkers have been detected with great clinical value in various types of cancer, Table 2 .

The protein content of the EVs can be potentially used in the early detection of cancer as suggested in a pilot study by Smalley et al. [151]. The plasma levels of exosomal proteins represents an important biomarker that discriminates between ovarian cancer patients and normal ones, and their values correlate with the stage of the disease [119]. Among exosomal proteins, TGF- $\beta 1$ and MAGE3/6 can be used as reliable biomarkers to discriminate between benign and malignant ovarian tumors, or to ascertain the efficacy of chemotherapy [119]. Although epithelial cell adhesion molecule (EpCAM) was demonstrated to promote epithelial-mesenchymal transition in advanced stages of endometrial cancer [152], studies indicated that EpCAM is not a robust biomarker to classify exosomes derived from benign and malignant ovarian tumors [134] or to detect early stages of the pathology [153]. Besides EpCAM, several exosomal proteins were identified to be overexpressed in ovarian cancer, including proliferation cell nuclear antigen (PCNA), tubulin beta-3 chain (TUBB3), epidermal growth factor receptor (EGFR), apolipoprotein E (APOE), claudin 3 (CLDN3), fatty acid synthase (FASN), ERBB2, and L1CAM (CD171) [127]. Additionally, claudin-4, but not claudin-3, is a valuable biomarker in the peripheral blood of ovarian cancer patients with almost $98 \%$ specificity [133]. Exosomal proteins can also represent important biomarkers for the evaluation of efficacy of therapies. Thus, annexin A3 can be employed for early detection of the resistance to platinum-based therapy in ovarian cancer patients $[135,136]$.

In breast cancer, several studies identified various exosomal miRNAs as potential biomarkers correlated with tumor malignancy degree and prognosis. Indeed, exosomal miR-21 and miR-1246 had higher levels in plasma of breast cancer 


\begin{tabular}{|c|c|c|c|}
\hline Biomarkers of EVs & Sample & Types of cancer & Reference \\
\hline $\begin{array}{l}\text { TGF-beta1, MAGE } 3 / 6 \text {, and } \\
\text { Claudin- } 4\end{array}$ & Plasma & \multirow[t]{2}{*}{ Ovarian cancer } & {$[119,133]$} \\
\hline EpCAM and annexin A3 & Serum & & [134-136] \\
\hline $\begin{array}{l}\text { Alpha-1-antitrypsin and } \\
\text { haptoglobin precursors }\end{array}$ & Serum & \multirow[t]{2}{*}{ Breast cancer } & [137] \\
\hline $\begin{array}{l}\text { miR-21, miR-939, miR-373, and } \\
\text { miR-1246 }\end{array}$ & Plasma & & {$[58,138,139]$} \\
\hline $\begin{array}{l}\text { miR-1290 and } \mathrm{miR}-375 \\
\text { Survivin, CD9+, CD63+, and } \\
\text { alpha-1-antitrypsin }\end{array}$ & Plasma & Prostate cancer & {$[140-144]$} \\
\hline IL-8 and TGF-beta mRNAs & Plasma & \multirow[t]{2}{*}{ Glioma } & {$[60]$} \\
\hline $\operatorname{miR}-21$ & CSF & & {$[145]$} \\
\hline $\begin{array}{l}\text { miR-1246, miR-4644, miR-3976, } \\
\text { and miR-4306 } \\
\text { CD44v6, Tspan8, EpCAM, and } \\
\text { CD104 }\end{array}$ & Serum & Pancreatic cancer & {$[146]$} \\
\hline $\begin{array}{l}\text { Alpha-1-antitrypsin, and histone } \\
\text { H2B1K }\end{array}$ & Urine & Urothelial carcinoma & {$[147]$} \\
\hline long coding RNA CRNDE-h & Serum & $\begin{array}{l}\text { Lymph node and distant metastasis of } \\
\text { colorectal cancer }\end{array}$ & {$[148]$} \\
\hline miR-21 & Plasma & Esophageal cancer & [149] \\
\hline miR-19a l & Serum & Colorectal cancer & {$[150]$} \\
\hline
\end{tabular}

Table 2.

Biomarkers contained in EVs relevant in different types of cancer.

patients compared to control patients [138]. Additionally, high levels of exosomal miR-939 were associated with low outcome in patients with triple-negative breast cancer [139], and high levels of exosomal miR-373 were identified in triplenegative, estrogen-receptor- and progesterone-receptor-negative, breast cancer patients [58]. Moreover, an extensive proteomics analysis identified alpha1antitrypsin and haptoglobin precursors as novel biomarkers in the serum of patients with infiltrating ductal breast carcinomas [137].

The release of EVs has a calcium-dependent mechanism, and alterations in calcium signaling have been described in tumorigenesis, metastasis, or drug resistance in various types of cancer, including breast and ovarian cancers [154, 155]. Therefore, more attention should be paid to the calcium-dependent signaling cascades in different cancer stages in direct relationship with the cell-to-cell communication mechanisms of EVs in order to identify novel specific and reliable biomarkers.

\section{Therapeutic roles of extracellular vesicles in cancer}

EVs have a big potential for cancer therapy monitoring (Table 3). These are described as secreted lipid bilayer-enclosed lumens and are claimed to be valuable reservoirs of liquid biopsy biomarker [156]. EVs (mainly EVs-associated proteins and microRNAs) are proved to be the biomarkers in breast cancer diagnosis $[157,158]$. 


\begin{tabular}{lll}
\hline Source of EVs & Therapeutic effect & Reference \\
\hline $\begin{array}{l}\text { Tumor peptide-loaded dendritic } \\
\text { cells-derived exosomes }\end{array}$ & $\begin{array}{l}\text { Immunotherapy-because they suppress } \\
\text { tumor growth }\end{array}$ & {$[159]$} \\
\hline $\begin{array}{l}\text { EVs from the rat pancreatic } \\
\text { adenocarcinoma cell line BSp73ASML }\end{array}$ & Adjuvant therapy in immunotherapy & {$[160]$} \\
\hline Tumor antigen containing EVs & $\begin{array}{l}\text { Activates an antitumor response against } \\
\text { OVA-transfected BL6-10 melanoma cells }\end{array}$ & {$[160]$} \\
\hline $\begin{array}{l}\text { EV vaccine derived from colorectal cancer } \\
\text { (NB4 cell-a human acute promyelocytic }\end{array}$ & $\begin{array}{l}\text { Activates CTLs through self-derived } \\
\text { dendritic cell activation }\end{array}$ & {$[161]$} \\
\hline EVs from self-derived dendritic cells & Immunotherapy in cases of unresectable & {$[162]$} \\
\hline $\begin{array}{l}\text { EVs from autologous self-derived dendritic } \\
\text { cells }\end{array}$ & Monsmall-cell lung cancer & \\
\hline $\begin{array}{l}\text { EVs from ascites in combination with } \\
\text { granulocyte macrophage colony- } \\
\text { stimulating factor }\end{array}$ & Immunotherapy in colorectal cancer & {$[163]$} \\
\hline $\begin{array}{l}\text { miR-9 in mesenchymal stem cell-derived } \\
\text { EVs }\end{array}$ & $\begin{array}{l}\text { Chemosensitive in glioblastoma multiforme } \\
\text { cells }\end{array}$ & {$[165]$} \\
\hline $\begin{array}{l}\text { iRGD-Exos-doxorubicin } \\
\text { endothelial cell line }\end{array}$ & $\begin{array}{l}\text { Suppressed breast tumor growth in an } \\
\text { MDA-MB-231 tumor-bearing nude mouse } \\
\text { model }\end{array}$ & {$[166]$} \\
\hline
\end{tabular}

Table 3.

EVs and their role in therapeutic approaches in cancer.

\section{Integrative overview}

EVs play an essential role in cellular communication both in physiological and pathological conditions. In pathological conditions, EVs have been implicated in cancer, spreading of viruses or other pathogens, altered immune response, development of neurodegenerative diseases, etc. In cancer, EVs ensure the cross talk between tumoral cells or between tumoral cells and nontumoral cells, and enable the development of multiple processes, including tumorigenesis, pre-metastatic niche formation, metastasis, and drug resistance. In ovarian and breast cancers, the involvement of EVs in all these processes of tumor evolution has been described and the analysis of EVs content is particularly useful for identifying biomarkers of the disease per se and, moreover, for the stage of the pathology evolution. However, there are still technical limitations for separation and/or analysis of EVs, and in clinical practice, the standardization of EVs-based reproductible protocols is required urgently. Considering the presence of EVs in such a variety of body fluids and tissues, an important conclusion is to consider EVs both as biomarkers and potential therapeutic targets (especially for immunotherapies) and to exploit them in the next future to improve the outcome of cancer patients. 


\section{Author details}

Andrei-Dennis Voichitoiu ${ }^{1,2 \dagger}$, Beatrice Mihaela Radu ${ }^{3,4 \dagger}$, Luciana Pavelescu ${ }^{5}$, Dragos Cretoiu ${ }^{5,6}$, Antonia Teona Deftu ${ }^{3,4}$, Nicolae Suciu ${ }^{1,2,6}$ and Sanda Maria Cretoiu ${ }^{5 *}$

1 Department of Obstetrics and Gynecology, Polizu Clinical Hospital, Alessandrescu-Rusescu National Institute of Mother and Child Health, Bucharest, Romania

2 Division of Obstetrics and Gynecology and Neonatology, Carol Davila University of Medicine and Pharmacy, Bucharest, Romania

3 Department of Anatomy, Animal Physiology and Biophysics, Faculty of Biology, University of Bucharest, Bucharest, Romania

4 Life, Environmental and Earth Sciences Division, Research Institute of the University of Bucharest (ICUB), Bucharest, Romania

5 Department of Cell and Molecular Biology and Histology, Carol Davila University of Medicine and Pharmacy, Bucharest, Romania

6 Alessandrescu-Rusescu National Institute of Mother and Child Health, Fetal Medicine Excellence Research Center, Bucharest, Romania

*Address all correspondence to: sanda@cretoiu.ro

$\uparrow$ Authors have contributed equally.

\section{IntechOpen}

(C) 2019 The Author(s). Licensee IntechOpen. This chapter is distributed under the terms of the Creative Commons Attribution License (http://creativecommons.org/licenses/ by/3.0), which permits unrestricted use, distribution, and reproduction in any medium, provided the original work is properly cited. (cc) BY 


\section{References}

[1] Camussi G et al. Exosomes/ microvesicles as a mechanism of cell-to-cell communication. Kidney International. 2010;78(9):838-848

[2] Nomura S. Extracellular vesicles and blood diseases. International Journal of Hematology. 2017;105(4):392-405

[3] Chargaff E, West R. The biological significance of the thromboplastic protein of blood. The Journal of Biological Chemistry. 1946;166(1):189-197

[4] Wolf P. The nature and significance of platelet products in human plasma. British Journal of Haematology. 1967;13(3):269-288

[5] Al-Nedawi K. The yin-yang of microvesicles (exosomes) in cancer biology. Frontiers in Oncology. 2014;4:172

[6] Gould SJ, Raposo G. As we wait: Coping with an imperfect nomenclature for extracellular vesicles. Journal of Extracellular Vesicles. 2013;2:20389

[7] Jo W et al. Microfluidic fabrication of cell-derived nanovesicles as endogenous RNA carriers. Lab on a Chip. 2014;14(7):1261-1269

[8] Wendler F, Stamp GW, Giamas G. Tumor-stromal cell communication: Small vesicles signal big changes. Trends Cancer. 2016;2(7):326-329

[9] Cheng L et al. A comprehensive overview of exosomes in ovarian cancer: Emerging biomarkers and therapeutic strategies. Journal of Ovarian Research. 2017;10(1):73

[10] Lowry MC, Gallagher WM, O'Driscoll L. The role of exosomes in breast cancer. Clinical Chemistry. 2015;61(12):1457-1465
[11] Zhou J et al. Tumor-derived exosomes in colorectal cancer progression and their clinical applications. Oncotarget.

2017;8(59):100781-100790

[12] Ruiz-Lopez L et al. The role of exosomes on colorectal cancer: A review. Journal of Gastroenterology and Hepatology. 2018;33(4):792-799

[13] Pan J et al. Exosomes in diagnosis and therapy of prostate cancer. Oncotarget. 2017;8(57):97693-97700

[14] Wozniak M et al. Analysis of the miRNA profiles of melanoma exosomes derived under normoxic and hypoxic culture conditions. Anticancer Research. 2017;37(12):6779-6789

[15] Wu Y et al. Melanoma exosomes deliver a complex biological payload that upregulates PTPN11 to suppress $\mathrm{T}$ lymphocyte function. Pigment Cell \& Melanoma Research. 2017;30(2):203-218

[16] Tucci M et al. Exosomes in melanoma: A role in tumor progression, metastasis and impaired immune system activity. Oncotarget. 2018;9(29):20826-20837

[17] Cretoiu D et al. Telocytes and their extracellular vesicles-evidence and hypotheses. International Journal of Molecular Sciences. 2016;17(8):1322

[18] van Niel G, D’Angelo G, Raposo G. Shedding light on the cell biology of extracellular vesicles. Nature Reviews Molecular Cell Biology. 2018;19(4):213-228

[19] Lunavat TR et al. Small RNA deep sequencing discriminates subsets of extracellular vesicles released by melanoma cells-Evidence of unique microRNA cargos. RNA Biology. 2015;12(8):810-823 
[20] Cocucci E, Meldolesi J. Ectosomes and exosomes: Shedding the confusion between extracellular vesicles. Trends in Cell Biology. 2015;25(6):364-372

[21] Stein JM, Luzio JP. Ectocytosis caused by sublytic autologous complement attack on human neutrophils. The sorting of endogenous plasma-membrane proteins and lipids into shed vesicles. The Biochemical Journal. 1991;274(Pt 2):381-386

[22] Bovellan M et al. Death-associated protein kinase (DAPK) and signal transduction: Blebbing in programmed cell death. The FEBS Journal. 2010;277(1):58-65

\section{[23] Escola JM et al. Selective} enrichment of tetraspan proteins on the internal vesicles of multivesicular endosomes and on exosomes secreted by human B-lymphocytes. The Journal of Biological Chemistry. 1998;273(32):20121-20127

\section{[24] Lotvall J et al. Minimal} experimental requirements for definition of extracellular vesicles and their functions: A position statement from the international society for extracellular vesicles. Journal of Extracellular Vesicles. 2014;3:26913

[25] Surman M et al. Deciphering the role of ectosomes in cancer development and progression: Focus on the proteome. Clinical \& Experimental Metastasis. 2017;34(3-4):273-289

[26] Muralidharan-Chari V et al. ARF6-regulated shedding of tumor cell-derived plasma membrane microvesicles. Current Biology. 2009;19(22):1875-1885

[27] Pokharel D et al. Proteome analysis of multidrug-resistant, breast cancerderived microparticles. Journal of Extracellular Vesicles. 2014;3:24384
[28] Minciacchi VR et al. Large oncosomes contain distinct protein cargo and represent a separate functional class of tumor-derived extracellular vesicles. Oncotarget. 2015;6(13):11327-11341

[29] Mause SF, Weber C. Microparticles: Protagonists of a novel communication network for intercellular information exchange. Circulation Research. 2010;107(9):1047-1057

[30] Gong J et al. Microparticles in cancer: A review of recent developments and the potential for clinical application. Seminars in Cell \& Developmental Biology. 2015;40:35-40

[31] Crescitelli R et al. Distinct RNA profiles in subpopulations of extracellular vesicles: Apoptotic bodies, microvesicles and exosomes. Journal of Extracellular Vesicles. 2013;2:20677

[32] van der Pol E et al. Recent developments in the nomenclature, presence, isolation, detection and clinical impact of extracellular vesicles. Journal of Thrombosis and Haemostasis. 2016;14(1):48-56

[33] Abels ER, Breakefield XO.

Introduction to extracellular vesicles: Biogenesis, RNA cargo selection, content, release, and uptake. Cellular and Molecular Neurobiology.

2016;36(3):301-312

[34] Caby MP et al. Exosomal-like vesicles are present in human blood plasma. International Immunology. 2005;17(7):879-887

[35] McDonald MK, Capasso KE, Ajit SK. Purification and microRNA profiling of exosomes derived from blood and culture media. Journal of Visualized Experiments. 2013;76:e50294

[36] Pisitkun T, Shen RF, Knepper MA. Identification and proteomic profiling 
of exosomes in human urine.

Proceedings of the National Academy of Sciences of the United States of America. 2004;101(36):13368-13373

[37] Bachy I, Kozyraki R, Wassef M. The particles of the embryonic cerebrospinal fluid: How could they influence brain development? Brain Research Bulletin. 2008;75(2-4):289-294

[38] Machida T et al. MicroRNAs in salivary exosome as potential biomarkers of aging. International Journal of Molecular Sciences. 2015;16(9):21294-21309

[39] Han Y et al. Salivary exosomes: Emerging roles in systemic disease. International Journal of Biological Sciences. 2018;14(6):633-643

[40] Hoog JL, Lotvall J. Diversity of extracellular vesicles in human ejaculates revealed by cryo-electron microscopy. Journal of Extracellular Vesicles. 2015;4:28680

[41] Lasser C et al. Human saliva, plasma and breast milk exosomes contain RNA: Uptake by macrophages. Journal of Translational Medicine. 2011;9:9

[42] Wang X. Isolation of extracellular vesicles from breast milk. Methods in Molecular Biology. 2017;1660:351-353

[43] Keller S et al. Body fluid derived exosomes as a novel template for clinical diagnostics. Journal of Translational Medicine. 2011;9:86

[44] Ebert B, Rai AJ. Isolation and characterization of amniotic fluidderived extracellular vesicles for biomarker discovery. Methods in Molecular Biology. 2019;1885:287-294

[45] Raposo G et al. B lymphocytes secrete antigen-presenting vesicles. The Journal of Experimental Medicine. 1996;183(3):1161-1172
[46] Alvarez V et al. The immunomodulatory activity of extracellular vesicles derived from endometrial mesenchymal stem cells on CD4+ T cells is partially mediated by TGFbeta. Journal of Tissue

Engineering and Regenerative Medicine. 2018;12(10):2088-2098

[47] Li QL et al. Exvivo experiments of human ovarian cancer ascites-derived exosomes presented by dendritic cells derived from umbilical cord blood for immunotherapy treatment. Clinical Medicine Oncology. 2008;2:461-467

[48] Contursi A et al. Platelets in cancer development and diagnosis. Biochemical Society Transactions. 2018;46(6):1517-1527

[49] Fevrier B et al. Cells release prions in association with exosomes. Proceedings of the National Academy of Sciences of the United States of America. 2004;101(26):9683-9688

[50] Console L, Scalise M, Indiveri C. Exosomes in inflammation and role as biomarkers. Clinica Chimica Acta. 2019;488:165-171

[51] Vrijsen KR et al. Cardiomyocyte progenitor cell-derived exosomes stimulate migration of endothelial cells. Journal of Cellular and Molecular Medicine. 2010;14(5):1064-1070

[52] Lai RC et al. Exosome secreted by MSC reduces myocardial ischemia/ reperfusion injury. Stem Cell Research. 2010;4(3):214-222

[53] Song D et al. Telocytes and lung disease. Histology and Histopathology. 2016;31(12):1303-1314

[54] Cretoiu D, Cretoiu SM. Telocytes in the reproductive organs: Current understanding and future challenges. Seminars in Cell \& Developmental Biology. 2016;55:40-49 
[55] Cretoiu D et al. Telocytes heterogeneity: From cellular morphology to functional evidence. Seminars in Cell \& Developmental Biology. 2017;64:26-39

[56] Bei Y et al. Circulating exosomes in cardiovascular diseases. Advances in Experimental Medicine and Biology. 2017;998:255-269

[57] Kalluri R. The biology and function of exosomes in cancer. The Journal of Clinical Investigation. 2016;126(4):1208-1215

[58] Takahashi RU, Miyazaki H, Ochiya $\mathrm{T}$. The roles of microRNAs in breast cancer. Cancers (Basel). 2015;7:598-616

[59] Willms E et al. Cells release subpopulations of exosomes with distinct molecular and biological properties. Scientific Reports. 2016;6:22519

[60] Muller L et al. Isolation of biologically-active exosomes from human plasma. Journal of Immunological Methods. 2014;411:55-65

[61] Hong CS et al. Isolation of biologically active and morphologically intact exosomes from plasma of patients with cancer. Journal of Extracellular Vesicles. 2016;5:29289

[62] Gao L et al. Tumor-derived exosomes antagonize innate antiviral immunity. Nature Immunology. 2018;19(3):233-245

[63] Raposo G, Stoorvogel W.

Extracellular vesicles: Exosomes, microvesicles, and friends. The Journal of Cell Biology. 2013;200(4):373-383

[64] Muralidharan-Chari V et al.

Microvesicles: Mediators of extracellular communication during cancer progression. Journal of Cell Science. 2010;123(Pt 10):1603-1611
[65] Pollet $\mathrm{H}$ et al. Plasma membrane lipid domains as platforms for vesicle biogenesis and shedding? Biomolecules. 2018;8(3):94

[66] Baj-Krzyworzeka M et al. Tumour-derived microvesicles contain interleukin- 8 and modulate production of chemokines by human monocytes. Anticancer Research. 2011;31(4):1329-1335

[67] Meehan B, Rak J, Di Vizio D. Oncosomes-large and small: What are they, where they came from?. Journal of Extracellular Vesicles. 2016;5:33109

[68] Kerr JF, Wyllie AH, Currie AR. Apoptosis: A basic biological phenomenon with wide-ranging implications in tissue kinetics. British Journal of Cancer. 1972;26(4):239-257

[69] Atkin-Smith GK et al. A novel mechanism of generating extracellular vesicles during apoptosis via a beads-ona-string membrane structure. Nature Communications. 2015;6:7439

[70] Jiang L et al. Determining the contents and cell origins of apoptotic bodies by flow cytometry. Scientific Reports. 2017;7(1):14444

[71] Berda-Haddad Y et al. Sterile inflammation of endothelial cellderived apoptotic bodies is mediated by interleukin-1alpha. Proceedings of the National Academy of Sciences of the United States of America. 2011;108(51):20684-20689

[72] Schiller M et al. Autoantigens are translocated into small apoptotic bodies during early stages of apoptosis. Cell Death and Differentiation. 2008;15(1):183-191

[73] Cocca BA, Cline AM, Radic MZ. Blebs and apoptotic bodies are B cell autoantigens. Journal of Immunology. 2002;169(1):159-166 
[74] Tran HB et al. Subcellular redistribution of la/SSB autoantigen during physiologic apoptosis in the fetal mouse heart and conduction system: A clue to the pathogenesis of congenital heart block. Arthritis and Rheumatism. 2002;46(1):202-208

[75] Singh P et al. Tubular cell HIV-entry through apoptosed CD4 T cells: A novel pathway. Virology. 2012;434(1):68-77

[76] Bergsmedh A et al. Horizontal transfer of oncogenes by uptake of apoptotic bodies. Proceedings of the National Academy of Sciences of the United States of America. 2001;98(11):6407-6411

[77] Sadallah S et al. Microparticles (ectosomes) shed by stored human platelets downregulate macrophages and modify the development of dendritic cells. Journal of Immunology. 2011;186(11):6543-6552

[78] Minciacchi VR et al. MYC mediates large oncosome-induced fibroblast reprogramming in prostate cancer. Cancer Research. 2017;77(9):2306-2317

[79] Diehl F et al. Circulating mutant DNA to assess tumor dynamics. Nature Medicine. 2008;14(9):985-990

[80] Vagner T et al. Large extracellular vesicles carry most of the tumour DNA circulating in prostate cancer patient plasma. Journal of Extracellular Vesicles. 2018;7(1):1505403

[81] Thakur BK et al. Double-stranded DNA in exosomes: A novel biomarker in cancer detection. Cell Research. 2014;24(6):766-769

[82] Wyatt AW et al. Concordance of circulating tumor DNA and matched metastatic tissue biopsy in prostate cancer. Journal of the National Cancer Institute. 2017;110(1):djx118
[83] Balaj L et al. Tumour microvesicles contain retrotransposon elements and amplified oncogene sequences. Nature Communications. 2011;2:180

[84] Wiemels JL et al. Chromosome 12p deletions in TEL-AML1 childhood acute lymphoblastic leukemia are associated with retrotransposon elements and occur postnatally. Cancer Research. 2008;68(23):9935-9944

[85] Hur K et al. Hypomethylation of long interspersed nuclear element-1 (LINE-1) leads to activation of protooncogenes in human colorectal cancer metastasis. Gut. 2014;63(4):635-646

[86] Sunami E et al. LINE-1

hypomethylation during primary colon cancer progression. PLoS One. 2011;6(4):e18884

[87] Pattamadilok J et al. LINE-1 hypomethylation level as a potential prognostic factor for epithelial ovarian cancer. International Journal of Gynecological Cancer. 2008;18(4):711-717

[88] Ohshima K et al. Let-7 microRNA family is selectively secreted into the extracellular environment via exosomes in a metastatic gastric cancer cell line. PLoS One. 2010;5(10):e13247

[89] Choi DS et al. The protein interaction network of extracellular vesicles derived from human colorectal cancer cells. Journal of Proteome Research. 2012;11(2):1144-1151

[90] Demory Beckler M et al. Proteomic analysis of exosomes from mutant KRAS colon cancer cells identifies intercellular transfer of mutant KRAS. Molecular \& Cellular Proteomics. 2013;12(2):343-355

[91] Tauro BJ et al. Oncogenic H-ras reprograms Madin-Darby canine kidney (MDCK) cell-derived exosomal proteins 
following epithelial-mesenchymal transition. Molecular \& Cellular Proteomics. 2013;12(8):2148-2159

[92] Al-Nedawi K et al. Endothelial expression of autocrine VEGF upon the uptake of tumorderived microvesicles containing oncogenic EGFR. Proceedings of the National Academy of Sciences of the United States of America. 2009;106(10):3794-3799

[93] Taraboletti G et al. Shedding of the matrix metalloproteinases MMP-2, MMP-9, and MT1-MMP as membrane vesicle-associated components by endothelial cells. The American Journal of Pathology. 2002;160(2):673-680

[94] Giusti I et al. Cathepsin B mediates the $\mathrm{pH}$-dependent proinvasive activity of tumor-shed microvesicles. Neoplasia. 2008;10:481-488

[95] Subra C et al. Exosomes account for vesicle-mediated transcellular transport of activatable phospholipases and prostaglandins. Journal of Lipid Research. 2010;51(8):2105-2120

[96] Haraszti RA et al. High-resolution proteomic and lipidomic analysis of exosomes and microvesicles from different cell sources. Journal of Extracellular Vesicles. 2016;5:32570

[97] Kim CW et al. Extracellular membrane vesicles from tumor cells promote angiogenesis via sphingomyelin. Cancer Research. 2002;62(21):6312-6317

[98] Beloribi S et al. Exosomal lipids impact notch signaling and induce death of human pancreatic tumoral SOJ-6 cells. PLoS One. 2012;7(10):e47480

[99] Vancheri C et al. The lung as a privileged site for the beneficial actions of PGE2. Trends in Immunology. 2004;25(1):40-46
[100] Xiang X et al. Induction of myeloid-derived suppressor cells by tumor exosomes. International Journal of Cancer. 2009;124(11):2621-2633

[101] Kumar V et al. The nature of myeloid-derived suppressor cells in the tumor microenvironment. Trends in Immunology. 2016;37(3):208-220

[102] Prima V et al. COX2/mPGES1/ PGE2 pathway regulates PD-L1 expression in tumor-associated macrophages and myeloid-derived suppressor cells. Proceedings of the National Academy of Sciences of the United States of America. 2017;114(5):1117-1122

[103] Ayob AZ, Ramasamy TS. Cancer stem cells as key drivers of tumour progression. Journal of Biomedical Science. 2018;25(1):20

[104] Ye J et al. The cancer stem cell niche: Cross talk between cancer stem cells and their microenvironment. Tumour Biology. 2014;35(5):3945-3951

[105] Allinen M et al. Molecular characterization of the tumor microenvironment in breast cancer. Cancer Cell. 2004;6(1):17-32

[106] Donnarumma E et al. Cancerassociated fibroblasts release exosomal microRNAs that dictate an aggressive phenotype in breast cancer. Oncotarget. 2017;8(12):19592-19608

[107] Chiquet-Ehrismann R et al. Tenascins in stem cell niches. Matrix Biology. 2014;37:112-123

[108] Minn AJ et al. Genes that mediate breast cancer metastasis to lung. Nature. 2005;436(7050):518-524

[109] Enriquez VA et al. High LIN28A expressing ovarian cancer cells secrete exosomes that induce invasion and migration in HEK293 
cells. BioMed Research International. 2015;2015:701390

[110] Nakamura K et al. Clinical relevance of circulating cell-free microRNAs in ovarian cancer. Molecular Cancer. 2016;15:48

[111] Chen Y et al. Aberrant low expression of p85alpha in stromal fibroblasts promotes breast cancer cell metastasis through exosomemediated paracrine Wnt10b. Oncogene. 2017;36(33):4692-4705

[112] Melo SA et al. Cancer exosomes perform cell-independent microRNA biogenesis and promote tumorigenesis. Cancer Cell. 2014;26(5):707-721

[113] Lee JE et al. Identification of EDIL3 on extracellular vesicles involved in breast cancer cell invasion. Journal of Proteomics. 2016;131:17-28

[114] Choi D et al. Extracellular vesicle communication pathways as regulatory targets of oncogenic transformation. Seminars in Cell \& Developmental Biology. 2017;67:11-22

[115] Sleeman JP. The metastatic niche and stromal progression. Cancer Metastasis Reviews. 2012;31(3-4):429-440

[116] Chin AR, Wang SE. Cancer tills the premetastatic field: Mechanistic basis and clinical implications. Clinical Cancer Research. 2016;22(15):3725-3733

[117] Liu Y, Cao X. Characteristics and significance of the pre-metastatic niche. Cancer Cell. 2016;30(5):668-681

[118] de la Fuente A et al. M-Trap: Exosome-based capture of tumor cells as a new technology in peritoneal metastasis. Journal of the National Cancer Institute. 2015;107(9):djv184

[119] Szajnik M et al. Exosomes in plasma of patients with ovarian carcinoma: Potential biomarkers of tumor progression and response to therapy. Gynecology \& Obstetrics. 2013;S4:3

[120] Maia J et al. Exosome-based cell-cell communication in the tumor microenvironment. Frontiers in Cell and Development Biology. 2018;6:18

[121] Zhang Y, Wang XF. A niche role for cancer exosomes in metastasis. Nature Cell Biology. 2015;17(6):709-711

[122] Yang N et al. The role of extracellular vesicles in mediating progression, metastasis and potential treatment of hepatocellular carcinoma. Oncotarget. 2017;8(2):3683-3695

[123] Dhondt B et al. Function of extracellular vesicle-associated miRNAs in metastasis. Cell and Tissue Research. 2016;365(3):621-641

[124] Robado de Lope L et al. Tumouradipose tissue crosstalk: Fuelling tumour metastasis by extracellular vesicles. Philosophical Transactions of the Royal Society of London. Series B, Biological Sciences. 2018;373(1737):20160485

[125] Maji S et al. Exosomal annexin II promotes angiogenesis and breast cancer metastasis. Molecular Cancer Research. 2017;15(1):93-105

[126] Nawaz M et al. Extracellular vesicles in ovarian cancer:

Applications to tumor biology, immunotherapy and biomarker discovery. Expert Review of Proteomics. 2016;13(4):395-409

[127] Liang B et al. Characterization and proteomic analysis of ovarian cancer-derived exosomes. Journal of Proteomics. 2013;80:171-182

[128] Yokoi A et al. Malignant extracellular vesicles carrying MMP1 mRNA facilitate peritoneal 
dissemination in ovarian cancer. Nature Communications. 2017;8:14470

[129] Samuel P et al. Cisplatin induces the release of extracellular vesicles from ovarian cancer cells that can induce invasiveness and drug resistance in bystander cells. Philosophical Transactions of the Royal Society of London. Series B, Biological Sciences. 2018;373(1737):20170065

[130] Yu DD et al. Exosomes in development, metastasis and drug resistance of breast cancer. Cancer Science. 2015;106(8):959-964

[131] Gomes FG et al. Breast-cancer extracellular vesicles induce platelet activation and aggregation by tissue factor-independent and -dependent mechanisms. Thrombosis Research. 2017;159:24-32

[132] O'Brien K et al. Exosomes from triple-negative breast cancer cells can transfer phenotypic traits representing their cells of origin to secondary cells. European Journal of Cancer. 2013;49(8):1845-1859

[133] Li J et al. Claudin-containing exosomes in the peripheral circulation of women with ovarian cancer. BMC Cancer. 2009;9:244

[134] Taylor DD, Gercel-Taylor C. MicroRNA signatures of tumor-derived exosomes as diagnostic biomarkers of ovarian cancer. Gynecologic Oncology. 2008;110(1):13-21

[135] Yin J et al. Secretion of annexin A3 from ovarian cancer cells and its association with platinum resistance in ovarian cancer patients. Journal of Cellular and Molecular Medicine. 2012;16(2):337-348

[136] Jin Y et al. Annexin A3 is a potential predictor of platinum resistance in epithelial ovarian cancer patients in a prospective cohort. Journal of Cancer. 2015;6(7):678-685

[137] Hamrita B et al. Proteomics-based identification of alpha1-antitrypsin and haptoglobin precursors as novel serum markers in infiltrating ductal breast carcinomas. Clinica Chimica Acta. 2009;404(2):111-118

[138] Hannafon BN et al. Plasma exosome microRNAs are indicative of breast cancer. Breast Cancer Research. 2016;18(1):90

[139] Di Modica M et al. Breast cancersecreted miR-939 downregulates VE-cadherin and destroys the barrier function of endothelial monolayers. Cancer Letters. 2017;384:94-100

[140] Kuvibidila S, Rayford W. Correlation between serum prostate-specific antigen and alpha1-antitrypsin in men without and with prostate cancer. The Journal of Laboratory and Clinical Medicine. 2006;147(4):174-181

[141] Khan S et al. Plasma-derived exosomal survivin, a plausible biomarker for early detection of prostate cancer. PLoS One. 2012;7(10):e46737

[142] Huang X et al. Characterization of human plasma-derived exosomal RNAs by deep sequencing. BMC Genomics. 2013;14:319

[143] Huang X et al. Exosomal miR-1290 and miR-375 as prognostic markers in castration-resistant prostate cancer. European Urology. 2015;67(1):33-41

[144] Soekmadji C et al. Extracellular vesicles for personalized therapy decision support in advanced metastatic cancers and its potential impact for prostate cancer. Prostate. 2017;77(14):1416-1423 
[145] Shi R et al. Exosomal levels of miRNA-21 from cerebrospinal fluids associated with poor prognosis and tumor recurrence of glioma patients. Oncotarget. 2015;6(29):26971-26981

[146] Madhavan B et al. Combined evaluation of a panel of protein and miRNA serum-exosome biomarkers for pancreatic cancer diagnosis increases sensitivity and specificity. International Journal of Cancer. 2015;136(11):2616-2627

[147] Lin SY et al. Proteome profiling of urinary exosomes identifies alpha 1-antitrypsin and $\mathrm{H} 2 \mathrm{~B} 1 \mathrm{~K}$ as diagnostic and prognostic biomarkers for urothelial carcinoma. Scientific Reports. 2016;6:34446

[148] Liu T et al. Exosomal long noncoding RNA CRNDE-h as a novel serum-based biomarker for diagnosis and prognosis of colorectal cancer. Oncotarget. 2016;7:85551-85563

[149] Liao J et al. Exosome-shuttling microRNA-21 promotes cell migration and invasion-targeting PDCD4 in esophageal cancer. International Journal of Oncology. 2016;48(6):2567-2579

[150] Matsumura T et al. Exosomal microRNA in serum is a novel biomarker of recurrence in human colorectal cancer. British Journal of Cancer. 2015;113(2):275-281

[151] Smalley DM et al. Isolation and identification of potential urinary microparticle biomarkers of bladder cancer. Journal of Proteome Research. 2008;7(5):2088-2096

[152] Hsu YT et al. EpCAM-regulated transcription exerts influences on nanomechanical properties of endometrial cancer cells that promote epithelial-to-mesenchymal transition. Cancer Research. 2016;76(21):6171-6182
[153] Zhang W et al. Characterization of exosomes derived from ovarian cancer cells and normal ovarian epithelial cells by nanoparticle tracking analysis. Tumour Biology. 2016;37(3):4213-4221

[154] Dumitru A, Toader DO, Cretoiu SM, Cretoiu D, Suciu N, Radu BM. Alterations in Calcium Signaling Pathways in Breast Cancer, Calcium and Signal Transduction. Rijeka: IntechOpen; 2018

[155] Xu M et al. A temporal examination of calcium signaling in cancer- from tumorigenesis, to immune evasion, and metastasis. Cell \& Bioscience. 2018;8:25

[156] Keup C et al. RNA profiles of circulating tumor cells and extracellular vesicles for therapy stratification of metastatic breast cancer patients. Clinical Chemistry. 2018;64(7):1054-1062

[157] Sadovska L, Eglitis J, Line A. Extracellular vesicles as biomarkers and therapeutic targets in breast cancer. Anticancer Research. 2015;35(12):6379-6390

[158] Konig L et al. Elevated levels of extracellular vesicles are associated with therapy failure and disease progression in breast cancer patients undergoing neoadjuvant chemotherapy. Oncoimmunology. 2017;7(1):e1376153

[159] Zitvogel L et al. Eradication of established murine tumors using a novel cell-free vaccine: Dendritic cellderived exosomes. Nature Medicine. 1998;4(5):594-600

[160] Zech D et al. Tumor-exosomes and leukocyte activation: An ambivalent crosstalk. Cell Communication and Signaling: CCS. 2012;10(1):37

[161] Shen C et al. Antileukaemia immunity: Effect of exosomes against NB4 acute promyelocytic leukaemia 
cells. The Journal Of International

Medical Research. 2011;39:740-747

[162] Morse MA et al. A phase I study of dexosome immunotherapy in patients with advanced non-small cell lung cancer. Journal of Translational Medicine. 2005;3(1):9

[163] Escudier B et al. Vaccination of metastatic melanoma patients with autologous dendritic cell (DC) derivedexosomes: Results of thefirst phase I clinical trial. Journal of Translational Medicine. 2005;3(1):10

[164] Dai S et al. Phase I clinical trial of autologous ascites-derived exosomes combined with GM-CSF for colorectal cancer. Molecular Therapy. 2008;16(4):782-790

[165] Munoz JL et al. Delivery of functional Anti-miR-9 by mesenchymal stem cell-derived exosomes to glioblastoma multiforme cells conferred chemosensitivity. Molecular Therapy-Nucleic Acids. 2013;2:e126

[166] Tian Y et al. A doxorubicin delivery platform using engineered natural membrane vesicle exosomes for targeted tumor therapy. Biomaterials. 2014;35(7):2383-2390

[167] Kalani A et al. Curcuminprimed exosomes mitigate endothelial cell dysfunction during hyperhomocysteinemia. Life Sciences. 2014;107(1-2):1-7 


\title{
Part One: Extracellular Vesicles as Valuable Players in Diabetic Cardiovascular Diseases
}

\author{
Mihaela Gherghiceanu, Nicoleta Alexandru, \\ Stefania Lucia Magda, Alina Constantin, Miruna Nemecz, \\ Alexandru Filippi, Octavian Costin Ioghen, \\ Laura Cristina Ceafalan, Florina Bojin, Gabriela Tanko, \\ Virgil Paunescu, Dragos Vinereanu, Ewa Stepien \\ and Adriana Georgescu
}

\begin{abstract}
Extracellular vesicles (EVs) are particles released in the extracellular space from all cell types in physiological and pathological conditions and emerge as a new way of cell-cell communication by transferring their biological contents into target cells. The levels and composition of circulating EVs differ from a normal condition to a pathological one, making them real circulating biomarkers. EVs have a very complex contribution in both health and disease, most likely in relationship between diabetes and cardiovascular disease. The involvement of EVs to the development of cardiovascular complications in diabetes remains an open discussion for therapists. Circulating EVs may offer a continuous access path to circulating information on the disease state and a new perspective in finding a correct diagnosis, in estimating a prognosis and also in applying an effective therapy. Besides their role as biomarkers and targets for therapy, EVs can be exploited as biological tools in influencing the different processes affected in diabetic cardiovascular diseases. This chapter will summarize the current knowledge about EVs as biological vectors modulating diabetic cardiovascular diseases, including atherosclerosis, coronary artery disease, and peripheral arterial disease. Finally, we will point out EVs' considerable value as clinical biomarkers, therapeutic targets, and potential biomedical tools for the discovery of effective therapy in diabetic cardiovascular diseases.
\end{abstract}

Keywords: extracellular vesicles, microvesicles, exosomes, diabetes, cardiovascular disease

\section{Introduction}

Lately, research has been increasingly focused on understanding of the biology of extracellular vesicles (EVs). Finding a more accurate name to define and classify EVs remains an open and, at the same time, a real challenge in the scientific world. 
There are many reasons why it is difficult to find a very precise name for EVs: they are secreted by near all cell types in living organisms; the mechanisms through which they are released into the biological fluids are different and multiple; moreover, they have different sizes (30-2000 $\mathrm{nm}$ in diameter) which make the methods of obtaining and analyzing them to be diverse, but at the same time, some of them are slightly controversial. Once released from the cells, EVs are not inert particles, but they have complex functions in both physiological and pathological processes due to their specific cargo and factors stimulating their secretion. Thus, EVs are now viewed as early noninvasive biomarkers for various disorders in order to establish a correct diagnosis, but they also can be real targets for an effective treatment and, at the same time, valuable tools for treating several diseases such as diabetic cardiovascular diseases.

\section{Terminology and biogenesis pathways of extracellular vesicles}

EVs are a large term used to define a variety of membrane-limited vesicles involved in the intercellular communication. A nomenclature has been proposed but there are still numerous papers using different terms for EVs [1-3]. The EVs comprise different types of vesicles, and based on the size, morphology, and mechanism of biogenesis, they are largely classified as: exosomes and ectosomes, also referred as shedding microvesicles (MVs) or microparticles (MPs) [4].

As for the apoptotic bodies, the researchers' opinions are different; some of them think that they can be included in the EV category and others do not include them. Apoptotic bodies result from cells undergoing programmed cell death (apoptosis) and could be identified in EV probes [5]. The large cellular fragments resulted from apoptosis are phagocyted by neighboring cells and recycled; therefore, they should not be regarded as EVs involved in intercellular communication.

Exosomes (50-100 nm) have been described since 1980s as "exfoliated membrane vesicles," which may serve as a physiologic function occurring in many normal and neoplastic cells [6]. An ultrastructural study [7] showed that about $50 \mathrm{~nm}$ small vesicles are exocyted from multivesicular bodies (MVBs) after receptormediated endocytosis. For reticulocytes, exosomes' exocytosis determines the loss of transferrin receptors during red cell maturation [8].

MVBs (Figure 1A-D) of 0.5-1 $\mu \mathrm{m}$ large vesicles containing 2-50 small intraluminal smaller vesicles belong to the endolysosomal compartment. This pleomorphic cellular compartment comprises early and late endosomes where a highly controlled molecular sorting mechanism drives MVBs to the lysosomes or to the extracellular space. During endosome maturation into late endosomes, inward budding from the limiting membrane of the endosome leads to the formation of intraluminal vesicles in MVBs [9]. Usually, MVBs fuse with lysosomes, the terminal compartment of the endocytic pathway, where they are digested and the final components are recycled. Some MVBs can fuse with the plasma membrane and their intralumenal vesicles are released from cells as exosomes. The process by which the fate of endosomal content is determined is not fully understood [10,11]. Accumulating evidence suggests that the release of EVs often serves as an alternative disposal pathway to the overloaded lysosomes $[12,13]$. This mechanism may be involved in a vascular calcification [14].

It is demonstrated that exosomes are not only cell specific but also they carry RNAs between cells and play major roles in intercellular communication [15]. How 

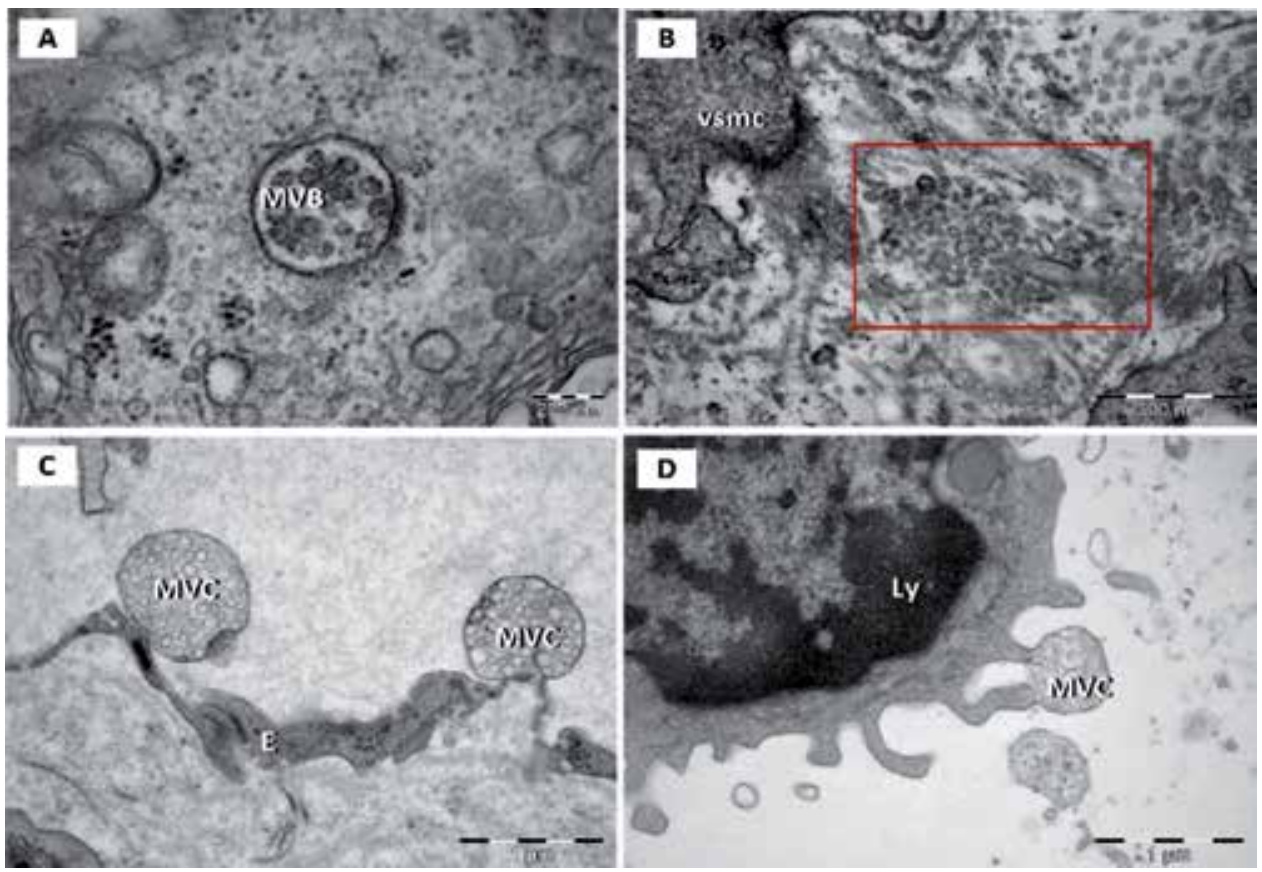

Figure 1.

Transmission electron microscopy of the extracellular vesicles in diabetic kidney. (A) Multivesicular body $(M V B)$ with intraluminal vesicles in the cytoplasm of endothelial cell. (B) Numerous extracellular vesicles (square area) present between vascular smooth muscles cells (VSMCs) in vascular media. (C) Multivesicular cargos $(M V C s)$ released by an endothelial cell $(E)$ into the lumen of a peritubular capillary.

(D) Multivesicular cargos (MVCs) released by a circulating lymphocyte (Ly).

RNAs reach the MVB vesicles is not clear, but it is supposed that cytosolic RNAs are taken up into intraluminal vesicles undergoing inward budding from the limiting membrane of the MVBs $[9,16]$.

Ectosomes (MVs or MPs) are slightly larger vesicles (100-500 nm) compared with exosomes and are also cell specific as they are released from plasma membrane by budding. Ectosomes do not require exocytosis as they are generated by outward budding of a plasma membrane domain, which enclose a cargo gathered at the cytosolic face. The detachment of the ectosomes from the donor cells involves contraction of cortical actin beneath the plasma membrane [17]. These plasma membrane-derived vesicles are also reported to carry RNAs and proteins as an effective mechanism for intercellular communication.

Multivesicular cargos (Figure 1A-D) have also been described as EVs with a particular appearance: clustered vesicles (80-200 nm) shielded by plasma membrane [18]. This type of EVs has been described as mediating bone mineralization [19], vascular calcifications [20], or intercellular communication between telocytes [18], which often surround the vessels [21]. In our experience, endothelial cells (ECs) from diabetic kidney often release multivesicular cargos in the vascular lumen (Figure 1C). Possible mechanism of multivesicular cargo biogenesis based on electron microscopy images $[18,19]$ involves an initial aggregation of vesicles in the cortical cytoplasm which further will bulge a segment of the plasma membrane. Finally, gathered vesicles are released into the extracellular space as a cargo shielded by plasma membrane. The dissolution of the shielding membrane of the multivesicular cargo will release individual or grouped cytoplasmic-derived vesicles into the extracellular space. 


\section{Function of extracellular vesicles in physiology}

\subsection{Physiological role of extracellular vesicles}

EVs are connected to different physiological and pathological processes, such as tumor growth modulation, cytokine production, or cardiovascular disorders [22-24].

EVs contain lipids, and pools of proteins, some specific for the cell type generating them-MHC class I and II, and some which are present in most EVs-proteins from the plasma membrane, cytosol, and endosome. This latest feature suggests the shared biogenesis pathway for these EVs. On the surface of EVs, proteins similar with the ones from the originating cells can be found [25-28]. Different types of nucleic acids such as DNA, small RNA, ribosomal RNA (rRNA), microRNA (miRNA), long noncoding RNA (lncRNA), and mRNA are enclosed within the EVs, which transfer their content into recipient cells, inducing transient or persistent phenotypic changes, which will modify their cellular functions.

According to Barros et al. [25], there are at least four mechanisms by which the EVs can influence the target cells: (1) direct contact between the proteins from the target cell and EV membrane, which changes the intracellular signaling of the recipient cells; (2) cleavage of proteins on the EVs' surface and further interaction between the protein fragments and receptor-proteins on the recipient cell; (3) fusion between EVs and target cell membrane, followed by EV content release within the recipient cell; and (4) internalization of EVs by phagocytosis or endocytosis.

\subsection{Role of extracellular vesicles in immunological response}

The immune response involves participation of innate and adaptive immune system to regulation of body homeostasis, defense, and surveillance, thus maintaining the equilibrium between health and disease.

\subsubsection{Activation of the helper T cells (CD4+)}

Molecules of MHC class II complex are specific to antigen-presenting cells (APCs), such as dendritic cells (DC), macrophages, and B lymphocytes, which present internalized exogenous peptides for the activation of CD4+ T cells. B cells release functional EVs with increased amounts of MHC class II molecules coupled with peptides, which are able to generate $\mathrm{T}$ helper cell response. $\mathrm{T}$ cells are strong stimulators of the EVs' synthesis by B cells due to activation of CD40, and IL-4 receptors [29-31], and the B cell-derived EVs also contain molecules of MHC class I, components of B cell receptor (BCR) - CD19, immunoglobulins, and tetraspanins $[30,31]$. Content of EVs derived from DC, with MHC class II-peptide complexes, contributes to amplification of adaptive immune response [32-34].

\subsubsection{Activation of the cytotoxic Tcells (CD8+)}

Because all nucleated cells express MHC class I molecules, the nucleated cellsderived EVs contain the MHC class I-endogenous/exogenous antigens complexes, thus giving the potential to activate the cytotoxic T cells [35]. These findings were confirmed for the first time by Admyre et al., who demonstrated that monocytederived DC released exosomes capable of inducing antigen-specific immune response from peripheral blood-isolated CD8+ T cells [36]. 


\subsubsection{Immunomodulation induced by EVs}

The production and release of EVs presenting on the surface factors which are capable of triggering apoptotic pathways, such as Fas ligand or galectin 9, can induce immunosuppression. On the other hand, platelet-secreted EVs can induce secretion of pro-inflammatory cytokines, such as IL-8, IL-1 $1 \beta$, and IL-6, thus triggering an inflammatory immune response [37].

\section{Extracellular vesicles as biological vectors modulating diabetic cardiovascular diseases}

\subsection{Role of extracellular vesicles in coronary artery disease}

Individuals with type 2 diabetes mellitus develop cardiovascular disorders, including coronary artery disease, more frequently than healthy controls, mainly through the chronic, damaging exposure of the vascular system to hyperglycemia. Therefore, it is important to understand the exact mechanisms through which diabetes contributes to the development and severity of these complications.

EVs generated in patients with diabetes mellitus promote inflammation and contribute to the development of atherosclerotic lesions, stimulating monocyte adhesion and their infiltration in the subendothelial layer, promoting the migration and proliferation of vascular smooth muscle cells (VSMCs) and also the calcification of the atherosclerotic plaque.

\subsubsection{Extracellular vesicles and the coronary atherosclerotic plaque}

Recent studies have shown that atherosclerotic lesions of all stages contain MVs. Higher levels of circulating MVs have been discovered in individuals with cardiovascular risk factors, such as smoking [38], dyslipidemia [39], diabetes mellitus [40], and arterial hypertension [41], probably through activation or from apoptosis of different cells being exposed to a damaging stimulus. Data extracted from in vitro studies suggest that MVs can have both pro-inflammatory and antiinflammatory effects, depending on the stimulus that induces their formation [42]. MVs increase the release of proinflammatory cytokines, mainly interleukin- 6 and -8 (IL-6 and IL-8), from ECs and leukocytes, promoting the adhesion of monocytes to the endothelium and their migration to the atherosclerotic plaque [42, 43]. Also, endothelial MVs can activate monocytes by transferring miR-10a and thus interfering with the nuclear factor- $\kappa \mathrm{B}$ inflammatory pathway. Another effect of MVs is the decrease of the nitric oxide (NO) production by ECs, consequently impairing endothelial vasodilating properties [44]. Endothelial-derived MVs and platelet-derived MVs increase endothelial permeability by delivering two enzymes (caspase 3 and Rho-kinase) to target cells and inducing apoptosis [45]. MVs promote adhesion of monocytes to the endothelium by increasing endothelial expression of adhesion molecules, such as intercellular adhesion molecule-1 (ICAM-1), or adhesion molecule receptors, such as CD11a, on monocytes [46]. ICAM1 expression can also be regulated by miR-222 in MVs $[42,47]$.

Various MVs contribute to foam cell formation in the atherosclerotic plaque by stimulating lipid and cholesterol formation in macrophages. Macrophages and foam cells undergo afterward apoptosis, forming a core of extracellular lipids. Increased monocyte and macrophage apoptosis contributes to augmented MV release in the plaque. MVs of monocyte and macrophage origin are the largest population of MVs in human atherosclerotic lesions [48]. 
Infiltration of LDL particles in the vascular wall during the atherosclerotic process can induce the formation and release of tissue factor-enriched MVs from the VSMCs, which in turn influence VSMC proliferation and migration [49].

EVs of different origins, with different miRNA content, contribute to VSMC proliferation and migration; for example, MVs with miR-223 induce a decrease in atherosclerotic plaque size by inhibiting VSMS proliferation and migration, while endothelial vesicles with miR-143 and miR-145 prevent VSMC dedifferentiation [50].

\subsection{Role of extracellular vesicles in peripheral arterial disease}

\subsubsection{Atherosclerosis and vascular calcification in diabetes mellitus}

Adipose tissue-derived EVs were shown to have immunomodulatory effects on macrophages which in turn, after contacting said EVs, secreted factors that interfered with insulin signaling in human adipocytes [51]. Moreover, EVs released from adipocytes from obese individuals act in a paracrine manner on neighboring adipocytes and impair insulin-mediated glucose transport [52]. In turn, the exosomes derived from insulin resistant adipocytes carry sonic hedgehog ( $\mathrm{SHH}$ ) protein that increases the expression levels of TNF- $\alpha$, IL-1 $\beta$, IL-6, VEGF-A, ICAM-1, MMP2, and MMP9 in the atheroma plaque and promotes vasa vasorum angiogenesis, leading to greater plaque burden and vulnerability [53]. Thus, EVs provide a link between obesity, low-grade inflammation, insulin resistance, and atherosclerosis progression.

EVs also play a key role in the cross talk between ECs and macrophages that can either act in the direction of vascular homeostasis or promote atherosclerosis, depending on their composition. It was shown that EVs secreted by Kruppel-like factor 2-treated ECs show anti-inflammatory actions, while oxidized-LDLtreated ECs produce EVs with high levels of miR-155, directing macrophage differentiation toward pro-inflammatory M1 macrophages [54]. In M1, but not in M2 macrophages, the inflammasome is known to be activated [55] and the inflammasome signaling leads to the secretion of pro-inflammatory exosomes [56], further favoring atherosclerosis progression. Furthermore, atherosclerotic patients have high numbers of monocyte/macrophage-derived miR-150-rich EVs that enhance EC migration, a major component of atherosclerosis [57]. Thus, circulating endothelial microparticles (EMPs) were shown to be an independent risk factor for endothelial dysfunction which occurs early in atherosclerosis, and the fact that in type 2 diabetes mellitus their number is increased [58] and their miRNA composition is altered containing miRNAs mainly involved in angiogenesis [59] proves the involvement of EVs in cardiovascular complications of diabetes mellitus.

However, exosomes from other sources can alleviate diabetes mellitus as shown at rats treated with exosomes from human umbilical cord derived multipotent mesenchymal stromal cells (MSCs) that have the ability to reverse peripheral insulin resistance and relieve $\beta$-cell destruction [60].

Atherosclerosis, old age, diabetes, and hyperphosphatemia induce VSMC transdifferentiation to osteoblasts [61] characterized as loss of SM22a and SMA markers and gain of Runx2, SP7, osteopontin, osteocalcin, alkaline phosphatase (ALP), transcription factor Sox9, collagen II, and collagen X [62]. These trans-differentiated cells secrete 50-150 nm calcium-phosphorus-rich exosomes that serve as calcification nuclei, in the same manner that osteoblast-secreted matrix vesicles lead to bone mineralization [63]. However, extracellular calcium leads to Fetuin-A uptake in VSMCs mediated by annexins, and high Fetuin-A levels in secreted exosomes prevent further calcification [64]. This control mechanism is affected when Fetuin-A 
levels are low due to chronic dialysis [65] and higher than normal plasma Fetuin-A levels can lead to insulin resistance and diabetes through the direct inhibition of the insulin receptor [66], thus only worsening the cardiovascular diseases (CVDs).

EVs found in intima and media of calcified vascular wall (Figure 2A-D) [14] seem to be different of matrix vesicle with role in physiological and pathological calcification [19]. Vascular cell-derived EVs may serve as a continuous source of damaging microcalcifications in atherosclerotic plaques [20]. These vesicles have been described as exosomes from endosomal compartment, plasma membranederived ectosomes, and vesicles shielded by a plasma membrane (multivesicular cargos) that are released into extracellular space as a cargo [14]. As the first two types are intense investigated and described, the last type derived from multivesicular cargos is less investigated.

\subsection{Role of extracellular vesicles in insulin resistance}

The prevalence of type 2 diabetes is rapidly increasing worldwide, in parallel with the current obesity epidemic, posing a major healthcare expenditure burden. Obesity increases the risk for development of diabetes, cancer, and CVDs. In the course of events leading from obesity to type 2 diabetes, several mechanisms are currently outlined. Among them, low-grade systemic inflammation in adipose tissue of obese persons has been proposed as a possible link between insulin resistance and altered functions of vascular cells by increased cytokines production. Furthermore, it has been shown that the molecules that are released by adipose
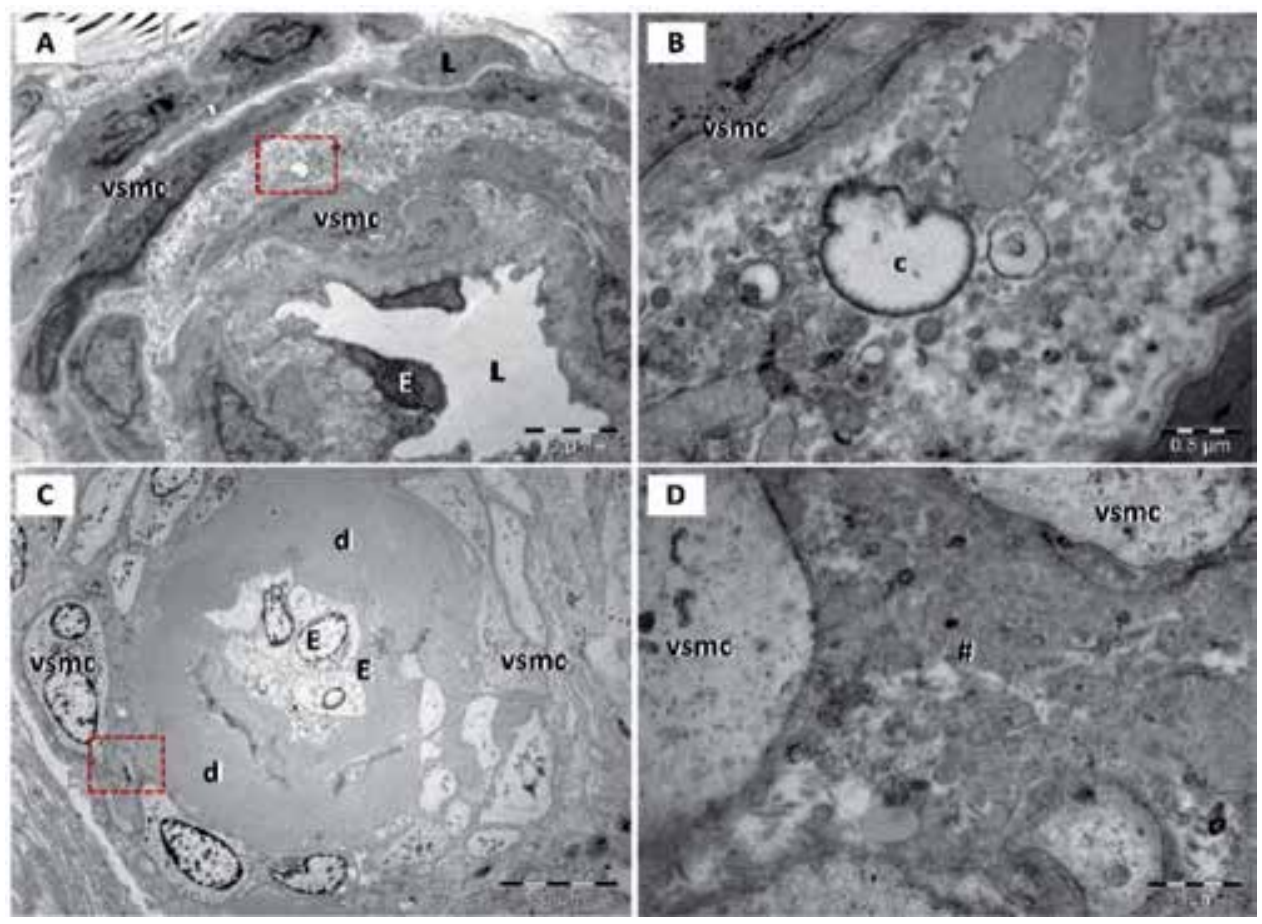

Figure 2.

Transmission electron microscopy of the diabetic arteries in diabetic kidney. (A) Large spaces with vesicular content [square marked area in $(A)$ is magnified in (B)] increase the vascular wall thickness. (B) Numerous extracellular vesicles accumulated between vascular smooth muscles cells (VSMCs) and small calcifications $(c)$ may be seen. (C) Concentric amorphous deposits $(d)$ are located between endothelium (E) and vascular smooth muscle cells (VSMCs). (D) Higher magnification of square marked area in (C) shows also numerous vesicles in the extracellular space (\#) between vascular smooth muscle cells (VSMCs). 
tissue cells into circulation are enclosed in vesicles. EVs derived from adipose tissue may play a role in the paracrine cross talk between adipocytes and macrophages in adipose tissue in obesity [51], and in endocrine manner for transmission of signals to other cells from cardiovascular system [67]. There are the studies that support the idea that EVs are important mediators for metabolic organ cross talk. Thus, it was hypothesized that insulin-secreting beta $(\beta)$ cells and insulin-sensitive tissues release exosomes that can be transferred to other metabolic organs, or to immune or endothelial cells. In this way, in an autocrine or paracrine manner, exosomes influence glucose homeostasis and insulin resistance [68].

When circulating miRNA profile of lean and obese individuals was compared, those miRNAs differentially expressed were predicted to regulate inflammatory and fibrotic signaling pathways [69]. Moreover, in obesity, exosomes from adipose tissue-derived MSCs have reduced pro-angiogenic properties due to decreased content in miR-126, VEGF, and MMP-2. A differential EV proteomic profile has also been observed between obese diabetic and obese nondiabetic rats [70]. In a recent study, the lean mice treated with exosomes from obese mice developed glucose intolerance and insulin resistance. In addition, using exosomes transfected with a specific siRNA targeting PPAR $\alpha$, the phenotype induced by obesity-associated miRNAs was recapitulated. Importantly, it was demonstrated that obesity-associated exosomal miRNAs modulate glucose and lipid metabolism in mice [71].

In type 1 diabetes, the imbalances between effector $\mathrm{T}$ cells and regulatory $\mathrm{T}$ cells, as well as dendritic cell presentation of islet auto-antigens, play an important role in the destruction of islet $\beta$ cells. It has been shown that MVs derived from endothelial progenitor cells (EPCs) combined with islets can activate angiogenesis, decrease leucocyte-endothelial interaction, and improve pancreatic $\beta$ cell function [72]. Another study revealed that insulinoma-released exosomes or MPs are immunostimulatory and can activate autoreactive $\mathrm{T}$ cells spontaneously developed in nonobese diabetic mice [73]. Exosomes could also serve as triggering factors for specific autoimmunity events leading to diabetes, as shown in another study where in NOD mice exosomes released by islet-derived MSCs trigger autoimmune responses [74]. Thus, specific biological roles of EVs are dependent on functional state and the type of cells from which the EVs are released.

\section{Extracellular vesicles as clinical biomarkers, therapeutic targets, and biomedical tools in diabetic cardiovascular diseases}

\subsection{Extracellular vesicles as clinical biomarkers}

Early recognition of prediabetes and diabetes is critical for the prevention or the successful treatment of diabetes-induced cardiovascular complications.

The traditional markers used in clinical practice, such as glycated hemoglobin and glucose determinations, are detected only when diabetes is already established and cannot precisely predict an individual's risk of developing diabetes [75].

Biomarkers for early detection of the disease and identification of individuals at risk of developing complications would greatly improve the care of diabetic patients.

The study of EVs is opening new horizons for their potential application not only as therapeutic tools but also as clinical biomarkers for monitoring disease progression. Even if most clinical data are derived from the studies of tumor patients, increased levels of EVs have been detected in body fluids in a variety of cardiovascular and inflammatory pathologies, obesity, atherosclerosis, diabetes, 
and metabolic syndrome-biomarkers of both incidence and progression diabetic retinopathy in diabetic patients.

Owing to their association with the onset, progression, and pathogenesis of type 2 diabetes, EVs are emerging as a new and attractive class of biomarkers for prognosis, diagnosis, progression/severity, and management of diabetes.

EVs are detectable in most of the body fluids, including blood, and their expression pattern appears to provide valuable information about the functional state of their parental cells [76].

In the study by Sun et al. [77], levels of urinary CD63-positive exosomes were found increased at the early stage of renal injury in diabetic nephropathic subjects.

On the other hand, circulating MPs, in particular platelet-derived microparticles (PMPs) and EMPs, have been found elevated in a wide range of thrombotic disorders, with an interesting relationship between their levels and disease pathophysiology, activity, or progression $[78,79]$. EMP plasma levels have been associated with several CVDs and risk factors. Circulating PMPs are also shown to be involved in the progressive formation of atherosclerotic plaque and development of arterial thrombosis [80, 81], especially in diabetic patients [59]. Indeed, diabetes is characterized by an increased procoagulant state and by a hyperreactive platelet phenotype, with enhanced adhesion, aggregation, and activation. Elevated MP levels, such as TF-positive MPs, have been shown to be one of the procoagulant determinants in patients with type 2 diabetes mellitus [82]. Also, it was demonstrated that EVs participate in the transport of cytokines and angiogenic factors in diabetic patients with ocular complications [83]. Moreover, a recent study showed that distribution of pro- and anti-angiogenic miRNAs in patients with type 2 diabetes is in close touch with the upregulation or downregulation of miRNAs in the plasma fraction enriched in ectosomes (MVs or MPs) [84]. This topic has been widely discussed in a paper by Alexandru et al. [84], in which MPs and MPs-associated miRNAs were presented as active players in vascular complications in diabetes.

More than that, since urinary EVs (UEVs) have been described in diabetic nephropathy ( $\mathrm{DN})$, they immediately became to be proposed and a biomarker in kidney complication $[85,86]$. Patients with DN have exceptionally high rates of cardiovascular morbidity and mortality; thus, there is an emerging need to find the link between the risk of DN and CVD progression.

Owing that urine is an easily accessible fluid sample, UEVs can be obtained in bulk, which make them emerging as a valuable source for disease stage-specific molecular signatures potentially useful in diagnostics. Therefore, UEVs has been proposed to be a novel biomarker in diagnostics, prognosis, and disease progression in diabetic kidney complications [87, 88].

Similar to CVDs, in DN, the profile and concentration of proteases and proteases inhibitors is changing in UEVs. For example, Musante et al. [89] have found that cathepsins (A, C, D, L, and XZP) are significantly increased in UEVs isolated from DN patients. Cathepsins are included to the class of lysosomal proteases and their proteolytic activity is related to ECM remodeling [90]. The proteomic study confirmed that in diabetic UEVs, serine proteases and their inhibitors, including SERPINA1 and SERPINA3, are present [90].

Besides protein cargo, also miRNA UEVs content have some specific features, strongly related to CVD pathomechanism. Barutta et al. showed a differential expression of 22 exosomal miRNAs between micro- and normoalbuminuric patients with DN [91]. Among them, miR-130a has been found to play a critical role in cardiac fibrosis by directly targeting peroxisome proliferator-activated receptor- $\gamma$ (PPAR- $\gamma$ ) [91]. Interestingly, miR-155 was significantly reduced in UEVs from DN patients. This $\mathrm{miR}$ is significantly expressed and secreted in Krüppel-like factor 5 
(KLF5)-overexpressing VSMCs and it is considered as a potent regulator of endothelium barrier function through regulating endothelial targeting tight junction protein expression. In murine model of atherosclerosis, VSMCs-derived exosomes mediated the transfer of miR-155 from VSMCs to ECs, which led to an increased endothelial permeability and enhanced atherosclerotic progression [92]. These data suggest the possible role of UEVs in kidney remodeling, which can bring the new insight into vascular complications and vascular risk in diabetes.

\subsubsection{Therapeutic potential of extracellular vesicles}

According to results from studies from the last 5 to 10 years, EVs could play an important role in different cardiac regenerative therapies and could also be used as therapeutic targets and vectors in cardiovascular medicine.

Platelet-derived vesicles induce vascular endothelial growth factor (VEGF)dependent angiogenesis and stimulate postischemic revascularization after chronic ischemia [93]. Also, plasma-derived exosomes activate Toll-like receptor 4 on cardiomyocytes and thus protect the myocardium from ischemia-reperfusion injury [94]. MSCs-derived EVs could be an alternative to stem cell transplantation after myocardial ischemia by transfer of specific miRNAs through embryonic stem cell EVs [95].

Different cardiovascular medications can influence the level of circulating MVs. Antiplatelet agents (ticlopidine and abciximab) inhibit platelet activation and also the release of platelet-derived MVs [96-98]. Antihypertensive agents (such as angiotensin II receptor inhibitors, beta blockers, and calcium channel blockers) lower the circulating levels of platelet- and monocyte-derived MVs [99]. The effects of statin treatment on circulating MVs of platelet and endothelial origin are still unclear $[100,101]$.

Statins and antihypertensive medication are able to modify the properties of in vivo-generated endothelial MVs and their effect on the expression of endothelial adhesion molecules, inhibiting the adhesion of monocytes to ECs and improving endothelial function [102].

In other words, MVs are now regarded as novel therapeutic targets to monitor the therapeutic response to treatments in diabetic macrovascular complications. The beneficial effects of several drugs, such as statins, antiplatelet agents, antioxidants, angiotensin II receptor blockers, and calcium-channel blockers, have been reported to be partially due to their effects on reduction of both MV numbers and/or procoagulant factors [103]. Moreover, the cardiovascular benefits of antihyperglycemic drugs used to treat type 2 diabetic patients, such as, glibenclamide [104], acarbose [105], miglitol [106], and gliclazide [107], might be at least partially attributed to the anti-atherothrombotic effects of medication, through the decrease of procoagulant MV levels and platelet-activating factors. Pioglitazone treatment reduced the level of circulating endothelial-derived-MVs and increased the level of EPCs and the endothelial-derived MVs/EPCs ratio, improving the imbalance between endothelial damage and repair capacity [108]. Moreover, in our studies on atherosclerotic animal model and patients with hypertension and dyslipidemia, we showed that administration of irbesartan, an AT1 receptor antagonist, decreases the levels of circulating MVs, and also of specific MVs (endothelial-, platelet-, and leukocyte-derived MVs), and increases EPC levels, preventing the appearance of vascular endothelial dysfunction [78]. The mechanisms underlying this response include the reduction/increase of a number of specific membrane receptors exposed by MPs (TF, P-selectin, E-selectin, PSGL-1, Rantes), respectively, by EPCs ( $\beta 2$-Integrins and $\alpha 4 \beta 1$-integrin), the augmentation of endothelium-mediated 
vasodilation and the reduction of protein expression of VEGF/stromal cell-derived factor-1 $\alpha$ (SDF-1 $\alpha)$ [109].

In addition to their role as drug targets, EVs are an attractive drug delivery vehicle. The use of EVs as therapeutic vectors could be done through bioengineering, either by modifying the cytosolic content of the vesicles which could be transferred to the target cells in order to influence cell metabolism, or by loading of EVs with molecules to be delivered to target cells. Studies regarding the use of EVs as therapeutic vectors in CVDs are few and are only on animal models.

EVs present some individual features, which make them promising therapeutic tools, and emphasize EV-based therapies as a promising alternative to cell therapy in cardiovascular medicine. Using EV-based therapeutics avoids biological issues associated with cell-based strategies, such as stress-induced necrosis or aberrant differentiation [110].

Thus, EVs have a particular stability over time conferred by their membranous structures that make them real "off-the-shelf" tools allowing careful maintenance of stability, integrity, and biological activity during their manufacture, storage, and subsequent administration [111]. Moreover, EV lipid bilayer coat protects their bioactive cargo from degradation when they circulate from one cell to another. The small size of EVs, compared to whole cells, also offers therapeutic benefits, such as decreased macrophage phagocytosis and vascular occlusion, and easier injection [110]. Additionally, EVs have innate biocompatibility, low toxicity and immunogenicity, and selective uptake that make them an excellent delivery vehicle for therapeutics [112].

With all these features, at this time, EVs represent attractive nanocarriers for drugs as well as therapeutic small molecules, nucleic acids, and proteins.

In order to enhance the EVs' therapeutic capabilities and applicability, methodologies have been developed for loading them with non-native cargo and also, several targeting strategies for systemically delivery. The two main categories of current strategies are: (i) approaches focused on cellular modification and

(ii) methods focused on direct EV alteration [113].

The most common therapeutic approaches that have used EVs are: (i) to deliver small RNAs attempting to reverse pathological miRNA-based communication with anti-miRNA oligonucleotides or (ii) to stimulate protective communication with synthetic miRNA mimics $[114,115]$. More specific delivery of anti-miRNAs or miRNA mimics to target cells is realized by engineering vesicles with cell-selective surface proteins [116], which should reduce off-target effects. The ability to load EVs with miRNAs suggests the possibility of using EVs to deliver miRNA-based therapeutics in CVDs. The field of miRNA-based therapies is advancing rapidly, and research focused on circulating EVs and their miRNA content has revealed diverse and important roles [112].

However, not many studies have focused their objective in the use of EVs as therapeutic tools against CVDs. In this regard, in a mouse model of type 1 diabetes, it was shown that MSCs-derived EVs delayed the onset of type 1 diabetes through modulation of IL-1 $\beta$-mediated pancreatic B-cell damage [117]. Moreover, EVs secreted by induced pluripotent stem cells deliver cardioprotective miR-21 and miR-210, preventing cardiomyocyte apoptosis in the ischemic myocardium [118].

More information exists in the literature concerning the individual subsets of EVs: exosomes and MVs as therapeutic targets and biomedical tools. For instance, it was reported that cardiomyocytes exert an anti-angiogenic function in type 2 diabetic rats through exosomal transfer of miR-320 into ECs [119]. Further research showed that exosomes derived from cardiomyocytes overexpressing 
heat shock protein 20 (Hsp20) protect against in vitro high glucose-triggered cell death as well as in vivo diabetes mellitus-induced cardiac adverse remodeling, suggesting that Hsp20-engineered exosomes might be a novel promising therapy [120]. Exosomes from human fibrocytes stimulated with platelet-derived growth factor-BB for 7 days and transforming growth factor- $\beta$ for the following 3 days displayed both, in vitro and in vivo, wound healing properties in diabetic $d b / d b$ mice [121]. Although it has been shown that this pharmacological treatment of human fibrocytes increased expressions of miR-126, miR-130a, miR-132, miR124a, miR-125b, and miR-21 into exosomes, the exact mechanism implicated in these effects is still unknown. In addition, administration of mouse brain endothelial cell-derived exosomes, loaded with miR-146a by chemical transfection method, into the brain's ventricle attenuates dementia-like pathology in diabetic $d b / d b$ mice [122].

Several experimental data and preclinical models have demonstrated the excellent potential of stem cell-derived exosomes to be used as therapeutic tools in CVDs [111]. Thus, exosomes enriched with miR-22 secreted by MSCs following ischemic preconditioning was reported to have a significant benefit in cardiac recovery after myocardial infarction, by targeting the methyl $\mathrm{CpG}$ binding protein 2 [123]. Exosomes derived from human MSCs, carrying miR-21-5p, mediates effects on cardiac contractility and calcium handling, likely via PI3K signaling, opening new research ways in optimizing future stem cell-based cardiotherapies [124]. Furthermore, it was shown that exosomes secreted by human cardiosphere-derived cells enriched in miR146a inhibited apoptosis and promoted proliferation of cardiomyocytes, improving in this way angiogenesis. In another study, it has been showed that in cardiomyocytes cultured in a hypoxic environment, GATA-4 overexpressing MSCs-derived exosomes contribute to increased cardiomyocyte survival, reduced cardiomyocyte apoptosis, and preserved mitochondrial membrane potential [125]. Importantly, the use of exosomes isolated from MSCs for the reduction of inflammatory state during type 1 diabetes mellitus is mentioned into an Egyptian clinical trial (phase II-III, NCT02138331) [126].

In addition, it has been demonstrated that abnormal miRNA expression in MVs is involved in neoangiogenesis: (i) diminished expression of miRNA-200b reduces VEGF levels [127] and (ii) augmented expression of miR-29b regulates certain apoptotic genes and increases VEGF levels [128]. These data suggested that acting on these miRNA levels in MVs may control cell proliferation in diabetic retinopathy. Likewise, MVs cargo with miR-126 play an important role in angiogenesis and vascular integrity [129], while administration of the miR-126-enriched MVs to ApoE-/- mice could reduce the development of aortic plaques of atherosclerosis [130]. Importantly, it has been shown that MVs derived from EPCs, carrying specific miRNAs, activate angiogenesis through phosphatidylinositol 3 kinase/protein kinase B signaling pathway [129]. MVs derived from human acute monocytic leukemia cell line (THP-1 cells) treated by inflammatory factors contain miR-150 which may be involved in EC migration [226]. In a recent study, we showed that MVs of healthy origins promote EPC proliferation, adhesion, and migration, supporting reestablishment of EPC ability to incorporate in damaged endothelium and working in concert with existing ECs to form blood vessels [131]. These beneficial effects of MVs on late EPC dysfunctionality in atherosclerosis could be explained by the ability of MVs to transfer specific miRNA (miR-10a, miR21, miR-126, miR-146a, and miR-223) into recipient cells and by insulin-like growth factor- 1 expression activation [228].

Data summary concerning exosome and MV charge and their therapeutic effects are presented in the Table 1. 
Part One: Extracellular Vesicles as Valuable Players in Diabetic Cardiovascular Diseases

DOI: http://dx.doi.org/10.5772/intechopen.85225

\begin{tabular}{|c|c|c|c|c|}
\hline $\begin{array}{l}\text { Exosome } \\
\text { charge }\end{array}$ & Exosome source & Recipient & Therapeutic effects & Reference \\
\hline $\operatorname{miR}-320$ & $\begin{array}{l}\text { Rat } \\
\text { cardiomyocytes }\end{array}$ & $\begin{array}{l}\text { Cardiac endothelial } \\
\text { cells }\end{array}$ & $\begin{array}{l}\text { Decreases } \\
\text { angiogenesis in type } 2 \\
\text { diabetes }\end{array}$ & [119] \\
\hline Hsp20 & $\begin{array}{l}\text { Mouse } \\
\text { cardiomyocytes }\end{array}$ & Endothelial cells & $\begin{array}{l}\text { Improves cardiac } \\
\text { function and } \\
\text { angiogenesis in } \\
\text { diabetes }\end{array}$ & {$[120]$} \\
\hline $\begin{array}{l}\text { miR-126, } \\
\text { miR-130a, } \\
\text { miR-132, } \\
\text { miR124a, } \\
\text { miR-125b, } \\
\text { miR-21 }\end{array}$ & Human fibrocytes & $\begin{array}{l}\text { Dermal fibroblasts, } \\
\text { keratinocytes }\end{array}$ & $\begin{array}{l}\text { Accelerate diabetic } \\
\text { wound healing }\end{array}$ & {$[121]$} \\
\hline miR-146a & $\begin{array}{l}\text { Mouse brain } \\
\text { endothelial cell }\end{array}$ & Brain's ventricles & $\begin{array}{l}\text { Attenuates dementia- } \\
\text { like pathology in } \\
\text { diabetes }\end{array}$ & {$[122]$} \\
\hline $\begin{array}{l}\operatorname{miR}-21 \\
\operatorname{miR}-210\end{array}$ & iPSCs & Cardiomyocytes & $\begin{array}{l}\text { Rescue ischemic } \\
\text { cardiomyocytes }\end{array}$ & {$[118]$} \\
\hline $\operatorname{miR}-22$ & hMSCs & Cardiomyocytes & $\begin{array}{l}\text { Enhances cardiac } \\
\text { function }\end{array}$ & {$[123]$} \\
\hline miR-19a & hMSCs & Cardiomyocytes & $\begin{array}{l}\text { Restores cardiac } \\
\text { contractile function } \\
\text { and reduces infarct } \\
\text { size }\end{array}$ & {$[125]$} \\
\hline miR-21-5p & hMSCs & $\begin{array}{l}\text { iPSCs-derived } \\
\text { cardiomyocytes } \\
\text { and iPSCs-derived } \\
\text { fibroblasts }\end{array}$ & $\begin{array}{l}\text { Increases engineered } \\
\text { cardiac tissue } \\
\text { contractility via PI3K } \\
\text { signaling }\end{array}$ & [124] \\
\hline MV charge & MV source & Recipient & Therapeutic effects & Reference \\
\hline miR-126 & ECs & $\begin{array}{l}\text { Vascular cells from } \\
\mathrm{ApoE}^{-} /^{-} \text {mice }\end{array}$ & $\begin{array}{l}\text { Reduces the } \\
\text { development of } \\
\text { aortic plaques of } \\
\text { atherosclerosis }\end{array}$ & [130] \\
\hline mRNAs & EPCs & hMECs & $\begin{array}{l}\text { Activates } \\
\text { angiogenesis through } \\
\text { phosphatidylinositol } 3 \\
\text { kinase/protein kinase } \\
\text { B signaling pathway }\end{array}$ & [129] \\
\hline $\operatorname{miR}-150$ & THP- 1 cells & hMECs & $\begin{array}{l}\text { Modulates endothelial } \\
\text { cell migration }\end{array}$ & [129] \\
\hline $\begin{array}{l}\operatorname{miR}-10 a \\
\text { miR21, } \\
\text { miR-126, } \\
\text { miR-146a, } \\
\text { miR-223 }\end{array}$ & $\begin{array}{l}\text { Plasma from } \\
\text { healthy hamsters }\end{array}$ & Late EPCs & $\begin{array}{l}\text { Promote EPC } \\
\text { proliferation, } \\
\text { adhesion and } \\
\text { migration in } \\
\text { atherosclerosis }\end{array}$ & {$[131]$} \\
\hline \multicolumn{5}{|c|}{$\begin{array}{l}\text { iPSCs, induced pluripotent stem cells; hMSCs, human mesenchymal stem cells; ECs, endothelial cells; EPCs, endothelia } \\
\text { progenitor cells; hMECs, human microvascular endothelial cells; and THP-1 cells, human acute monocytic leukemia } \\
\text { cell line. }\end{array}$} \\
\hline
\end{tabular}

Table 1.

Exosome and MV charge components and their therapeutic effects in diabetes and CVDs. 


\section{Progress and challenges in extracellular vesicle field}

Although research into EV field is gaining ground, some challenges need to be overcome before using them in the clinic, such as: (i) optimization of EV isolation procedures, especially the time of protocols, decrease of amount of samples, and the selective isolation of distinct EV subtypes; (ii) the large-scale production in good manufacturing conditions; and (iii) increase of the specificity of engineered EVs vis-à-vis target cells to avoid the possible side effects [126].

Additionally, much still remains to be revealed regarding the role of EVs in cell-cell communication both in health and diabetic cardiovascular disorders. Specifically, understanding the effects of the chronic inflammatory environment in diabetes on the packaging and release of endothelial-EVs and their following interactions with cardiomyocytes could be useful [112]. Advancing the knowledge regarding the cellular source and destination of EVs in CVDs will allow exploration of the specific cellular interactions, while understanding EV organ-tropism will help to target specific tissues, improving the efficiency of miRNA-based therapies.

Even so, with many problems remaining to be resolved, as we mentioned above, prior EV-based therapeutics might be clinically used to treat CVDs. Anywise, the many studies underline their potential as successful therapeutic targets in combatting the heavy millstone of metabolic disease [112].

\section{Conclusions}

Overall, our chapter strongly suggests that EVs may function as significant regulators of both physiological and pathological conditions and demonstrates their universal role in the relationship between diabetes and cardiovascular disease. Their unique properties as biological vectors modulating diabetic cardiovascular diseases, including atherosclerosis, coronary artery disease, and peripheral arterial disease, are also highlighted.

Undoubtedly, elucidation of terminology, biogenesis, biological content, and function of EVs contributes to better understanding of the complexity of their role in influencing the different processes affected in diabetic cardiovascular diseases. Consequently, we envisage that for EVs used as clinical biomarkers, therapeutic targets, and biomedical tools in diabetes and associated complications, there is a need for developing a molecular system of EVs based on their lipidomic, metabolomic, and miRnomic signature. Once these issues are clarified, preventative and therapeutic strategies can be implemented and further developed.

Despite the fact that existing literature discussed in this chapter describes the EV importance in diabetic cardiovascular diseases, it also leaves some significant questions unanswered. Thus, it becomes increasingly complicated to establish an EV structure either beneficial or harmful, to clarify their role either good or bad, in both health and disease. Incontestably, more research evaluating such properties is necessary to establish EVs' value as clinical biomarkers, therapeutic targets, and biomedical tools based on concrete scientific results for diabetic cardiovascular disease treatment.

\section{Acknowledgements}

The authors are grateful to the work supported by grants of the Romanian National Authority for Scientific Research, CNCS-UEFISCDI, project no. PN-IIIP1-1.2-PCCDI-2017-0527, project no. PN-III-P1-1.2-PCCDI-2017-0797, and by the Romanian Academy. 


\section{Conflict of interest}

The authors declare that the research was conducted in the absence of any either commercial or financial relationships that could be construed as a potential conflict of interest.

\section{Author details}

Mihaela Gherghiceanu ${ }^{1,2}$, Nicoleta Alexandru ${ }^{3}$, Stefania Lucia Magda ${ }^{2,4}$, Alina Constantin ${ }^{3}$, Miruna Nemecz ${ }^{3}$, Alexandru Filippi ${ }^{3}$, Octavian Costin Ioghen ${ }^{1,2}$, Laura Cristina Ceafalan ${ }^{1,2}$, Florina Bojin ${ }^{5,6}$, Gabriela Tanko ${ }^{3}$, Virgil Paunescu ${ }^{5,6}$, Dragos Vinereanu ${ }^{2,4}$, Ewa Stepien ${ }^{7}$ and Adriana Georgescu ${ }^{3 *}$

1 Victor Babeș National Institute of Pathology, Bucharest, Romania

2 Carol Davila University of Medicine, Bucharest, Romania

3 Pathophysiology and Pharmacology Department, Institute of Cellular Biology and Pathology 'Nicolae Simionescu' of Romanian Academy, Bucharest, Romania

4 Cardiology Department, University and Emergency Hospital, Bucharest, Romania

5 Department of Functional Sciences, 'Victor Babes' University of Medicine and Pharmacy, Timisoara, Romania

6 'Pius Brinzeu' Clinical Emergency County Hospital, OncoGen-Center for Gene and Cellular Therapies in the Treatment of Cancer, Timisoara, Romania

7 Department of Medical Physics, M. Smoluchowski Institute of Physics, Jagiellonian University, Kraków, Poland

*Address all correspondence to: adriana.georgescu@icbp.ro

\section{IntechOpen}

(C) 2019 The Author(s). Licensee IntechOpen. This chapter is distributed under the terms of the Creative Commons Attribution License (http://creativecommons.org/licenses/ by/3.0), which permits unrestricted use, distribution, and reproduction in any medium, provided the original work is properly cited. (cc) BY 


\section{References}

[1] Gould SJ, Raposo G. As we wait: Coping with an imperfect nomenclature for extracellular vesicles. Journal of Extracellular Vesicles. 2013;2:1-3. DOI: 10.3402/jev.v2i0.20389

[2] Cocucci E, Meldolesi J. Ectosomes and exosomes: Shedding the confusion between extracellular vesicles. Trends in Cell Biology. 2015;25:364-372. DOI: 10.1016/j.tcb.2015.01.004

[3] van der Pol E, Boing AN, Gool EL, Nieuwland R. Recent developments in the nomenclature, presence, isolation, detection and clinical impact of extracellular vesicles. Journal of Thrombosis and Haemostasis. 2016;14:48-56. DOI: 10.1111/jth.13190

[4] Alexandru N, Costa A, Constantin A, Cochior D, Georgescu A. Microparticles: From biogenesis to biomarkers and diagnostic tools in cardiovascular disease. Current Stem Cell Research \& Therapy. 2017;12:89-102. DOI: 10.2174/1 574888X11666151203224058

[5] Hauser P, Wang S, Didenko VV. Apoptotic bodies: Selective detection in extracellular vesicles. Methods in Molecular Biology. 2017;1554:193-200. DOI: 10.1007/978-1-4939-6759-9_12

[6] Trams EG, Lauter CJ, Salem N Jr, Heine U. Exfoliation of membrane ecto-enzymes in the form of microvesicles. Biochimica et Biophysica Acta. 1981;645:63-70

[7] Pan BT, Teng K, Wu C, Adam M, Johnstone RM. Electron microscopic evidence for externalization of the transferrin receptor in vesicular form in sheep reticulocytes. The Journal of Cell Biology. 1985;101:942-948

[8] Johnstone RM, Adam M, Hammond JR, Orr L, Turbide C. Vesicle formation during reticulocyte maturation. Association of plasma membrane activities with released vesicles (exosomes). The Journal of Biological Chemistry. 1987;262:9412-9420

[9] Frankel EB, Audhya A. ESCRTdependent cargo sorting at multivesicular endosomes. Seminars in Cell \& Developmental Biology. 2018;74:4-10. DOI: 10.1016/j. semcdb.2017.08.020

[10] Baixauli F, Lopez-Otin C, Mittelbrunn M. Exosomes and autophagy: Coordinated mechanisms for the maintenance of cellular fitness. Frontiers in Immunology. 2014;5:403. DOI: $10.3389 /$ fimmu.2014.00403

[11] Palmulli R, van Niel G. To be or not to be... secreted as exosomes, a balance finely tuned by the mechanisms of biogenesis. Essays in Biochemistry. 2018;62:177-191. DOI: 10.1042/ EBC20170076

[12] Eitan E, Suire C, Zhang S, Mattson MP. Impact of lysosome status on extracellular vesicle content and release. Ageing Research Reviews. 2016;32:65-74. DOI: 10.1016/j. arr.2016.05.001

[13] Xu J, Camfield R, Gorski SM. The interplay between exosomes and autophagy_-Partners in crime. Journal of Cell Science. 2018;131:1-11. DOI: 10.1242/jcs. 215210

[14] Aikawa E. Extracellular vesicles in cardiovascular disease: Focus on vascular calcification. The Journal of Physiology. 2016;594:2877-2880. DOI: 10.1113/JP272112

[15] Mathieu M, Martin-Jaular L, Lavieu G, Thery C. Specificities of secretion and uptake of exosomes and other extracellular vesicles for 
cell-to-cell communication. Nature Cell Biology. 2019;21:9-17. DOI: 10.1038/ s41556-018-0250-9

[16] Janas T, Janas MM, Sapon K, Janas T. Mechanisms of RNA loading into exosomes. FEBS Letters. 2015;589: 1391-1398. DOI: 10.1016/j.febslet. 2015.04.036

[17] Meldolesi J. Exosomes and ectosomes in intercellular communication. Current Biology: CB. 2018;28:R435-R444. DOI: 10.1016/j.cub.2018.01.059

[18] Fertig ET, Gherghiceanu M, Popescu LM. Extracellular vesicles release by cardiac telocytes: Electron microscopy and electron tomography. Journal of Cellular and Molecular Medicine. 2014;18:1938-1943. DOI: 10.1111/jcmm.12436

[19] Xiao Z, Blonder J, Zhou M, Veenstra TD. Proteomic analysis of extracellular matrix and vesicles. Journal of Proteomics. 2009;72:34-45. DOI: 10.1016/j.jprot.2008.11.011

[20] Hutcheson JD, Aikawa E. Extracellular vesicles in cardiovascular homeostasis and disease. Current Opinion in Cardiology. 2018;33:290-297. DOI: $10.1097 / \mathrm{HCO} .0000000000000510$

[21] Gherghiceanu M, Popescu LM. Cardiac telocytes-their junctions and functional implications. Cell and Tissue Research. 2012;348:265-279. DOI: 10.1007/s00441-012-1333-8

[22] Lawson C, Vicencio JM, Yellon DM, Davidson SM. Microvesicles and exosomes: New players in metabolic and cardiovascular disease. The Journal of Endocrinology. 2016;228:R57-R71. DOI: 10.1530/JOE-15-0201

[23] Baroni S, Romero-Cordoba S, Plantamura I, Dugo M, D'Ippolito E, Cataldo A, et al. Exosomemediated delivery of miR-9 induces cancer-associated fibroblast-like properties in human breast fibroblasts. Cell Death \& Disease. 2016;7:e2312. DOI: $10.1038 /$ cddis.2016.224

[24] Blin J, Fitzgerald KA. Perspective: The RNA exosome, cytokine gene regulation and links to autoimmunity. Cytokine. 2015;74:175-180. DOI: 10.1016/j.cyto.2015.03.005

[25] Barros FM, Carneiro F, Machado JC, Melo SA. Exosomes and immune response in cancer: Friends or foes? Frontiers in Immunology. 2018;9:730. DOI: 10.3389/ fimmu.2018.00730

[26] Silva M, Melo SA. Non-coding RNAs in exosomes: New players in cancer biology. Current Genomics. 2015;16:295-303. DOI: 10.2174/13892029 16666150707154719

[27] Colombo M, Raposo G, Thery C. Biogenesis, secretion, and intercellular interactions of exosomes and other extracellular vesicles. Annual Review of Cell and Developmental Biology. 2014;30:255-289. DOI: $10.1146 /$ annurev-cellbio-101512-122326

[28] Anand PK. Exosomal membrane molecules are potent immune response modulators. Communicative \& Integrative Biology. 2010;3:405-408. DOI: $10.4161 /$ cib.3.5.12474

[29] Muntasell A, Berger AC, Roche PA. $\mathrm{T}$ cell-induced secretion of MHC class II-peptide complexes on B cell exosomes. The EMBO Journal. 2007;26:4263-4272. DOI: 10.1038/ sj.emboj.7601842

[30] Saunderson SC, Schuberth PC, Dunn AC, Miller L, Hock BD, MacKay PA, et al. Induction of exosome release in primary $\mathrm{B}$ cells stimulated via CD40 and the IL-4 receptor. Journal of Immunology. 2008;180:8146-8152 
[31] Arita S, Baba E, Shibata Y, Niiro H, Shimoda S, Isobe T, et al. $\mathrm{B}$ cell activation regulates exosomal HLA production. European Journal of Immunology. 2008;38:1423-1434. DOI: 10.1002/eji.200737694

[32] Chaput N, Thery C. Exosomes: Immune properties and potential clinical implementations. Seminars in Immunopathology. 2011;33:419-440. DOI: $10.1007 / \mathrm{s} 00281-010-0233-9$

[33] Segura E, Nicco C, Lombard B, Veron P, Raposo G, Batteux F, et al. ICAM-1 on exosomes from mature dendritic cells is critical for efficient naive T-cell priming. Blood. 2005;106:216-223. DOI: 10.1182/ blood-2005-01-0220

[34] Pitt JM, Andre F, Amigorena S, Soria JC, Eggermont A, Kroemer G, et al. Dendritic cell-derived exosomes for cancer therapy. The Journal of Clinical Investigation. 2016;126: 1224-1232. DOI: 10.1172/JCI81137

[35] Thery C, Zitvogel L, Amigorena S. Exosomes: Composition, biogenesis and function. Nature Reviews. Immunology. 2002;2:569-579. DOI: $10.1038 /$ nri855

[36] Admyre C, Johansson SM, Paulie S, Gabrielsson S. Direct exosome stimulation of peripheral human T cells detected by ELISPOT. European Journal of Immunology. 2006;36:1772-1781. DOI: 10.1002/eji.200535615

[37] Libby P. Inflammation in atherosclerosis. Arteriosclerosis, Thrombosis, and Vascular Biology. 2012;32:2045-2051. DOI: 10.1161/ ATVBAHA.108.179705

[38] Gordon C, Gudi K, Krause A, Sackrowitz R, Harvey BG, StruloviciBarel Y, et al. Circulating endothelial microparticles as a measure of early lung destruction in cigarette smokers.
American Journal of Respiratory and Critical Care Medicine. 2011;184:224-232. DOI: $10.1164 / \mathrm{rccm} .201012-20610 \mathrm{C}$

[39] Ferreira AC, Peter AA, Mendez AJ, Jimenez JJ, Mauro LM, Chirinos JA, et al. Postprandial hypertriglyceridemia increases circulating levels of endothelial cell microparticles. Circulation. 2004;110:3599-3603. DOI: 10.1161/01. CIR.0000148820.55611.6B

[40] Sabatier F, Darmon P, Hugel B, Combes V, Sanmarco M, Velut JG, et al. Type 1 and type 2 diabetic patients display different patterns of cellular microparticles. Diabetes. 2002;51:2840-2845

[41] Preston RA, Jy W, Jimenez JJ, Mauro LM, Horstman LL, Valle M, et al. Effects of severe hypertension on endothelial and platelet microparticles. Hypertension. 2003;41:211-217

[42] Boulanger CM, Loyer X, Rautou PE, Amabile N. Extracellular vesicles in coronary artery disease. Nature Reviews. Cardiology. 2017;14:259-272. DOI: 10.1038/nrcardio.2017.7

[43] Nomura S, Tandon NN, Nakamura T, Cone J, Fukuhara S, Kambayashi J. High-shear-stressinduced activation of platelets and microparticles enhances expression of cell adhesion molecules in THP-1 and endothelial cells. Atherosclerosis. 2001;158:277-287

[44] Boulanger CM, Scoazec A, Ebrahimian T, Henry P, Mathieu E, Tedgui A, et al. Circulating microparticles from patients with myocardial infarction cause endothelial dysfunction. Circulation. 2001;104:2649-2652

[45] Edrissi H, Schock SC, Hakim AM, Thompson CS. Microparticles generated during chronic cerebral 
ischemia increase the permeability of microvascular endothelial barriers in vitro. Brain Research. 2016;1634:83-93. DOI: 10.1016/j.brainres.2015.12.032

[46] Barry OP, Pratico D, Savani RC, FitzGerald GA. Modulation of monocyte-endothelial cell interactions by platelet microparticles. The Journal of Clinical Investigation. 1998;102: 136-144. DOI: 10.1172/JCI2592

[47] Jansen F, Yang X, Baumann K, Przybilla D, Schmitz T, Flender A, et al. Endothelial microparticles reduce ICAM-1 expression in a microRNA222-dependent mechanism. Journal of Cellular and Molecular Medicine. 2015;19:2202-2214. DOI: 10.1111/ jcmm.12607

[48] Leroyer AS, Isobe $H$, Leseche $G$, Castier Y, Wassef M, Mallat Z, et al. Cellular origins and thrombogenic activity of microparticles isolated from human atherosclerotic plaques. Journal of the American College of Cardiology. 2007;49:772-777. DOI: $10.1016 / j$. jacc.2006.10.053

[49] Brousseau C, Morissette G, Fortin JP, Marceau F, Petitclerc E. Tumor cells expressing tissue factor influence the migration of smooth muscle cells in a catalytic activitydependent way. Canadian Journal of Physiology and Pharmacology. 2009;87:694-701. DOI: 10.1139/y09-063

[50] Shan Z, Qin S, Li W, Wu W, Yang J, Chu M, et al. An endocrine genetic signal between blood cells and vascular smooth muscle cells: Role of microRNA-223 in smooth muscle function and atherogenesis. Journal of the American College of Cardiology. 2015;65:2526-2537. DOI: 10.1016/j. jacc. 2015.03 .570

[51] Kranendonk ME, Visseren FL, van Balkom BW, Nolte-'t Hoen EN, van Herwaarden JA, de Jager W, et al. Human adipocyte extracellular vesicles in reciprocal signaling between adipocytes and macrophages. Obesity. 2014;22:1296-1308. DOI: 10.1002/ oby.20679

[52] Mleczko J, Ortega FJ, Falcon-Perez JM, Wabitsch M, Fernandez-Real JM, Mora S. Extracellular vesicles from hypoxic adipocytes and obese subjects reduce insulin-stimulated glucose uptake. Molecular Nutrition \& Food Research. 2018;62:1-6. DOI: 10.1002/ mnfr.201700917

[53] Wang F, Chen FF, Shang YY, Li Y, Wang ZH, Han L, et al. Insulin resistance adipocyte-derived exosomes aggravate atherosclerosis by increasing vasa vasorum angiogenesis in diabetic ApoE(-/-) mice. International Journal of Cardiology. 2018;265:181-187. DOI: 10.1016/j.ijcard.2018.04.028

[54] He S, Wu C, Xiao J, Li D, Sun Z, Li M. Endothelial extracellular vesicles modulate the macrophage phenotype: Potential implications in atherosclerosis. Scandinavian Journal of Immunology. 2018;87:e12648. DOI: 10.1111/sji.12648

[55] Awad F, Assrawi E, Jumeau C, Georgin-Lavialle S, Cobret L, Duquesnoy $\mathrm{P}$, et al. Impact of human monocyte and macrophage polarization on NLR expression and NLRP3 inflammasome activation. PLoS One. 2017;12:e0175336. DOI: 10.1371/journal.pone.0175336

[56] Zhang Y, Liu F, Yuan Y, Jin C, Chang C, Zhu Y, et al. Inflammasomederived exosomes activate NF-kappaB signaling in macrophages. Journal of Proteome Research. 2017;16:170-178. DOI: 10.1021/acs.jproteome.6b00599

[57] Zhang Y, Liu D, Chen X, Li J, Li L, Bian Z, et al. Secreted monocytic miR150 enhances targeted endothelial cell migration. Molecular Cell. 2010;39: 133-144. DOI: 10.1016/j.molcel. 2010.06.010 
[58] Feng B, Chen Y, Luo Y, Chen M, Li X, Ni Y. Circulating level of microparticles and their correlation with arterial elasticity and endotheliumdependent dilation in patients with type 2 diabetes mellitus. Atherosclerosis. 2010;208:264-269. DOI: 10.1016/j. atherosclerosis.2009.06.037

[59] Stepien EL, Durak-Kozica M, Kaminska A, Targosz-Korecka M, Libera M, Tylko G, et al. Circulating ectosomes: Determination of angiogenic microRNAs in type 2 diabetes. Theranostics. 2018;8:3874-3890. DOI: 10.7150/thno.23334

[60] Sun Y, Shi H, Yin S, Ji C, Zhang X, Zhang B, et al. Human mesenchymal stem cell derived exosomes alleviate type 2 diabetes mellitus by reversing peripheral insulin resistance and relieving beta-cell destruction. ACS Nano. 2018;12:7613-7628. DOI: 10.1021/ acsnano.7b07643

[61] Jono S, McKee MD, Murry CE, Shioi A, Nishizawa Y, Mori K, et al. Phosphate regulation of vascular smooth muscle cell calcification. Circulation Research. 2000;87:E10-E17

[62] Durham AL, Speer MY, Scatena M, Giachelli CM, Shanahan CM. Role of smooth muscle cells in vascular calcification: Implications in atherosclerosis and arterial stiffness. Cardiovascular Research. 2018;114: 590-600. DOI: $10.1093 / \mathrm{cvr} / \mathrm{cvy} 010$

[63] Ahmed S, O’Neill KD, Hood AF, Evan AP, Moe SM. Calciphylaxis is associated with hyperphosphatemia and increased osteopontin expression by vascular smooth muscle cells. American Journal of Kidney Diseases: The Official Journal of the National Kidney Foundation. 2001;37:1267-1276

[64] Chen NX, O’Neill KD, Chen X, Moe SM. Annexin-mediated matrix vesicle calcification in vascular smooth muscle cells. Journal of Bone and Mineral Research: The Official Journal of the American Society for Bone and Mineral Research. 2008;23:1798-1805. DOI: $10.1359 /$ jbmr.080604

[65] Shroff RC, Shah V, Hiorns MP, Schoppet M, Hofbauer LC, Hawa G, et al. The circulating calcification inhibitors, fetuin-A and osteoprotegerin, but not matrix Gla protein, are associated with vascular stiffness and calcification in children on dialysis. Nephrology Dialysis Transplantation. 2008;23:3263-3271. DOI: $10.1093 / \mathrm{ndt} / \mathrm{gfn} 226$

[66] Srinivas PR, Wagner AS, Reddy LV, Deutsch DD, Leon MA, Goustin AS, et al. Serum alpha 2-HS-glycoprotein is an inhibitor of the human insulin receptor at the tyrosine kinase level. Molecular Endocrinology. 1993;7:1445-1455. DOI: $10.1210 /$ mend.7.11.7906861

[67] Thomou T, Mori MA, Dreyfuss JM, Konishi M, Sakaguchi M, Wolfrum C, et al. Adipose-derived circulating miRNAs regulate gene expression in other tissues. Nature. 2017;542:450-455. DOI: $10.1038 /$ nature21365

[68] Guay C, Regazzi R. Exosomes as new players in metabolic organ crosstalk. Diabetes, Obesity \& Metabolism. 2017;19(Suppl 1):137-146. DOI: 10.1111/ dom.13027

[69] Ferrante SC, Nadler EP, Pillai DK, Hubal MJ, Wang Z, Wang JM, et al. Adipocyte-derived exosomal miRNAs: A novel mechanism for obesityrelated disease. Pediatric Research. 2015;77:447-454. DOI: 10.1038/ pr.2014.202

[70] Lee JE, Moon PG, Lee IK, Baek MC. Proteomic analysis of extracellular vesicles released by adipocytes of Otsuka long-Evans tokushima fatty (OLETF) rats. The Protein Journal. 2015;34:220-235. DOI: $10.1007 /$ s10930-015-9616-z 
[71] Castano C, Kalko S, Novials A, Parrizas M. Obesity-associated exosomal miRNAs modulate glucose and lipid metabolism in mice. Proceedings of The National Academy of Sciences of the United States of America. 2018;115:12158-12163. DOI: 10.1073/pnas.1808855115

[72] Cantaluppi V, Biancone L, Figliolini F, Beltramo S, Medica D, Deregibus MC, et al. Microvesicles derived from endothelial progenitor cells enhance neoangiogenesis of human pancreatic islets. Cell Transplantation. 2012;21:1305-1320. DOI: 10.3727/096368911X627534

[73] Sheng H, Hassanali S, Nugent C, Wen L, Hamilton-Williams E, Dias P, et al. Insulinoma-released exosomes or microparticles are immunostimulatory and can activate autoreactive $T$ cells spontaneously developed in nonobese diabetic mice. Journal of Immunology. 2011;187:1591-1600. DOI: 10.4049/ jimmunol.1100231

[74] Rahman MJ, Regn D, Bashratyan R, Dai YD. Exosomes released by isletderived mesenchymal stem cells trigger autoimmune responses in NOD mice. Diabetes. 2014;63:1008-1020. DOI: 10.2337/db13-0859

[75] Cohen RM, Haggerty S, Herman WH. HbA1c for the diagnosis of diabetes and prediabetes: Is it time for a mid-course correction? The Journal of Clinical Endocrinology and Metabolism. 2010;95:5203-5206. DOI: 10.1210/ jc. 2010-2352

[76] Berezin AE, Kremzer A, Berezina T, Martovitskaya $Y$. The signature of circulating microparticles in heart failure patients with metabolic syndrome. Journal of Circulating Biomarkers. 2016;5:1849454416663659. DOI: $10.1177 / 1849454416663659$

[77] Sun H, Yao W, Tang Y, Zhuang W, $\mathrm{Wu} \mathrm{D}$, Huang S, et al. Urinary exosomes as a novel biomarker for evaluation of alpha-lipoic acid's protective effect in early diabetic nephropathy. Journal of Clinical Laboratory Analysis. 2017;31:1-7. DOI: 10.1002/jcla.22129

[78] Georgescu A, Alexandru N, Andrei E, Titorencu I, Dragan E, Tarziu C, et al. Circulating microparticles and endothelial progenitor cells in atherosclerosis: Pharmacological effects of irbesartan. Journal of Thrombosis and Haemostasis. 2012;10:680-691. DOI: 10.1111/j.1538-7836.2012.04650.x

[79] Orbe J, Alexandru N, Roncal C, Belzunce M, Bibiot P, Rodriguez JA, et al. Lack of TAFI increases brain damage and microparticle generation after thrombolytic therapy in ischemic stroke. Thrombosis Research.

2015;136:445-450. DOI: 10.1016/j. thromres.2015.06.010

[80] Alexandru N, Popov D, Dragan E, Andrei E, Georgescu A. Circulating endothelial progenitor cell and platelet microparticle impact on platelet activation in hypertension associated with hypercholesterolemia. PLoS One. 2013;8:e52058. DOI: 10.1371/journal. pone. 0052058

[81] Georgescu A, Alexandru N, Andrei E, Dragan E, Cochior D, Dias S. Effects of transplanted circulating endothelial progenitor cells and platelet microparticles in atherosclerosis development. Biology of the Cell. 2016;108:219-243. DOI: 10.1111/ boc. 201500104

[82] Santilli F, Marchisio M, Lanuti P, Boccatonda A, Miscia S, Davi G. Microparticles as new markers of cardiovascular risk in diabetes and beyond. Thrombosis and Haemostasis. 2016;116:220-234. DOI: 10.1160/ TH16-03-0176

[83] Tokarz A, Szuscik I, KusnierzCabala B, Kapusta M, Konkolewska M, 
Zurakowski A, et al. Extracellular vesicles participate in the transport of cytokines and angiogenic factors in diabetic patients with ocular complications. Folia Medica Cracoviensia. 2015;55:35-48

[84] Alexandru N, Badila E, Weiss E, Cochior D, Stepien E, Georgescu A. Vascular complications in diabetes: Microparticles and microparticle associated microRNAs as active players. Biochemical and Biophysical Research Communications. 2016;472:1-10. DOI: 10.1016/j.bbrc.2016.02.038

[85] Pisitkun T, Shen RF, Knepper MA. Identification and proteomic profiling of exosomes in human urine.

Proceedings of the National Academy of Sciences of the United States of America. 2004;101:13368-13373. DOI: 10.1073/pnas.0403453101

[86] Kanno K, Sasaki S, Hirata Y, Ishikawa S, Fushimi K, Nakanishi S, et al. Urinary excretion of aquaporin-2 in patients with diabetes insipidus. The New England Journal of Medicine. 1995;332:1540-1545. DOI: 10.1056/NEJM199506083322303

[87] Kaminska A, Platt M, Kasprzyk J, Kusnierz-Cabala B, Gala-Bladzinska A, Woznicka O, et al. Urinary extracellular vesicles: Potential biomarkers of renal function in diabetic patients. Journal Diabetes Research. 2016;2016:5741518. DOI: $10.1155 / 2016 / 5741518$

[88] Musante L, Tataruch DE, Holthofer $\mathrm{H}$. Use and isolation of urinary exosomes as biomarkers for diabetic nephropathy. Frontiers in Endocrinology. 2014;5:149. DOI: 10.3389/fendo.2014.00149

[89] Musante L, Tataruch D, Gu D, Liu X, Forsblom C, Groop PH, et al. Proteases and protease inhibitors of urinary extracellular vesicles in diabetic nephropathy. Journal Diabetes
Research. 2015;2015:289734. DOI: $10.1155 / 2015 / 289734$

[90] Wyczalkowska-Tomasik A, Bartlomiejczyk I, Gornicka B, Paczek L. Strong association between fibronectin accumulation and lowered cathepsin $B$ activity in glomeruli of diabetic rats. Journal of Physiology and Pharmacology: An Official Journal of the Polish Physiological Society. 2012;63:525-530

[91] Barutta F, Tricarico M, Corbelli A, Annaratone L, Pinach S, Grimaldi S, et al. Urinary exosomal microRNAs in incipient diabetic nephropathy. PLoS One. 2013;8:e73798. DOI: 10.1371/ journal.pone. 0073798

[92] Zheng B, Yin WN, Suzuki T, Zhang $\mathrm{XH}$, Zhang Y, Song LL, et al. Exosomemediated miR-155 transfer from smooth muscle cells to endothelial cells induces endothelial injury and promotes atherosclerosis. Molecular Therapy: The Journal of the American society of Gene Therapy. 2017;25:1279-1294. DOI: 10.1016/j.ymthe.2017.03.031

[93] Brill A, Dashevsky O, Rivo J, Gozal Y, Varon D. Platelet-derived microparticles induce angiogenesis and stimulate post-ischemic revascularization. Cardiovascular Research. 2005;67:30-38. DOI: 10.1016/j. cardiores.2005.04.007

[94] Vicencio JM, Yellon DM, Sivaraman V, Das D, Boi-Doku C, Arjun S, et al. Plasma exosomes protect the myocardium from ischemia-reperfusion injury. Journal of the American College of Cardiology. 2015;65:1525-1536. DOI: 10.1016/j. jacc.2015.02.026

[95] Ratajczak MZ, Ratajczak J. Horizontal transfer of RNA and proteins between cells by extracellular microvesicles: 14 years later. Clinical and Translational Medicine. 2016;5:7. DOI: 10.1186/s40169-016-0087-4 
[96] Goto S, Tamura N, Li M, Handa M, Ikeda Y, Handa S, et al. Different effects of various anti-GPIIb-IIIa agents on shear-induced platelet activation and expression of procoagulant activity. Journal of Thrombosis and Haemostasis. 2003;1:2022-2030

[97] Shouzu A, Nomura S, Omoto S, Hayakawa T, Nishikawa M, Iwasaka T. Effect of ticlopidine on monocytederived microparticles and activated platelet markers in diabetes mellitus. Clinical and Applied Thrombosis/ Hemostasis: Official Journal of the International Academy of Clinical and Applied Thrombosis/Hemostasis. 2004;10:167-173

[98] Kagawa H, Nomura S, Nagahama M, Ozaki Y, Fukuhara S. Effect of ticlopidine on plateletderived microparticles in patients with connective tissue diseases. Haemostasis. 1999;29:255-261. DOI: $10.1159 / 000022510$

[99] Nomura S, Shouzu A, Omoto S, Nishikawa M, Iwasaka T. Benidipine improves oxidized LDL-dependent monocyte and endothelial dysfunction in hypertensive patients with type 2 diabetes mellitus. Journal of Human Hypertension. 2005;19:551-557. DOI: 10.1038/sj.jhh.1001863

[100] Huang B, Cheng Y, Xie Q, Lin G, $\mathrm{Wu} Y$, Feng Y, et al. Effect of $40 \mathrm{mg}$ versus $10 \mathrm{mg}$ of atorvastatin on oxidized low-density lipoprotein, high-sensitivity C-reactive protein, circulating endothelial-derived microparticles, and endothelial progenitor cells in patients with ischemic cardiomyopathy. Clinical Cardiology. 2012;35:125-130. DOI: 10.1002/clc. 21017

[101] Suades R, Padro T, Alonso R, Mata P, Badimon L. Lipidlowering therapy with statins reduces microparticle shedding from endothelium, platelets and inflammatory cells. Thrombosis and Haemostasis. 2013;110:366-377. DOI: 10.1160/TH13-03-0238

[102] Zu L, Ren C, Pan B, Zhou B, Zhou E, Niu C, et al. Endothelial microparticles after antihypertensive and lipid-lowering therapy inhibit the adhesion of monocytes to endothelial cells. International Journal of Cardiology. 2016;202:756-759. DOI: 10.1016/j.ijcard.2015.10.035

[103] Wang Y, Chen LM, Liu ML. Microvesicles and diabetic complications--novel mediators, potential biomarkers and therapeutic targets. Acta Pharmacologica Sinica. 2014;35:433-443. DOI: $10.1038 /$ aps. 2013.188

[104] Henriksson CE, Hellum M, Haug KB, Aass HC, Joo GB, Ovstebo R, et al. Anticoagulant effects of an antidiabetic drug on monocytes in vitro. Thrombosis Research. 2011;128:e100-e106. DOI: 10.1016/j. thromres.2011.07.007

[105] Shimazu T, Inami N, Satoh D, Kajiura T, Yamada K, Iwasaka T, et al. Effect of acarbose on platelet-derived microparticles, soluble selectins, and adiponectin in diabetic patients. Journal of Thrombosis and Thrombolysis. 2009;28:429-435. DOI: $10.1007 /$ s11239-008-0301-3

[106] Nomura S, Omoto S, Yokoi T, Fujita S, Ozasa R, Eguchi N, et al. Effects of miglitol in platelet-derived microparticle, adiponectin, and selectin level in patients with type 2 diabetes mellitus. International Journal of General Medicine. 2011;4:539-545. DOI: 10.2147/IJGM.S22115

[107] Leroyer AS, Tedgui A, Boulanger CM. Microparticles and type 2 diabetes. Diabetes \& Metabolism. 2008;34(Suppl 1):S27-S32. DOI: 10.1016/S1262-3636(08)70100-9 
[108] Esposito K, Maiorino MI, Di Palo C, Gicchino M, Petrizzo M, Bellastella G, et al. Effects of pioglitazone versus metformin on circulating endothelial microparticles and progenitor cells in patients with newly diagnosed type 2 diabetes-A randomized controlled trial. Diabetes, Obesity \& Metabolism. 2011;13:439-445. DOI: 10.1111/j.1463-1326.2011.01367.x

[109] Georgescu A, Alexandru N, Nemecz M, Titorencu I, Popov D. Irbesartan administration therapeutically influences circulating endothelial progenitor cell and microparticle mobilization by involvement of pro-inflammatory cytokines. European Journal of Pharmacology. 2013;711:27-35. DOI: 10.1016/j.ejphar.2013.04.004

[110] Armstrong JP, Holme MN, Stevens MM. Re-engineering extracellular vesicles as smart nanoscale therapeutics. ACS Nano. 2017;11:69-83. DOI: 10.1021/acsnano.6b07607

[111] Amosse J, Martinez MC, Le Lay S. Extracellular vesicles and cardiovascular disease therapy. Stem Cell Investigation. 2017;4:102. DOI: 10.21037/sci.2017.11.07

[112] Gustafson D, Veitch S, Fish JE. Extracellular vesicles as protagonists of diabetic cardiovascular pathology. Frontiers in Cardiovascular Medicine. 2017;4:71. DOI: 10.3389/ fcvm.2017.00071

[113] Mentkowski KI, Snitzer JD, Rusnak S, Lang JK. Therapeutic potential of engineered extracellular vesicles. The AAPS Journal. 2018;20:50. DOI: 10.1208/s12248-018-0211-z

[114] Janssen HL, Reesink HW, Lawitz EJ, Zeuzem S, Rodriguez-Torres M, Patel K, et al. Treatment of HCV infection by targeting microRNA. The New England Journal of Medicine.
2013;368:1685-1694. DOI: $10.1056 /$

NEJMoa1209026

[115] Rupaimoole R, Slack FJ. MicroRNA therapeutics: Towards a new era for the management of cancer and other diseases. Nature Reviews Drug Discovery. 2017;16:203-222. DOI: 10.1038/nrd.2016.246

[116] Alvarez-Erviti L, Seow Y, Yin H, Betts C, Lakhal S, Wood MJ. Delivery of siRNA to the mouse brain by systemic injection of targeted exosomes. Nature Biotechnology. 2011;29:341-345. DOI: 10.1038/nbt.1807

[117] Kusuma GD, Barabadi M, Tan JL, Morton DAV, Frith JE, Lim R. To protect and to preserve: Novel preservation strategies for extracellular vesicles. Frontiers in Pharmacology. 2018;9:1199. DOI: 10.3389/fphar.2018.01199

[118] Wang Y, Zhang L, Li Y, Chen L, Wang X, Guo W, et al. Exosomes/ microvesicles from induced pluripotent stem cells deliver cardioprotective miRNAs and prevent cardiomyocyte apoptosis in the ischemic myocardium. International Journal of Cardiology. 2015;192:61-69. DOI: 10.1016/j. ijcard.2015.05.020

[119] Wang X, Huang W, Liu G, Cai W, Millard RW, Wang Y, et al. Cardiomyocytes mediate antiangiogenesis in type 2 diabetic rats through the exosomal transfer of miR-320 into endothelial cells. Journal of Molecular and Cellular Cardiology. 2014;74:139-150. DOI: 10.1016/j.yjmcc.2014.05.001

[120] Wang X, Gu H, Huang W, Peng J, Li Y, Yang L, et al. Hsp20-mediated activation of exosome biogenesis in cardiomyocytes improves cardiac function and angiogenesis in diabetic mice. Diabetes. 2016;65:3111-3128. DOI: 10.2337/db15-1563

[121] Geiger A, Walker A, Nissen E. Human fibrocyte-derived exosomes 
accelerate wound healing in genetically diabetic mice. Biochemical and Biophysical Research Communications. 2015;467:303-309. DOI: 10.1016/j. bbrc.2015.09.166

[122] Kalani A, Chaturvedi P, Maldonado C, Bauer P, Joshua IG, Tyagi SC, et al. Dementia-like pathology in type-2 diabetes: A novel microRNA mechanism. Molecular and Cellular Neurosciences. 2017;80:58-65. DOI: 10.1016/j.mcn.2017.02.005

[123] Feng Y, Huang W, Wani M, Yu X, Ashraf M. Ischemic preconditioning potentiates the protective effect of stem cells through secretion of exosomes by targeting Mecp2 via miR-22. PLoS One. 2014;9:e88685. DOI: 10.1371/journal. pone. 0088685

[124] Mayourian J, Ceholski DK, Gorski PA, Mathiyalagan P, Murphy JF, Salazar SI, et al. Exosomal microRNA21-5p mediates mesenchymal stem cell paracrine effects on human cardiac tissue contractility. Circulation Research. 2018;122:933-944. DOI: 10.1161/CIRCRESAHA. 118.312420

[125] Yu B, Kim HW, Gong M, Wang J, Millard RW, Wang Y, et al. Exosomes secreted from GATA-4 overexpressing mesenchymal stem cells serve as a reservoir of anti-apoptotic microRNAs for cardioprotection. International Journal of Cardiology. 2015;182:349-360. DOI: 10.1016/j. ijcard.2014.12.043

[126] Martinez MC, Andriantsitohaina R. Extracellular vesicles in metabolic syndrome. Circulation Research. 2017;120:1674-1686. DOI: 10.1161/ CIRCRESAHA.117.309419

[127] McArthur K, Feng B, Wu Y, Chen S, Chakrabarti S. MicroRNA-200b regulates vascular endothelial growth factor-mediated alterations in diabetic retinopathy. Diabetes. 2011;60: 1314-1323. DOI: $10.2337 / \mathrm{db} 10-1557$
[128] Silva VA, Polesskaya A, Sousa TA, Correa VM, Andre ND, Reis RI, et al. Expression and cellular localization of microRNA-29b and RAX, an activator of the RNA-dependent protein kinase (PKR), in the retina of streptozotocininduced diabetic rats. Molecular Vision. 2011;17:2228-2240

[129] Chen Y, Li G, Liu ML. Microvesicles as emerging biomarkers and therapeutic targets in cardiometabolic diseases. Genomics, Proteomics \& Bioinformatics. 2018;16:50-62. DOI: 10.1016/j.gpb.2017.03.006

[130] Zernecke A, Bidzhekov K, Noels H, Shagdarsuren E, Gan L, Denecke B, et al. Delivery of microRNA-126 by apoptotic bodies induces CXCL12dependent vascular protection. Science Signaling. 2009;2:ra81. DOI: 10.1126/ scisignal.2000610

[131] Alexandru N, Andrei E, Niculescu L, Dragan E, Ristoiu V, Georgescu A. Microparticles of healthy origins improve endothelial progenitor cell dysfunction via microRNA transfer in an atherosclerotic hamster model. Acta Physiologica. 2017;221:230-249. DOI: 10.1111/apha.12896 



\title{
Part Two: Extracellular Vesicles as a Risk Factor in Neurodegenerative Diseases
}

Laura Cristina Ceafalan, Octavian Costin Ioghen, Daciana Silvia Marta, Alina Constantin, Nicoleta Alexandru, Miruna Nemecz, Gabriela Tanko, Alexandru Filippi, Stefania Lucia Magda, Florina Bojin, Virgil Paunescu, Dragos Vinereanu, Adriana Georgescu and Mihaela Gherghiceanu

\begin{abstract}
Extracellular vesicles (EVs) involved in the intercellular communication hold cell-specific cargos that contain proteins, various species of RNA and lipids. EVs are emerging as powerful tools for diagnosis and therapy in most diseases but little is known about their role in central nervous system (CNS) physiology or disease. Considering the extraordinary intricated cytoarchitecture of the brain, the implication of EVs in its pathophysiology is difficult to establish. Blood circulating EVs derived from local or distant vascular cells or EVs released from brain into the cerebrospinal fluid (CSF) may influence the brain activity. EVs released in the blood stream from various tissues may influence the brain by passing through the blood-brain barrier (BBB) or through choroid plexus. Since the choroid plexus has also a clearance role, it might be possible that EVs carrying brain abnormal proteins to pass into the blood can be detected. Thus, considering that EVs are specialized cargos bearing combined signals between cells, they might be an interesting therapy target in the future for both regulating neurogenesis and abnormal protein clearance. We present here data gathered about EVs that may influence the CNS functionality and be involved in most common neurodegenerative diseases.
\end{abstract}

Keywords: extracellular vesicles, exosomes, intercellular communication, brain barriers, neurodegenerative diseases

\section{Introduction}

Extracellular vesicle (EV) is a term used to define a heterogeneous group of vesicles isolated from biological fluids or tissues. EVs seem to mediate complex cell-to-cell communication over long distances or nearby through various macromolecules: polypeptides, various species of RNAs, and/or lipids. 
The classification of EVs is based on their size and mechanism of biogenesis and includes: exosomes, less than $100 \mathrm{~nm}$ small vesicles released from multivesicular bodies after endocytosed materials have been sorted in the endolysosomal compartment $[1,2]$; ectosomes, up to $500 \mathrm{~nm}$ larger vesicles budding from the plasma membrane $[2,3]$; and multivesicular cargos, consisting of numerous vesicles, about $150 \mathrm{~nm}$, enclosed in a plasma membrane-derived shield [4]. Although many medical fields experienced real progress with newly discovered diagnostic tools or treatments for several diseases, smaller steps are taken in the field of cerebrovascular and neurodegenerative diseases. Age-related changes, cardiac diseases, and atherosclerosis are known to contribute to the pathogenic mechanism of cerebrovascular and neurodegenerative diseases affecting the elderly.

\section{Biological content of extracellular vesicles}

An increasing body of evidence proves that EVs are not only involved in the waste disposal system, but, more importantly, they function as membrane-bound carriers for intercellular communication $[5,6]$. This type of intercellular communication was proven to modulate cellular functions both in homeostatic and pathological conditions $[6,7]$. High concentrations of EVs were detected in culture supernatants and biological fluids $[8,9]$. For example, EVs have been isolated from CSF and proved to contain overrepresentation of brain-specific proteins derived from cerebral white mater and choroid plexus [10]. Several studies demonstrated that the level and composition of circulating EVs are altered in disease states, neurodegenerative diseases included [10-12]. Endothelial cells (ECs) and platelets have been most studied as sources for EVs $[13,14]$, but circulating cells as monocytes or lymphocytes may also be a source for EVs.

Protein composition of the EV-enclosing membrane, mainly different types of integrins, cell adhesion molecules, and tetraspanins, guides the interaction with the recipient cells, the targeting, or recruitment once EVs are released into the extracellular environment [15]. Specific molecules allow EVs either to interact with surface receptors on recipient cells to activate signaling cascades, or to promote their docking and uptake. One potential mechanism is direct membrane fusion with direct transfer of the cargo molecules into the recipient cytosol [16]. Endocytosis, including clathrin-dependent endocytosis, lipid raft-dependent pathways, phagocytosis, and even micropinocytosis, was more frequently considered [15].

A recent quantitative proteomic analysis allowing comparison of different EV subpopulations [17] proved that several classic exosome markers such as flotillin-1, heat-shock 70-kDa proteins, actin, and MHC I and II are present in all EV fractions obtained by successive centrifugation. Moreover, classic exosomal tetraspanins CD9, CD63, and CD81 were unreached in the exosomal fraction but also detected in different amounts in larger EVs. The study suggests a further classification of EV pelleting at high speed into four subcategories: (a) EVs enriched in all tetraspanins and endosome markers (bona fide exosomes); (b) EVs devoid of CD63 and CD81 but enriched in CD9 (associated with plasma membrane and an early endocytic signature); (c) EVs devoid of CD63/CD9/CD81; and (d) EVs enriched in extracellular matrix (ECM) or serum-derived factors. They also propose five categories of proteins with different relative distributions in different EV populations that relate them to their intracellular source [17]. Thus, exosomes contain ECM proteins, receptors, heparin-binding, phospholipid-binding, integrins, immune response, 
and cell adhesion molecules, while ectosomes are enriched in endoplasmic reticulum proteasome and mitochondrial proteins [9].

The amounts of different lipid classes in EVs have been determined in several studies [23,34], and the enrichment of EV membranes for cholesterol, sphingomyelin, glycosphingolipids, and phosphatidylserine compared with their cellular sources was proved. However, differences in lipid composition were reported between vesicle type and cellular source. Generally, exosomes seem to be enriched in glycolipids, phosphatidylserine, and free fatty acids, while ceramides and sphingomyelins were consistently enriched in ectosomes. Still, phosphatidylcholines were depleted in exosomes but unchanged or enriched in ectosomes [9].

EVs contain not only proteins and lipids, but several classes of RNAs. Most of the recent in vitro studies have proved that EVs contain functional RNA molecules that reflect the cellular status and are involved in intercellular crosstalk $[18,19]$. Different species of RNA have been reported to be enclosed in EVs derived from various sources-mRNA, rRNA, and tRNA fragments and especially microRNA (miRs) [5]. Several mechanisms for RNA selection, loading into EVs, and their uptake by various target cells have been proposed [5, 20]. Packing into EVs protects the molecules from RNase degradation once released into the extracellular environment. Thus, RNA molecules can be transferred to distant recipient cells, their protein production can be modulated $[8,21]$, or they may be used as predictive biomarkers for the occurrence of cardiovascular events as demonstrated by the study of EVs containing miR-199a and miR-126 in patients with stable coronary artery disease [22]. In atherosclerotic disease, miR-containing circulating EVs and apoptotic bodies, along with other bioactive molecules, are released by proinflammatory stimulated monocytes and T cells; ECs and activated platelets initiate hyperplasia of vascular smooth muscle cells (VSMCs) which leads to phenotype switching from contractile to synthetic and activates their proliferation and migration [23].

Besides membrane proteins and RNA cargo, EVs may contain cytosolic proteins, such as cytokines, chemokines, growth factors, enzymes or transcription factors, functional organelles, and other bioactive molecules such as lipid mediators, derived from arachidonic acid [5]. Also, some EVs seem to retain the capacity to synthesize eicosanoids using their phospholipid content both by enzymatic and nonenzymatic processes [24].

All neural cells from rodent $[25,26]$ and human $[25,27]$, even immortalized human brain microvascular ECs $[25,28]$, release EVs which contain mRNA and miRs for epigenetic reprogramming of neural cells or post-transcriptional control of specific genes [25]. In vitro studies of brain angiogenesis revealed that EVs deliver proangiogenic protein, mRNAs, and miRs from cultured glioblastoma cells into cerebral ECs $[25,29]$, especially increased VEGFR-B from immortalized mouse cerebral ECs stimulated with LPS and cytokines into targeted cerebral vascular pericytes $[25,30]$. In vitro and in vivo studies showed that neuronal exosomes containing miR-132 could mediate neuronal regulation of brain vascular integrity. Thus, in zebrafish larvae and cultured rodent brain cells, it has been shown that neurons transfer miR-132, a highly conserved and neuron-enriched miR, via secreting exosomes to ECs to maintain brain vascular integrity. Following translocation to ECs through exosome internalization, miR-132 regulates the expression of vascular ECs cadherin (VE-cadherin), an important adherens junction protein, by directly targeting eukaryotic elongation factor 2 kinase [31]. In addition, two proteins found in peripherally circulating plasma EVs, cystatin C and CD14, have been linked to the development of brain atrophy and to cerebral white matter lesions, a small vessel disease within the brain [32]. Because exosomes contain transferrin and insulin receptor $[25,28]$, which mediate macromolecular passing through the blood-brain 



Figure 1.

Transmission electron microscopy of the isolated extracellular vesicles: (A) negative staining and (B) cryo-electron microscopy.

barrier (BBB), peripherally infused modified exosomes containing specific RNA were used to knockdown a specific gene in mouse brain [32-34]. Considering the extraordinary intricate cytoarchitecture of the brain, the presence of EVs in the adult brain is hard to be documented. Fetal brain and neurospheres contain cells which seem to release vesicles into the extracellular space (Figure 1). EVs are easier to be seen near ependymal cells floating in the ventricles from where they can be isolated [11].

\section{Methods of isolation and analysis of extracellular vesicles}

Minimal experimental requirements for definition of EVs and their functions have been proposed [35], and isolated EVs should be characterized, and the morphology, protein composition, and functionality should be tested before any new enquiries are pursued. Whether the chosen isolation technique for the experiment consists in ultracentrifugation or any other technique, after collecting the sample it is necessary to perform two low-speed centrifugations as soon as possible after the sample collection [36]. The first low-speed centrifugation $(300-800 \times g)$ removes cells, lipid droplets, and macromolecules from the sample, while the second low-speed centrifugation $(2.500 \times \mathrm{g})$ removes platelets and apoptotic bodies. Cell removal is an important step; otherwise, the following high-speed centrifugations break the cells, leading to EV release and sample contamination [37].

Differential ultracentrifugation is the most widely used method for EV isolation [36], which involves multiple centrifugations at increasingly higher speeds obtaining a particle separation based on the sedimentation coefficient [38]. Establishing the appropriate speed and duration of centrifugation is a very important step in EV isolation [36]. Several inconveniences can occur using this technique such as the loss of certain subpopulations of EVs or simultaneous isolation of lipo/ protein aggregates $[39,40]$.

Density gradient ultracentrifugation is a method that isolates the particles by size and mass density [41], and its usefulness lies in the fact that it can isolate several subpopulations of EVs which are lost using differential ultracentrifugation; therefore, it increases the purity of the isolated EVs [42].

Size exclusion chromatography is an easy handling method by which a sizebased separation is achieved [43]. It allows the electron microscopy to be performed immediately after isolation and the proteins and lipoproteins are removed 
from the sample without losing any subpopulation, thus achieving a high-yield separation [44].

Precipitation kits gained a lot of attention during the last years involving a concentration method based on the use of polyethylene glycol polymers. The price for the kits is low, the protocol is easy to perform, it is compatible with both low and high volumes of samples, and the method can be applied on large scale [45]. It must be taken into account that the precipitation kits are not the best method for EV isolation, having a low-yield purification because of the co-precipitations [37]. Anyway, for validating the results, it is recommended to use one of the ultracentrifugation methods in parallel with this method.

After the isolation step, a general description of the protein composition should be made even though there are no specific EV markers discovered yet. EVs are enriched in certain proteins such as tetraspanins (CD63, CD81, and CD9) and TSG 101 for exosomes, annexin V for ectosomes, etc. [46]. To exclude a contamination, the presence or absence of proteins that are not expected to be found in EVs, intracellular proteins like calnexin, cytochrome C, histones, GRP94, and Argonaute complex must be detected [35]. Western blot, flow cytometry, or mass spectroscopy can be used for this protein characterization step.

The next step consists in individual characterization of the EVs using at least two methods: electron microscopy [35, 45], atomic force microscopy [47], or nanoparticle tracking analysis [48]. Transmission electron microscopy (TEM) is the most used method for visualization of EVs considering their nanoscale size (Figures 1 and 2). Negative staining [49], TEM on thin section from plastic

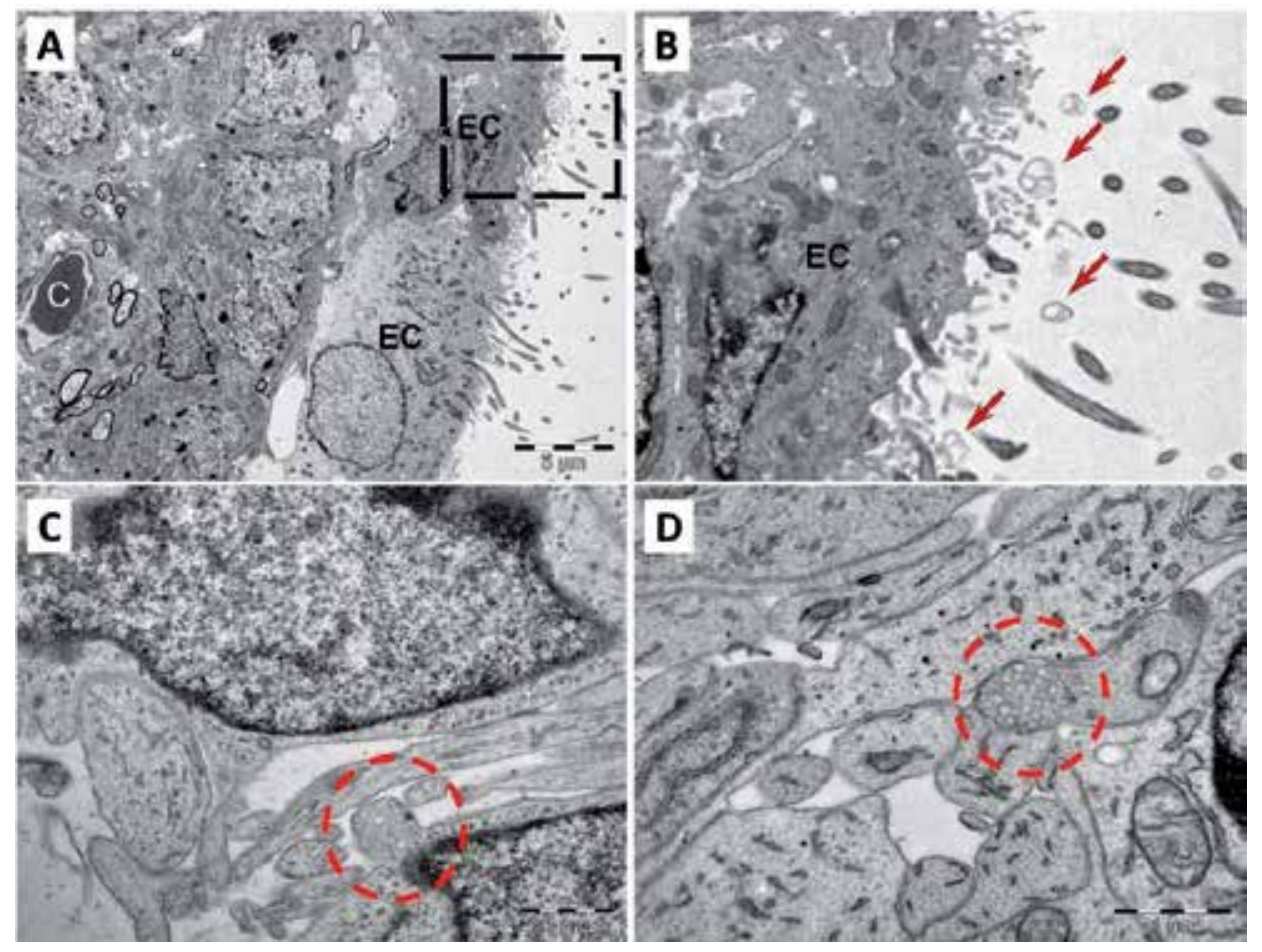

Figure 2.

Transmission electron microscopy: $(A)$ ependymal cells (EC) facing the ventricular system of the mouse brain control the communication between cerebrospinal fluid and brain parenchyma; $C$-capillary. (B) Higher magnification of the square-marked area in $(A)$ shows extracellular vesicles (arrows) close to cilia and microvilli of the ependymal cell (EC). Volume transmission may be mediated by multivesicular cargoes (encircled) which could be seen released from neurons in fetal mouse brain (C) or neurons from neurospheres generated from stem cells (D). 
embedded EVs [49], can also be used to confirm the presence of the lipid bilayer of the isolated $\mathrm{EV}$ membrane and an election method to investigate EVs in tissue. Cryo-TEM [50] is a high resolution method to visualize the lipid bilayer. Electron tomography $[4,51]$ allows $3 \mathrm{D}$ reconstruction of the EVs with a very good imaging of the different types. For surface protein recognition, immuno-EM [52, 53] allows imaging of EV-specific markers.

Flow cytometry is a method based on measuring the signal of the light scattering from a structure passing through a laser beam. The smaller the particles, the less the light scattering, and therefore, conventional cytometry has a detection limit of approximately $200 \mathrm{~nm}$ [54]. Fluorescence-based detection is used to overcome this inconvenience $[45,55]$, the background noise being higher than the EV signal.

Nanoparticle tracking analysis involves the passing of a laser beam through a suspension that contains EVs and the scattering light is captured by a camera [48]. The Brownian movement of the EVs in the suspension is recorded, and according to their movement, the size can be measured [48].

The last step to fulfill the minimal experimental requirements involves the functional assays [35]. Multiple in vitro models can be designed for this step; co-incubating EVs with different culture cells and migration, proliferation, coagulation, and fibrinolysis may be quantified depending on the chosen model [45].

There is no gold-standard method yet, but researchers are encouraged to explore and to standardize their methods of isolation with the hope that someday, easy EV isolation will be possible.

\section{Extracellular vesicles and cardiovascular risk for brain pathology}

All cells are capable of secreting specific arrays of EVs. Furthermore, the same cells may produce EVs by different biogenesis pathways, with different intracellular origins, of various sizes, with diverse composition and consequently, different functional properties [17]. Crucial feature for the normal functionality of the CNS and brain microenvironment homeostasis is sustained by vascular integrity which is highly dependent on the systemic status.

Several studies of patients with stable coronary artery disease have reported increased levels of circulating EVs which may influence the BBB integrity. Specific EV subpopulations, especially those of ECs origin, characterized by CD144 ${ }^{+}$, $\mathrm{CD} 131^{+} /$annexin $\mathrm{A5}^{+}$, or EVs containing miR-199a and miR-126, are currently researched as interesting biomarkers for cardiovascular risk and mortality in these patients $[22,56,57]$.

Calcifications present in the atherosclerotic plaque [58] have a destabilizing effect in early lesions, favoring the rupture, but gain a potential protective effect in advanced lesions with heavy calcium deposits [59]. As several studies have shown, atherosclerotic plaque calcifications are associated with EVs of ECs, VSMCs, and macrophage origin. VSMCs can release EVs with low levels of calcification-inhibiting enzymes and annexin A6/phosphatidylserine nucleation complexes. Exposure of VSMCs to proinflammatory cytokines can stimulate the release of EVs that can mineralize when inhibitors of calcification are missing [60]. Also, ECs exposed to proinflammatory stimuli can release EVs rich in bone morphogenetic protein 2, promoting calcification in VSMs [61]. Alterations in local homeostasis of calcium and phosphate lead to the formation of macrophage-derived exosomes which stimulate mineralization, through an annexin-dependent mechanism [62].

Recent studies have also noted that in humans, advanced atherosclerotic plaques have a high content of procoagulant EVs, originating form leukocytes, erythrocytes, and VSMCs $[63,64]$. In opposition to ectosomes, exosomes have shown 
antithrombotic effects. In animal studies, platelet-derived exosomes suppressed platelet aggregation and occlusive thrombosis by inhibiting platelet CD36 and decreasing CD36-dependent oxidized LDL binding and macrophage cholesterol loading [65]. EVs influence the different mechanisms that lead to plaque destabilization and rupture. Intraplaque hemorrhages are produced by neovascularization originating from adventitial tissue, stimulated by plaque EVs, such as CD40+ vesicles of macrophage origin. Hemorrhages are also favored by leukocyte and ECs-EVs with fibrinolytic activity $[66,67]$. Fibrous cap weakening is associated with VSMC apoptosis, induced by the presence of EVs, released in some pathological conditions [100]. Moreover, EVs can influence breakdown of matrix structural proteins through metalloproteinase interactions [68].

Circulating levels of procoagulant EVs are higher in patients with acute coronary syndromes compared to healthy controls or patients with stable coronary artery disease $[57,69]$. Circulating EVs alter endothelial-dependent NO mediated vasodilation, and endothelial EVs increase ECs thrombogenicity [70, 71]. Circulating EVs have also been investigated as prognostic markers in secondary prevention, in order to identify patients at high cardiovascular risk $[56,57]$. Increased levels of CD11b ${ }^{+}$ $\mathrm{CD}^{+} 6^{+}$leukocyte-derived EVs could be useful in identifying asymptomatic patients at high risk for plaque rupture [72], while $\mathrm{CD}^{+} / \mathrm{CD} 45^{+}$EVs could identify individuals who will develop a major cardiovascular event [73].

All these circulating EVs associated with coronary disease [74] may affect the vascular bed of the brain and disrupt the functionality of BBB. Aging and cardiovascular-associated disease are associated with BBB alteration [75] and blood circulating EVs may mediate early dysfunctions or progression of cerebral associated pathology. EVs associated with hypercholesterolemia [76] and atherosclerosis $[77,78]$ may have an impact on BBB function, and reducing the proinflammatory cytokines enrolling in EVs [79] may be beneficial.

Different neuronal cell types and molecules concur to regulate the improvement of brain vasculature [31, 80-82]. Each cell, including neurons and astrocytes [32, 83], is able to produce EVs enriched in specific proteins, lipids, and RNAs. EVs can stimulate targeted neural cells and surrounding neural tissues, which are important elements of vascular integrity preservation. The brain pathological condition changes the EV content profile of proteins and miRs [84]. A number of studies have shown that EVs regulate arterial stiffness $[32,85]$ which is linked to small vessel $[32,86-88]$, and platelet-derived EVs seem to be important players in the formation of cerebral microthrombi which lead to brain atrophy and consequent cognitive degeneration. It is believed that the prothrombotic nature of an elevated number of platelet-derived EVs reported in the acute phase of cerebral infarction may conduct to infarct progression $[32,84,89,90]$. EV proteins cystatin C and CD14 have been shown to be related to cerebral white matter lesions and the progression of brain atrophy in patients with manifest vascular disease, suggesting a role for EVs in the etiology of structural brain changes [32].

The role of cardiovascular disease risk factors in the occurrence and progression of cognitive impairment is widely accepted. There is a link between elevated levels of cholesterol and amyloid deposition in the brain, and the relationship between atherosclerotic injury and sporadic Alzheimer's disease is investigated.

\section{Extracellular vesicles in neurodegenerative diseases}

The pathology of Alzheimer's disease (AD) consists in the extracellular amyloid plaques formed by aggregated amyloid beta peptides and in the intraneuronal neurofibrillary tangles made of hyperphosphorylated tau proteins [91]. The 
accumulation of the proteins induces an apoptotic response with neuronal loss and occurs especially in the cerebral cortex [92].

It has been observed that the pathological findings in AD have a typical spatial distribution suggesting a neuron-to-neuron spread of the amyloid and hyperphosphorylated tau proteins, which promote aggregation, acting as "seeds" [93]. Therefore AD is considered to have a prion-like model of propagation [94]. The immediate question that rises is: what is the mechanism of the propagation?

Amyloid beta is mainly formed extracellularly from the cleavage of APP by beta and gamma secretases, which are found at the level of the plasma membrane [95]. But in some degree, the secretases are present in endoplasmic reticulum and Golgi apparatus, and there is a certain intracellular production of amyloid beta [96]. It is removed from the cell via exosomes embedded in a multivesicular body as an alternative pathway to lysosomal degradation [97]. A new study suggests that exosomes containing amyloid beta are present in higher concentrations in the AD brain compared to the healthy brain [98]. Moreover, the study shows that exosomes are the carriers of the toxic amyloid beta from one neuron to another [98]. Also, it is thought that exosomes mediate the intercellular transfer of hyperphosphorylated tau protein, and the exosome-mediated tau protein induces the formation of neurofibrillary tangles [99].

The evolution of AD is insidious with an asymptomatic stage that lasts several years [100]. Although asymptomatic, the pathological changes in the brain are present in this stage [93]. These findings suggest the value of discovering biomarkers that can anticipate the onset of the clinical symptoms or can facilitate a window for the possibility of a future therapy that could stop the progression. Amyloid beta and hyperphosphorylated tau proteins are of great value as biomarkers when dosed from the cerebrospinal fluid [101]. Nevertheless, performing lumbar puncture in a wide population is almost impossible. Thereby, the discovery of new biomarkers is a valuable research theme.

Several types of miRs isolated from cerebrospinal fluid are differentially expressed in AD, such as miR-100, miR-146, miR-505, and miR-1274a [102]. The presence of several types of exosomal miRs isolated from serum (miR-361-5p, miR-93-5p, miR-335-5p, and miR-30e-5p) correlates with the neuropsychological evaluation and brain imaging [103]. It is to be mentioned that exosome-containing proteins like tau, apolipoprotein E, cystatin E, and HSP-90 alpha were isolated in the cerebrospinal fluid and were present in patients with $\mathrm{AD}$ [104]. This evidence proposes both miRs and protein-containing exosomes as a promising source of biomarkers for AD.

Parkinson's disease (PD) is a neurodegenerative disease that consists in the loss of dopaminergic neurons localized in the substantia nigra [105]. The pathology of the disease implies the deposition of Lewy bodies in the neurons which are mostly made of misfolded and aggregated alpha-synuclein protein [105]. The Braak staging explains the spatio-temporal dissemination of Lewy bodies into the neurons from caudal to rostral, starting in the medulla oblongata and spreading to the level of the cerebral cortex, damaging various structures on this way [106]. The starting point is thought to be either the enteric nervous system or the olfactory bulb [106]. Thereby, it is suggested that PD has a prion-like propagation [94]. Are exosomes responsible for carrying alpha-synuclein from neuron to neuron? The mechanism could be similar to the one described in $\mathrm{AD}$, but there are fewer studies to draw certain conclusions regarding the involvement of exosomes in the pathogenesis of PD. Excessive intracellular alpha-synuclein is thought to be transported out of the cell via multivesicular body containing exosomes in a similar manner as in AD in an attempt to clean the intracellular space [107]. 
Studies of neuronal cell cultures expressing alpha-synuclein noticed that the protein is released by the cell free in the extracellular space but also incorporated in the exosomes [108]. Furthermore, neighboring cells take up the exosomes, and the transferred alpha-synuclein acts as seed for the formation of the aggregate [109]. Evidence to prove that in vivo alpha-synuclein is transferred by exosomes is not available yet, but it can be speculated that exosomes play an important role as in vitro.

The use of EVs as a biomarker tool in PD is a promising field too [110]. Several miRs carried by exosomes were increased in the CSF of PD patients, such as miR10a-5p, miR-153, and miR-409-3p, while some miRs such as miR-19b-3p and miR-1 were significantly reduced [111]. Exosomes containing alpha-synuclein and LRRK proteins were also isolated in the CSF of PD patients $[109,112]$.

\section{Extracellular vesicles' perspective use in brain pathology}

The discovery of the EV involvement in several biological processes gave hope that some questions regarding neurodegenerative diseases will be answered. First of all, it is important to clarify which are the cellular mechanisms involved in the progression of the disease and if exosomes play any role. Based on the spatio-temporal spreading of the pathological proteins in the brain, an appealing theory is the prionlike propagation theory [113]. It is presumed that exosomes play an important role by facilitating the interneuronal transport of the proteins [114]. As well, there is a critical need in finding accessible biomarkers that can diagnose a neurodegenerative disease in the asymptomatic stage [115]. Dosing certain free proteins in biofluids can be an option, but several problems are experienced because of their low concentrations [115]. Therefore, a new approach is being attempted consisting in finding the proteins encapsulated in extracellular vesicles [116]. Micro-RNAs and different proteins carried by exosomes are attractive options for finding new biomarkers in several diseases as well as in neurodegenerative diseases [117].

Recently, it was discovered that an important player in the field of neural diseases is EV derived from stem cells [118], mainly in the case of stroke [118-120]. In stroke pathophysiology, inflammation plays a significant role, circulating EV-activating immune cells. Neurons quickly depolarize and die, being next phagocytosed by infiltrating circulating macrophages and microglia [84, 121].

Because of their $\beta 1$ and $\alpha 2 b$ integrin-enriched content, human neural stem cell-derived EV administration recovers both tissue and sensorimotor function and may protect the BBB integrity, in the preclinical mouse thromboembolic model of stroke [122, 123]. Similarly, multipotent mesenchymal stromal cells (MSCs), through their capacity to secrete soluble factors, play an important role in brain repair. It was demonstrated that MSC cargos modulate cell signaling in ischemic stroke by PI3K/Akt pathway activation $[123,124]$ and EVs facilitated secretion of miRs sustaining MSC neuroprotective effects in ischemic stroke as well. Previous research demonstrated that intravenous administration of bone marrow-MSCs containing exosomes transferred miR-133b to astrocytes and neurons into the ischemic boundary zone [120, 123], and MSCs cultured in the presence of extracts from rat ischemic brain induced increased expression of exosomal miR133b [123, 125]. Also, EVs released by human MSCs seem to have an anti-inflammatory effect on mast cells, by increased prostaglandin E2 (PGE2) synthesis and up-regulation of EP4 receptor which might prevent the rupture of intracranial aneurysms [126]. All these data suggest that EVs from various sources may contribute to the neurogenesis and angiogenesis during brain repair processes in cerebral diseases. 


\section{Conclusion}

The EVs emerge as a powerful tool for early diagnosis and subsequent prevention of pathologies with high risk for the brain dysfunction. Still, EVs investigation as biomarkers and therapeutic agents is in its infancy. There is increasing evidence that EVs have an important role in brain pathophysiology. Thus, their potential application as prognostic and diagnostic biomarkers and targeted therapeutic tools relies on their subsequent isolation for molecular and functional characterization that can relate them with the cellular source and cellular mechanisms in both health and disease.

\section{Acknowledgements}

This work was supported by grants of UEFISCDI, projects no. PN-III-P11.2-PCCDI-2017-0527 and PN-III-P1-1.2-PCCDI-2017-0797 and the Romanian Academy and Romanian Ministry of Research and Innovation, projects no. 1N/2019_19.29.01.02 and 7PFE/16.10.2018.

\section{Conflict of interest}

The authors declare that the research was conducted in the absence of any either commercial or financial relationships that could be construed as a potential conflict of interest. 


\section{Author details}

Laura Cristina Ceafalan ${ }^{1,2}$, Octavian Costin Ioghen ${ }^{1,2}$, Daciana Silvia Marta ${ }^{1}$, Alina Constantin ${ }^{3}$, Nicoleta Alexandru ${ }^{3}$, Miruna Nemecz ${ }^{3}$, Gabriela Tanko ${ }^{3}$, Alexandru Filippi ${ }^{3}$, Stefania Lucia Magda ${ }^{2,4}$, Florina Bojin ${ }^{5,6}$, Virgil Paunescu ${ }^{5,6}$, Dragos Vinereanu ${ }^{2,4}$, Adriana Georgescu ${ }^{3}$ and Mihaela Gherghiceanu ${ }^{1,2 *}$

1 Victor Babeș National Institute of Pathology, Bucharest, Romania

2 Carol Davila University of Medicine, Bucharest, Romania

3 Pathophysiology and Pharmacology Department, Institute of Cellular Biology and Pathology, 'Nicolae Simionescu' of Romanian Academy, Bucharest, Romania

4 Cardiology Department, University and Emergency Hospital Bucharest, Bucharest, Romania

5 Department of Functional Sciences, 'Victor Babeș' University of Medicine and Pharmacy Timisoara, Timisoara, Romania

6 'Pius Brinzeu' Clinical Emergency County Hospital Timisoara, OncoGen-Center for Gene and Cellular Therapies in the Treatment of Cancer, Timisoara, Romania

*Address all correspondence to: mihaela.gherghiceanu@ivb.ro

\section{IntechOpen}

(C) 2019 The Author(s). Licensee IntechOpen. This chapter is distributed under the terms of the Creative Commons Attribution License (http://creativecommons.org/licenses/ by/3.0), which permits unrestricted use, distribution, and reproduction in any medium, provided the original work is properly cited. (cc) BY 


\section{References}

[1] Gould SJ, Raposo G. As we wait: Coping with an imperfect nomenclature for extracellular vesicles. Journal of Extracellular Vesicles. 2013;2:20389. DOI: 10.3402/jev.v2i0.20389

[2] Cocucci E, Meldolesi J. Ectosomes and exosomes: Shedding the confusion between extracellular vesicles. Trends in Cell Biology. 2015;25:364-372. DOI: 10.1016/j.tcb.2015.01.004

[3] van der Pol E, Böing AN, Gool EL, Nieuwland R. Recent developments in the nomenclature, presence, isolation, detection and clinical impact of extracellular vesicles. Journal of Thrombosis and Haemostasis. 2016;14:48-56. DOI: 10.1111/jth.13190

[4] Fertig ET, Gherghiceanu M, Popescu LM. Extracellular vesicles release by cardiac telocytes: Electron microscopy and electron tomography. Journal of Cellular and Molecular Medicine. 2014;18:1938-1943. DOI: 10.1111/ jcmm.12436

[5] Abels ER, Breakefield

XO. Introduction to extracellular vesicles: Biogenesis, RNA cargo selection, content, release, and uptake. Cellular and Molecular Neurobiology. 2016;36:301-312. DOI: $10.1007 /$ s10571-016-0366-z

[6] Maas SLN, Breakefield XO, Weaver AM. Extracellular vesicles: Unique intercellular delivery vehicles. Trends in Cell Biology. 2017;27:172-188. DOI: 10.1016/j.tcb.2016.11.003

[7] van Niel G, D’Angelo G, Raposo G. Shedding light on the cell biology of extracellular vesicles. Nature Reviews. Molecular Cell Biology. 2018;19:213-228. DOI: $10.1038 / \mathrm{nrm} .2017 .125$

[8] Valadi H, Ekström K, Bossios A, Sjöstrand M, Lee JJ, Lötvall JO.
Exosome-mediated transfer of mRNAs and microRNAs is a novel mechanism of genetic exchange between cells. Nature Cell Biology. 2007;9:654-659. DOI: 10.1038/ncb1596

[9] Haraszti RA, Didiot M-C, Sapp E, Leszyk J, Shaffer SA, Rockwell HE, et al. High-resolution proteomic and lipidomic analysis of exosomes and microvesicles from different cell sources. Journal of Extracellular Vesicles. 2016;5:32570. DOI: 10.3402/jev.v5.32570

[10] Thompson AG, Gray E, Mager I, Fischer R, Thézénas $M$, Charles PD, et al. UFLC-derived CSF extracellular vesicle origin and proteome. Proteomics. 2018;18:1800257. DOI: 10.1002/pmic. 201800257

[11] Welton JL, Loveless S, Stone T, von Ruhland C, Robertson NP, Clayton A. Cerebrospinal fluid extracellular vesicle enrichment for protein biomarker discovery in neurological disease; multiple sclerosis. Journal of Extracellular Vesicles. 2017;6:1369805. DOI: 10.1080/20013078.2017.1369805

[12] Pulliam L, Sun B, Mustapic M, Chawla S, Kapogiannis D. Plasma neuronal exosomes serve as biomarkers of cognitive impairment in HIV infection and Alzheimer's disease. Journal of Neurovirology. 2019. DOI: 10.1007/s13365-018-0695-4.

[Epub ahead of print]

[13] Georgescu A, Alexandru N, Popov D, Amuzescu M, Andrei E, Zamfir C, et al. Chronic venous insufficiency is associated with elevated level of circulating microparticles. Journal of Thrombosis and Haemostasis. 2009;7:1566-1575. DOI: 10.1111/j.1538-7836.2009.03525.x

[14] Pardo F, Villalobos-Labra R, Sobrevia B, Toledo F, Sobrevia L. 
Extracellular vesicles in obesity and diabetes mellitus. Molecular Aspects of Medicine. 2018;60:81-91. DOI: 10.1016/j. mam.2017.11.010

[15] French KC, Antonyak MA, Cerione RA. Extracellular vesicle docking at the cellular port: Extracellular vesicle binding and uptake. Seminars in Cell \& Developmental Biology. 2017;67:48-55. DOI: 10.1016/j.semcdb.2017.01.002

[16] Tkach M, Théry C. Communication by extracellular vesicles: Where we are and where we need to go. Cell. 2016;164:1226-1232. DOI: 10.1016/j. cell.2016.01.043

[17] Kowal J, Arras G, Colombo M, Jouve M, Morath JP, Primdal-Bengtson B, et al. Proteomic comparison defines novel markers to characterize heterogeneous populations of extracellular vesicle subtypes. Proceedings of the National Academy of Sciences of the United States of America. 2016;113:E968-E977. DOI: $10.1073 /$ pnas. 1521230113

[18] de Jong OG, Verhaar MC, Chen Y, Vader P, Gremmels H, Posthuma G, et al. Cellular stress conditions are reflected in the protein and RNA content of endothelial cell-derived exosomes. Journal of Extracellular Vesicles. 2012;1:18396. DOI: 10.3402/jev. v1i0.18396

[19] Pérez-Boza J, Lion M, Struman I. Exploring the RNA landscape of endothelial exosomes. RNA. 2018;24:423-435. DOI: 10.1261/ rna.064352.117

[20] Frankel EB, Audhya A. ESCRTdependent cargo sorting at multivesicular endosomes. Seminars in Cell \& Developmental Biology. 2018;74:4-10. DOI: 10.1016/j. semcdb.2017.08.020

[21] Njock M-S, Cheng HS, Dang LT, Nazari-Jahantigh M, Lau AC, Boudreau E, et al. Endothelial cells suppress monocyte activation through secretion of extracellular vesicles containing anti-inflammatory microRNAs. Blood. 2015;125:3202-3212. DOI: 10.1182/ blood-2014-11-611046

[22] Jansen F, Yang X, Proebsting S, Hoelscher M, Przybilla D, Baumann $\mathrm{K}$, et al. MicroRNA expression in circulating microvesicles predicts cardiovascular events in patients with coronary artery disease. Journal of the American Heart Association. 2014;3:e001249. DOI: 10.1161/ JAHA.114.001249

[23] Chistiakov DA, Orekhov AN, Bobryshev YV. Extracellular vesicles and atherosclerotic disease. Cellular and Molecular Life Sciences. 2015;72:26972708. DOI: 10.1007/s00018-015-1906-2

[24] Boilard E. Extracellular vesicles and their content in bioactive lipid mediators: More than a sack of microRNA. Journal of Lipid Research. 2018;59:2037-2046. DOI: 10.1194/jlr. R084640

[25] Zhang ZG, Chopp M. Exosomes in stroke pathogenesis and therapy. The Journal of Clinical Investigation. 2016;126:1190-1197. DOI: 10.1172/ JCI81133

[26] Perez-Gonzalez R, Gauthier SA, Kumar A, Levy E. The exosome secretory pathway transports amyloid precursor protein carboxyl-terminal fragments from the cell into the brain extracellular space. The Journal of Biological Chemistry. 2012;287:4310843115. DOI: 10.1074/jbc.M112.404467

[27] Banigan MG, Kao PF, Kozubek JA, Winslow AR, Medina J, Costa J, et al. Differential expression of exosomal microRNAs in prefrontal cortices of schizophrenia and bipolar disorder patients. PLoS One. 2013;8:e48814. DOI: 10.1371/journal.pone.0048814 
[28] Haqqani AS, Delaney CE, Tremblay T-L, Sodja C, Sandhu JK, Stanimirovic DB. Method for isolation and molecular characterization of extracellular microvesicles released from brain endothelial cells. Fluids and Barriers of the CNS. 2013;10:4. DOI: $10.1186 / 2045-8118-10-4$

[29] Skog J, Würdinger T, van Rijn S, Meijer DH, Gainche L, Sena-Esteves $\mathrm{M}$, et al. Glioblastoma microvesicles transport RNA and proteins that promote tumour growth and provide diagnostic biomarkers. Nature Cell Biology. 2008;10:1470-1476. DOI: $10.1038 / \mathrm{ncb} 1800$

[30] Yamamoto S, Niida S, Azuma E, Yanagibashi T, Muramatsu M, Huang $\mathrm{TT}$, et al. Inflammation-induced endothelial cell-derived extracellular vesicles modulate the cellular status of pericytes. Scientific Reports. 2015;5:8505. DOI: 10.1038/srep08505

[31] Xu B, Zhang Y, Du X-F, Li J, Zi H-X, $\mathrm{Bu} J-W$, et al. Neurons secrete miR132-containing exosomes to regulate brain vascular integrity. Cell Research. 2017;27:882-897. DOI: $10.1038 /$ cr.2017.62

[32] Kanhai DA, de Kleijn DPV, Kappelle LJ, Uiterwaal CSPM, van der Graaf Y, Pasterkamp G, et al. Extracellular vesicle protein levels are related to brain atrophy and cerebral white matter lesions in patients with manifest vascular disease: The SMART-MR study. BMJ Open. 2014;4:e003824. DOI: 10.1136/bmjopen-2013-003824

[33] Alvarez-Erviti L, Seow Y, Yin H, Betts C, Lakhal S, Wood MJA. Delivery of siRNA to the mouse brain by systemic injection of targeted exosomes. Nature Biotechnology. 2011;29:341-345. DOI: 10.1038/nbt.1807

[34] Graner MW, Alzate O, Dechkovskaia AM, Keene JD, Sampson JH, Mitchell DA, et al. Proteomic and immunologic analyses of brain tumor exosomes. The FASEB Journal. 2009;23:1541-1557. DOI: 10.1096/ fj. 08-122184

[35] Lötvall J, Hill AF, Hochberg F, Buzás EI, Di Vizio D, Gardiner C, et al. Minimal experimental requirements for definition of extracellular vesicles and their functions: A position statement from the International Society for Extracellular Vesicles. Journal of Extracellular Vesicles. 2014;3:26913

[36] Théry C, Amigorena S, Raposo $\mathrm{G}$, Clayton A. Isolation and characterization of exosomes from cell culture supernatants and biological fluids. Current Protocols in Cell Biology. 2006;30:3.22.1-3.22.29. DOI: 10.1002/0471143030.cb0322s30

[37] Witwer KW, Buzás EI, Bemis LT, Bora A, Lässer C, Lötvall J, et al. Standardization of sample collection, isolation and analysis methods in extracellular vesicle research. Journal of Extracellular Vesicles. 2013;2:20360. DOI: $10.3402 /$ jev.v2i0.20360

[38] Livshits MA, Khomyakova E, Evtushenko EG, Lazarev VN, Kulemin NA, Semina SE, et al. Isolation of exosomes by differential centrifugation: Theoretical analysis of a commonly used protocol. Scientific Reports. 2015;5:17319. DOI: 10.1038/srep17319

[39] Gyorgy B, Modos K, Pallinger E, Paloczi K, Pasztoi M, Misjak P, et al. Detection and isolation of cell-derived microparticles are compromised by protein complexes resulting from shared biophysical parameters. Blood. 2011;117:e39-e48. DOI: 10.1182/

blood-2010-09-307595

[40] Yuana Y, Böing AN, Grootemaat AE, van der Pol E, Hau CM, Cizmar P, et al. Handling and storage of human body fluids for analysis of extracellular vesicles. Journal of Extracellular Vesicles. 2015;4:29260. DOI: 10.3402/jev. v4.29260 
[41] Greening DW, Xu R, Ji H, Tauro BJ, Simpson RJ. A protocol for exosome isolation and characterization: Evaluation of ultracentrifugation, density-gradient separation, and immunoaffinity capture methods. Methods in Molecular Biology. 2015;1295:179-209. DOI: 10.1007/978-1-4939-2550-6_15

[42] Willms E, Johansson HJ, Mäger I, Lee Y, Blomberg KEM, Sadik M, et al. Cells release subpopulations of exosomes with distinct molecular and biological properties. Scientific Reports. 2016;6:22519. DOI: 10.1038/srep22519

[43] Koh YQ, Almughlliq FB, Vaswani K, Peiris HN, Mitchell MD. Exosome enrichment by ultracentrifugation and size exclusion chromatography. Frontiers in Bioscience (Landmark Ed). 2018;23:865-874

[44] Böing AN, van der Pol E, Grootemaat AE, Coumans FAW, Sturk A, Nieuwland R. Single-step isolation of extracellular vesicles by size-exclusion chromatography. Journal of Extracellular Vesicles. 2014;3:23430. DOI: $10.3402 /$ jev.v3.23430

[45] Coumans FAW, Brisson AR, Buzas EI, Dignat-George F, Drees EEE, El-Andaloussi S, et al. Methodological guidelines to study extracellular vesicles. Circulation Research. 2017;120:1632-1648. DOI: 10.1161/ CIRCRESAHA.117.309417

[46] Kalra H, Drummen GPC, Mathivanan S. Focus on extracellular vesicles: Introducing the next small big thing. International Journal of Molecular Sciences. 2016;17:170. DOI: 10.3390/ijms17020170

[47] Yuana Y, Oosterkamp TH, Bahatyrova S, Ashcroft B, Garcia Rodriguez P, Bertina RM, et al. Atomic force microscopy: A novel approach to the detection of nanosized blood microparticles. Journal of Thrombosis and Haemostasis. 2010;8:315-323. DOI: 10.1111/j.1538-7836.2009.03654.x

[48] Gardiner C, Shaw M, Hole P, Smith J, Tannetta D, Redman CW, et al. Measurement of refractive index by nanoparticle tracking analysis reveals heterogeneity in extracellular vesicles. Journal of Extracellular Vesicles. 2014;3:25361. Available from: http://www.ncbi.nlm.nih.gov/ pubmed/25425324. [Accessed: 14 Oct 2018]

[49] Jung MK, Mun JY. Sample preparation and imaging of exosomes by transmission electron microscopy. Journal of Visualized Experiments. 2018. DOI: $10.3791 / 56482$

[50] Yuana Y, Koning RI, Kuil ME, Rensen PCN, Koster AJ, Bertina RM, et al. Cryo-electron microscopy of extracellular vesicles in fresh plasma. Journal of Extracellular Vesicles. 2013;2:21494. DOI: $10.3402 /$ jev. v2i0.21494

[51] Coleman BM, Hanssen E, Lawson VA, Hill AF. Prion-infected cells regulate the release of exosomes with distinct ultrastructural features. The FASEB Journal. 2012;26:4160-4173. DOI: 10.1096/fj.11-202077

[52] Cizmar P, Yuana Y. Detection and characterization of extracellular vesicles by transmission and cryo-transmission electron microscopy. Methods in Molecular Biology. 2017;1660:221-232. DOI: 10.1007/978-1-4939-7253-1_18

[53] Arraud N, Linares R, Tan S, Gounou C, Pasquet J-M, Mornet $S$, et al. Extracellular vesicles from blood plasma: Determination of their morphology, size, phenotype and concentration. Journal of Thrombosis and Haemostasis. 2014;12:614-627. DOI: $10.1111 /$ jth.12554

[54] Nolan JP. Flow cytometry of extracellular vesicles: Potential, pitfalls, 
and prospects. Current Protocols in Cytometry. 2015;73:13.14.1-16. DOI: 10.1002/0471142956.cy1314s73

[55] van der Vlist EJ, Nolte-'t Hoen ENM, Stoorvogel W, Arkesteijn GJA, Wauben MHM. Fluorescent labeling of nano-sized vesicles released by cells and subsequent quantitative and qualitative analysis by high-resolution flow cytometry. Nature Protocols. 2012;7:1311-1326. DOI: 10.1038/ nprot.2012.065

[56] Sinning J-M, Losch J, Walenta K, Böhm M, Nickenig G, Werner N. Circulating CD31+/Annexin V+ microparticles correlate with cardiovascular outcomes. European Heart Journal. 2011;32:2034-2041. DOI: 10.1093/eurheartj/ehq478

[57] Nozaki T, Sugiyama S, Koga H, Sugamura K, Ohba K, Matsuzawa Y, et al. Significance of a multiple biomarkers strategy including endothelial dysfunction to improve risk stratification for cardiovascular events in patients at high risk for coronary heart disease. Journal of the American College of Cardiology. 2009;54:601-608. DOI: 10.1016/j. jacc.2009.05.022

[58] Aikawa E. Extracellular vesicles in cardiovascular disease: Focus on vascular calcification. The Journal of Physiology. 2016;594:2877-2880. DOI: 10.1113/JP272112

[59] Hsu JJ, Lim J, Tintut Y, Demer LL. Cell-matrix mechanics and pattern formation in inflammatory cardiovascular calcification. Heart. 2016;102:1710-1715. DOI: 10.1136/ heartjnl-2016-309667

[60] Kapustin AN, Chatrou MLL, Drozdov I, Zheng Y, Davidson SM, Soong D, et al. Vascular smooth muscle cell calcification is mediated by regulated exosome secretion. Circulation Research.
2015;116:1312-1323. DOI: 10.1161/

CIRCRESAHA.116.305012

[61] Buendía P, Montes de Oca A, Madueño JA, Merino A, MartínMalo A, Aljama P, et al. Endothelial microparticles mediate inflammationinduced vascular calcification. The FASEB Journal. 2015;29:173-181. DOI: 10.1096/fj.14-249706

[62] New SEP, Aikawa E. Role of extracellular vesicles in de novo mineralization: An additional novel mechanism of cardiovascular calcification. Arteriosclerosis, Thrombosis, and Vascular Biology. 2013;33:1753-1758. DOI: 10.1161/ ATVBAHA.112.300128

[63] Mallat Z, Hugel B, Ohan J, Lesèche G, Freyssinet JM, Tedgui A. Shed membrane microparticles with procoagulant potential in human atherosclerotic plaques: A role for apoptosis in plaque thrombogenicity. Circulation. 1999;99:348-353

[64] Leroyer AS, Isobe $H$, Lesèche $G$, Castier Y, Wassef M, Mallat Z, et al. Cellular origins and thrombogenic activity of microparticles isolated from human atherosclerotic plaques. Journal of the American College of Cardiology. 2007;49:772-777. DOI: 10.1016/j. jacc.2006.10.053

[65] Srikanthan S, Li W, Silverstein RL, McIntyre TM. Exosome polyubiquitin inhibits platelet activation, downregulates CD36 and inhibits pro-atherothombotic cellular functions. Journal of Thrombosis and Haemostasis. 2014;12:1906-1917. DOI: 10.1111/ jth.12712

[66] Leroyer AS, Rautou P-E, Silvestre J-S, Castier Y, Lesèche G, Devue C, et al. CD40 ligand+ microparticles from human atherosclerotic plaques stimulate endothelial proliferation and angiogenesis. Journal of the American College of Cardiology. 
2008;52:1302-1311. DOI: $10.1016 / \mathrm{j}$. jacc.2008.07.032

[67] Lacroix R, Sabatier F, Mialhe A, Basire A, Pannell R, Borghi H, et al. Activation of plasminogen into plasmin at the surface of endothelial microparticles: A mechanism that modulates angiogenic properties of endothelial progenitor cells in vitro. Blood. 2007;110:2432-2439. DOI: 10.1182/blood-2007-02-069997

[68] Boulanger CM, Loyer X, Rautou P-E, Amabile N. Extracellular vesicles in coronary artery disease. Nature Reviews. Cardiology. 2017;14:259-272. DOI: 10.1038/nrcardio.2017.7

[69] Bernal-Mizrachi L, Jy W, Jimenez JJ, Pastor J, Mauro LM, Horstman LL, et al. High levels of circulating endothelial microparticles in patients with acute coronary syndromes. American Heart Journal. 2003;145:962-970. DOI: 10.1016/S0002-8703(03) 00103-0

[70] Boulanger CM, Scoazec A, Ebrahimian T, Henry P, Mathieu E, Tedgui A, et al. Circulating microparticles from patients with myocardial infarction cause endothelial dysfunction. Circulation. 2001;104:2649-2652

[71] Abbas M, Jesel L, Auger C, Amoura L, Messas N, Manin G, et al. Endothelial microparticles from acute coronary syndrome patients induce premature coronary artery endothelial cell aging and thrombogenicity: Role of the Ang II/AT1 receptor/NADPH oxidase-mediated activation of MAPKs and PI3-kinase pathways. Circulation. 2017;135:280-296. DOI: 10.1161/ CIRCULATIONAHA.116.017513

[72] Sarlon-Bartoli G, Bennis Y, Lacroix R, Piercecchi-Marti MD, Bartoli MA, Arnaud L, et al. Plasmatic level of leukocyte-derived microparticles is associated with unstable plaque in asymptomatic patients with high-grade carotid stenosis. Journal of the American College of Cardiology. 2013;62:1436-1441. DOI: 10.1016/j. jacc.2013.03.078

[73] Chiva-Blanch G, Suades R, Crespo J, Vilahur G, Arderiu G, Padró T, et al. $\mathrm{CD} 3(+) / \mathrm{CD} 45(+)$ and SMA- $\alpha(+)$ circulating microparticles are increased in individuals at high cardiovascular risk who will develop a major cardiovascular event. International Journal of Cardiology. 2016;208:147-149. DOI: 10.1016/j.ijcard.2016.01.211

[74] Alexandru N, Costa A, Constantin A, Cochior D, Georgescu A. Microparticles: From biogenesis to biomarkers and diagnostic tools in cardiovascular disease. Current Stem Cell Research \& Therapy. 2017;12:89-102. DOI: 10.2174/1574888X1 1666151203224058

[75] Ceafalan LC, Fertig TE, Gheorghe TC, Hinescu ME, Popescu BO, Pahnke J, et al. Age-related ultrastructural changes of the basement membrane in the mouse blood-brain barrier. Journal of Cellular and Molecular Medicine. 2019;23:819-827. DOI: 10.1111/ jcmm.13980

[76] Alexandru N, Popov D, Dragan E, Andrei E, Georgescu A. Circulating endothelial progenitor cell and platelet microparticle impact on platelet activation in hypertension associated with hypercholesterolemia. PLoS One. 2013;8:e52058. DOI: 10.1371/journal. pone. 0052058

[77] Alexandru N, Andrei E, Niculescu L, Dragan E, Ristoiu V, Georgescu A. Microparticles of healthy origins improve endothelial progenitor cell dysfunction via microRNA transfer in an atherosclerotic hamster model. Acta Physiologica (Oxford, England). 2017;221:230-249. DOI: 10.1111/ apha.12896

[78] Georgescu A, Alexandru N, Andrei E, Dragan E, Cochior D, Dias S. 
Effects of transplanted circulating endothelial progenitor cells and platelet microparticles in atherosclerosis development. Biology of the Cell. 2016;108:219-243. DOI: 10.1111/ boc. 201500104

[79] Georgescu A, Alexandru N, Nemecz M, Titorencu I, Popov D. Irbesartan administration therapeutically influences circulating endothelial progenitor cell and microparticle mobilization by involvement of proinflammatory cytokines. European Journal of Pharmacology. 2013;711:2735. DOI: 10.1016/j.ejphar.2013.04.004

[80] Armulik A, Genové G, Mäe M, Nisancioglu $\mathrm{MH}$, Wallgard E, Niaudet C, et al. Pericytes regulate the bloodbrain barrier. Nature. 2010;468:557-561. DOI: $10.1038 /$ nature09522

[81] Daneman R, Zhou L, Kebede AA, Barres BA. Pericytes are required for blood-brain barrier integrity during embryogenesis. Nature. 2010;468:562566. DOI: $10.1038 /$ nature09513

[82] Argaw AT, Asp L, Zhang J, Navrazhina K, Pham T, Mariani JN, et al. Astrocyte-derived VEGF-A drives blood-brain barrier disruption in CNS inflammatory disease. The Journal of Clinical Investigation. 2012;122:24542468. DOI: $10.1172 / J C I 60842$

[83] Fauré J, Lachenal G, Court M, Hirrlinger J, Chatellard-Causse C, Blot B, et al. Exosomes are released by cultured cortical neurones. Molecular and Cellular Neurosciences. 2006;31:642-648. DOI: 10.1016/j. mcn.2005.12.003

[84] Couch Y, Akbar N, Davis S, Fischer R, Dickens AM, Neuhaus AA, et al. Inflammatory stroke extracellular vesicles induce macrophage activation. Stroke. 2017;48:2292-2296. DOI: 10.1161/STROKEAHA.117.017236

[85] Amabile N, Guérin AP, Leroyer A, Mallat Z, Nguyen C, Boddaert J, et al.
Circulating endothelial microparticles are associated with vascular dysfunction in patients with end-stage renal failure. Journal of the American Society of Nephrology. 2005;16:3381-3388. DOI: 10.1681/ASN.2005050535

[86] O'Rourke MF, Safar ME.

Relationship between aortic stiffening and microvascular disease in brain and kidney: Cause and logic of therapy. Hypertension (Dallas, Tex 1979). 2005;46:200-204. DOI: 10.1161/01. HYP.0000168052.00426.65

[87] Ohmine T, Miwa Y, Yao H, Yuzuriha T, Takashima Y, Uchino A, et al. Association between arterial stiffness and cerebral white matter lesions in community-dwelling elderly subjects. Hypertension Research. 2008;31:75-81. DOI: 10.1291/hypres.31.75

[88] Kuo H-K, Chen C-Y, Liu H-M, Yen C-J, Chang K-J, Chang C-C, et al. Metabolic risks, white matter hyperintensities, and arterial stiffness in high-functioning healthy adults. International Journal of Cardiology. 2010;143:184-191. DOI: 10.1016/j. ijcard.2009.02.005

[89] Cherian P, Hankey GJ, Eikelboom JW, Thom J, Baker RI, McQuillan A, et al. Endothelial and platelet activation in acute ischemic stroke and its etiological subtypes. Stroke. 2003;34:2132-2137. DOI: 10.1161/01. STR.0000086466.32421.F4

[90] Jimenez JJ, Jy W, Mauro LM, Horstman LL, Ahn YS. Elevated endothelial microparticles in thrombotic thrombocytopenic purpura: Findings from brain and renal microvascular cell culture and patients with active disease. British Journal of Haematology. 2001;112:81-90. Available from: http://www.ncbi.nlm. nih.gov/pubmed/11167788. [Accessed: 30 Mar 2019]

[91] Gomez-Isla T, Spires T, De Calignon A, Hyman BT. Neuropathology of 
Alzheimer's disease. Handbook of Clinical Neurology. 2008;89:233-243. DOI: $10.1016 / \mathrm{S} 0072-9752(07) 01222-5$

[92] Cai Z, Zhao B, Ratka A. Oxidative stress and $\beta$-amyloid protein in Alzheimer's disease. Neuromolecular Medicine. 2011;13:223-250. DOI: 10.1007/s12017-011-8155-9

[93] Braak H, Braak E. Neuropathological stageing of Alzheimer-related changes. Acta Neuropathologica. 1991;82:239-259

[94] Duyckaerts C, Clavaguera F, Potier $\mathrm{M}-\mathrm{C}$. The prion-like propagation hypothesis in Alzheimer's and Parkinson's disease. Current Opinion in Neurology. 2019;32:266-271. DOI: 10.1097/WCO.0000000000000672

[95] Gouras GK, Tampellini D, Takahashi RH, Capetillo-Zarate E. Intraneuronal beta-amyloid accumulation and synapse pathology in Alzheimer's disease. Acta Neuropathologica. 2010;119:523-541. DOI: $10.1007 / \mathrm{s} 00401-010-0679-9$

[96] Hartmann T, Bieger SC, Brühl B, Tienari PJ, Ida N, Allsop D, et al. Distinct sites of intracellular production for Alzheimer's disease A beta40/42 amyloid peptides. Nature Medicine. 1997;3:1016-1020

[97] Takahashi RH, Milner TA, Li F, Nam EE, Edgar MA, Yamaguchi $\mathrm{H}$, et al. Intraneuronal Alzheimer abeta42 accumulates in multivesicular bodies and is associated with synaptic pathology. The American Journal of Pathology. 2002;161:1869-1879

[98] Sinha MS, Ansell-Schultz A, Civitelli L, Hildesjö C, Larsson M, Lannfelt L, et al. Alzheimer's disease pathology propagation by exosomes containing toxic amyloid-beta oligomers. Acta Neuropathologica. 2018;136:41. DOI: 10.1007/ S00401-018-1868-1
[99] Saman S, Kim W, Raya M, Visnick Y, Miro S, Saman S, et al. Exosome-associated tau is secreted in tauopathy models and is selectively phosphorylated in cerebrospinal fluid in early Alzheimer disease. The Journal of Biological Chemistry. 2012;287:3842-3849. DOI: 10.1074/jbc. M111.277061

[100] Perl DP. Neuropathology of Alzheimer's disease. Mount Sinai Journal of Medicine A Journal of Translational and Personalized Medicine. 2010;77:32-42. DOI: 10.1002/ msj.20157

[101] Tapiola T, Alafuzoff I, Herukka S-K, Parkkinen L, Hartikainen P, Soininen $\mathrm{H}$, et al. Cerebrospinal fluid $\beta$-amyloid 42 and tau proteins as biomarkers of Alzheimer-type pathologic changes in the brain. Archives of Neurology. 2009;66. DOI: 10.1001/archneurol.2008.596

[102] Denk J, Boelmans K, Siegismund C, Lassner D, Arlt S, Jahn H. MicroRNA profiling of CSF reveals potential biomarkers to detect Alzheimer's disease. PLoS One. 2015;10:e0126423. DOI: 10.1371/journal.pone.0126423

[103] Cheng L, Doecke JD, Sharples RA, Villemagne VL, Fowler CJ, Rembach A, et al. Prognostic serum miRNA biomarkers associated with Alzheimer's disease shows concordance with neuropsychological and neuroimaging assessment. Molecular Psychiatry. 2015;20:1188-1196. DOI: 10.1038/ mp.2014.127

[104] Chiasserini D, van Weering JRT, Piersma SR, Pham TV, Malekzadeh A, Teunissen CE, et al. Proteomic analysis of cerebrospinal fluid extracellular vesicles: A comprehensive dataset. Journal of Proteomics. 2014;106:191204. DOI: 10.1016/j.jprot.2014.04.028

[105] Dickson DW. Neuropathology of Parkinson disease. Parkinsonism \& 
Related Disorders. 2018;46:S30-S33.

DOI: 10.1016/j.parkreldis.2017.07.033

[106] Braak H, Del Tredici K, Rüb U, de Vos RAI, Jansen Steur ENH, Braak E. Staging of brain pathology related to sporadic Parkinson's disease. Neurobiology of Aging. 2013;24:197-211

[107] Danzer KM, Kranich LR, Ruf WP, Cagsal-Getkin O, Winslow AR, Zhu L, et al. Exosomal cell-to-cell transmission of alpha synuclein oligomers. Molecular Neurodegeneration. 2012;7:42. DOI: $10.1186 / 1750-1326-7-42$

[108] Emmanouilidou E, Melachroinou K, Roumeliotis T, Garbis SD, Ntzouni M, Margaritis LH, et al. Cell-produced -synuclein is secreted in a calcium-dependent manner by exosomes and impacts neuronal survival. The Journal of Neuroscience. 2010;30:6838-6851. DOI: 10.1523/ JNEUROSCI.5699-09.2010

[109] Stuendl A, Kunadt M, Kruse N, Bartels C, Moebius W, Danzer KM, et al. Induction of $\alpha$-synuclein aggregate formation by CSF exosomes from patients with Parkinson's disease and dementia with Lewy bodies. Brain. 2016;139(Pt 2):481-494. DOI: 10.1093/ brain/awv346

[110] Tofaris GK. A critical assessment of exosomes in the pathogenesis and stratification of Parkinson's disease. Journal of Parkinson's Disease. 2017;7:569-576. DOI: 10.3233/ JPD-171176

[111] Gui Y, Liu H, Zhang L, Lv W, $\mathrm{Hu} \mathrm{X}$. Altered microRNA profiles in cerebrospinal fluid exosome in Parkinson disease and Alzheimer disease. Oncotarget. 2015;6:3704337053. DOI: 10.18632 /oncotarget.6158

[112] Fraser KB, Moehle MS, Daher JPL, Webber PJ, Williams JY, Stewart CA, et al. LRRK2 secretion in exosomes is regulated by 14-3-3. Human Molecular
Genetics. 2013;22:4988-5000. DOI: 10.1093/hmg/ddt346

[113] Walker LC. Prion-like mechanisms in Alzheimer disease. Handbook of Clinical Neurology. 2018;153:303-319. DOI: 10.1016/ B978-0-444-63945-5.00016-7

[114] Jan AT, Malik MA, Rahman S, Yeo HR, Lee EJ, Abdullah TS, et al. Perspective insights of exosomes in neurodegenerative diseases: A critical appraisal. Frontiers in Aging Neuroscience. 2017;9:317. DOI: 10.3389/ fnagi.2017.00317

[115] Beach TG. A review of biomarkers for neurodegenerative disease: Will they swing us across the valley? Neurology and Therapy. 2017;6(Suppl 1):5-13. DOI: 10.1007/s40120-017-0072-x

[116] Lin J, Li J, Huang B, Liu J, Chen X, Chen X-M, et al. Exosomes:

Novel biomarkers for clinical diagnosis. ScientificWorldJournal. 2015;2015:657086. DOI:

$10.1155 / 2015 / 657086$

[117] Soria FN, Pampliega O, Bourdenx M, Meissner WG, Bezard E, Dehay B. Exosomes, an unmasked culprit in neurodegenerative diseases. Frontiers in Neuroscience. 2017;11:26. DOI: 10.3389/ FNINS.2017.00026

[118] Otero-Ortega L, Gómez de Frutos MC, Laso-García F, Rodríguez-Frutos B, Medina-Gutiérrez E, López JA, et al. Exosomes promote restoration after an experimental animal model of intracerebral hemorrhage. Journal of Cerebral Blood Flow and Metabolism. 2018;38:767-779. DOI: 10.1177/0271678X17708917

[119] Doeppner TR, Herz J, Görgens A, Schlechter J, Ludwig A-K, Radtke S, et al. Extracellular vesicles improve post-stroke neuroregeneration and prevent postischemic immunosuppression. Stem Cells 
Translational Medicine. 2015;4:11311143. DOI: $10.5966 /$ sctm.2015-0078

[120] Xin H, Li Y, Liu Z, Wang X, Shang $\mathrm{X}$, Cui Y, et al. MiR-133b promotes neural plasticity and functional recovery after treatment of stroke with multipotent mesenchymal stromal cells in rats via transfer of exosomeenriched extracellular particles. Stem Cells. 2013;31:2737-2746. DOI: 10.1002/ stem.1409

[121] Maestrini I, Strbian D, Gautier S, Haapaniemi E, Moulin S, Sairanen T, et al. Higher neutrophil counts before thrombolysis for cerebral ischemia predict worse outcomes. Neurology. 2015;85:1408-1416. DOI: 10.1212/ WNL.0000000000002029

[122] Webb RL, Kaiser EE, Jurgielewicz BJ, Spellicy S, Scoville SL, Thompson TA, et al. Human neural stem cell extracellular vesicles improve recovery in a porcine model of ischemic stroke. Stroke. 2018;49:1248-1256. DOI: 10.1161/STROKEAHA.117.020353

[123] Li Y, Cheng Q, Hu G, Deng T, Wang Q, Zhou J, et al. Extracellular vesicles in mesenchymal stromal cells: A novel therapeutic strategy for stroke. Experimental and Therapeutic Medicine. 2018;15:4067-4079. DOI: 10.3892/etm.2018.5993

[124] Lin S-S, Zhu B, Guo Z-K, Huang G-Z, Wang Z, Chen J, et al. Bone marrow mesenchymal stem cellderived microvesicles protect rat pheochromocytoma PC12 cells from glutamate-induced injury via a PI3K/ Akt dependent pathway. Neurochemical Research. 2014;39:922-931. DOI: 10.1007/s11064-014-1288-0

[125] Xin H, Li Y, Buller B, Katakowski M, Zhang Y, Wang X, et al. Exosomemediated transfer of miR-133b from multipotent mesenchymal stromal cells to neural cells contributes to neurite outgrowth. Stem Cells.
2012;30:1556-1564. DOI: $10.1002 /$ stem.1129

[126] Liu J, Kuwabara A, Kamio Y, Hu S, Park J, Hashimoto T, et al. Human mesenchymal stem cell-derived microvesicles prevent the rupture of intracranial aneurysm in part by suppression of mast cell activation via a PGE2-dependent mechanism. Stem Cells. 2016;34:2943-2955. DOI: $10.1002 /$ stem. 2448 
